ORNL/TM-12216

Dist. Category UC-420

Fusion Energy Division

\title{
THE TST: A SMALL STEADY-STATE TOKAMAK FOR INTEGRATED DIVERTOR TESTING
}

\author{
Y.-K. M. Peng \\ R. J. Colchin \\ D. W. Swain \\ B. E. Nelson \\ J. F. Monday
}

Date Completed-January 1993

Date Published-September 1993

Prepared for the

Office of Fusion Energy

Budget Activity No. AT 15

\footnotetext{
Prepared by

OAK RIDGE NATIONAL LABORATORY

Oak Ridge, Tennessee 37831-6285

managed by

MARTIN MARIETTA ENERGY SYSTEMS, INC.

for the

U.S. DEPARTMENT OF ENERGY

under contract DE-AC05-84OR21400
} 


\section{TABLE OF CONTENTS}

ACKNOWLEDGMENTS

EXECUTIVE SUMMARY

I. THE TST PROGRAM

I.1 MISSION, GOALS, AND GENERAL REQUIREMENTS ............. I-

I.2 PLASMA PARAMETERS ........................................................ I-2

I.3 DIVERTOR AND VESSEL FEATURES ……............................... I-3

I.4 H\&CD APPROACHES …….............................................. I-4

I.5 DEVICE FEATURES …........................................................ I-5

I.6 ADDITIONAL CONSIDERATIONS ……................................. I-7

References for Sect. I ........................................................................ I-9

II. THE TST PHYSICS BASIS ……………………............................. II-

II.1 THE PLASMA OPERATION WINDOW ....................................... II-

II. 2 PLASMA CURRENT INITIATION ……………............................ II-3

II.3 PLASMA CURRENT MAINTENANCE AT MODEST

DENSITIES

II-5

II.4 PLASMA CURRENT MAINTENANCE AT HIGH

DENSITIES: NEUTRAL BEAM AND LOWER HYBRID

CURRENT DRIVE

II-10

II.5 OTHER CURRENT DRIVE POSSIBILITIES ………...................... II-13

II.6 PF COILS AND EQUILIBRIUM FLEXIBILITY _....................... II- 15

References for Sect. II ......................................................................... II-19

III. THE TST AUXILIARY H\&CD SYSTEMS …….................................... III-1

III.1 ECH SYSTEM ....................................................................... III-1

III.2 LH WAVE SYSTEM ................................................................ III-6

III.3 ICH SYSTEM ………......................................................... III-9

III.4 NEUTRAL BEAM SYS'IEM ……………..................................... III-12

References for Sect. III ....................................................................... III-18

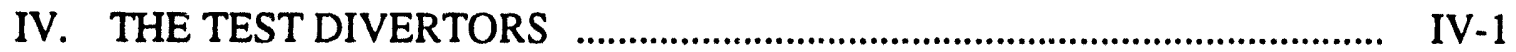

IV.1 POWER AND PARTICLE HANDLING FOR STEADYSTATE OPERATION

IV-1

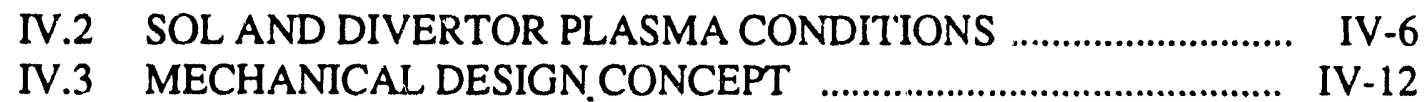

IV.4 DIVERTOR CASSETTE INTERFACE CONCEPT ……............... IV-19

References for Sect. IV ……......................................................... IV-25

V. THE TST DEVICE .................................................................... V

V.1 DEVICE CONFIGURATION …………………........................... V

V.2 CENTRAL CORE ASSEMBLY ……....................................... V. V.6

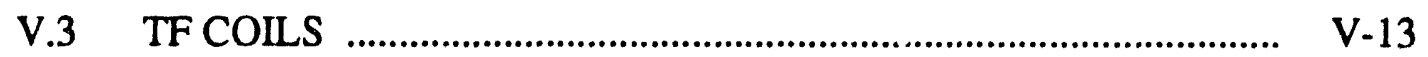

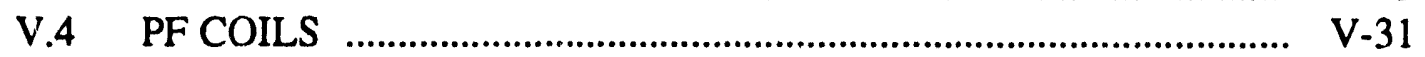

V.5 VACUUM VESSEL .......................................................... V-35

V.6 SUPPORT STRUCTURE _......................................................... V V-35

V.7 DEVICE LOCATION …………................................................. V-38 
VI. ANCILLARY SYSTEMS

VI-1

VI.1 POWER SUPPLIES

VI-1

VI.2 WATER COOLING SYSTEM ................................................... VI-3

VI.3 DIAGNOSTICS .................................................................... VI-4

VI.4 TST CONTROL ROOM AND DATA ACQUISITION …………... VI-12

APPENDIX A. MODELING ASSUMPTIONS AND RESULTS FOR

TST TRADES

A-1

APPENDIX B. VOLTAGE REQUIREMENTS FOR TST OHMIC

HEATING SUPPLIES ON STARTUP

B-1 


\section{ACKNOWLEDGMENTS}

This study was made possible by the contributions of many staff members at Oak Ridge National Laboratory (ORNL), including D. B. Batchelor, T. S. Bigelow, C. L. Hedrick, J. T. Hogan, W. A. Houlberg, E. F. Jaeger, P. K. Mioduszewski, D. A. Spong, W. L. Stirling, C. C. Tsai, and J. A. White of the ORNL Fusion Energy Division; S. E. Attenberger, J. D. Galambos, R. O. Sayer, and D. J. Strickler of the Computing and Telecommunications Division of Martin Marietta Energy Systems, Inc.; and J. G.

Arterburn, P. J. Fogarty, P. L. Goranson, G. H. Jones, D. J. Taylor, D. E. Williamson, and J. J. Yugo of the Energy Systems Engineering Division. Advice from L. A. Berry, R. A. Dory, H. H. Haselton, S. P. Hirshman, and R: L. Johnson has been very helpful.

We are further grateful to R. R. Parker and colleagues at Massachusetts Institute of Technology for making possible the contributions of S. C. Luckhardt and P. T. Bonoli in key calculations of current drive; to P. H. Rutherford and colleagues at Princeton Plasma Physics Laboratory (PPPL) for use of information on the PPPL lower hybrid systems supplied by S. Bernabei; to D. P. Dautovich and colleagues at the Canadian Fusion Fuels Technology Project for making possible the contributions of J. Blevins, J. Stringer, and M. Delisle in the divertor cassette interface concept; and to I. C. Nascimento for making possible the contribution of R. Pauletti in the mechanical analysis of the TST device.

Finally, the support of Fusion Energy Division managers J. Sheffield, C. C. Baker, and T. E. Shannon; ORNL management; and the Applied Physics Division of OFE/DOE is gratefully acknowledged.

The TST team is indebted to M. B. Nestor, D. Y. Johnson, B. J. Smith, J. C. Parrott, P. A. Sumner, and their colleagues in the Engineering Technology/Fusion Energy Division Publications Office, for their support in the production of this document.

We would like to dedicate this report to the memory of our colleague J. F. Monday, who passed away in July 1993. 


\section{EXECUTIVE SUMMARY}

Steady-state divertors that handle high particle and heat fluxes while maintaining adequate core plasma conditions have been identified $[1,2]$ as the most critical nearterm R\&D need for the main-line tokamaks of the next decade. A Small Steady-State Tokamak (Triple-ST $\rightarrow$ TST) is identified for integrated testing and development of such divertor solutions in this decade. The TST can be driven with modest powers to produce the plasma edge and divertor conditions needed for this mission, according to known physics and technology data from small to medium-size tokamaks.

The severity of this divertor challenge is shown in Fig. S.1, which contrasts the kinetic heat flux at the plasma edge $\left(\dot{Q}_{\perp}\right)$ and plasma duration $\left(\tau_{\text {dura }}\right)$ projected for the International Thermonuclear Experimental Reactor (ITER) [1] and the Steady-State Advanced Tokamak (SSAT) [2] with the values achieved in tokamaks to date. The gap to be covered spans three orders of magnitude in $\tau_{\text {dura }}$ for $\dot{Q}_{\perp} \sim 0.1-0.3 \mathrm{MW} / \mathrm{m}^{2}$ and over one order of magnitude in $\dot{Q}_{\perp}$ for $\tau_{\text {dura }} \sim 10^{3}-10^{5} \mathrm{~s}$. While an advanced divertor is

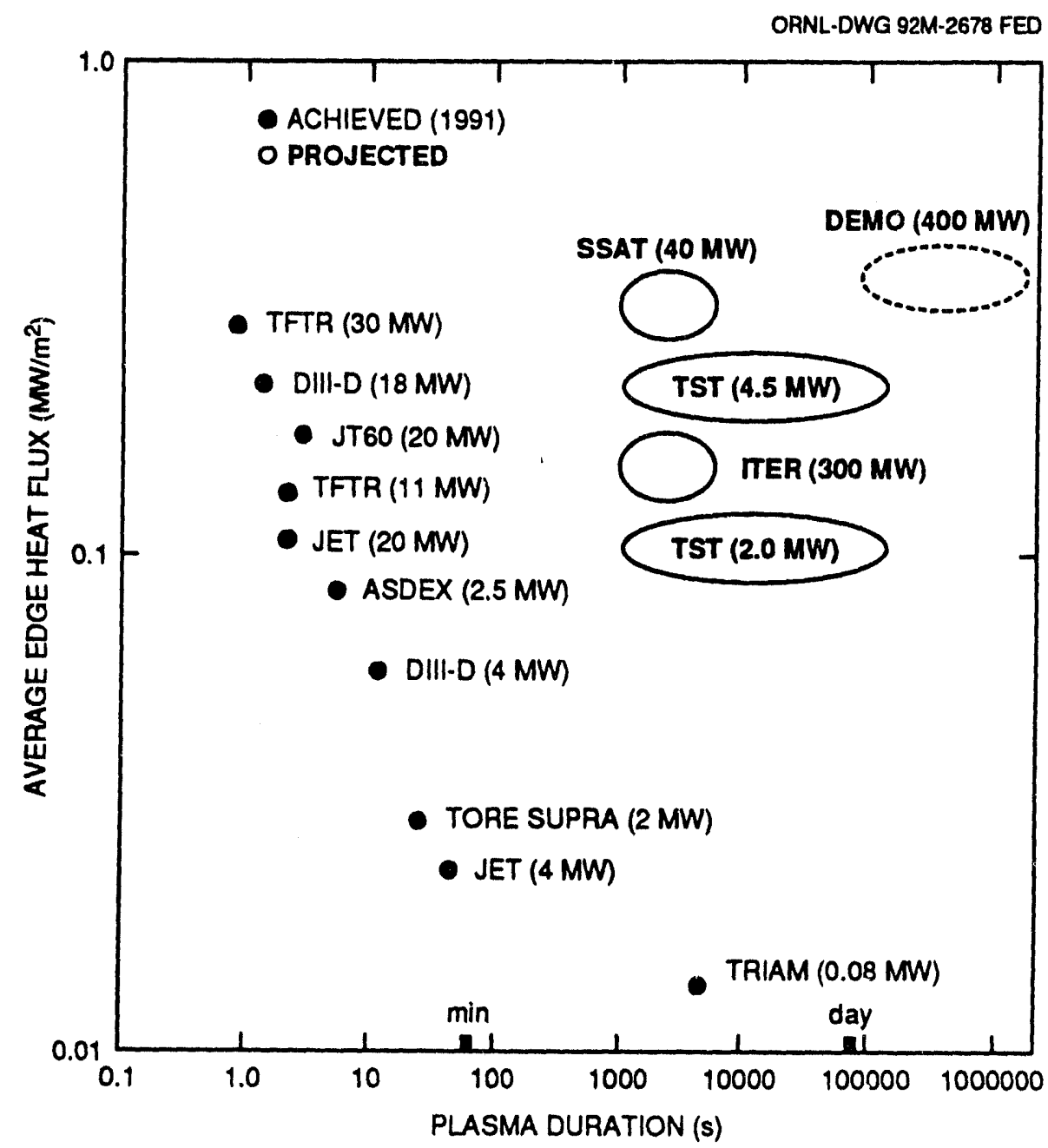

Fig. S.1. Average plasma edge heat flux (with heating power in parentheses) and plasma duration achieved in tokamaks to date and projected for TST, SSAT, ITER, and DEMO. 
already in operation on DIII-D and another is being installed on the Joint European Torus (JET) to increase $\tau_{\text {dura }}$ by about one order of magnitude, the duration will still be two orders of magnitude below the operational needs of ITER and SSAT.

SSAT will include the demonstration of steady-state operation of a tokamak and the exploration of advanced tokamak physics under steady-state conditions with the goal of improving the Demonstration Power Plant (DEMO). A TST used to test divertors will utilize divertor physics data from experiments with limited plasma durations, such as DIII-D, and fill the R\&D gap between DIII-D and the large steady-state tokamaks, thus enabling SSAT and ITER to address their missions expeditiously. Development needs for DEMO and the key missions suggested for DIII-D, TST, SSAT, and ITER are summarized in Table S.1.

Table S.1. The tokamak fusion energy development needs and the TST mission addressing the steady-state power and particle handling of divertors $(\bullet=$ mission, $\mathrm{O}=$ database required, $-=$ database not required $)$

\begin{tabular}{lccccc}
\hline Tokamak development needs & DIII-D & TST & SSAT & ITER & DEMO \\
\hline Divertor plasma physics & $\bullet$ & 0 & 0 & 0 & 0 \\
Steady-state divertors & & $\bullet$ & 0 & 0 & 0 \\
Steady-state demonstration & & $\bullet$ & $\bullet$ & - & 0 \\
Steady-state advanced physics & & & $\bullet$ & - & 0 \\
Ignition and stationary burn & & & & - & 0 \\
Nuclear technologies & & & - & 0 \\
Electric power production & & & & & $\bullet$ \\
\hline
\end{tabular}

We present the TST design concept and plasma operation characteristics that meet the divertor test mission. Table S.2 shows that the TST is smaller than DIII-D but has heat fluxes and a divertor configuration similar to those of SSAT and TTER, using standard (not advanced) tokamak physics and a modest auxiliary drive power ( $2.0 \mathrm{MW}$ for the first phase and $4.5 \mathrm{MW}$ for the second). The steady-state power supply needed by the normal-conductor magnets in TST is less than $40 \mathrm{MW}$.

To ensure that the divertor test mission can be carried out, a duty factor of $\geq 10 \%$ is targeted for the TST, suggesting plasma durations up to $10^{5} \mathrm{~s}$. To permit testing of many divertor concepts without reducing availability, a modular cassette divertor design is used, which sets the number of toroidal field (TF) coils at eight. To provide flexibility and repairability, fully demountable TF coils are incorporated. The design permits 24 ports, each about $80 \mathrm{~cm}$ wide $\times 50 \mathrm{~cm}$ high, that provide radial ascess: 8 for divertor cassettes (single-null divertor), 8 for midplane auxiliary drive systems and plasma diagnostics, and 8 upper ports for pumping, additional diagnostics, or the double-null configuration. This configuration is shown in Fig. S.2.

Facilities and equipment needed for TST are currently available. For example, resources at Oak Ridge National Laboratory (ORNL) include a building with adequate space and cranes, steady-state power supplies, $\mathrm{rf}$ systems in the electron cyclotron and ion cyclotron frequency ranges, major comr nents for a steady-state neutral beam 
Table S.2. TST parameters compared with those of DIII-D, SSAT, and ITER

\begin{tabular}{|c|c|c|c|c|}
\hline & DIII-D & TST & SSAT & ITER \\
\hline Major radius $R_{0}, \mathrm{~m}$ & 1.65 & $\leq 0.75$ & 2.25 & $\sim 7.8$ \\
\hline Minor radius $a, \mathrm{~m}$ & $\leq 0.64$ & $\leq 0.38$ & $\leq 0.5$ & $\sim 2.8$ \\
\hline Aspect ratio $R_{0} / a$ & $\geq 2.5$ & $.1 .8-2.5$ & $\geq 4.5$ & $\geq 2.8$ \\
\hline Plasma current $I_{\mathrm{p}}$, MA & $\leq 2.0$ & $\sim 0.5$ & $\leq 2.0$ & $\sim 25$ \\
\hline Toroidal field $B, \mathrm{~T}$ & 2 & $\leq 2.2$ & $3.4-5$ & 5 \\
\hline Average density, $10^{20} \mathrm{~m}^{-3}$ & $\leq 1.2$ & $\leq 0.6$ & $\leq 1.5$ & 1.1 \\
\hline Average temperature, $\mathrm{keV}$ & $\leq 5$ & $\leq 2$ & $\leq 7$ & 15 \\
\hline Heating and current drive power, MW & 20 & $2.0-4.5$ & 40 & $\sim 300$ \\
\hline Average edge heat flux, MW $/ \mathrm{m}^{2}$ & $\sim 0.2$ & $\sim 0.1-0.22$ & $\sim 0.35$ & $\sim 0.15$ \\
\hline Scrape-off layer connection length, $m$ & $\sim 25$ & $\sim 30$ & $\sim 40$ & $\sim 100$ \\
\hline Total steady-state supply required, MW & - & $\sim 55$ & $\sim 200$ & $\sim 500$ \\
\hline Plasma duration, $\mathbf{s}$ & $\sim 10$ & $\sim 10^{5}$ & $\sim 10^{5}$ & $\sim 10^{3}$ \\
\hline
\end{tabular}

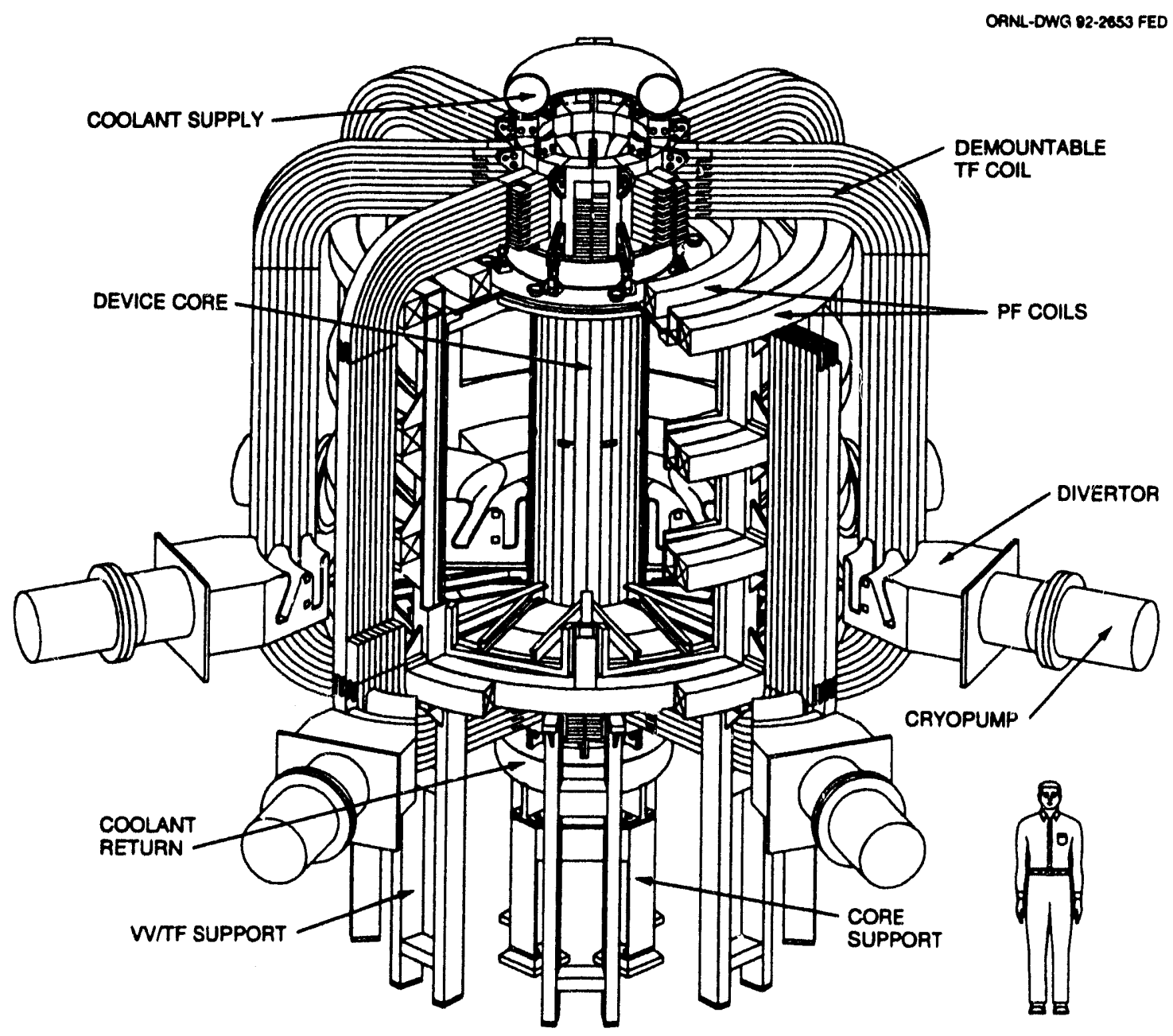

Fig. S.2. TST design configuration for a duty factor target of $10 \%$, using a modular cassette divertor, large access ports, and eight demountable TFCs. 
injection (NBI) system, and a steady-state water cooling system capable of removing a minimum of $50 \mathrm{MW}$. Existing lower hybrid (LH) systems such as those at Princeton Plasma Physics Laboratory or Frascati $(1.5 \mathrm{MW}$ at $2.45 \mathrm{GHz}$ ) are also suitable for use on TST.

The device can accommodate an additional $2.5 \mathrm{MW}$ of auxiliary drive power [1 MW of ion cyclotron heating (ICH) and $1.5 \mathrm{MW}$ of NBI] for a second phase of operation. This will produce plasma edge heat fluxes $\left(\dot{Q}_{\perp} \sim 0.22 \mathrm{MW} / \mathrm{m}^{2}\right)$ exceeding those anticipated in ITER and similar to those of SSAT. If the present current drive experiments in DIII-D, Tore Supra, JT-60U, and JET are successful, then auxiliary drive power for this full-power (4.5-MW), full-density $\left(-5 \times 10^{19} \mathrm{~m}^{-3}\right)$ phase of operation will be provided instead by fast wave current drive (FWCD) systems.

While the focus of the study is on TST with full capabilities, the device also accommodates a smaller central core assembly to permit steady-state operation with $R_{0} / a=1.8$ and $B_{\mathrm{t} 0}=1.4 \mathrm{~T}$. Assuming tokamak-like behavior in confinement, stability, current drive, and divertor, the lower $R / a$ plasma will rely on noninductive initiation and ramp-up of the plasma current and on early introduction of NBI, in place of $\mathrm{ICH}$, to maintain current at densities $\geq 0.3 \times 10^{20} \mathrm{~m}^{-3}$. The window of plasma operation will remain nearly identical to the design with $R_{0} / a=2.5$ and $B_{10}=2.2 \mathrm{~T}$. The added physics risk is attended by the capability for physics investigations at lower $R_{0} / a$, while still carrying out the mission of divertor testing.

\section{REFERENCES}

[1] D. E. Baldwin (Chair) et al., "U.S. National Review of the TTER Conceptual Design Activity," Univ. Texas, March 1991; P. H. Rebut, presentation to the U.S. Department of Energy Fusion Energy Advisory Committee, Panel 1, St. Louis, January 16, 1992.

[2] K. Thomassen et al., "Steady State Advanced Tokamak (SSAT), the Mission and the Machine," presented to the U.S. Department of Energy Fusion Energy Advisory Committee, Panel 2, Livermore, California, February 24-25, 1992 (also UCRL-ID-109807, Lawrence Livermore National Laboratory, March 1992). 


\section{THE TST PROGRAM}

A recent review [1] of the design produced by the International Thermonuclear Experimental Reactor (ITER) Conceptual Design Activity (CDA) identified the divertors and the associated plasma power and particle handling as an area in critical need of development. Divertor solutions are also needed by all large steady-state tokamaks that are driven with high auxiliary power. This echoes the fact that new pumped divertors are being or have already been installed in the Joint European Torus (JET) [2] and DIII-D [3] to begin to address this issue for significant but limited plasma durations $(10-100 \mathrm{~s})$. Here we summarize the mission, the plasma and device parameters, and the device features of a small steady-state tokamak (triple-S tokamak, or TST) that fulfills this R\&D need in the near term, relying only on the physics and technology data of small to medium-size tokamaks and using the facilities and equipment available at a typical fusion institution such as Oak Ridge National Laboratory (ORNL).

\section{I.1 MISSION, GOALS, AND GENERAL REQUIREMENTS}

The mission of TST is to provide a near-term integrated environment to test advanced steady-state divertor concepts, power and particle handling techniques, and, when appropriate, the lower $R_{0} / a(=2.5-1.8)$ physics.

To achieve this mission, TST must achieve the following goals:

1. demonstrate steady-state plasma operation scenarios at ITER-relevant heat and particle flux densities, but at plasma core parameters of the standard small to mediumsize tokamaks;

2. demonstrate steady-state operation of plasma technologies already used in small to medium-size tokamaks for limited plasma durations;

3. produce steady-state, ITER-relevant plasma edge, scrape-off layer (SOL), and divertor conditions;

4. test and qualify reduced-scale divertors of advanced concepts planned for ITER and other steady-state tokamaks with high heat fluxes;

5. test steady-state wall conditioning techniques;

6. reach a significant duty factor for divertor testing, $210 \%$; and

7. study the physics of lower aspect ratios $\left(R_{0} / a=2.5-1.8\right)$, when appropriate.

To reach these goals, the general requirements are for the TST to provide:

1. single-null (SN) or double-null (DN) poloidal divertors with adequate $\mathrm{SOL}$ connection length $L_{\mathrm{SOL}} \sim \lambda_{\text {ex }}$, the electron collisional mean free path in the SOL;

2. an ITER-level plasma edge, that is, at the plasma edge, an average heat flux $\dot{Q}_{\perp} \approx$ $0.1-0.2 \mathrm{MW} / \mathrm{m}^{2}$, a temperature $T_{\times} \sim 200 \mathrm{eV}$, and a density $n_{\times} \sim 0.15-0.3 \times$ $10^{20} \mathrm{~m}^{-3}$

3. operation free of disruptions, that is, $n_{\times} \leq n_{\times}$dis, the critical density at the plasma edge beyond which the plasma disrupts;

4. adequate opacity to particle influxes to the plasma, $\left\langle n_{\mathrm{e}}\right\rangle a \geq 0.2 \times 10^{20} \mathrm{~m}^{-2}$ and $a \geq$ $0.3 \mathrm{~m}$, to ensure an adequate plasma core and target for heating and current drive $(\mathrm{H} \& \mathrm{CD})$; 
5. steady-state operation, with plasma durations $\tau_{\text {dura }}$ up to $10^{5} \mathrm{~s}$;

6. ample divertor access and flexibility for fast turnaround of divertor tests, by using modular divertor cassettes inserted through large access ports, limiting the number of toroidal field (TF) coils to eight; and

7. demountable TF coils and central core, to ensure a repairable device and permit flexibility in $R_{0} / a$ over the range of 2.5 to 1.8 .

The mission of testing many divertor concepts in TST dictates a goal of $\geq 10 \%$ for the duty factor, the fraction of time of successful operation. Such a goal is one to two orders of magnitude beyond the present experience of tokamaks, including tokamaks with divertors or superconducting magnets. The duty factor is constrained by the plasma duration and the time to replace or repair major components such as the divertor. As a result, TST is required to have steady-state capability ( $\tau_{\text {dura }}$ up to $100,000 \mathrm{~s}$, as opposed to $10-100 \mathrm{~s}$ ) and cassette divertors with ample access to permit rapid divertor turnaround times (1-2 months, as opposed to 1-2 years as in DIII-D, Tore Supra, and JET).

The cassette divertor drives the overall configuration of the TST device, for example, the eight demountable TF coils and the internal poloidal field (PF) coils for flexibility of the magnetic configuration. The demountable central core (to retain flexibility in $R_{0}(a)$ introduces a relatively minor additional impact on the design, which is localized to the inner joints of the TF coils and the inner interface of the vacuum vessel. This flexibility in turn permits a focus on the full-capability design for $R_{0} / a=2.5$, which enjoys a strong tokamak database, without losing the potential benefits of $R_{0} / a=1.8$, which has a limited but growing database. The TST design presented here is optimized for $R_{0} / a=2.5$, while identifying only the necessary adjustments for the option of $R_{0} / a=$ 1.8 .

The following sections summarize the plasma parameters (Sect. I.2), the divertor and vessel features (Sect. I.3), the H\&CD approaches (Sect. I.4), and the tokamak device features (Sect. I.5) that satisfy these requirements. Additional considerations are addressed in Sect. I.6.

\section{I.2 PLASMA PARAMETERS}

The major plasma parameters that fulfill the requirements listed in Sect. I.1 are given in Table I.1. They are based on standard tokamak plasma assumptions for $R_{0} / a=2.5$ : first stability beta limit, stationary $\mathrm{H}$-mode $\left(\mathrm{H}\right.$-factor $\left.H_{\mathrm{f}}=1.5\right), \mathrm{H}$-mode plasma edge conditions, a moderately elongated and triangular divertor plasma cross section, a moderate plasma current $(0.5 \mathrm{MA})$ with a high safety factor $\left(q_{95} \approx 7\right)$, moderate plasma core temperatures and densities, and current drive approaches based on lower hybrid (LH) waves and neutral beam injection (NBI) assisted by ion cyclotron heating (ICH) with an ample database, albeit for limited plasma durations. A relatively large inductive capability is also provided to help ensure adequate flexibility for the plasma transition to steady state. The details of the considerations that provided the basis for these parameters are provided in Sect. II, "The TST Physics Basis."

For $R_{0} / a \sim 1.8$, we assume that the plasma will be tokamak-like; that is, models of the $R_{0} / a$ dependence based on the database of $R_{0} l a=2.5$ are used in estimating the plasma parameters. The absence of significant inductive capability at $R_{0} / a=1.8\left(\psi_{\text {ind }} \approx\right.$ 
Table I.1. Reference parameters for TST

\begin{tabular}{lll}
\hline \multicolumn{1}{c}{ Parameter } & \multicolumn{1}{c}{$R_{0} / a=2.5$} & \multicolumn{1}{c}{$R_{0} / a=1.8$} \\
\hline Major radius $R_{0}, \mathrm{~m}$ & 0.75 & 0.68 \\
Minor radius $a, \mathrm{~m}$ & 0.30 & 0.38 \\
Toroidal field $\left(\mathrm{at} R_{0}\right) B_{\mathrm{t} 0}, \mathrm{~T}$ & 2.2 & 1.4 \\
Plasma current $I_{\mathrm{p}}, \mathrm{MA}$ & 0.5 & 0.5 \\
×-point elongation $\mathrm{K}_{\times}$ & 1.9 & 2.0 \\
×-point triangularity $\delta_{\times}$ & 0.2 & 0.25 \\
Edge safety factor $q_{95}$ & 7 & 7 \\
Average density $\left\langle n_{\mathrm{e}}\right\rangle, 10^{20} \mathrm{~m}^{-3}$ (phase I, II) & $0.3,0.45$ & $0.3,0.45$ \\
Average temperature $\langle T\rangle_{\mathrm{n}}, \mathrm{keV}$ & $1,1.5$ & $1,1.5$ \\
Edge density $n_{\times}, 10^{20} \mathrm{~m}^{-3}$ (phase I, I) & $0.15,0.23$ & $0.15,0.23$ \\
Auxiliary drive power $P_{\text {tor }}, \mathrm{MW}$ (phase I, II) & $2.0,4.5$ & $2.0,4.5$ \\
Current drive method, phase I & $\mathrm{LH}+\mathrm{ICH}$ & $\mathrm{LH}+\mathrm{NBI}$ \\
Current drive method, phase II & $\mathrm{LH}+\mathrm{ICH}+\mathrm{NBI}$ & $\mathrm{LH}+\mathrm{NBI}+\mathrm{ICH}$ \\
Inductive flux capability $\Psi_{\text {ind }}, \mathrm{Wb}$ & 2.7 & 0.3 \\
Plasma duration $\tau_{\text {dura, }} \mathrm{s}$ & $10^{5}$ & $10^{5}$ \\
\hline
\end{tabular}

$0.3 \mathrm{~Wb}$ as opposed to $2.7 \mathrm{~Wb}$ ) limits the scenario of plasma initiation and ramp-up to noninductive means. The lower toroidal field $\left(B_{\mathfrak{t} 0}=1.4 \mathrm{~T}\right.$ as opposed to $\left.2.2 \mathrm{~T}\right)$ will limit LH current drive operation to lower densities $\left(\left\langle n_{\mathrm{e}}\right\rangle=0.1 \times 10^{20} \mathrm{~m}^{-3}\right.$ as opposed to $0.3 \times 10^{20} \mathrm{~m}^{-3}$ ). Neutral beam power must be introduced to permit the higher density operation during phase II. Other parameters are estimated to be similar to those of the higher $R_{0} / a$ case.

\section{I.3 DIVERTOR AND VESSEL FEATURES}

The plasma conditions needed to provided adequate tests of divertors for ITER and other large, driven steady-state tokamaks are summarized in Table I.2. The considerations that determined these parameters are presented in Sects. IV.1 and IV.2. Here, the subscripts $\times$ and $d$ denote the plasma edge defined by the separatrix $\times$-point and the divertor plate, respectively.

The cassette modules for the divertor will require access ports about $80 \mathrm{~cm}$ wide and $50 \mathrm{~cm}$ high. This feature dominates the vessel configuration and the interface with the cassettes. Because of the relatively large tolerance $(-10 \mathrm{~mm})$ between the axisymmetric plasma and the vessel in most tokamaks in operation, an interface concept was developed by J. Blevins and J. Stringer of the Canadian Fusion Fuels Technology Project (CFFTP) to provide flexibility in alignment of the divertor cassettes in situ. The need for access also dictates that the number of TF coils be limited to eight. The plasma conditions for divertor testing and the cassette divertor designs apply equally to $R_{0} / a=$ 1.8 and $R_{0} / a=2.5$. 
Table I.2. Conditions needed for testing divertors

\begin{tabular}{ll}
\hline \multicolumn{1}{c}{ Condition } & \multicolumn{1}{c}{ Considerations } \\
\hline $\begin{array}{l}\text { Single- or double-null poloidal } \\
\text { divertors }\end{array}$ & Correct magnetic field configuration \\
$Q_{\perp} \geq 0.2 \mathrm{MW} / \mathrm{m}^{2}$ & High average heat flux at edge \\
$T_{\times} \sim 0.1-0.2 \mathrm{keV}$ & H-mode plasma edge, plate erosion \\
$n_{\times} \sim(0.15-0.3) \times 10^{20} \mathrm{~cm}^{-3} \leq n_{\times}$dis & High-recycle divertor conditions \\
$n_{\times} \leq n_{\times \text {dis }} \sim 0.32 \times 10^{20} \mathrm{~cm}^{-3}$ & Disruption-free operation \\
$L_{\mathrm{SOL}} \sim \lambda_{\mathrm{ex}} \sim 30 \mathrm{~m}$ & Connection length for perpendicular diffusion and \\
& electron-ion equilibration \\
$Q_{\mathrm{div}} \sim 5 \mathrm{MW} / \mathrm{m}^{2}$ & High average heat flux on plate \\
$T_{\mathrm{ed}} \sim 5-50 \mathrm{eV}$ & High-recycle and high-erosion divertor conditions \\
$\tau_{\text {dura }} \sim 10^{5} \mathrm{~s}$ & Particle equilibration; plate impurity erosion, \\
& migration, and redeposition; duty factor of \\
& $10-20 \%$ \\
\hline
\end{tabular}

\section{I.4 H\&CD APPROACHES}

The H\&CD system has three purposes:

- It must heat the plasma with enough total heating power that the heat flux to the divertor and the conditions of the plasma near the divertor (density and temperature) will be good simulations of large-machine divertor conditions.

- It must drive the full amount of plasma current in steady state.

- It must provide an initial plasma to allow the use of relatively low loop voltage for plasma startup when necessary.

Table I.3 describes the three types of $H \& C D$ systems proposed for initial operation. The main challenge is providing enough current drive. To this end, a 1-MW LH system operating at $2.45 \mathrm{GHz}$ is proposed for the dominant current drive source because of its demonstrated high efficiency on many major tokamaks at average densities as high as $0.3 \times 10^{20} \mathrm{~m}^{-3}$. A 1-MW ICH system $(6-20 \mathrm{MHz})$ will provide additional heating power, while the electron cyclotron heating $(\mathrm{ECH})$ system will be used for initial plasma breakdown.

Table I.3. Heating and current drive systems for TST

\begin{tabular}{|c|c|c|c|c|}
\hline \multirow[b]{2}{*}{ System } & \multicolumn{2}{|c|}{$\begin{array}{l}\text { Power to plasma } \\
\text { (MW) }\end{array}$} & \multirow[b]{2}{*}{ Specifications } & \multirow[b]{2}{*}{ Purpose and comment } \\
\hline & Steady state & 30-s pulse & & \\
\hline $\mathrm{ECH}$ & 0.2 & 0.2 & $53 \mathrm{GHz}$ & Plasma breakdown \\
\hline LH & 1.0 & 1.5 & $2.45 \mathrm{GHz}$ & Heating and current drive \\
\hline $\mathrm{ICH}$ & 1 & 2 & $6-20 \mathrm{MHz}$ & Heating \\
\hline
\end{tabular}


The H\&CD system should be able to deliver up to $2.2 \mathrm{MW}$ of total power to the plasma (after accountung for transmission losses, etc.), which will provide a heat flux at the divertors similar to that on ITER and other fusion devices.

For high-density operation $\left(\geq 3 \times 10^{19} \mathrm{~m}^{-3}\right)$, the $2.45-\mathrm{GHz} \mathrm{LH}$ system cannot drive current at the core of the plasma. The addition of $1.5 \mathrm{MW}$ of neutral beam power, and/or another $1 \mathrm{MW}$ of $\mathrm{ICH}$ power, could increase the density operating limit for steady-state operation and provide the capability to extend the heat flux limits to the divertor. Fast wave current drive (FWCD) is also a possibility. Table 1.4 describes possible H\&CD system upgrades. The neutral beam system can be used for driving a central "seed current," while the LH system drives the bulk of the current at larger radii. By using this technique, along with bootstrap current, the system could operate steady state at densities up to $\sim 5 \times 10^{19} \mathrm{~m}^{-3}$. For $R_{0} / a=1.8,1.5 \mathrm{MW}$ of neutral beam power is needed in place of the ICH to ensure steady-state operation at average densities greater than $0.3 \times 10^{20} \mathrm{~m}^{-3}$.

Table 1.4. Heating and current drive upgrade possibilities

\begin{tabular}{lcccc}
\hline & \multicolumn{2}{c}{ Power (MW) } & & \\
\cline { 2 - 5 } \multicolumn{1}{c}{ System } & $\begin{array}{c}\text { Steady } \\
\text { state }\end{array}$ & $\begin{array}{c}30-\mathrm{s} \\
\text { pulse }\end{array}$ & Specifications & \multicolumn{1}{c}{ Purpose and comment } \\
\hline ICH & 1 & 1.5 & $40-80 \mathrm{MHz}$ & Heating \\
Neutral beam & 1.5 & 1.5 & $56 \mathrm{kV}, \mathrm{D}^{+}$or $\mathrm{H}^{+}$ & $\begin{array}{l}\text { Heating and central current drive } \\
\text { at high density }\end{array}$ \\
\hline
\end{tabular}

\section{I.5 DEVICE FEATURES}

The TST mission of testing advanced concept divertors and tokamak improvements at a small aspect ratio imposes unique requirements on the TST device, which include:

- Maximum access for the test divertors, to permit flexibility in the test divertor concepts.

- Provisions for efficient replacement of test divertor modules, to permit testing of a progression of $\%$ ivanced concept divertors.

- Duty factor of $\geq 10 \%$, to accumulate ITER-level exposure to the divertor and first wall surfaces per annum.

- Built-in capability for small-aspect-ratio plasmas by identical interfaces to a "fat" and a "skinny" central core assembly, without substantial cost increase.

The TST device components, including the divertors, need to be modular with relatively unencumbered interfaces to reduce the time to maintain, replace, or repair them. The device configuration therefore has demountable TF coils surrounding a cylindrical vacuum vessel, similar to the ISX tokamak. The main features of the device include the cassette divertor and a compact central core assembly that can be removed and replaced to change the aspect ratio from 2.5 to 1.8 . The device will be 
designed to use existing power supplies and cooling water systems. The principal design parameters are listed in Table 1.5.

Table 1.5. TST general design parameters and requirements

\begin{tabular}{lc}
\hline \multicolumn{1}{c}{ Parameter } & Value \\
\hline Number of TF coils & 8 \\
Plasma current $I_{\mathrm{p}}, \mathrm{MA}$ & $0.3-1.0$ \\
Auxiliary drive power $P_{\text {aux }}, \mathrm{MW}$ & $2.0-4.5$ \\
TF coil steady-state resistive power $P_{\mathrm{TFC}}, \mathrm{MW}$ & $\leq 40$ \\
Total steady-state heat removal $P_{\text {cool }}, \mathrm{MW}$ & $\leq 50$ \\
\hline
\end{tabular}

\section{I.5.1 Cassette Divertor Assemblies}

The divertor assemblies are divided toroidally into eight identical modules (or cassettes) that are inserted into radial ports in the vacuum vessel. The design allows quick repair or changeout of a divertor without disturbing other systems. No service connections are made inside the vacuum vessel. All piping, instrumentation, current feeds, etc., can be premade and leak checked before installation of the cassette. Finally, small window-frame coils can be readily incorporated in the divertor module to control the divertor strike point locations. The divertor assembly can be adjusted nonaxisymmetrically over a range of $\pm 10 \mathrm{~mm}$ relative to the vacuum vessel.

\subsubsection{Demountable TF Coils and Centra: Core Assembly}

The eight multiturn TF coils provide up to $2.2 \mathrm{~T}$ steady state at the major radius of $0.75 \mathrm{~m}$. Each coil turn would be made from three sections connected at bolted joints. The jointed TF coil has several advantages. First, the PF coil set can be located inside the bore of the TF coils, which results in smaller, lower power PF coils; smaller out-ofplane forces on the TF coils; and easy replacement of the PF coil set. Second, the outer portion of the vacuum vessel can be fabricated as a complete unit that can be pretested before installation in the device. This allows more assembly and fabrication operations to proceed in parallel and can substantially shorten the overall construction schedule. Third, it is possible to replace a section of the TF coil, including the central core assembly, without disassembly of the entire machine.

The inner sections of all the TF coils form one assembly called the central core. The solenoid and divertor coils and the inner portion of the vacuum vessel are integral with the central core assembly. It is thus possible to replace this critical item without dismantling the entire machine. This also provides flexibility to install a modified central core to allow operation at lower (or higher) aspect ratios.

\section{I.5.3 Vacuum Vessel}

The vacuum vessel is a double-wall, water-cooled structure with maximum access to the plasma. Eight large radial ports at the midplane offer access for current drive and heating (normal or tangential), diagnostics, vacuum pumping or other services. Additional large $(80-\mathrm{cm}$ by $50-\mathrm{cm})$ radial ports above and below the midplane allow the cas- 
sette divertor modules to be inserted radially without disturbing the remainder of the tokamak device.

\section{I.5.4 PF Coils}

A versatile set of PF coils accommodates both $S N$ and DN plasma configurations and a range of aspect ratios from 1.8 to 3.2. All coils are located inside the bore of the TF coil set. The inner PF coils or solenoid coils are integral with the central core assembly and would be reconfigured with any changeout of the central core. Although there are no fast control coils inside the vacuum vessel, two passive stability loops on the outboard side of the plasma also serve as toroidal belt limiters.

\section{I.6 ADDITIONAL CONSIDERATIONS}

The TST relies on the physics and technology of existing small to medium-size tokamaks and uses the facilities and equipment available at a typical fusion institution (e.g., ORNL).

For the given physics and engineering assumptions, the requirements of $a \geq 0.3 \mathrm{~m}$, adequate induction flux ( $\psi_{\text {ind }} \geq 3 \times \psi_{\text {startup }}$ ), and $B_{\mathfrak{t} 0} \geq 2 \mathrm{~T}$ constrain the minimum-cost TST to $R_{0} / a=2.5$. If the latter two constraints are removed, the minimum cost (covering the tokamak, the divertor, and the H\&CD systems) occurs near $R_{0} / a=1.8$ (see Fig. I.1) [4].

These results provide the basis for the present choices of $R_{0} / a=2.5$ and 1.8 , the former dictated by solid database, the latter retained for potential physics improvements gained by using the cost-effective design while carrying out the mission of testing divertors.

The contribution of TST to fusion energy development relative to existing and other proposed tokamaks is shown by Table I.6, which lists the parameters of DIII-D, TST, SSAT, and ITER. TST is near the minimum size for producing high steady-state particle and heat fluxes in a divertor configuration, based on standard tokamak data. The contribution of TST to the testing of steady-state divertors is inserted among the major tokamak development needs for electric power production in Table 1.7. Here it is seen that TST relies on the divertor plasma physics innovations and development for limited plasma durations carried out for tokamaks such as DIII-D to select viable divertor concepts for steady-state tests. Fast turnaround times in replacing the cassette divertors, together with the steady-state capability (up to $100,000 \mathrm{~s}$ ), will permit comprehensive testing of many advanced concept divertors in TST within this decade. Demonstration of steady-state plasma operation, albeit at modest plasma core conditions, will complement the more advanced core parameters produced in DIII-D and to be tested in SSAT. A proven steady-state divertor will ensure that SSAT and ITER can carry out their missions expeditiously, especially if the cost and schedule impact of divertor repair or replacement in the latter tokamaks are judged to be unacceptably high.

The plans for SSAT and ITER will subject the divertors to integrated energy depositions of the order of $\dot{Q}_{\perp} \tau_{\mathrm{dura}}-200 \mathrm{MJ}$ for $\dot{Q}_{\perp}-0.2 \mathrm{MW} / \mathrm{m}^{2}$ in a single plasma pulse, more than three orders of magnitude beyond those achieved in tokamaks to date. 
ORNL-DWG 91M-2904R2 FED
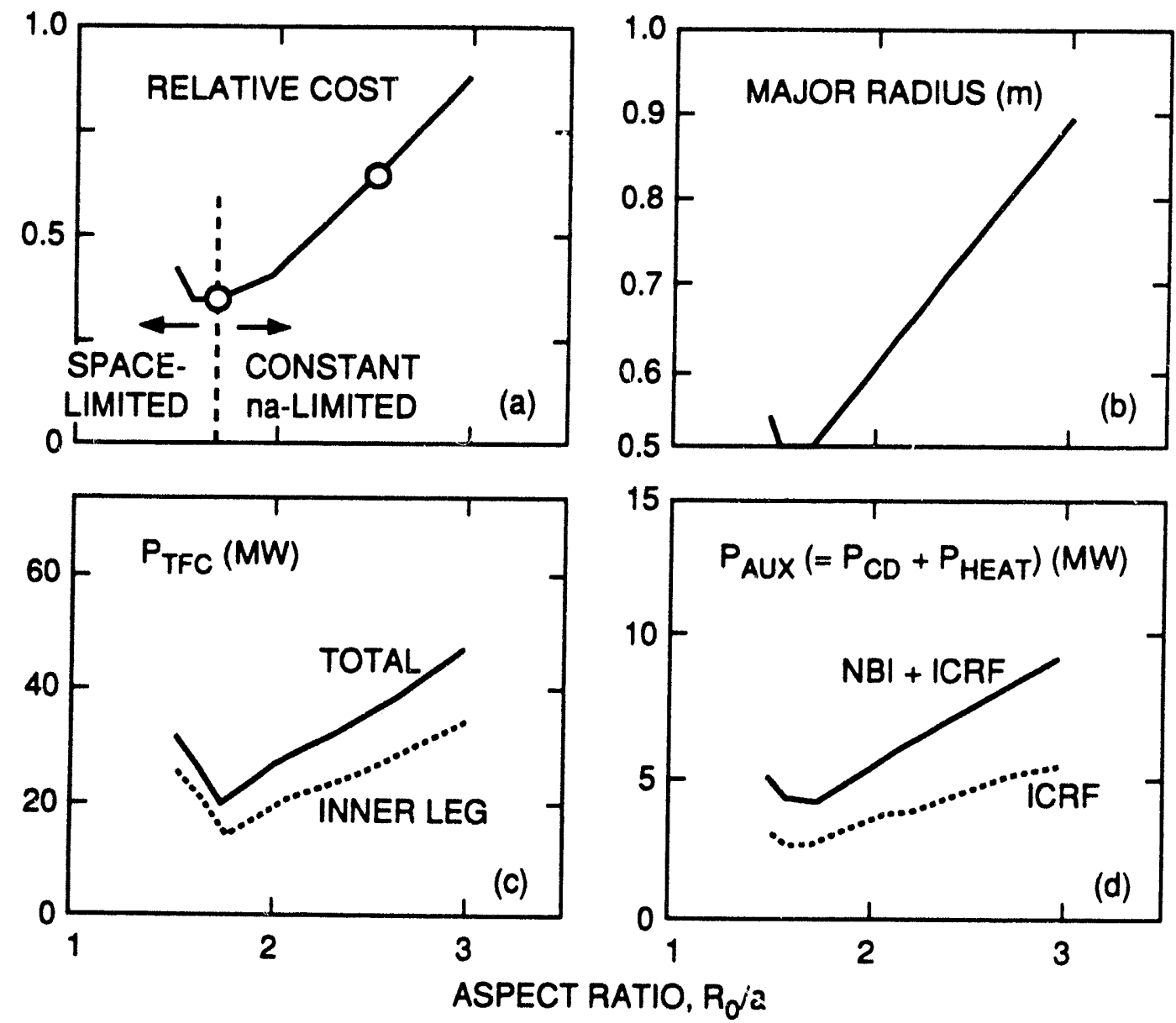

Fig. I.1. The $R_{0} / a$ dependence of the TST parameters with minimum $R_{0}$ and constant conditions for testing divertors: (a) relative cost for the tokamak, divertor, and auxiliary $H \& C D$, (b) the major radius $R_{0}$, (c) the resistive power of the TF coils $P_{\mathrm{TFC}}$, and (d) the total auxiliary power $P_{\text {aux }}$. The design is space-limited at low $R_{0} / a$ and naconstrained at larger $R_{0} / a$.

Possible upgrades to DIII-D and planned upgrades to JET will reduce this gap in $Q_{\perp} \tau_{\text {dura }}$ to two orders of magnitude. The need for listing divertors to $Q \perp \tau_{\text {dura }}-200$ $20,000 \mathrm{MJ} / \mathrm{m}^{2}$ in a tokamak is imminent, whether it is accomplished first in SSAT, ITER, or a dedicated small tokamak such as the TST. There is a strong basis for expecting that the integrated cost of fusion energy development with an R\&D step defined by the TST will be significantly lower than the integrated cost without this step. TST is therefore an R\&D device directed toward the divertor needs of SSAT and ITER, in the interest of increasing the cost-effectiveness of the latter.

Aside from the potential of a substantially lower cost and some added physics risks, the option of $R_{0} / a=1.8$ permits contributions to physics investigations of the lower $R_{0} / a$ regime under steady-state conditions in addition to testing divertor solutions. 
Table I.6. TST parameters compared with those of DIII-D, SSAT, and ITER

\begin{tabular}{|c|c|c|c|c|}
\hline & DIII-D & TST & SSAT & ITER \\
\hline Major radius $R_{0}, \mathrm{~m}$ & 1.65 & $\leq 0.75$ & 2.25 & $\sim 7.8$ \\
\hline Minor radius $a, \mathrm{~m}$ & $\leq 0.64$ & $\leq 0.38$ & $\leq 0.5$ & $\sim 2.8$ \\
\hline Aspect ratio $R N a$ & $\geq 2.5$ & $1.8-2.5$ & $\geq 4.5$ & $\geq 2.8$ \\
\hline Plasma current $I_{\mathrm{p}}, \mathrm{MA}$ & $\leq 2.0$ & $\sim 0.5$ & $\leq 2.0$ & 25 \\
\hline Toroidal field $B, T$ & 2 & $\leq 2.2$ & $3.4-5$ & 5 \\
\hline Average density, $10^{20} \mathrm{~m}^{-3}$ & $\leq 1.2$ & $\leq 0.6$ & $\leq 1.5$ & 1.1 \\
\hline Average temperature, $\mathrm{keV}$ & $\leq 5$ & $\leq 2$ & $\leq 7$ & 15 \\
\hline Heating and current drive power, $\mathrm{MW}$ & 20 & $2.0-4.5$ & 40 & 300 \\
\hline Average edge heat flux, $\mathrm{MW} / \mathrm{m}^{2}$ & $\sim 0.2$ & $-0.1-0.22$ & $\sim 0.35$ & $\sim 0.15$ \\
\hline Scrape-off layer connection length, $m$ & $\sim 25$ & -30 & $\sim 40$ & $\sim 100$ \\
\hline Total steady-state supply required, MW & - & $\sim 55$ & $\sim 200$ & $\sim 500$ \\
\hline Plasma duration, $\mathbf{s}$ & $\sim 10$ & $\sim 10^{5}$ & $\sim 10^{5}$ & $\sim 10^{3}$ \\
\hline
\end{tabular}

Table 1.7. The tokamak fusion energy development needs and the TST mission addressing the steady-state power and particle handling of divertors $(\bullet=$ mission, $\mathrm{O}=$ database required, $-=$ database not required $)$

\begin{tabular}{lccccc}
\hline Tokamak development needs & DIII-D & TST & SSAT & ITER & DEMO \\
\hline Divertor plasma physics & - & 0 & 0 & 0 & 0 \\
Steady-state divertors & & $:$ & 0 & 0 & 0 \\
Steady-state demonstration & & & $:$ & - & 0 \\
Steady-state advanced physics & & & & - & 0 \\
Ignition and stationary burn & & & & - & 0 \\
Nuclear technologies & & & & $\bullet$ \\
Electric power production & & & & \\
\hline
\end{tabular}

This direction of fusion research is related to tokamak improvements that could make possible tests of nuclear technology using units at modest sizes $\left(R_{0} \leq 1 \mathrm{~m}\right)$ and fusion powers $(\sim 15 \mathrm{MW})$ and significant neutron wall loads $\left(W_{\mathrm{L}} \sim 1 \mathrm{MW} / \mathrm{m}^{2}\right)[5]$.

\section{References for Section I}

[1] D. E. Baldwin (Chair) et al., "U.S. National Review of the ITER Conceptual Design Activity," Univ. Texas, March 1991.

[2] P. H. Rebut, "Future Prospects for JET and Next Step Tokamaks," p. 171 in Fusion Technology 1990, Vol. 1, North-Holland, Amsterdam, 1991.

[3] M. A. Mahdavi et al., "Divertor Baffling and Biasing Experiments on DIII-D," p. 335 in Plasma Physics and Controlled Nuclear Fusion Research 1990, Vol. 1, IAEA, Vienna, 1991.

[4] J. Galambos, Y.-K. M. Peng, B. Nelson, S. P. Hirshman, and P. J. Fogarty, "Scoping Studies for Small Steady-State Tokamaks for Divertor Testing," p. 1114 
in Proceedings of the 14th IEEE Symposium on Fusion Engineering, San Diego, 1991, IEEE, New York, 1991.

[5] Y-K. M. Peng, J. D. Galambos, and P. C. Shipe, "Small Tokamaks for Fusion Technology Testing," Fusion Technol. 21, 1729 (1992). 


\section{THE TST PHYSICS BASIS}

The physics basis for the plasma behavior projected for the TST is discussed and summarized in this section. The plasma operation window is presented first to quantify the reference parameters chosen for the design (Sect. II.1). Among the constraints that limit the window are the steady-state current drive considerations (Sects. II.3-II.5) and the plasma edge and divertor conditions (Sects IV.1 and IV.2). The considerations for plasma startup and shaping of magnetohydrodynamic (MHD) equilibrium divertor configurations are summarized in Sects. II.2 and II.6. These subjects are important in setting requirements for the TST design. Our emphasis is on the full-size $\left(R_{0} / a=2.5\right)$, fullfield $\left(B_{t 0}=2.2 \mathrm{~T}\right)$ design, with the option for $R_{0} / a=1.8$ discussed to highlight differences in database and operation approaches.

\section{II.1 THE PLASMA OPERATION WINDOW}

The plasma behavior expected in the full-capability TST $\left(R_{0} / a=2.5, B_{\mathrm{t} 0}=2.2 \mathrm{~T}\right)$ is within the standard tokamak database and can therefore be defined with confidence. Here we summarize the well-known linits on tokamak confinement and stability. Limits stemming from current drive (Sects. II.2-II.5) and divertors (Sects. IV.1 and IV.2) are also included here to bound the reference parameters listed in Table I.1.

ICH is added to TST to produce plasma temperatures and edge heat fluxes adequate for steady-state operation and divertor testing. With a proper launcher design (Sect. III.3), ion cyclotron fast waves can also be launched to take advantage of the possible success of FWCD tests in DIII-D, Tore Supra, JET, and JT-60 in the next few years (Sect. II.5). The key difference for operation with $R 0 / a=1.8$ and $B_{\mathfrak{t} 0}=1.4 \mathrm{~T}$ is the need to use NBI current drive (NBCD) during Phase I to produce $\left\langle n_{\mathrm{e}}\right\rangle \sim 0.3 \times 10^{20} \mathrm{~m}^{-3}$. Use of LH current drive (LHCD) alone will limit $\left\langle n_{\mathrm{e}}\right\rangle$ to $0.1 \times 10^{20} \mathrm{~m}^{-3}$ because of the lowered $B_{\mathrm{t} 0}$ (Sect. II.3). This density would be inadequate for the high-recycle conditions needed for testing divertors (Sect. IV.2). The absence of a significant inductive capability also suggests the need for noninductive current initiation and ramp-up, the database for which is readily available from LHCD experiments on the Princeton Large Torus (PLT) and JT-60 over the past ten years.

The reference parameters in Table I.1 are based on the physics constraints given in Table II.1 [1-3]. Here the $\mathrm{H}$-factor $\left(H_{f}\right)$ is set at 1.5 because this value has been observed for stationary H-mode plasmas in DIII-D. The H-mode ensures that the stationary plasma temperature at the edge will be similar to that in future large tokamaks $\left(T_{X} \approx 0.2 \mathrm{keV}\right)$. The threshold power for access to the H-mode is estimated to be $P_{\mathrm{Hth}} \approx$ $0.5 \mathrm{MW}$, well below the power level of Phase I $\left(P_{\text {tot }}=2.0 \mathrm{MW}\right)$. For the plasma densities and temperatures indicated in Table I.1, the Troyon factor for the thermal beta $(g$ Tth) is calculated to be less than $0.02 \mathrm{~T} \cdot \mathrm{m} / \mathrm{MA}$.

With NBI and/or ICH at $1.5 \mathrm{MW}$ and $2.0 \mathrm{MW}$, respectively (Sects. II.3 and II.4), the plasma beta due to the suprathermal component $\left(\beta_{h}\right)$ can be as high as $30 \%$ of the total, particularly when $\left\langle n_{\mathrm{e}}\right\rangle$ is near $0.3 \times 10^{20} \mathrm{~m}^{-3}$. Here the subscript $\mathrm{h}$ denotes the suprathermal particles. The fraction of these particles $\left(n_{\mathrm{h}} / n_{\mathrm{e}}\right)$ is estimated to be about 0.02 . For stability of the toroidal Alfven eigenmodes, the suprathermal particle density gradient length scale $\left(L_{\mathrm{nh}}\right)$ [2] needs to be greater than about $5 \mathrm{~cm}$, assuming that the 
Table II.1. Tokamak physics asslunptions and constraints for TST

\begin{tabular}{|c|c|}
\hline Assumption & Constraint \\
\hline Stationary ELMing H-mode & H-factor $\left(H_{\mathrm{f}}\right)=1.5$ \\
\hline Access to $\mathrm{H}$-mode & $P_{\text {tot }} \geq P_{\text {Hth }} \approx 0.5 R_{00995} B_{t 0} \mathrm{MW}[1]$ \\
\hline First MHD stability regime & Troyon factor $g_{\mathrm{T}} \leq 0.03 \mathrm{~T} \cdot \mathrm{m} / \mathrm{MA}$ \\
\hline $30 \%$ of pressure due to energetic particles & Thermal component $g \mathrm{Tth} \leq 0.02 \mathrm{~T} \cdot \mathrm{m} / \mathrm{MA}$ \\
\hline Stability of toroidal Alfvén eigenmodes [2] & Scale length $L_{\mathrm{nh}} \geq 6 \beta_{\mathrm{h}} m_{\mathrm{h}} n_{\mathrm{e}} / m_{\mathrm{i}} n_{\mathrm{h}} \mathrm{cm}$ \\
\hline $\begin{array}{l}\text { ITER-level plasma edge heat flux } \\
\text { (phase I, II) }\end{array}$ & $\begin{aligned} \dot{Q}_{\perp} & \approx 0.7 P_{\mathrm{to}} / 4 \pi^{2} R_{0 a \mathrm{~K}} 95 \\
& \geq(0.1,0.2) \mathrm{MW} / \mathrm{m}^{2}\end{aligned}$ \\
\hline Disruption-free operation [3] & $\begin{array}{l}\text { Edge density } n_{\times} \leq n_{\times} \text {dis } \\
\qquad 00.72 Q_{\perp} 0.57 B_{\mathfrak{t} 0} 0.31 /\left(q_{95} R_{0}\right)^{0.09} 10^{20} \mathrm{~m}^{-3}\end{array}$ \\
\hline $\begin{array}{l}\text { Capability of high-recycle divertor } \\
\text { conditions }\end{array}$ & Edge density $n_{\times} \geq 0.15 \times 10^{20} \mathrm{~m}^{-3}$ \\
\hline Adequate connection length in SOL & Edge-to-divertor $L_{\mathrm{SOL}} \approx 6 R_{0995} \geq 30 \mathrm{~m}$ \\
\hline
\end{tabular}

mass ratio of the species $\left(m_{\mathrm{h}} / m_{\mathrm{i}}\right)$ can be as high as two. This condition is readily satisfied in TST.

For $P_{\text {tot }}=2.0 \mathrm{MW}$ and $4.5 \mathrm{MW}$ for Phases I and II, respectively, the average heat flux at the plasma edge $\left(Q_{\perp}\right)$ is estimated to be at the levels anticipated for ITER. This in turn determines the density limit on $n_{\times}$to avoid disruptions. Furthermore, the edge density can be related to $\left\langle n_{\mathrm{e}}\right\rangle$ according to recent data for H-mode plasmas in DIII-D (Sect. IV.2), which suggest that $n_{\times} /\left\langle n_{\mathrm{e}}\right\rangle \approx 0.5$ can be regularly produced for the $n_{\times}$and $T_{X}$ values expected in the TST. To ensure a connection length of the SOL $L S O L \approx 30 \mathrm{~m}$, adequate for simulating the edge and divertor condition of ITER and other large steady-state tokamaks, the safety factor at the plasma edge $\left(q_{95}\right)$ is maintained at seven or more for the reference plasma current $\left(I_{\mathrm{p}}\right)$ of $0.5 \mathrm{MA}$.

With these considerations, the steady-state operation window for TST can be calculated [4] and is shown in Fig. II.1. It is seen that a region of $\langle T\rangle_{n}=1.0-1.5 \mathrm{keV}$ and $\left\langle n_{\mathrm{e}}\right\rangle=(0.30-0.45) \times 10^{20} \mathrm{~m}^{-3}$ is available. The boundaries to the window are (1) the high-recycle condition, $\left\langle n_{\mathrm{e}}\right\rangle=2 n_{\times} \geq 0.3 \times 10^{20} \mathrm{~m}^{-3}$ (Sect. IV.2), (2) the total power limit $P_{\text {tot }} \leq 4.5 \mathrm{MW}$ assuming $H_{\mathrm{f}}=1.5$, and (3) the steady-state current drive (CD) requirements (Sects. II.3 and II.4). This window is expected to be adequate for the mission of testing divertors.

Note that recent data not assumed in Table II.1 may relax the latter two boundaries. Experiments on ASDEX have suggested that $H_{\mathrm{f}}$ approaching $2.0 \mathrm{can}$ be obtained for stationary $\mathrm{H}$-mode plasmas. Experiments with combined $\mathrm{NBCD}, \mathrm{ICH}$, and $\mathrm{LHCD}$ in TEXTOR and JET have suggested that the CD efficiencies can be enhanced significantly by certain synergistic mechanisms, not yet adequately understood (Sect. II.5). These improvements could expand the projected window toward the bounds set by MHD stability $\left(g_{\text {Tth }}=0.02 \mathrm{~T} \cdot \mathrm{m} / \mathrm{MA}\right)$ and disruptions $\left(n_{\times}=n_{\mathrm{Xdis}}\right)$. In this case, the operation window for the TST could be as large as $\langle T\rangle_{n}=0.7-2.1 \mathrm{keV}$ and $\left\langle n_{\mathrm{e}}\right\rangle=$ $(0.3-0.7) \times 10^{20} \mathrm{~m}^{-3}$. 


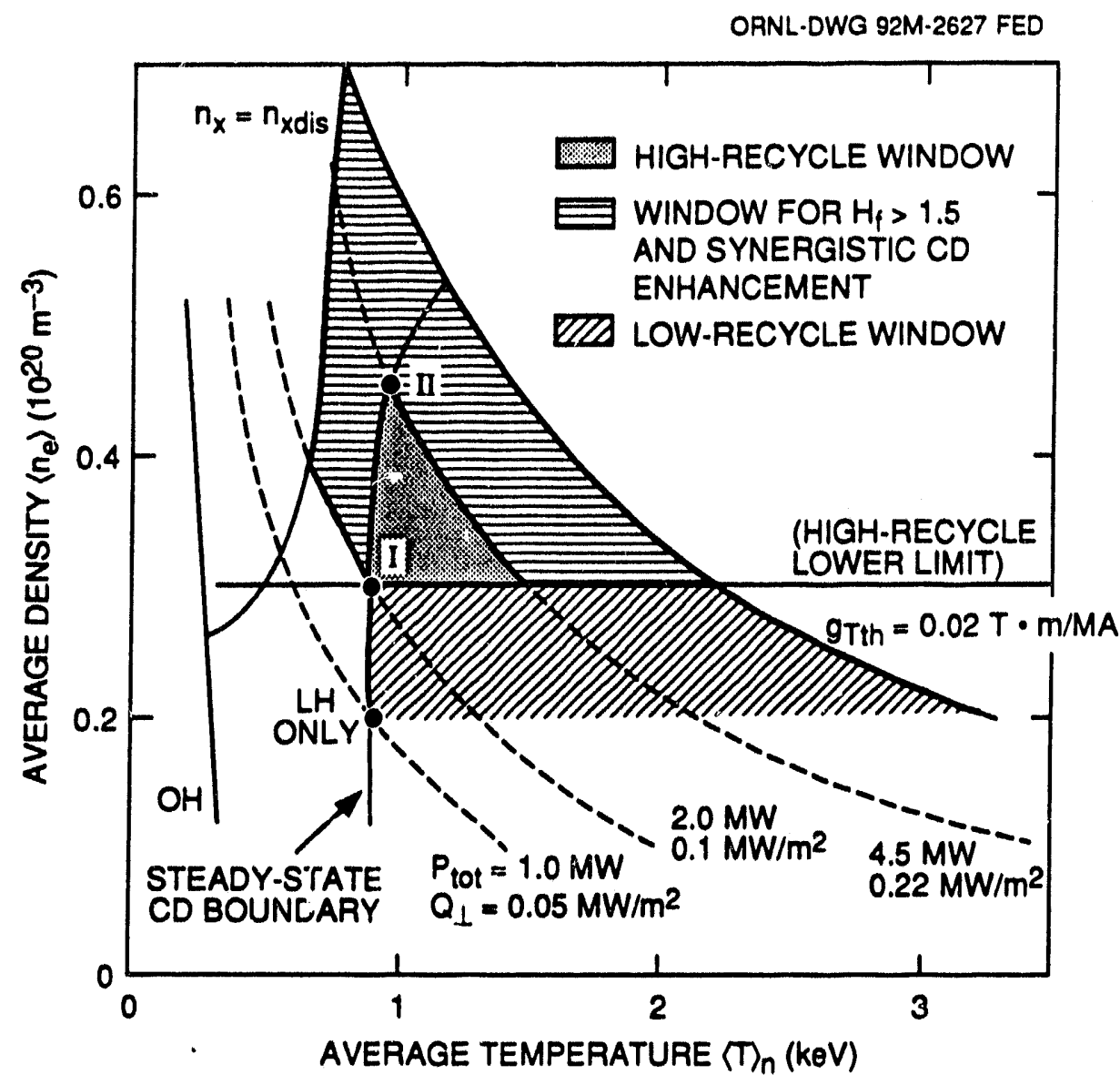

Fig. II.1. Operation window of the TST plasma for Phases I and II, bounded by steady-state current drive (CD), high-recycle divertor, and $P_{\text {tot }} \leq 4.5 \mathrm{MW}$ constraints. An enlarged window (bounded only by $g_{\mathrm{T} \text { th }} \leq 0.02 \mathrm{~T} \cdot \mathrm{m} / \mathrm{MA}$ and $n_{x} \leq n_{x \text { dis }}$ ) could become available if $H_{\mathrm{f}}>1.5$ and the $C D$ efficiencies are enhanced by synergistic effects, as suggested by recent data from JET and TEXTOR (Sect. II.5).

\section{II.2 PLASMA CURRENT INITIATION}

The requirements for plasma breakdown and ramp-up are calculated using analytical formulas to represent the circuits of the Ohmic heating $(\mathrm{OH})$ coils. The result is an initial estimate of the $\mathrm{OH}$ power supply requirements. The inductive coupling of the $\mathrm{OH}$ coils with the inner wall of the vacuum chamber is taken into account, but inductive couplings with other coils are neglected.

Details of the formulas used in the discussion are given in Appendix B. The TST design calls for four $\mathrm{OH}$ coils wound on the center column of TST. For calculational simplicity, these coils are considered as a single coil with $97 \mathrm{turns} / \mathrm{m}$, a resistance of $15.2 \mathrm{~m} \Omega$, an area of $0.42 \mathrm{~m}^{2}$, and an inductance of $8.1 \mathrm{mH}$. Full voltage from a $300-\mathrm{V}$ power supply is assumed to be switched on for plasma breakdown. The plasma breakdown voltage from this coil will be 


$$
V_{\text {loop }}=-\mu_{0} \frac{N_{\text {sol }}}{l_{\text {sol }}} \frac{A_{\text {sol }}}{R_{\text {sol }}} \frac{V_{\text {sol }}}{\tau_{1}}=3.6 \mathrm{~V} \text {, }
$$

where

$$
\tau_{1}=\frac{L_{\mathrm{sol}} L_{\mathrm{vv}}-M^{2}}{R_{\mathrm{sol}} L_{\mathrm{vv}}} \approx 0.28 \mathrm{~s} .
$$

In this equation, the vacuum vessel inductance $L_{\mathrm{vv}}=0.6 \mu \mathrm{H}$, and the mutual inductance with the solenoid $M=48 \mu \mathrm{H}$. The time constant $\tau_{1}$ is dominated by the $L / R$ time constant of the $\mathrm{OH}$ solenoid. The interaction of the $\mathrm{OH}$ coils with the vacuum vessel decreases the solenoid's time constant by about a factor of two.

Since there are four $\mathrm{OH}$ coils, the inductance of each one will be a quarter of that of the composite coil, so that the loop voltage will be $-14.4 \mathrm{~V}$. This should be more than adequate for breakdown even if electron cyclotron heating (ECH) assist is not applied. However, further refinements in the calculations to take into account the inductive couplings with the other poloidal coils and the internal capacitance of the power supply could significantly modify this voltage.

The vo'age necessary for breakdown was studied in DIII-D [6]. Ohmic voltage breakdown was achieved with $E \sim 0.25 \mathrm{~V} / \mathrm{m}(1.25 \mathrm{~V} / \mathrm{m}$ in TST) and with $E \sim 0.15 \mathrm{~V} / \mathrm{m}$ $(0.75 \mathrm{~V} / \mathrm{m}$ in TST) employing an ECH assist. The limit in achieving lower breakdown voltages in DIII-D seemed to be the effective connection length of magnetic field lines to the vacuum vessel walls.

A crude model (see Appendix B) for the volt-seconds necessary to establish a plasma current $I_{\mathrm{p}}=0.5 \mathrm{MA}$ shows that about $1 \mathrm{~V} \cdot \mathrm{s}$ is needed. It is assumed that after breakdown (10-30 ms) the solenoid voltage is decreased and then ramped up to increase the plasma current. This must be done in a manner that compensates for the exponential $L / R$ loop voltage decay. The maximum current density in the solenoid windings will be $4.6 \mathrm{kA} / \mathrm{cm}^{2}$. The current in the vacuum vessel inner wall will be $1.1 \mathrm{kA}$.

Given that the confinement and $\mathrm{CD}$ properties for $R_{0} / a=1.8$ remain tokamak-like, the operation window for the plasma with lower $R_{0} / a$ will be similar to that shown in Fig. II.1. This can be seen by examining the $R_{0} / a$ dependence of the beta limit. Over the range of interest, it can be shown that [5]

$$
I_{\mathrm{p}} / a B_{\mathrm{t} 0} \approx 1.9 \kappa_{95}^{2} \varepsilon^{0.5} / 995(1-\varepsilon)^{0.9}, \varepsilon \equiv a / R_{0} .
$$

Thus for constant $q_{95}, I_{\mathrm{p}} / a B_{\mathrm{t} 0}$ increases by a factor of about 2 if $R_{0} / a$ is reduced from 2.5 to 1.8 . This leads to a similar increase in the first stability $\beta$ limit, for a constant $g_{\mathrm{T}}$. This effect permits a nearly constant plasma pressure as $B_{\mathrm{t} 0}$ is reduced from $2.2 \mathrm{~T}$ to $1.4 \mathrm{~T}$, leaving the stability boundary in Fig. II.1 unchanged. As can be seen from Table II. $1, n_{\times \text {dis }}$ is reduced by about $20 \%$ from the previous case, leading to no impact on the standard operational window and a relatively minor reduction of the larger window in $\langle T\rangle_{n}$. 


\section{II.3 PLASMA CURRENT MAINTENANCE AT MODEST DENSITIES}

\section{II.3.1 Lower Hybrid Current Drive}

LH waves have been used to maintain current in a number of tokamaks with no loop voltage. Figure II. 2 shows experimental data from a number of tokamaks that have operated in this mode. LHCD is a reliable method of current drive that has been demonstrated in many machines, both large and small.

A 2.45-GHz, 1.5-MW LH system is adequate to drive current on TST. For purposes of system design, we assume that such a system will be available for use on TST and will be able to deliver $\sim 1 \mathrm{MW}$ of LH power to the plasma steady state.

Depending on the magnetic field and on the frequency and lau, shed spectrum of the $\mathrm{LH}$ wave, the density range at which current can be driven is restri.ted. Figure II. 3 shows a plot of this limitation in magnetic field and density space. The curves show an accessibility requirement for LH propagation: for a frequency of $2.45 \mathrm{GHz}$, a given value of $B$ (the absiissa), and a prescribed value of $N_{\|}$(the labels on the curves), only density values to the right of and below the curve are accessible. Points obtained from the literature at which various machines have operated are shown by the shaded circles. In most cases, the points described in the literature are those at which the maximum current drive efficiency has been obtained, corresponding to the uppermost data points in Fig. II.2, with values of $N_{\|} \leq 1.8$. The operating point that we propose for TST is shown by the black circle. For this case, operation at $0.3 \times 10^{20} \mathrm{~m}^{-3}$ will be obtained at a value of launched $N_{\|}$of 2.1 or larger.

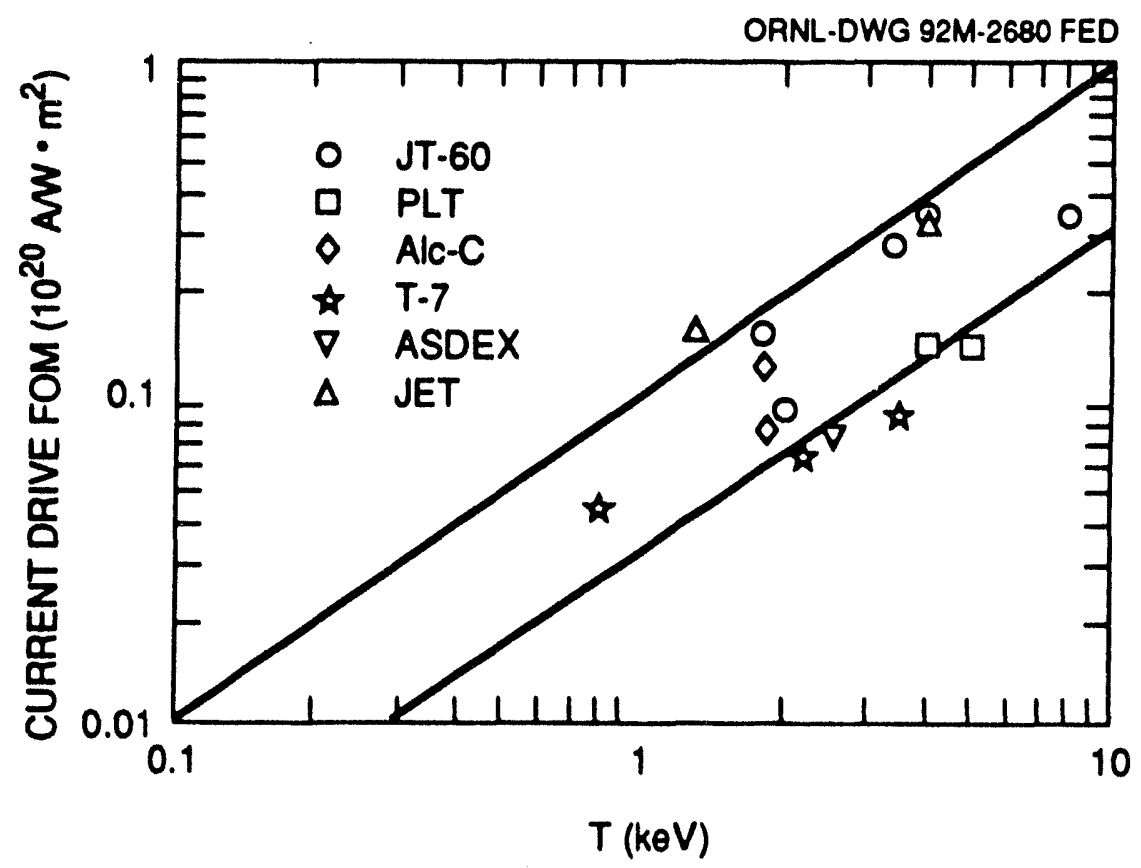

Fig. II.2. Experimental results for $\gamma_{\mathrm{LH}}\left(10^{20} \mathrm{~A} / \mathrm{W} \cdot \mathrm{m}^{2}\right)$ vs central electron temperature for a number of different tokamaks. Results plotted are only for those cases with $V_{\text {loop }}=d I / d t=0$. Graph from INTOR Report Phase Two A, Part III, Chapter V (IAEA, Vienna, 1988), with recent points added. Recent points are plotted assuming that $T_{\mathrm{e} 0} \approx 2\left\langle T_{\mathrm{e}}\right\rangle$. 
ORNL-DWG 92M-2681 FED

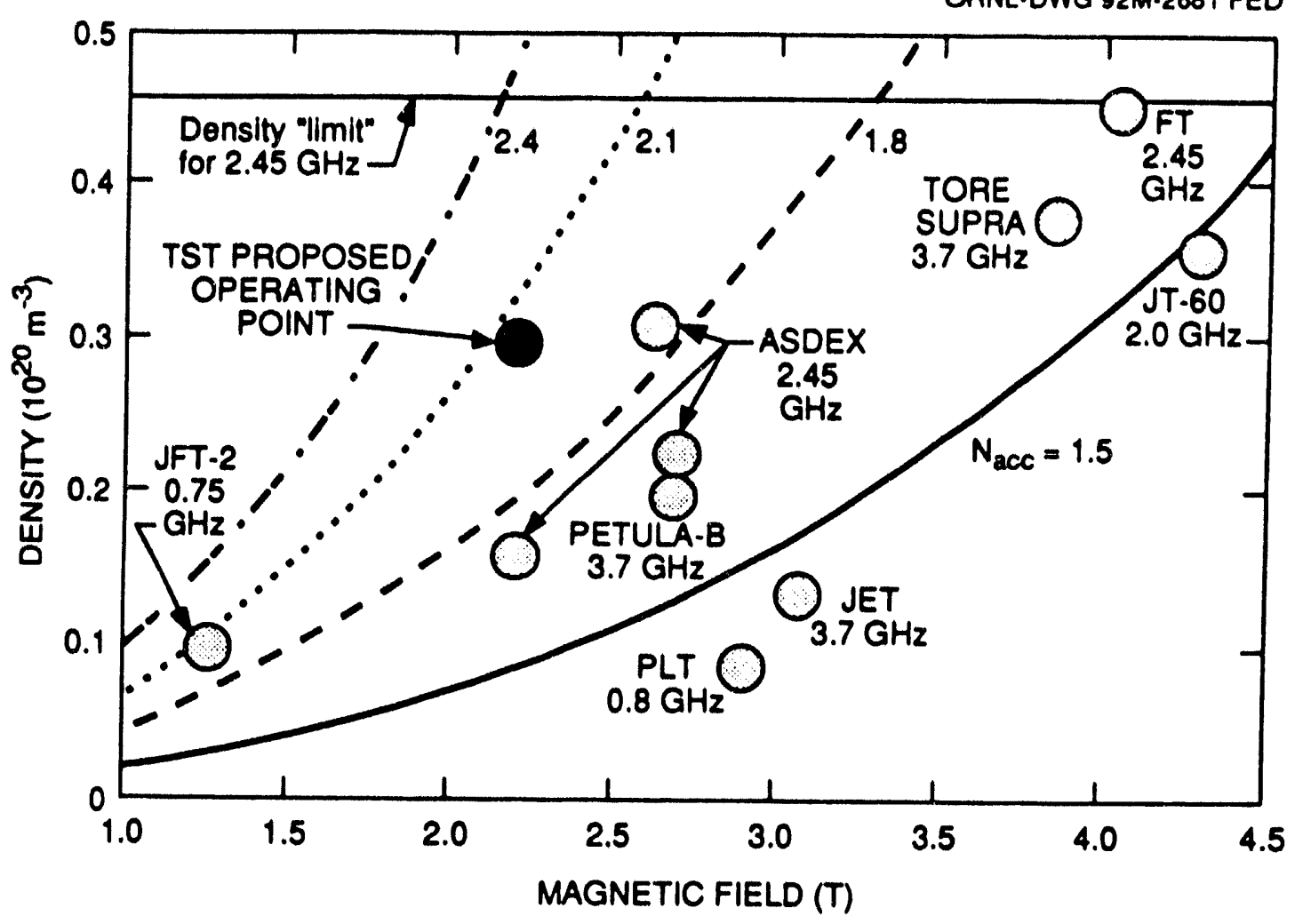

Fig. II.3. Accessibility curves in density vs magnetic field for different values of launched wave index $\left(N_{\mathrm{acc}}\right)$. Shaded points indicate experimental operation of different machines; the large black point indicates a proposed operating point for TST. on $N_{\|}$,

The CD efficiency figure of merit $\gamma$ for LHCD has an inverse square dependence

$$
\gamma_{\mathrm{LH}}\left(\equiv \frac{n R_{0} I_{\mathrm{cd}}}{P_{\mathrm{cd}}}\right) \sim \frac{1}{N_{\|}^{2}},
$$

according to most theories. Calculations indicate that the steady-state 1.0-MW LH system will provide adequate power to drive $0.5 \mathrm{MA}$ of current. Bonoli [7] has carried out calculations for TST using the ACCOME code [8] to estimate the LH current and current profile that can be attained. For $P_{\mathrm{LH}}=0.9 \mathrm{MW}$ and a volume-averaged density $n=3 \times 10^{19} \mathrm{~m}^{-3}$, the calculations gave $600-800 \mathrm{kA}$ of driven current. This included LH-driven current only; the bootstrap current (typically 60-100 kA) would be in addition to this value. Key assumptions made for this calculation include:

$N_{\|}$spectrum

Temperature profile

Density profile

$T_{0}$

$n_{0}$

Launcher location
Peak at 3.0, extending \pm 0.5

$$
\begin{aligned}
& \left.T_{0}\left[1-(r / a)^{2}\right)\right]^{1.0} \\
& \left.n_{0}\left[1-(r / a)^{2}\right)\right]^{0.5} \\
& 3.33 \mathrm{keV} \\
& 4.5 \times 10^{19} \mathrm{~m}^{-3} \\
& 20-30 \mathrm{~cm} \text { above midplane }
\end{aligned}
$$


Figure II. 4 shows the results of this calculation. The left side is a plot of the current density generated by the absorbed LH power vs the normalized poloidal flux $\psi$, and the right side is a plot of the resulting $q$ profile for a total current of $600 \mathrm{kA}$.

In addition to the accessibility limitations, there is an approximate absolute upper bound on the use of $\mathrm{LH}$ for $\mathrm{CD}$, given by the horizontal line in Fig. II.3. This line is the value of density at which most of the LH power is absorbed directly by the ions instead of the electrons (and so is not available to drive current) [9]. In order to drive current at higher density values, the operating frequency must be increased. However, the accessibility condition becomes more restrictive as the frequency is increased (i.e., the curve for a given value of $N_{\text {acc }}$ moves to the right in Fig. II. 3 for higher frequency), so in order to operate at higher density values, both the frequency and the magnetic field must be increased. Practically, this limits the use of LHCD in TST to volume-averaged densities no greater than 0.3 (possibly 0.4$) \times 10^{20} \mathrm{~m}^{-3}$.

\section{II.3.2 Ion Cyclotron Heating}

ICH will be used to provide auxiliary heating power to the plasma in TST. This may be of particular importance to ensuring a temperature adequate for efficient LHCD. Figure II.5 shows a plot of the resonant frequencies of hydrogen and helium ions as a function of major radius in the TST plasma, for $B_{0}=2.2 \mathrm{~T}$ and $R_{0} / a=2.5$. Also shown are the frequency ranges that are covered by the Brown Boveri (BBC) power units (6-20 MHz, $1 \mathrm{MW}$ steady state) and the Fusion Materials Irradiation Test (FMIT) unit (40-80 MHz, $1 \mathrm{MW}$ steady state) at ORNL; these units are described in more detail in Sect. III.3. The frequency range of the BBC units can be extended up to $26 \mathrm{MHz}$ with some minor modifications; this would provide the capability to heat exactly at the center of the plasma at full field, if needed.

The main heating mode to be used for the $20-\mathrm{MHz}$ system is $\mathrm{He}^{3}$ minority heating in a deuterium majority background. This will deposit the heat slightly outside the geometric center of the machine, at $R / R_{0} \approx 1.1$. Figure II.6 shows the radial power deposi-
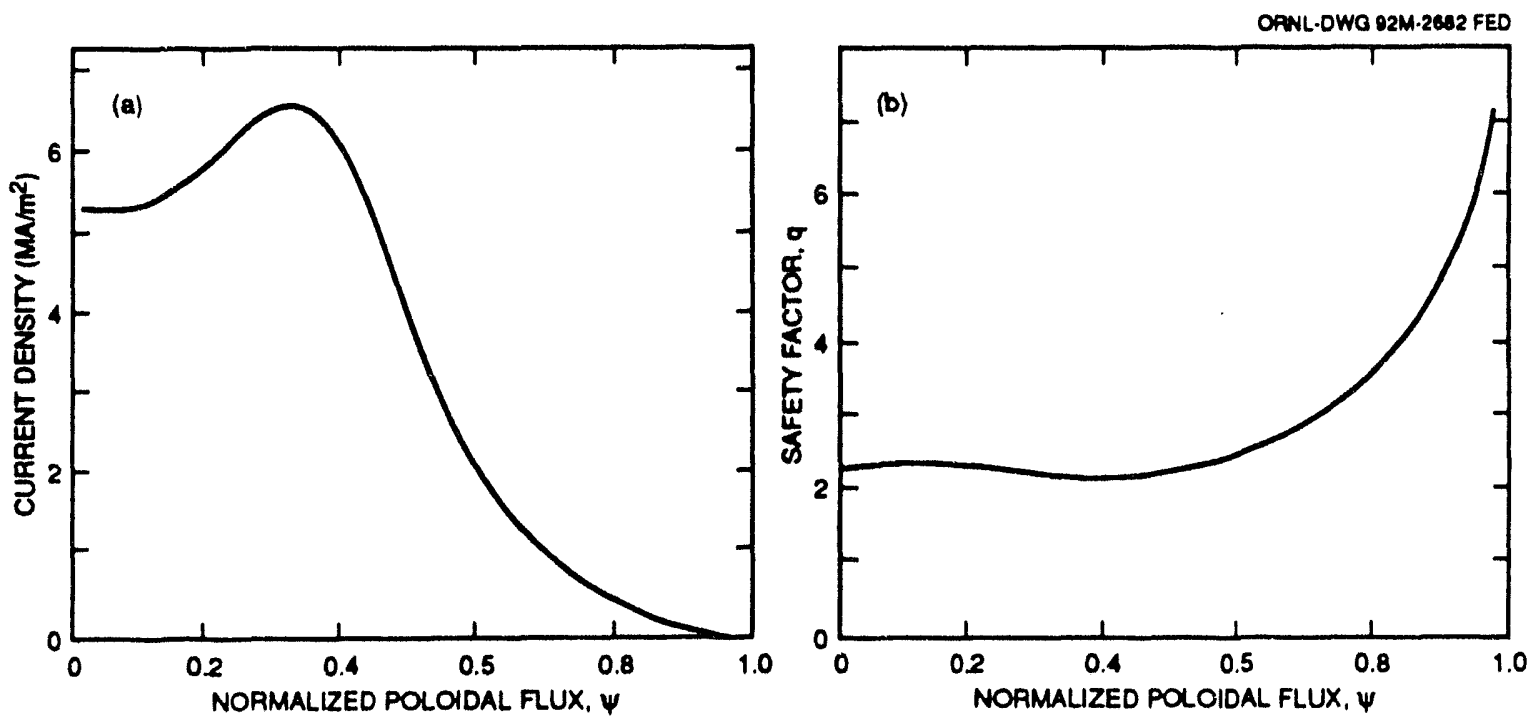

Fig. II.4. Calculated current density profile and $q$ profile from $0.9 \mathrm{MW}$ of LHCD power injected into a TST plasma with $n \approx 0.3 \times 10^{20} \mathrm{~m}^{-3}$ and $T_{\mathrm{e}} \approx 3.3 \mathrm{keV}$. 


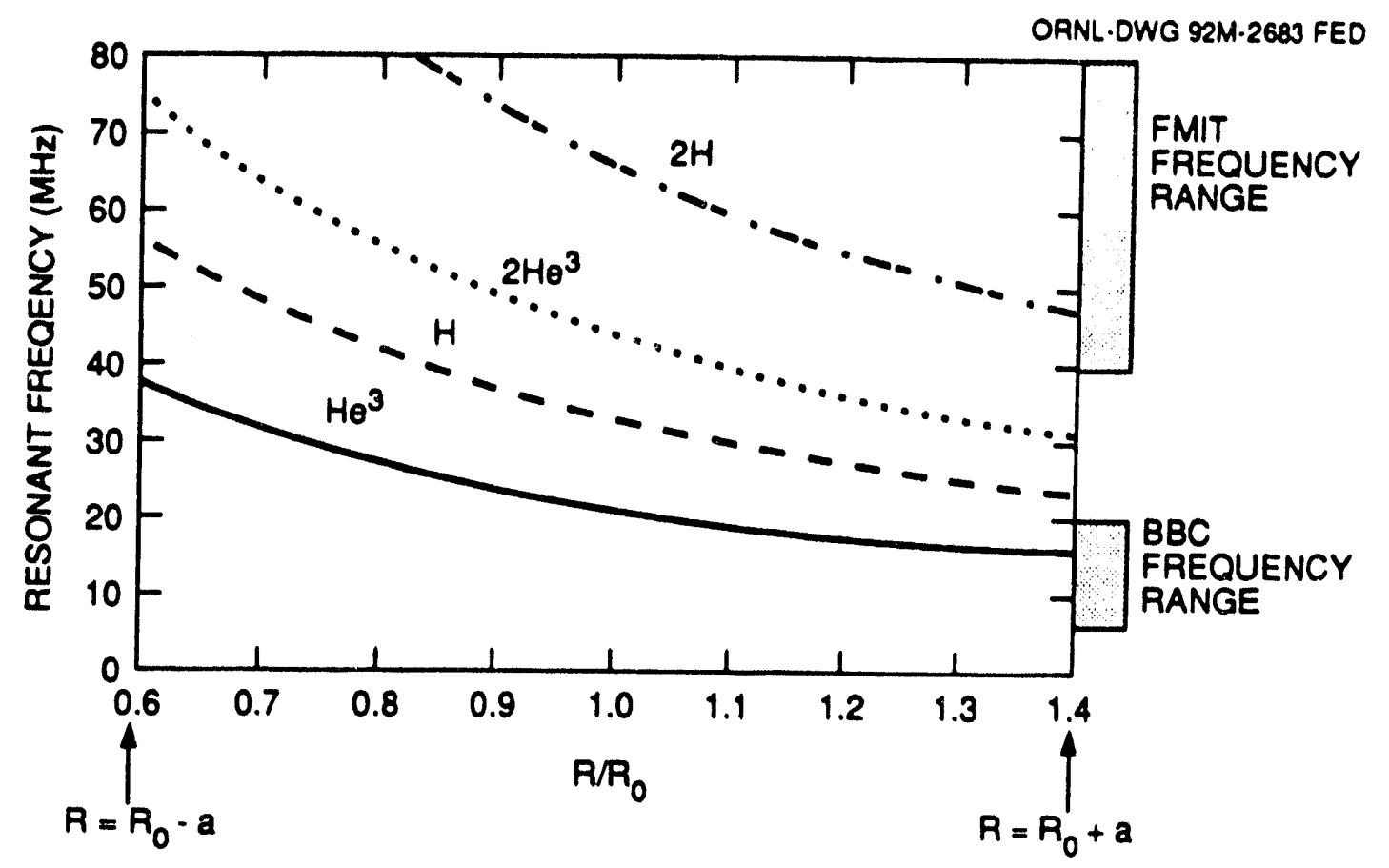

Fig. II.5. Resonant frequencies of ion species in TST, and the frequency ranges covered by existing if power units at ORNL.

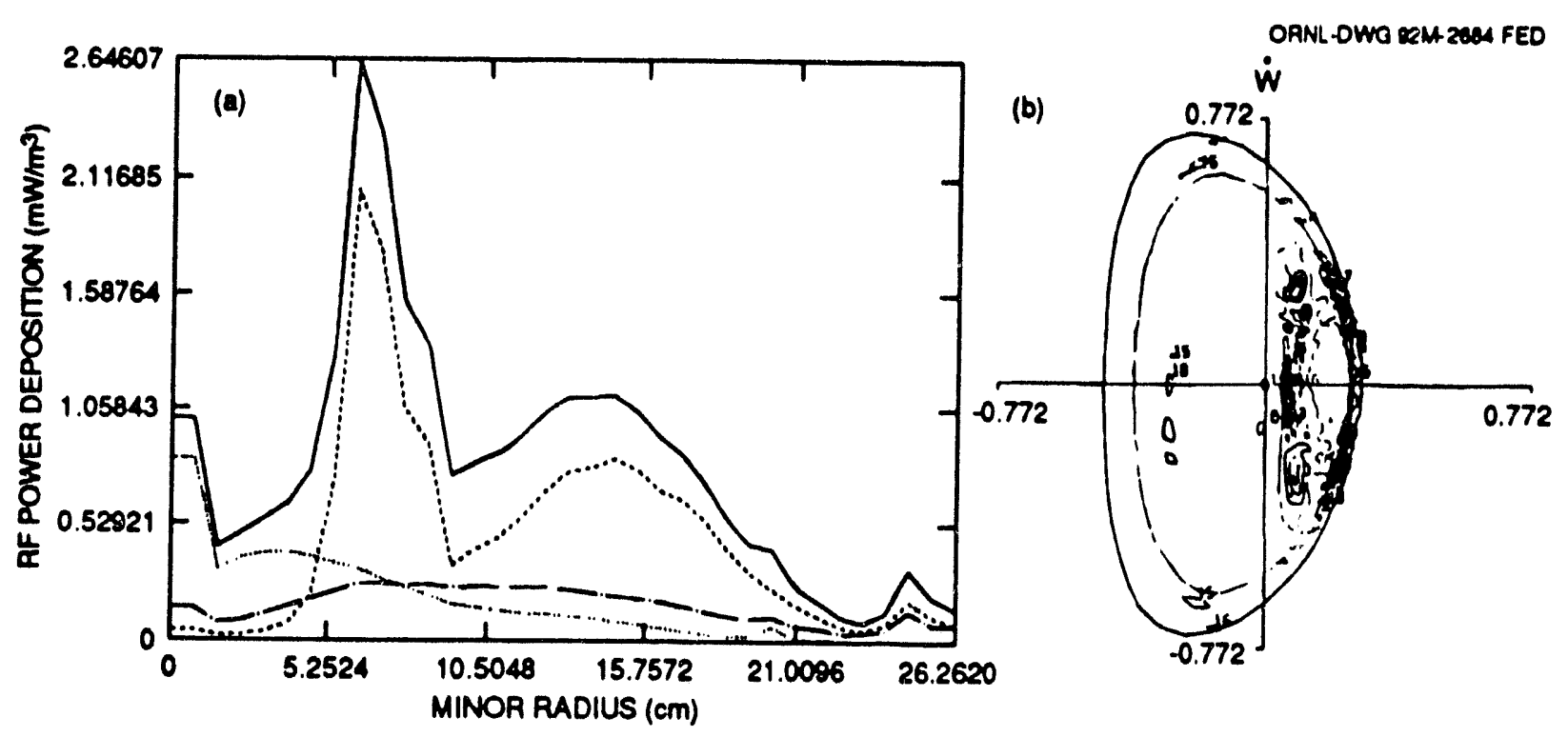

Fig. II.6. (a) Flux-surface-average rf power deposition vs minor radius for a $20-\mathrm{MHz}$ wave launched into a $5 \% \mathrm{He}^{3}$ minority, D background with volume-average density $n=0.3 \times 10^{20} \mathrm{~m}^{-3}$. Solid curve: total absorption; dashed curve: $\mathrm{He}^{3}$ absorption; dotted curve: electron absorption; chain-dash curve: $\mathrm{D}$ absorption. (b) 2-D distribution of the ICH power deposition. 
tion $p$ rofile calculated from a full-wave rf coupling and absorption code [10] for TST parameters. The left plot shows the absorbed power averaged over a flux surface, and the right plot is a two-dimensional (2-D) power deposition contour plot for $20 \mathrm{MHz}$. The majority of the power is absorbed by the $5 \% \mathrm{He}^{3}$ minority; a high-energy minority tail will be formed that will then transfer its energy to the bulk plasma via Coulomb collisions.

Figure II.7 is a similar plot for $75 \mathrm{MHz}$. In this case, the absorption is almost completely by the electrons, since no hydrogen is present in the plasma. For this case, the antenna described in Sect. III. 3 with adjacent straps driven with $\pi$ phasing generates a $k$ spectrum with peaks near $N_{z}\left(=c k_{z} / \omega\right) \approx \pm 6$. An H-mode plasma with $n=0.3 \times$ $10^{20} \mathrm{~m}^{-3}$ and $P_{\text {aux }} \approx 4 \mathrm{MW}$ (see Sect. II.1) will have $T \approx 3 \mathrm{keV}$ and $T_{0} \approx 5 \mathrm{keV}$, so $\omega / k_{2} v \mathrm{Te} \approx 1-1.5$ near the center of the machine, resulting in relatively strong single-pass absorption for heating.

The combination of the two heating frequencies can provide $2 \mathrm{MW}$ steady state. For operation for up to $30 \mathrm{~s}$, a total of $3.5 \mathrm{MW}$ can be obtained from the transmitters.

Figure II.8 shows the loading resistance per unit length of the antenna current strap as a function of density. These values of loading resistance are quite adequate to deliver the power needed. In addition, the power flux through the Faraday shields is quite modest; for the case of $2 \mathrm{MW}$ through one port, the resulting if power flux is only about $5 \mathrm{MW} / \mathrm{m}^{2}$, well below the values of $7-12 \mathrm{MW} / \mathrm{m}^{2}$ now observed experimentally on the Tokamak Fusion Test Reactor (TFTR), Tore Supra, JT-60, and other devices.

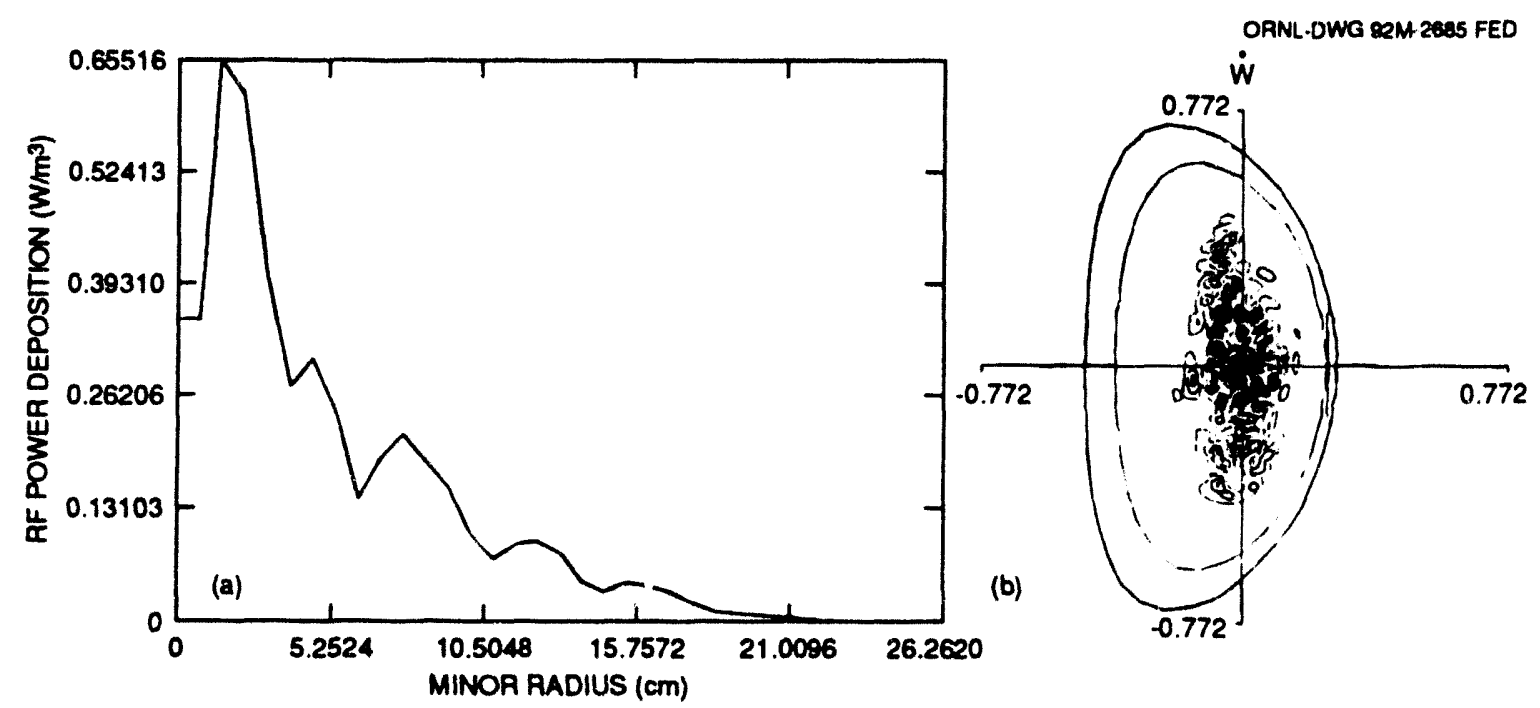

Fig. II.7. (a) Flux-surface-average if power deposition vs minor radius for a $75-\mathrm{MHz}$ wave launched into a $5 \% \mathrm{He}^{3}$ minority, $\mathrm{D}$ background with volume-average density $n=0.3 \times 10^{20} \mathrm{~m}^{-3}$. Essentially all absorption is by electrons via TTMP/Landau damping. (b) 2-D distribution of the ICH power deposition. 


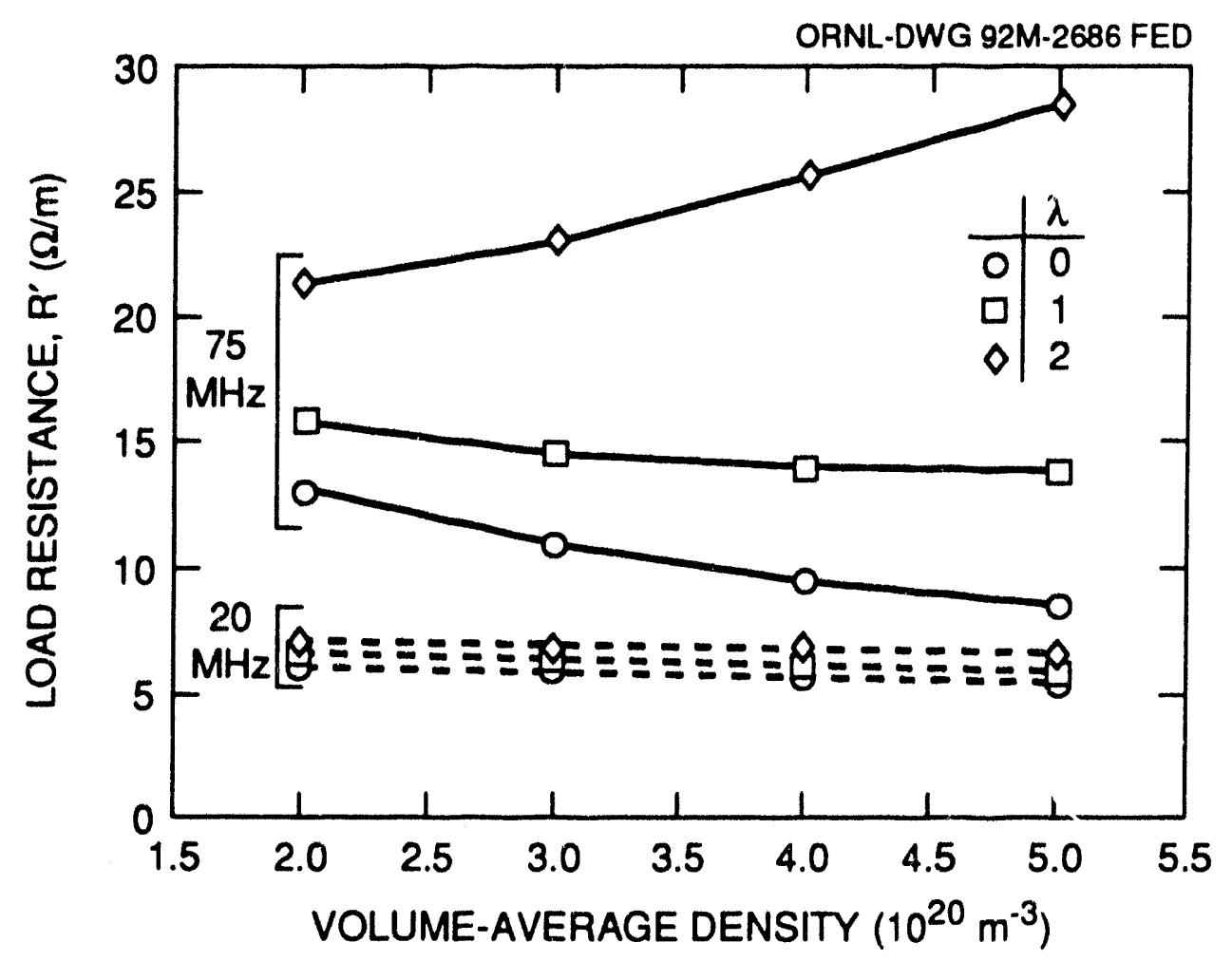

Fig. II.8. Loading resistance $R^{\prime}(\Omega / \mathrm{m})$ vs density, for frequencies of 75 and $20 \mathrm{MHz}$. For these calculations, we assume $n_{\text {separatix }} \approx 0.33 n_{0}$ and a square-root-parabola density profile. The region outside the separatrix is modeled as an exponential density decrease with $\lambda=1 \mathrm{~cm}$.

\section{II.4 PLASMA CURRENT MAINTENANCE AT HIGH DENSITIES: NEUTRAL BEAM AND LOWER HYBRID CURRENT DRIVE}

The combination of ICH and LHCD will ensure steady-state currents above $0.5 \mathrm{MA}$ for average densities $n$ up to $0.3 \times 10^{20} \mathrm{~m}^{-3}$, which is considered to be the minimum required for producing an edge density $n_{\times}$above $0.1 \times 10^{20} \mathrm{~m}^{-3}$ appropriate for testing divertors (see Sect. IV.2). However, for $n$ up to $0.5 \times 10^{20} \mathrm{~m}^{-3}$, an additional $\mathrm{CD}$ method will most likely be needed to drive currents at the plasma center. Here we consider the option of adding up to $1.5 \mathrm{MW}$ of neutral beam (NB) power to help achieve steady-state conditions at the higher densities in TST. The efficiency of this method depends on the beam energy and the temperature of the plasma. Calculations indicate that for $n=0.5 \times 10^{20} \mathrm{~m}^{-3}$, over $5 \mathrm{MW}$ of NB power at a beam energy of $50 \mathrm{kV}$ will be needed to drive $0.5 \mathrm{MA}$.

Scenarios with a combination of NB for core CD, LH for CD near the edge, and ICH with bootstrap current included look promising, however. Luckhardt [11] has used the BBK code [12] to compute time-dependent scenarios for TST with these heating and current sources. Figure II.9 shows the evolution of the $\mathrm{OH}$ power (which is essentially zero for $t>1 \mathrm{~s}$ ), electron density and temperature, and current density profile vs time and minor radius. Figure II.10 shows the $q$ profile, plasma beta, and total beta (including the beam contribution). For these cases, NBCD power was turned on at 

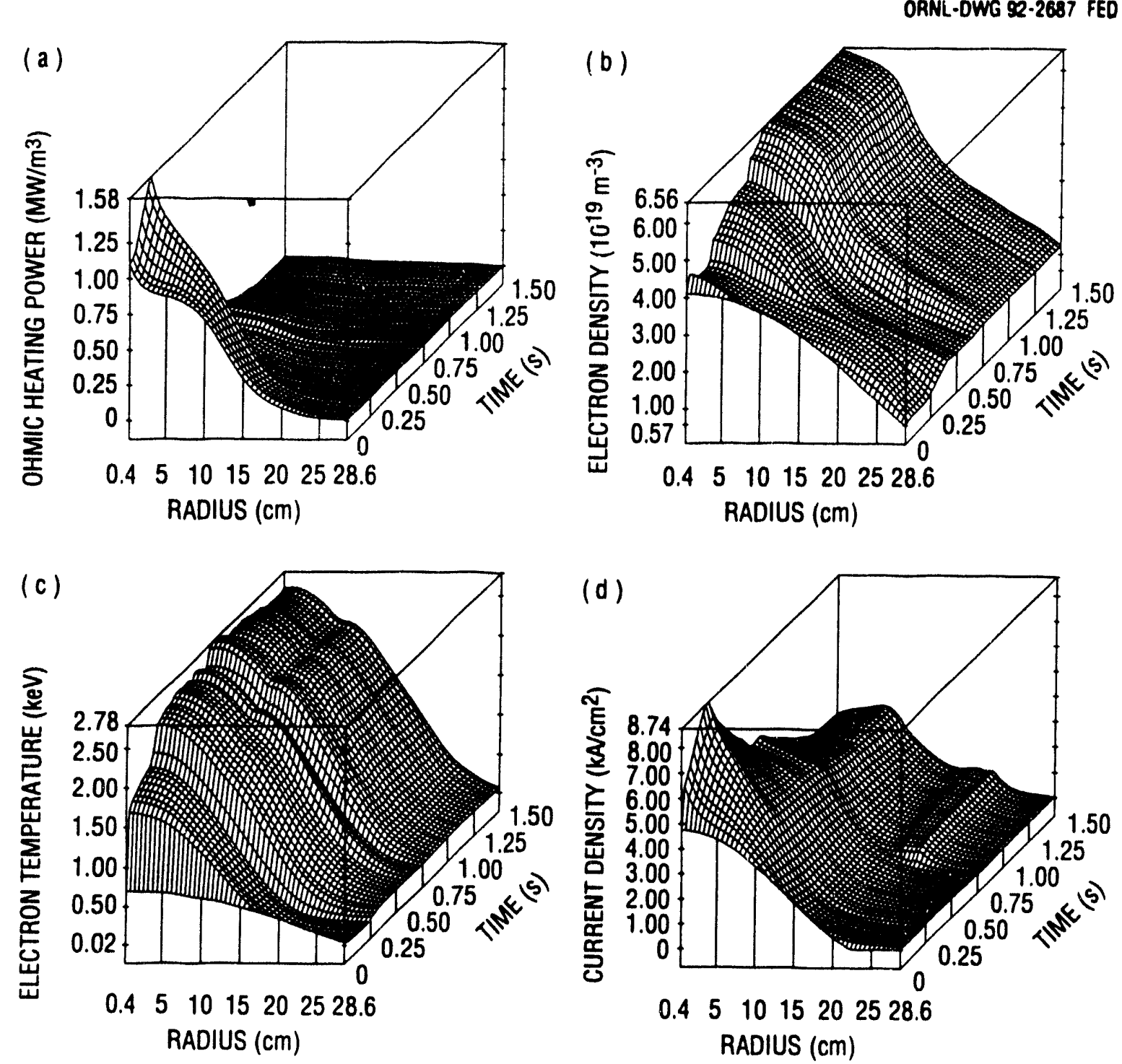

Fig. II.9. BBK code results for (a) OH power, (b) electron density, (c) electron temperature, and (d) total current density vs time and minor radius.

$0.25 \mathrm{~s}$ and additional heating power at $0.6 \mathrm{~s}$; the density increase was achieved by simulated gas puffing. The results indicate that for this case, in which the line-averaged density is $\sim 0.45 \times 10^{20} \mathrm{~m}^{-3}$ late in the pulse, the combination of approximately $1 \mathrm{MW}$ of LHCD, 1.5 MW of NBCD, and 1.1 MW of ICH is adequate to maintain $0.4 \mathrm{MA}$ of current when bootstrap current is included. Figure II.11 shows the resulting current density profiles at $t=1.5 \mathrm{~s}$ from the $\mathrm{LH}, \mathrm{NB}$, and bootstrap sources. 
(a)

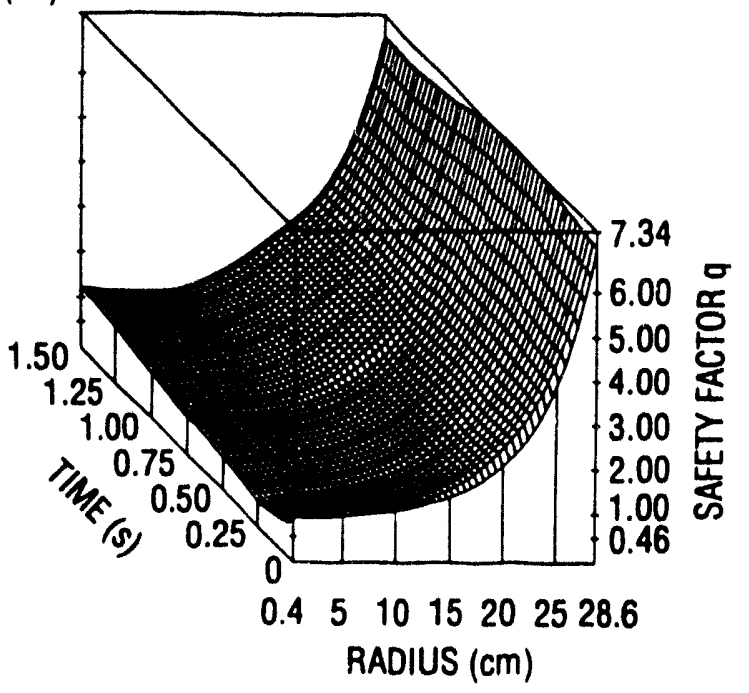

(b)

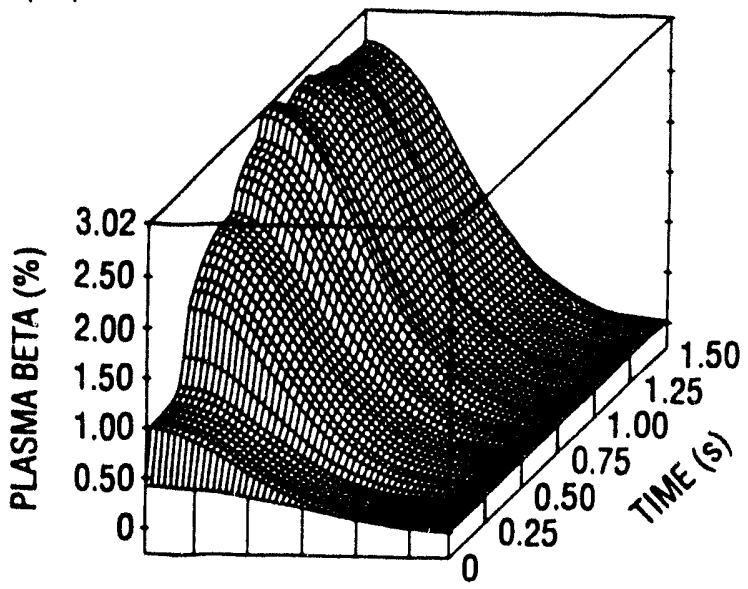

$0.4 \quad 5 \quad 1015202528.6$ RADIUS (cm)

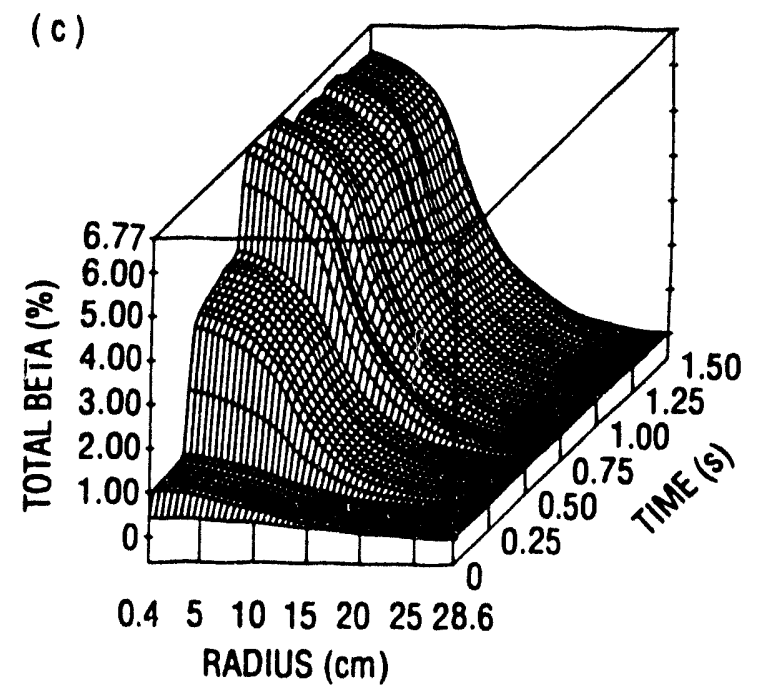

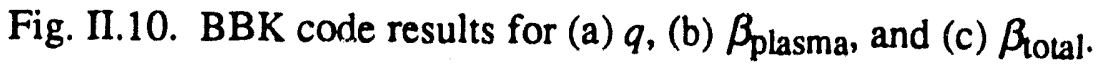




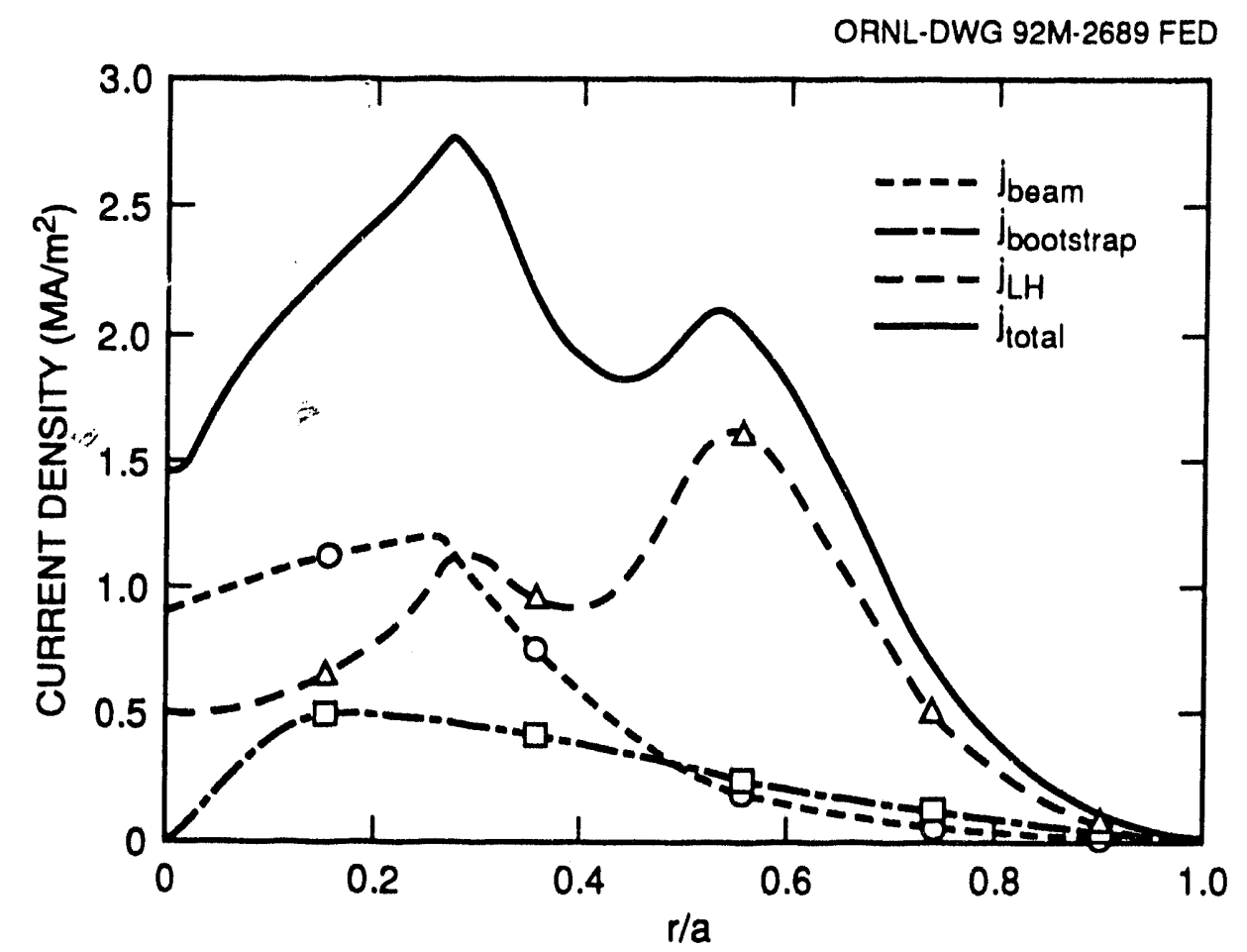

Fig. II.11. Radial profiles of the current density from the beam-driven current, LH driven current, and bootstrap current at $t=1.5 \mathrm{~s}$. Conditions are the same as for Figs. 11.9 and II.10.

\section{II.5 OTHER CURRENT DRIVE POSSIBILITIES}

Much research is being conducted at present on new or improved CD techniques. While we are not counting on them for the successful operation of TST, it is likely that one or more of these mechanisms will be able to be used to provide added margin in current drive or eliminate the need for NBI. A few of the most likely are mentioned here.

\section{II.5.1 Fast Wave Ion Cyclotron Current Drive}

FWCD has been calculated theoretically to have good CD efficiency, with no known intrinsic density limit on the wave propagation or absorption. Experimental tests are under way on DIII-D, with some initial results expected within the year. Experiments are also planned on JET to test FWCD in 1994.

Calculations have been made of the FWCD efficiency with a six-strap antenna array (two three-strap antennas mounted in adjacent ports) operating at $75 \mathrm{MHz}$, with phasing of $60^{\circ}$ to $120^{\circ}$ between current straps. Figure II.12 shows a typical spectrum of power launched for $90^{\circ}$ phasing. Preliminary calculations by Jaeger and Batchelor [13] using the PICES code indicate values of $\gamma \approx 0.1 \times 10^{20} \mathrm{~A} / \mathrm{W} \cdot \mathrm{m}^{2}$. While it is premature at present to base the operation of TST at higher density on FWCD alone, the possibility of using this technique should not be ruled out. Positive experimental results in 


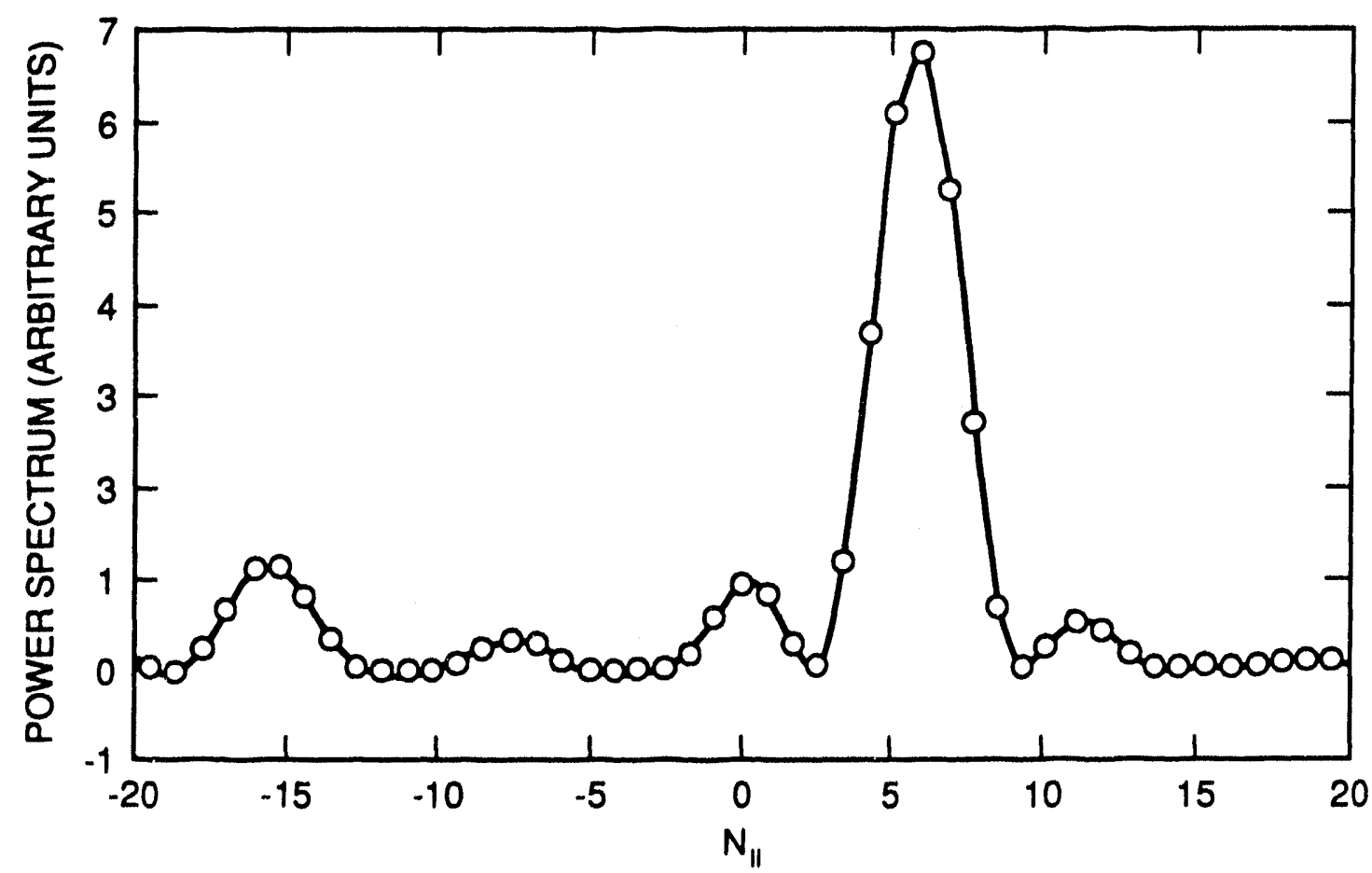

Fig. II.12. Power spectrum launched by a six-strap ICH antenna at $75 \mathrm{MHz}$ with $90^{\circ}$ phasing. $N_{\|}=c k_{\|} / \omega$ is the index of propagation in the toroidal direction.

1993-1994 would permit the use of FWCD instead of NBI. If the installation of neutral bearns could be eliminated, the cost of the H\&CD system would be reduced.

\section{II.5.2 LH and ICH Current Drive Synergism}

JET has both $\mathrm{LH}$ and ICH; experiments indicate that there may be a synergistic effect between the two waves for CD [14]. Two effects have been observed when ICH (normal antenna spectrum with $\pi$ phasing between the antennas) is added to a discharge driven with LHCD:

1. The total current driven is increased, and the efficiency of the $\mathrm{ICH}$ power added is equal to the efficiency of the LH power (that is, the amperes/watt obtained from the incremental ICH power equals that observed with LH power only).

2. $\mathrm{X}$-ray diagnostics indicate that, while the fast electron profile is somewhat hollow for the electrons generated with $\mathrm{LH}$ alone, the profile fills in and becomes radially peaked when ICH is added.

A plausible explanation for the observations is that the IC waves interact with the fast electron tail generated by the $\mathrm{LH}$, further accelerating these electrons and driving current. The reason for the filling in of the center of the fast electron profile is less obvious.

These results are very encouraging, in that it may be possible to drive current near the center of the plasma even at high density using $\mathrm{LH}$ and $\mathrm{ICH}$. This can be tried with the systems that we are proposing to use on TST. 


\section{II.5.3 NBCD and ICH Synergism}

Results from TEXTOR [15] indicate some enhancement of NBCD with the addition of $\mathrm{ICH}$, in addition to that expected from simple heating of the plasma. The increase in driven current is modest; the incremental amperes/watt for added $\mathrm{ICH}$ power is about $50 \%$ of what could be obtained by adding additional NBCD power directly. However, an ICH system is needed anyway on TST to provide relatively cheap heating power. The addition of increased CD capability due to this synergistic interaction would allow operation at higher densities, or with lower total power to the plasma.

An explanation proposed for this phenomenon is that the ICH waves increase the perpendicular energy of the beam ions, thereby increasing their slowing-down time and thus the NBCD efficiency. However, because the dominant interaction between the energetic beam ions and the ICH waves is through transit-time magnetic pumping (TTMP) damping, there is little change in the parallel momentum of the ions.

\section{II.6 PF COILS AND EQUILIBRIUM FLEXIBILITY}

The TST PF system consists of six pairs of coils, symmetric with respect to the TF coil. Small "window-frame" coils are added to each divertor segment for precise control of the divertor strike point. This approach can accommodate both the open and the closed divertor concepts (see Sect. IV.3). The TST PF design attempts to (1) minimize the size of inboard shaping coils for $A=2.5$ and eliminate them for $A=1.8$, (2) position coils to be consistent with TF joints, divertor structure, and access ports for beams and diagnostics, (3) operate within steady-state current density limits, and (4) provide flexibility in the plasma configuration. Coil locations and sizes are listed in Table II.2 for $A=2.5$ and in Table II. 3 for $A=1.8$.

Table II.2. PF coil system for the $A=2.5$ TST

\begin{tabular}{ccccc}
\hline PF coil & $R(\mathrm{~m})$ & $Z(\mathrm{~m})$ & $d R(\mathrm{~m})$ & $d Z(\mathrm{~m})$ \\
\hline 1 & 0.360 & 0.235 & 0.050 & 0.350 \\
2 & 0.370 & 0.780 & 0.030 & 0.660 \\
3 & 0.490 & 1.438 & 0.200 & 0.200 \\
4 & 1.110 & 1.438 & 0.200 & 0.200 \\
5 & 1.781 & 1.438 & 0.200 & 0.200 \\
6 & 1.781 & 0.430 & 0.200 & 0.200 \\
7 & 0.360 & -0.235 & 0.050 & 0.350 \\
8 & 0.370 & -0.780 & 0.030 & 0.660 \\
9 & 0.490 & -1.438 & 0.200 & 0.200 \\
10 & 1.110 & -1.438 & 0.200 & 0.200 \\
11 & 1.781 & -1.438 & 0.200 & 0.200 \\
12 & 1.781 & -0.430 & 0.200 & 0.200 \\
13 & 0.650 & -0.750 & 0.050 & 0.050 \\
14 & 0.650 & -0.950 & 0.050 & 0.050 \\
\hline
\end{tabular}


Table II.3. PF coil system for the $\boldsymbol{A}=1.8 \mathrm{TST}$

\begin{tabular}{ccccc}
\hline PF coil & $R(\mathrm{~m})$ & $Z(\mathrm{~m})$ & $d R(\mathrm{~m})$ & $d Z(\mathrm{~m})$ \\
\hline 1 & 0.333 & 1.438 & 0.200 & 0.200 \\
2 & 1.110 & 1.438 & 0.200 & 0.200 \\
3 & 1.781 & 1.438 & 0.200 & 0.200 \\
4 & 1.781 & 0.430 & 0.200 & 0.200 \\
5 & 0.333 & -1.438 & 0.200 & 0.200 \\
6 & 1.110 & -1.438 & 0.200 & 0.200 \\
7 & 1.781 & -1.438 & 0.200 & 0.200 \\
8 & 1.781 & -0.430 & 0.200 & 0.200 \\
9 & 0.580 & -0.900 & 0.050 & 0.050 \\
10 & 0.620 & -1.050 & 0.050 & 0.050 \\
\hline
\end{tabular}

Free-boundary MHD equilibrium calculations demonstrate the feasibility and flexibility of the system. Solutions are developed for SN and DN divertor modes and for possible variation in aspect ratio.

1. $A=2.5$, DN divertor: Figure II.13 shows a free-boundary plasma equilibrium for the $A=2.5$, DN divertor. Plasma position, size, and symmetric $\times$-points are constrained in the equilibria. This permits a poloidal distance of up to $50 \mathrm{~cm}$ for the outer divertor channels and up to $25 \mathrm{~cm}$ for the inner channels. This configuration is similar to that of the ITER CDA.

2. $A=2.5, \mathrm{SN}$ divertor: The $A=2.5, \mathrm{SN}$ plasma equilibrium is shown in Fig. II.14. In this configuration, PF4 is turned off, and currents in PF3, PF5, PF6, and PF9-PF12 are driven independently in order to control the position of the $x$-points and the flux linkage in an asymmetric plasma with an active null point below the midplane. The $X$-points are again nearly symmetric, and the asymmetry and shape of the scrape-off region are prescribed by a flux difference between the $x$-points equal to $5 \%$ of the total plasma flux. Small coils near the active $x$-point ("window-frame" coils) are introduced to accurately shape the flux surfaces in the divertor region.

3. $A=1.8, \mathrm{DN}$ divertor: The PF system is simplified for low-aspect-ratio operation by eliminating the central solenoid windings and reducing the major radius of the main divertor coils. Coils PF2-PF4 are unchanged from the $A=2.5$ configuration. This approach permits the replacement of the central core assembly for either aspect ratio with minimum perturbation to the device. The DN divertor equilibrium in Fig. II.15 is a "natural divertor shape" in the sense that currents in two pairs of PF coils, PFI and PF4, are found such that the $x$-point-limited plasma satisfies exactly two shape constraints-prescribed major and minor radius. The $x$-point location so determined requires no additional $P F$ shaping currents.

4. $A=1.8, \mathrm{SN}$ divertor: For the $A=1.8, \mathrm{SN}$ plasma (Fig. II.16), all eight of the main $\mathrm{PF}$ coils carry independent currents. Again, small coils near the lower $\times$-point help to control the flux surfaces striking the divertor plates. To help make the divertor design possible for this low-aspect-ratio plasma of larger cross section, the plasma is shifted vertically upward by $10 \mathrm{~cm}$ reiative to the TF coil midplane. This is simulated in the equilibrium calculation by shifting the PF coils down by $10 \mathrm{~cm}$. 


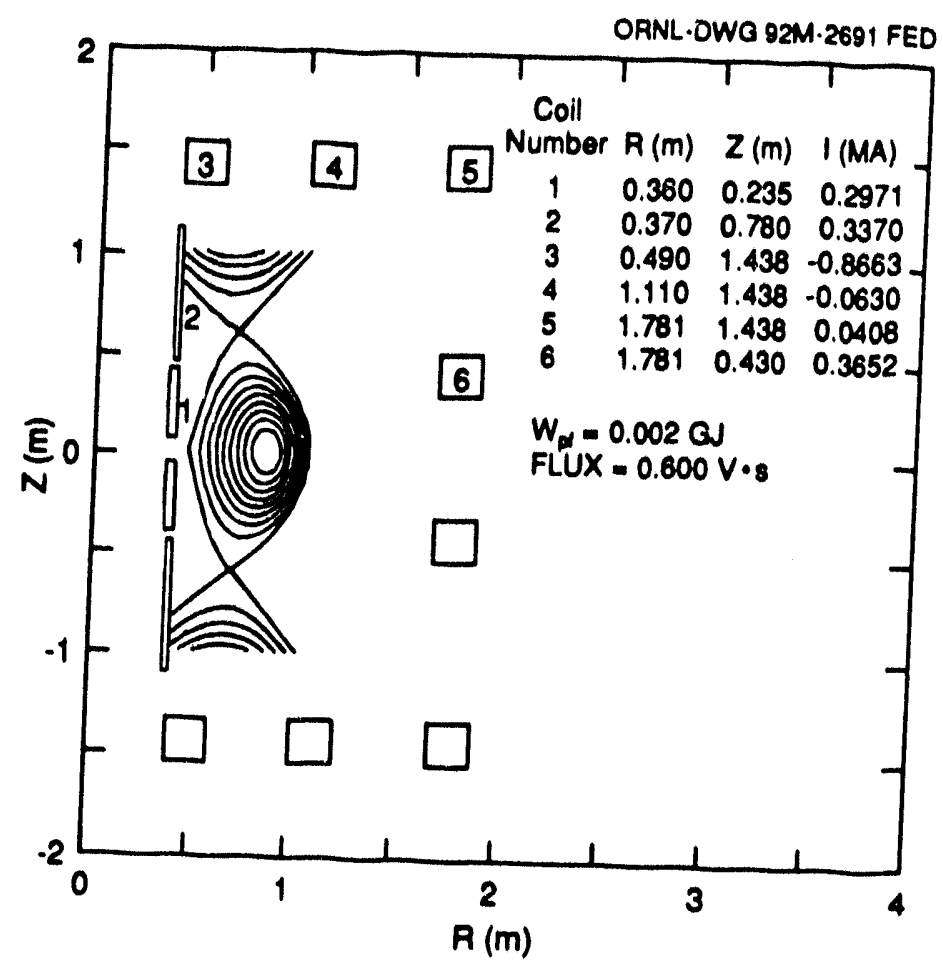

Fig. II.13. $A=2.5$, DN divertor.

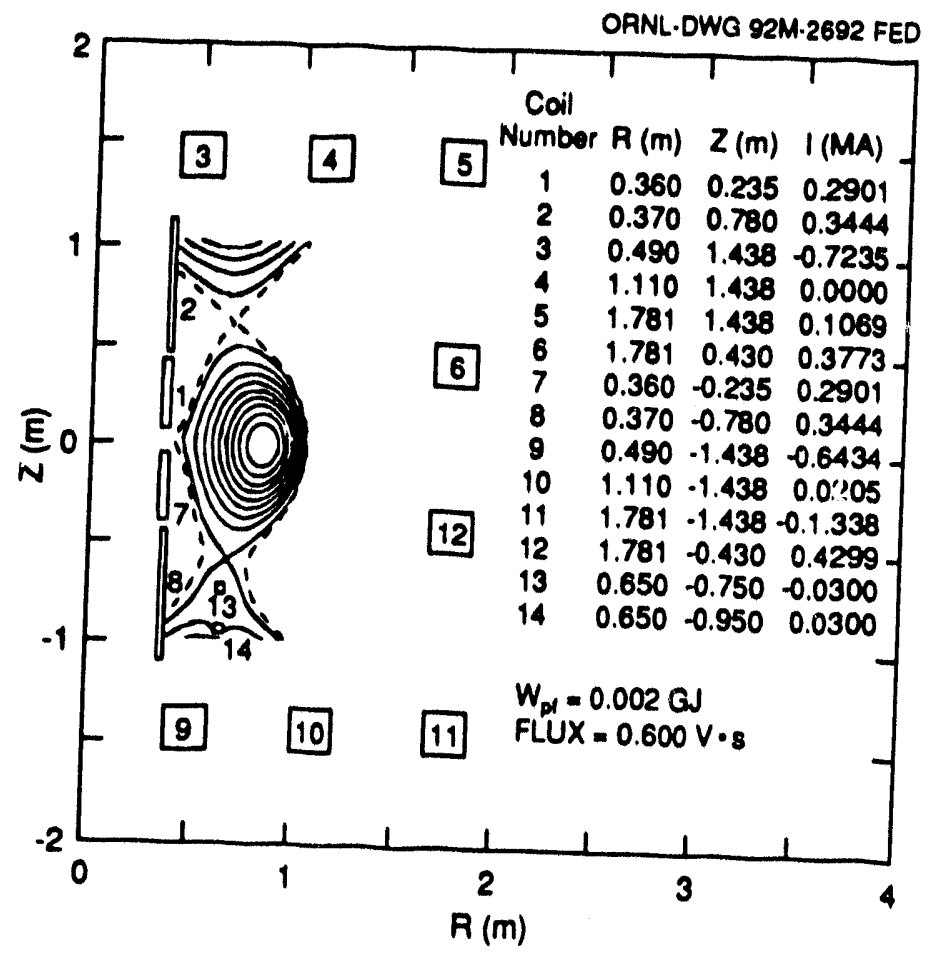

Fig. II.14. $A=2.5$, SN divertor. 


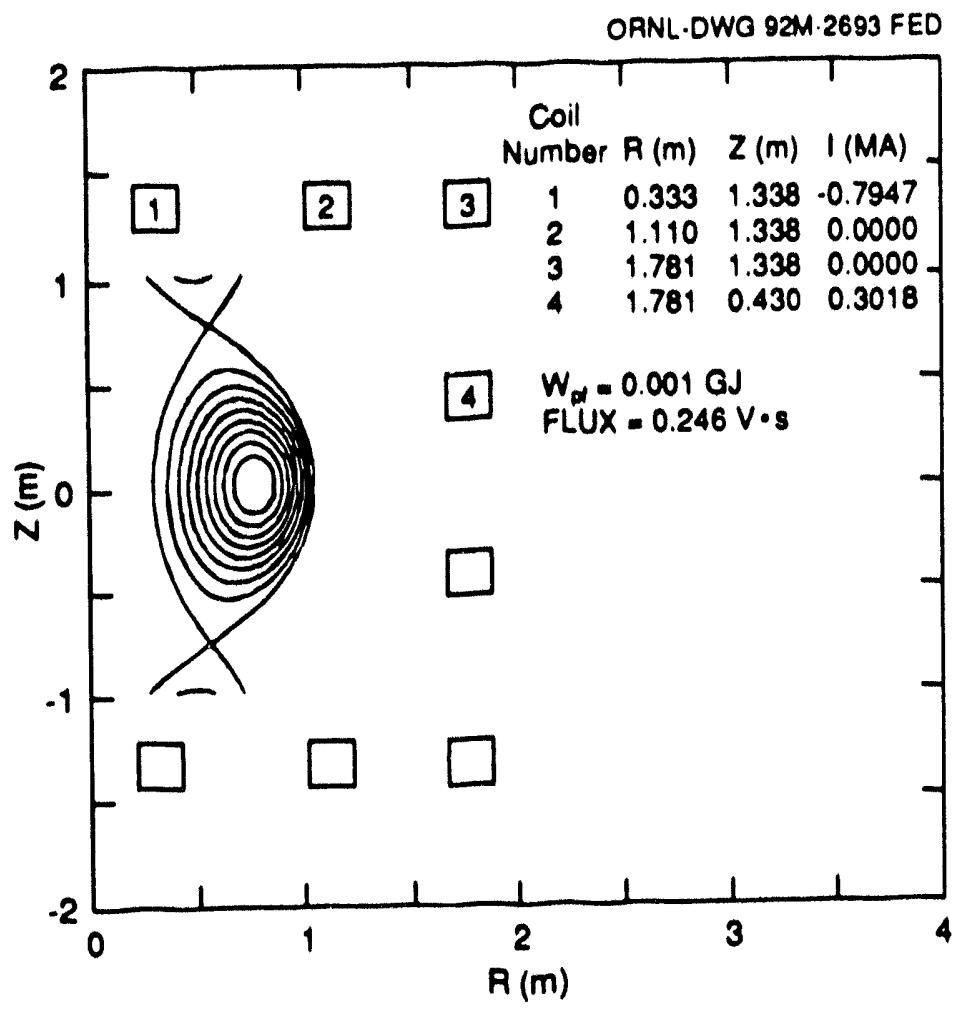

Fig. II.15. $A=1.8, \mathrm{DN}$ divertor.

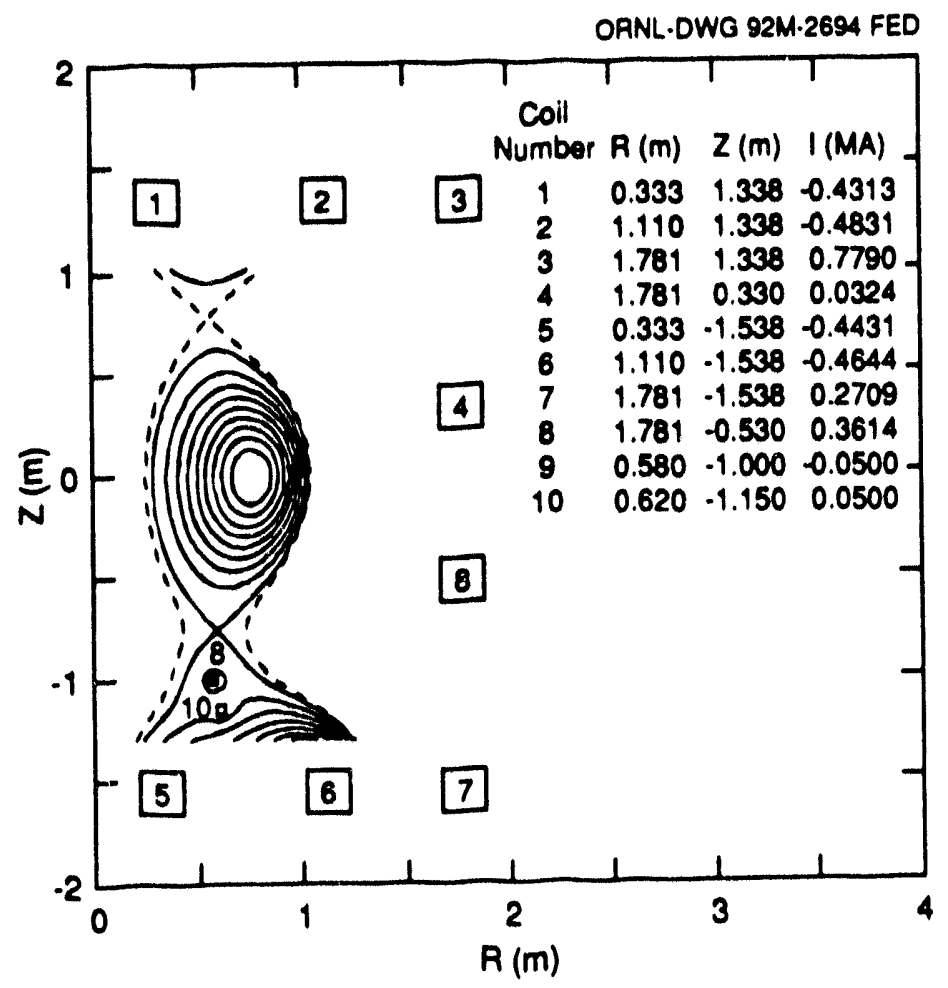

Fig. II.16. $A=1.8, \mathrm{SN}$ divertor. 


\section{References for Sect. II}

[1] R. J. Goldston et al., "Burning Plasma Experiment Physics Design Description," Fusion Technol. 21, 1047 (1992).

[2] C. L. Hedrick, J. N. Leboeuf, and D. A. Spong, "Alpha-Alfvén Local Dispersion Relation and Solutions," Phys. Fluids B, accepted for publication (1992).

[3] K. Borrass, "Disruptive Tokamak Density Limit as Scrape-off Layer/Divertor Phenomenon," Nucl. Fusion 31, 1035 (1991).

[4] W. A. Houlberg, S. E. Attenberger, and L. M. Hively, "Contour Analysis of Fusion Reactor Plasma Periormance," Nucl. Fusion 22, 935 (1982).

[5] Y-K. M. Peng, J. D. Galambos, and P. C. Shipe, "Small Tokamaks for Fusion Technology Testing," Fusion Technol. 21, 1729 (1992).

[6] B. Lloyd et al., "Low Voltage Ohmic Heating and Electron Cyclotron Heating Assisted Startup in DIII-D," Nucl. Fusion 31, 2031 (1991).

[7] P. T. Bonoli, Massachusetts Institute of Technology, personal communication, March 1992.

[8] P. T. Bonoli et al., Nucl. Fusion 30, 533 (1990); R. S. DeVoto et al., Nucl. Fusion 32, accepted for publication (1992).

[9] For summaries of LH wave physics and experiments (to about 1984), see Wave Heating and Current Drive in Plasmas, V. L. Granatstein and P. L. Colestock, eds., Gordon and Breach, Amsterdam, 1985, Chapters 5 and 6.

[10] E. F. Jaeger and D. B. Batchelor, "Fast Wave Current Drive in Tokamaks," Phys. Rev. Lett., submitted for publication (1992); "Full Wave Calculation of Fast Wave Current Drive in Tokamaks Including $k_{\|}$Upshifts," p. 159 in Radio Frequency Power in Plasmas, D. B. Batchelor, ed., American Institute of Physics, New York, 1992.

[11] S. Luckhardt, Massachusetts Institute of Technology, personal communication, March 1992.

[12] The BBK code combines the transport code BALDUR with the LHCD ray tracing/Fokker-Planck code of Bonoli. It was described by J. Kesner at the 1992 Sherwood Theory Conference.

[13] E. F. Jaeger and D. B. Batchelor, Oak Ridge National Laboratory, personal communication, March 1992.

[14] F. Rimini et al., "Synergistic Effects Between Lower Hybrid and Fast Magnetosonic Waves in JET," Bull. Am. Phys. Soc. 36, 2240 (1991).

[15] A. M. Messiaen et al., "Synergy between Neutral Beam Current Drive and ICRH in TEXTOR," in Fast Wave Current Drive in Reactor Scale Tokamaks, D. Moreau, A. Bécoulet, and Y. Peysson, eds., Association EURATOM-CEA, Cadarache, France, 1991. 
. 


\section{THE TST AUXILIARY H\&CD SYSTEMS}

The auxiliary H\&CD systems needed for steady-state operation on TST are described. A summary of the systems proposed both for initial operation and for an upgrade is given in Tables I.3 and I.4. Details of the ECH, LH, ICH, and NBI systems are given in this section.

\section{III.1 ECH SYSTEM}

\section{III.1.1 Purpose}

The primary mission of the ECH system on TST is plasma initiation by currentless breakdown of the fill gas. ECH reliably forms a modest-temperature, low-density plasma that permits tokamak startup with significantly lower loop voltage at the plasma; in DIII-D, for example, ECH-assisted startup has been possible with $\mathrm{OH}$-induced electric fields as low as $0.15 \mathrm{~V} / \mathrm{m}$ (see Sect. II.2). This will permit the use of a vacuum vessel without insulated breaks.

\section{III.1.2 Requirements}

Absorption of the 53-GHz power occurs at a magnetic field of $1.92 \mathrm{~T}$ for fundamental or $0.96 \mathrm{~T}$ for second harmonic resonance. For full-field operation (i.e., $2.2 \mathrm{~T}$ at the plasma center), the $53-\mathrm{GHz}$ waves will experience cyclotron resonance at $r / a \approx 0.3$, as shown in Fig. III.1. When launched from the low-field side, the ordinary mode

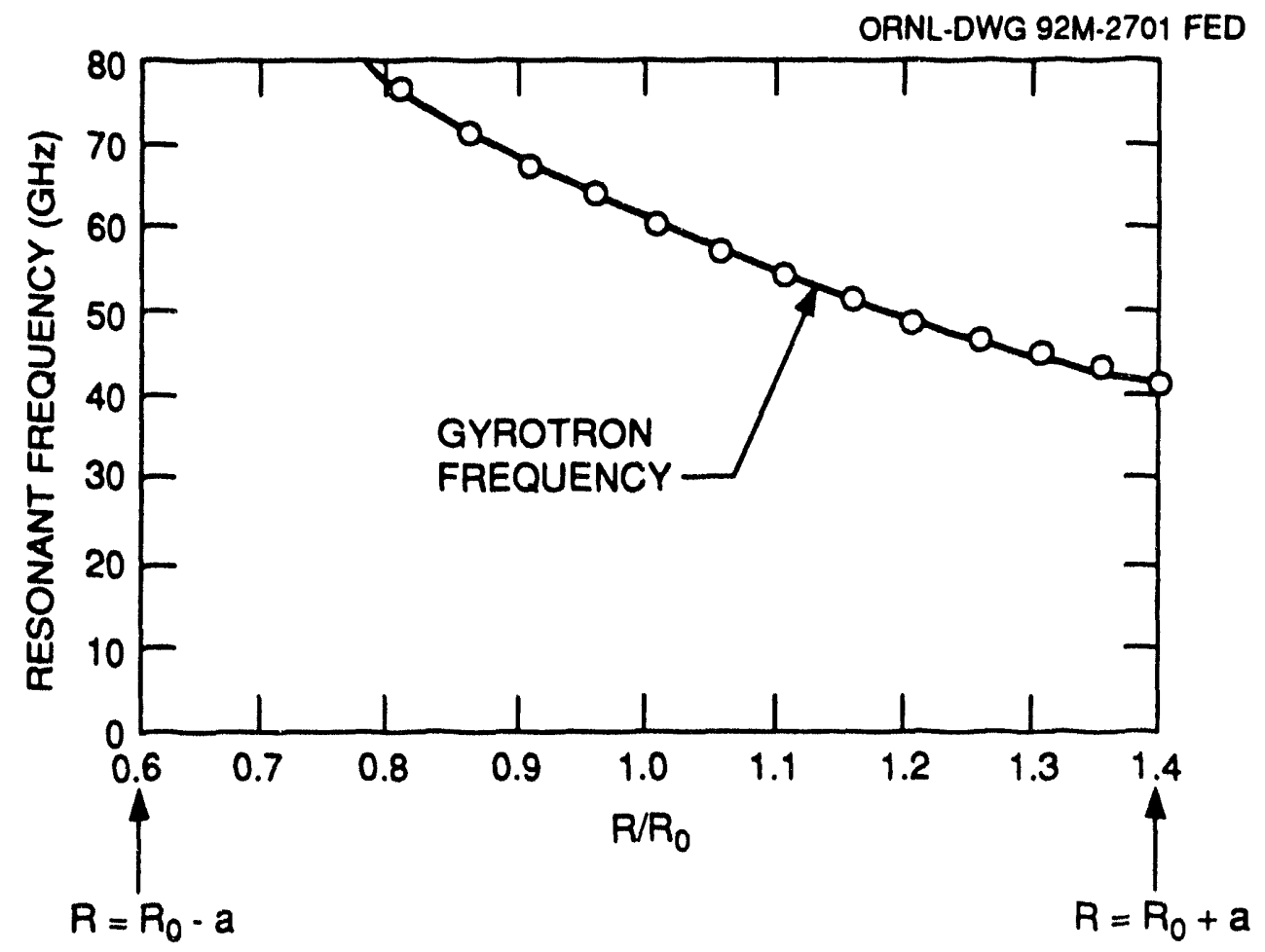

Fig. III.1. Electron cyclotron resonant frequency vs position. 
(O-mode) has access to the fundamental resonance at a plasma density up to $3.3 \times$ $10^{19} \mathrm{~m}^{-3}$ and is nearly completely absorbed on the first pass by warm plasmas. The extraordinary mode (X-mode) has access to $\sim 1.7 \times 10^{19} \mathrm{~m}^{-3}$ and is also absorbed efficiently with sufficient density and temperature at second harmonic fields. For a wave launched perpendicular to $B_{0}$, the O-mode is linearly polarized parallel to $B_{0}$ and the $\mathrm{X}$-mode is perpendicular. The optimum launcher for TST operation at $2.2 \mathrm{~T}$ will be a linearly polarized beam near the midplane with the plane of polarization horizontal. When the power is launched from the high-field side, the X-mode has an increased density limit of $-6 \times 10^{19} \mathrm{~m}^{-3}$. This launch requires that the power pass once through a resonance layer where the plasma density must be very low to prevent absorption. For all launch methods, it is desirable to maximize first-pass absorption by having a transmission system and beam launcher that will maintain high mode purity.

Unabsorbed power scatters from the vacuum vessel wall and will be widely distributed around the vacuum vessel. Scattered power is absorbed by the plasma at all flux surfaces, and some power is lost to windows, walls, and other dumps. The overall efficiency is decreased by low first-pass absorption, and with cw operation the power can lead to arcing and damage to other components in the tokamak.

\section{III.1.3 System Description}

The major components of the ECH system are listed in Table III.1. The ECH system on the Advanced Toroidal Facility (ATF) at ORNL is used as an example of an available resource that could be adapted for the TST.

The ATF ECH system has three $200-\mathrm{kW}$ gyrotrons, which operate at a frequency of $53 \mathrm{GHz}$; one $35-\mathrm{GHz}$ compatible gyrotron is also available. Since the main application for ECH on TST is plasma startup, only a single $200-\mathrm{kW}, 53-\mathrm{GHz}$ gyrotron will be used. The transmission system efficiency for an ATF-type system with the additional length to TST (see Sect. V) is estimated to be $80 \%$, so a single gyrotron system will inject approximately $160 \mathrm{~kW}$ into the TST vacuum vessel. It is expected that this will be sufficient power for startup, provided that a reasonably good launcher beam pattern exists. More gyrotrons can be added later if additional power is required.

The ECH high-voltage power supply and a proposed waveguide configuration are shown in Figs. III.2 and III.3. The existing equipment has been designed to be capable

Table III.1. ECH system components

\begin{tabular}{ll}
\hline \multicolumn{1}{c}{ Component } & \multicolumn{1}{c}{ Remarks } \\
\hline ECH launcher & Low-field launcher, simple open-ended waveguide \\
Gate valve & Vacuum valve between launcher and line \\
Miter bends & Standard design \\
Waveguide & Circular aluminum corrugated waveguide \\
Gyrotron & \\
Power supply and & \\
regulator & \\
Control system & \\
\hline
\end{tabular}


OANL-OWG 92-2702 FEO
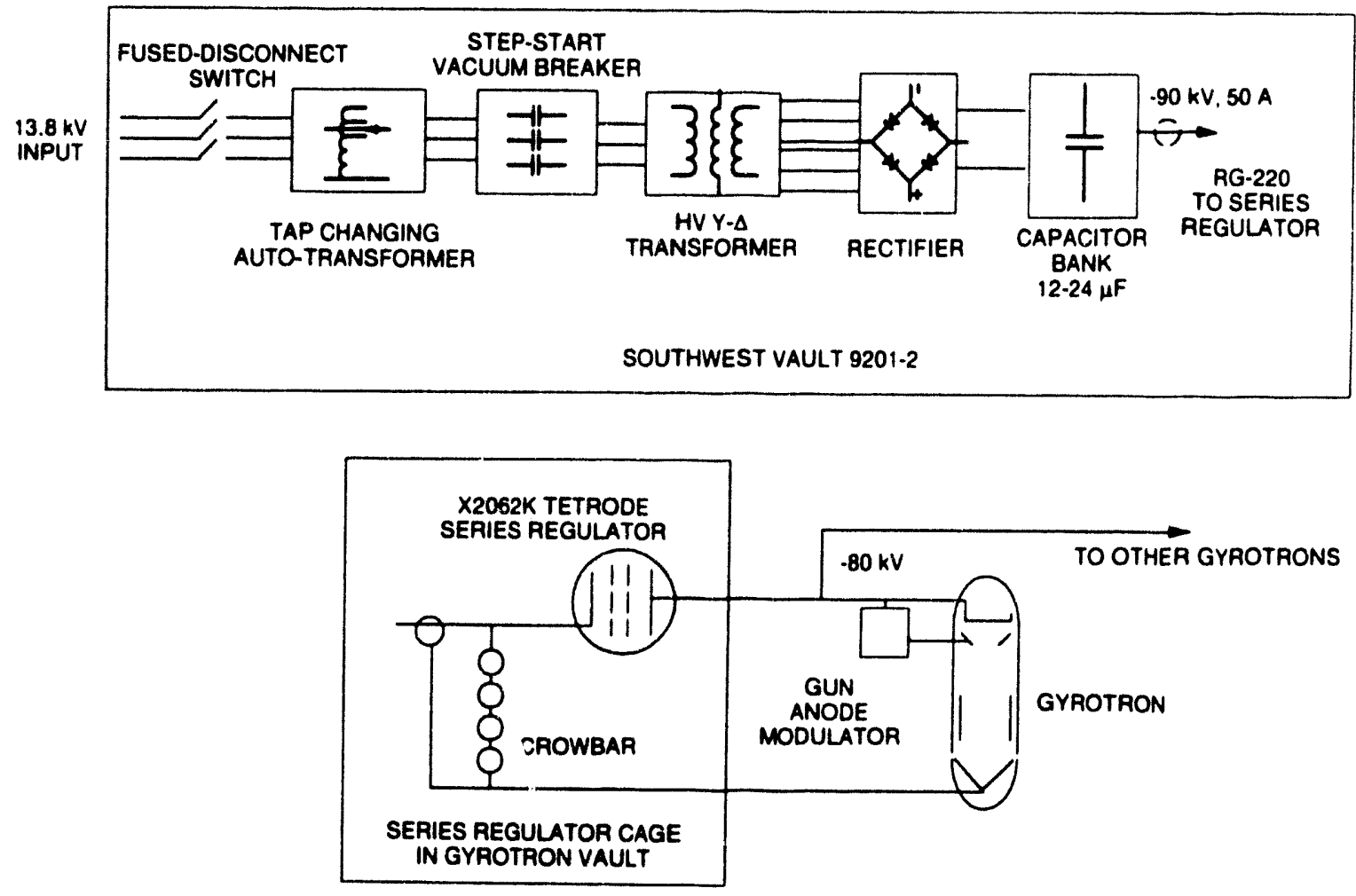

Fig. III.2. ECH system power supply configuration.

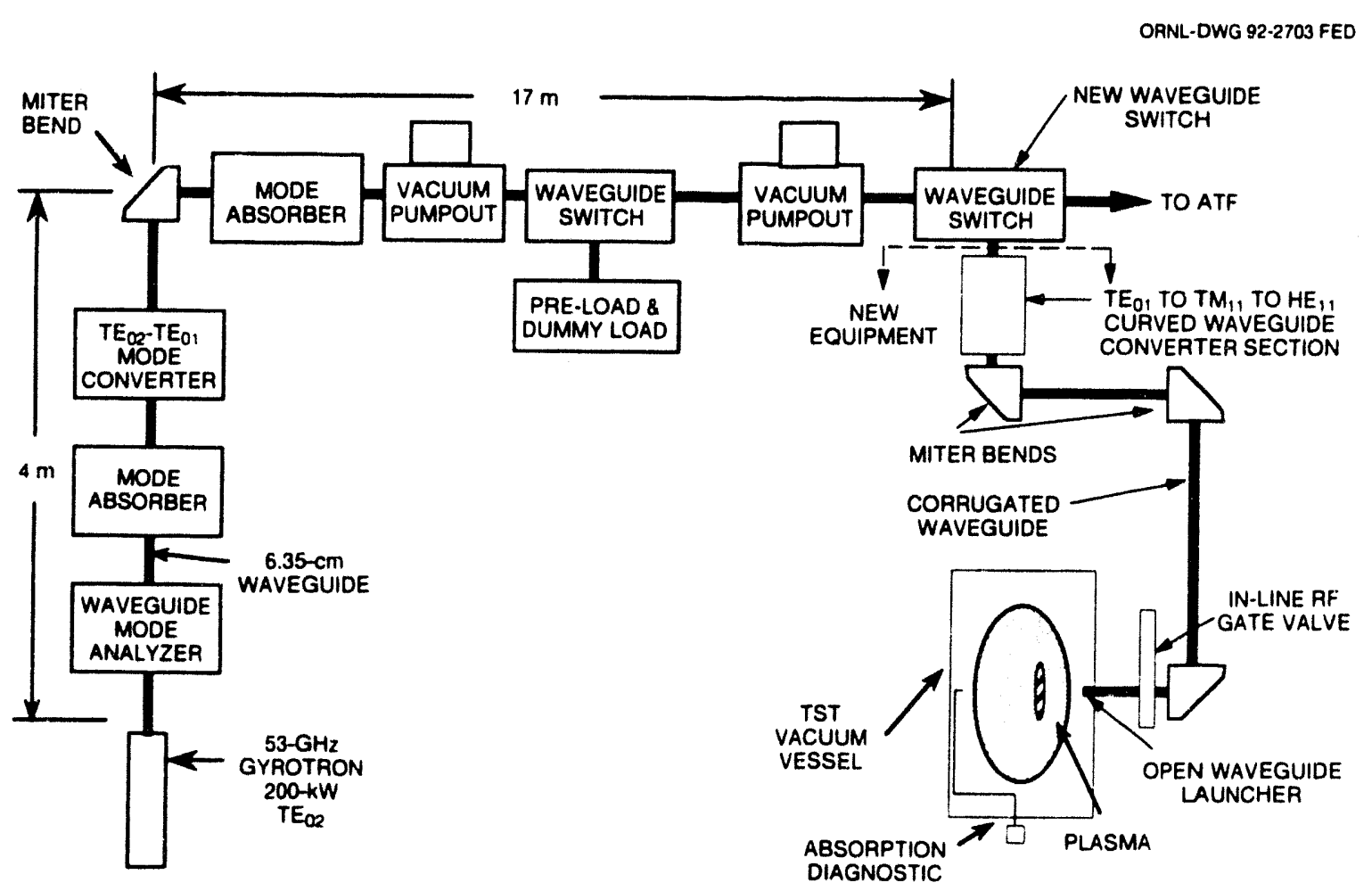

Fig. III.3. Block diagram of the ATF ECH system with added components for TST operation. 
of cw operation. Some waveguide components may need a small amount of water cooling for full $\mathrm{cw}$ operation. No modifications are required for the power supply system. Some additional controls and interlock circuitry will be required to interface with the TST system. The ECH system will be operated from the existing ATF control room location.

Waveguide equipment required to connect to TST is shown in Figs. III.3 and III.4. The simplest launcher with reasonable efficiency is a simple open-end corrugated waveguide carrying the Gaussian-like $H_{11}$ mode. Radiation patterns from this waveguide are also Gaussian-like and are ideal for coupling to the plasma. The plane of polarization will be set by a cooled miter bend mirror with a corrugated surface. This launcher design is very compact, and it will be possible to feed up to three waveguides through half of a TST port, although only one guide connected to one gyrotron will be used for initial operation. The waveguide will be evacuated to eliminate the need for a dangerous double-disk FC-75 cooled window. An rf-style gate valve will be used for vacuum isolation. A vacuum pumpout system will be required for the transmission line.

The $\mathrm{HE}_{11}$ mode is ideal for low-loss propagation over long distances. With a diameter of 3.5 in., simple miter bends work well and have mode conversion loss of $\sim 1.4 \%$. A corrugated aluminum waveguide will run to the ATF waveguide platform along a frame supported by the ATF enclosure wall. A waveguide switch similar to the existing dummy load switches on ATF will allow connection to one of the ATF systems. The switch allows nearly instantaneous selection of operation into ATF or TST.

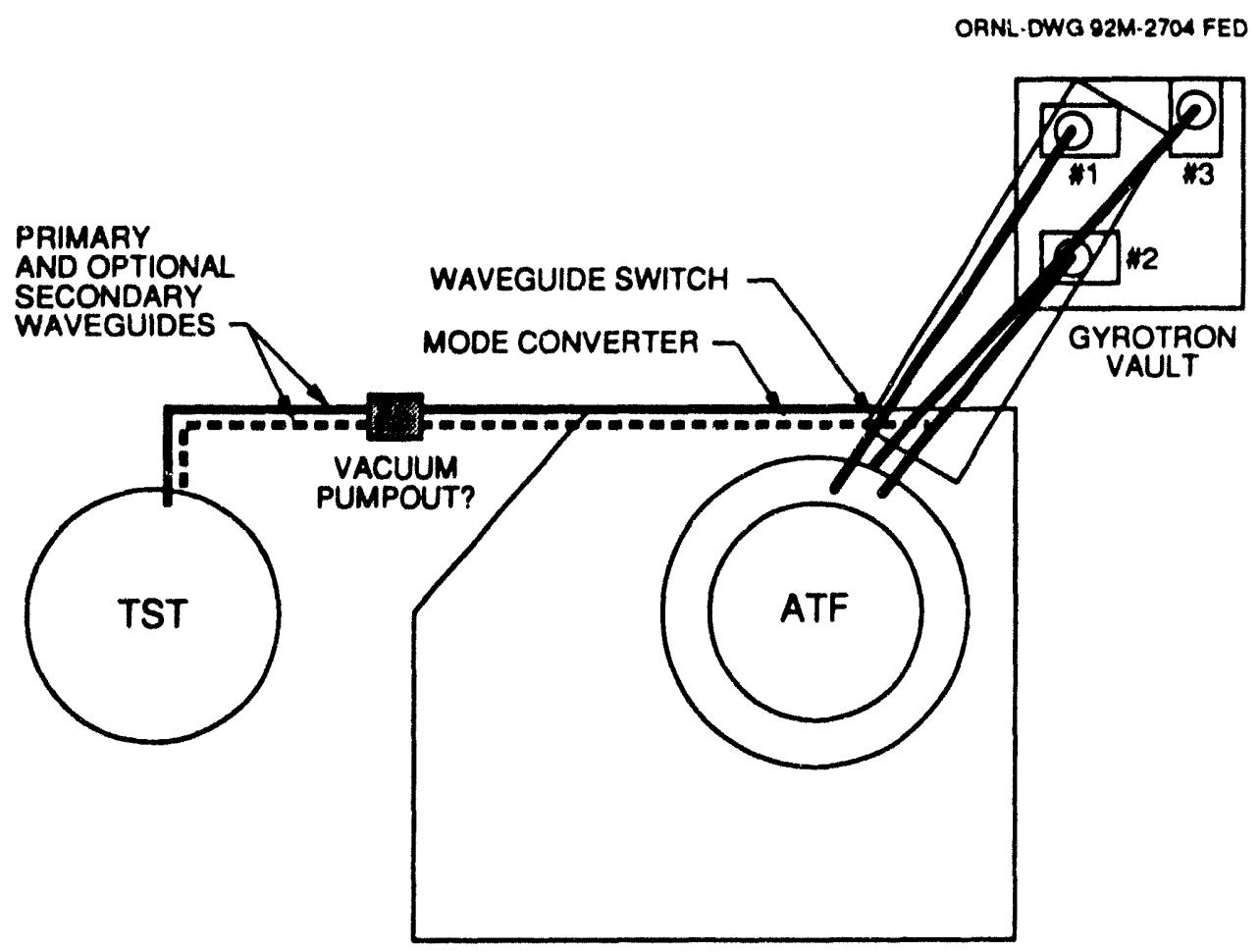

Fig. III.4. ECH waveguide configuration for TST. 
To convert from the $\mathrm{TE}_{01}$ mode used in the ATF system, a curved $\mathrm{TE}_{01}$ to $\mathrm{TM}_{11}$ waveguide section coupled to a tapered corrugation $\mathrm{TM}_{11}$ to $\mathrm{HE}_{11}$ mode converter will be used. A low mode conversion taper will increase the diameter to $3.5 \mathrm{in}$.

\section{III.1.4 Additional Uses}

ECH can also be used for highly localized heating of electrons. This effect can be used for central or edge heating, which allows modification of the local temperature and particle transport. Modulation of the ECH power level is the ideal tool for the measurement of energy transport. Other possible applications for $\mathrm{ECH}$ are disruption control by heating at the $q=2$ surface and bakeout of the vacuum vessel.

\section{III.1.5 Enhancements or Upgrades}

A high-field launch option, shown in Fig. III.5, increases the operating density range of the ECH system to $\sim 6 \times 10^{19} \mathrm{~m}^{-3}$. This launcher is similar to the low-field version except that the feed is through an upper TST port. A curved mirror is mounted

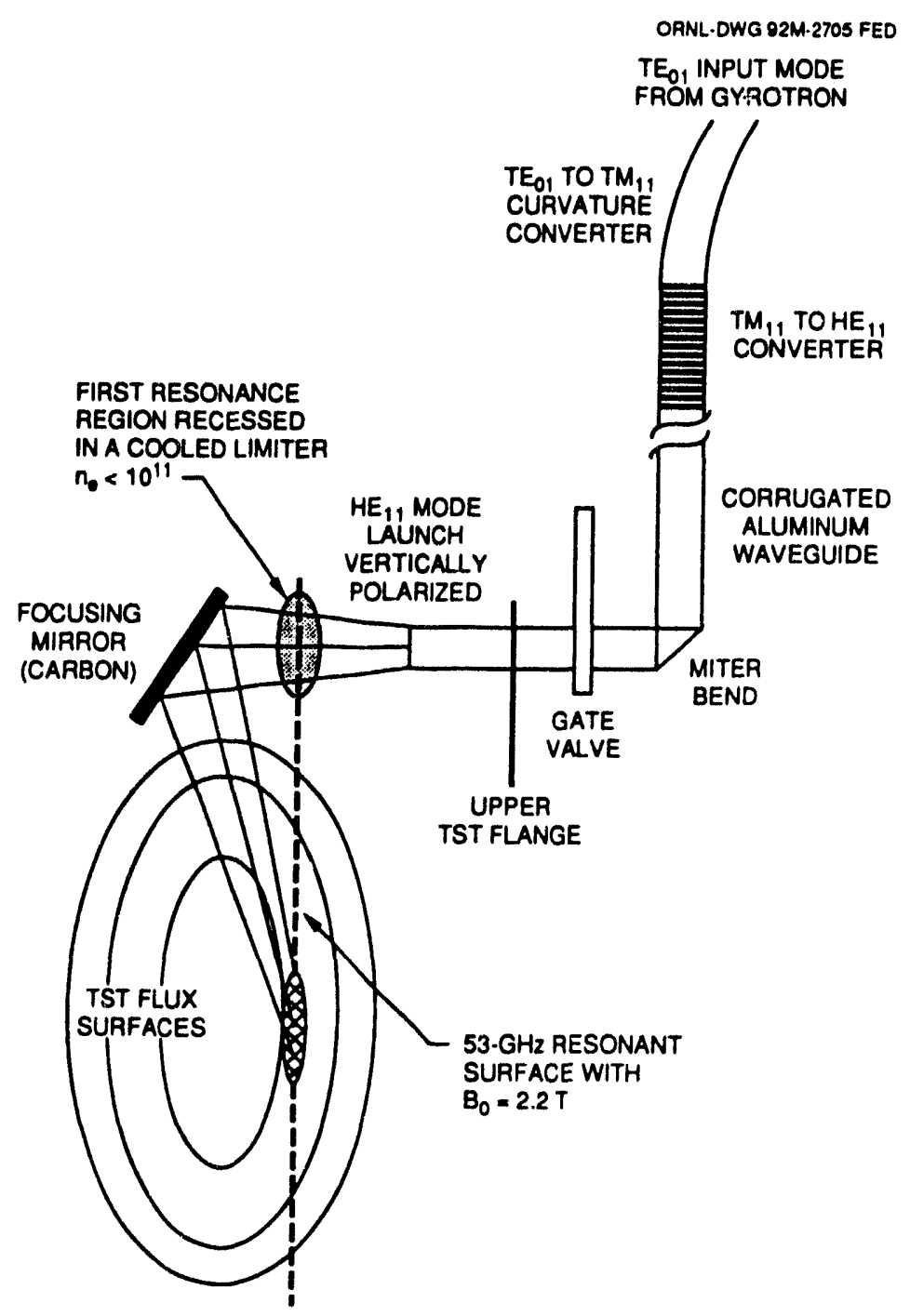

Fig. III.5. High-field launch configuration option for TST ECH system. 
in the high-field region to reflect the beam toward the resonance. A slight toroidal tilt is required for adequate absorption of the $\mathrm{X}$-mode from the high-field side. Since the beam passes through the resonance layer first at a region outside the plasma, steps must be taken to prevent absorption at this point. The plasma density should be quite low in this region so absorption is minimal, especially if this region is recessed behind a divertorlike panel.

Several options for an expanded ECH mission on TST could take advantage of existing and proposed ECH equipment for ATF. Effective heating is possible with $84 \mathrm{GHz}$ at $1.5 \mathrm{~T}$ (second harmonic), which is very close to the outer plasma edge for $B_{0}=2.2 \mathrm{~T}$. A $500-\mathrm{kW}$ gyrotron system of this frequency is planned for installation on ATF as part of a collaboration with Japan. An existing $35-\mathrm{GHz}, 200-\mathrm{kW}$ gyrotron could be used for edge heating with a central field of $1.83 \mathrm{~T}$, which is very close to heating on axis with $53 \mathrm{GHz}$. Edge heating may offer a useful knob on divertor plasma parameters.

\section{III.2 LH WAVE SYSTEM}

\section{III.2.1 Purpose}

The primary purpose of the LH system on TST will be to drive current in the plasma to permit steady-state operation. In addition, the LH power will act as a heating source to the plasma. Details of the current drive capabilities of the LH system are given in Sect. II.3.1.

\section{III.2.2 System Description}

The major components of the LH system are listed in Table III.2. A $2.45-\mathrm{GHz}$ LHCD system with 1.5 MW of source power (resulting in over $1 \mathrm{MW}$ being launched into the plasma) has been selected for driving continuous current in TST. Equipment used in the PLT and ASDEX current drive experiments would be well suited for this purpose. Three 500-kW, steady-state Varian klystron amplifier tubes from PLT are currently installed at ASDEX. The only major items that must be added for TST are a highvoltage dc power supply, a modulator/regulator, high-power phase shifters, and a launcher.

Table III.2. LH system components

\begin{tabular}{ll}
\hline \multicolumn{1}{c}{ Component } & \multicolumn{1}{c}{ Remarks } \\
\hline Launcher & $\begin{array}{c}\text { 24-element water-cooled grill, radially } \\
\text { movable }\end{array}$ \\
Phase shifter & \\
Power divider/waveguide transmission system & \\
Klystron sockets/driver & \\
Power supply & \\
Series regulator & \\
I\&C, interlocks & \\
\hline
\end{tabular}


A slow wave must be launched into the plasma to drive currents. A grill-shaped array of closely spaced, narrow waveguides with variable phase between adjacent waveguides has been widely used to launch such a wave into the plasma. High current drive efficiency and good impedance matching to the plasma require good control over the wave number spectrum, so individual waveguide phases and the grill position relative to the plasma edge must be adjustable. Because of the relatively wide ports $(\approx 80 \mathrm{~cm}$ toroidally) that will be available on TST, up to $24 \mathrm{LH}$ launcher waveguides (each $\approx 1 \mathrm{~cm}$ wide with a $0.4-\mathrm{cm}$-thick septum between them) can be mounted next to each other toroidally, resulting in a relatively well-defined $N_{\|}$spectrum with a width of $\Delta N_{\|} \approx 0.25$. This is similar to the LHCD system used on ASDEX [1], in which good current drive efficiencies were observed. Figure III.6 shows a sketch of the launcher. Figure III.7 is a plot of the $k$-spectrum calculated for the launcher.

ORNL.DWG 92M-2706 FED

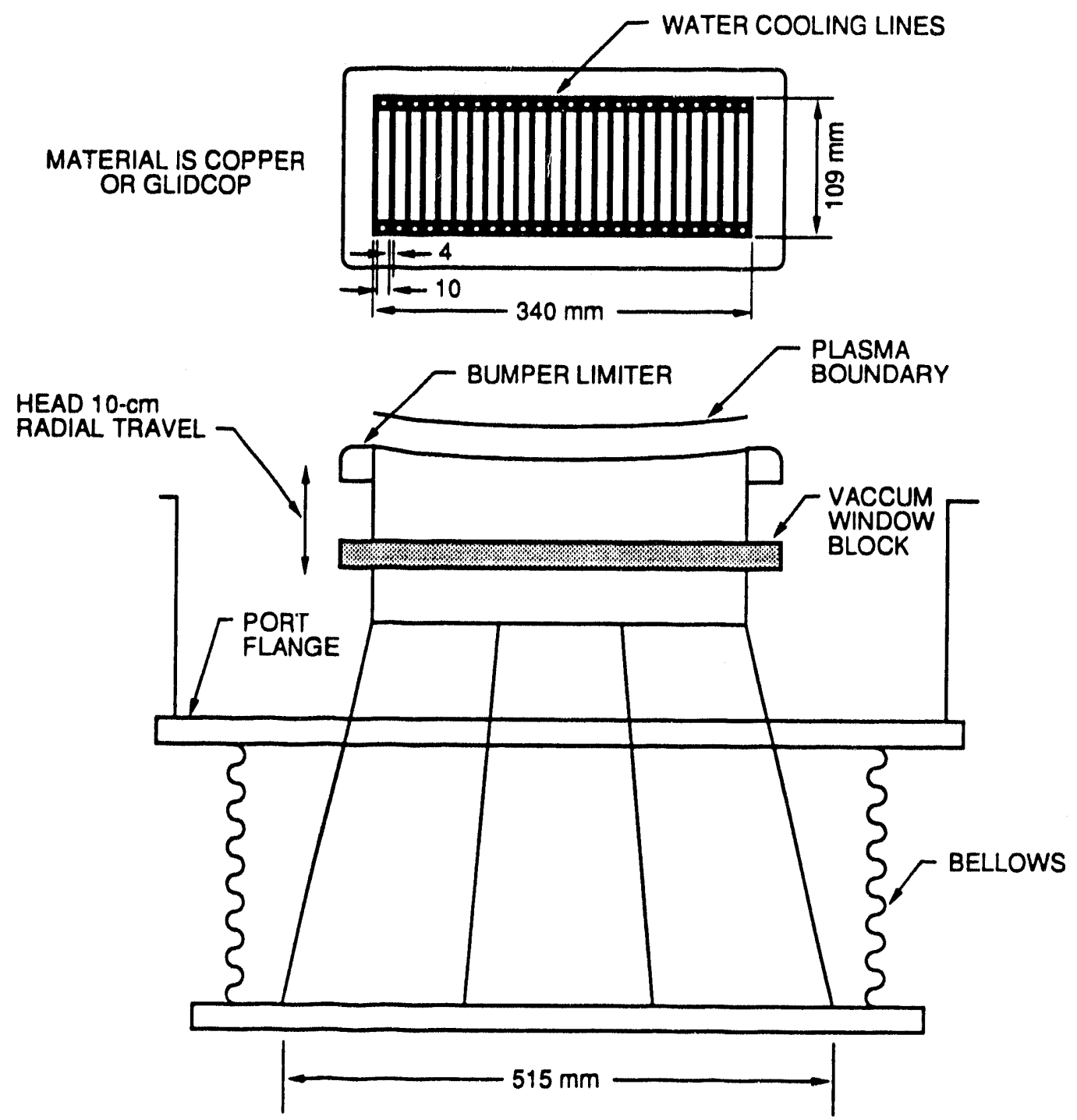

Fig. III.6. Diagram of the 24-waveguide LH launcher. 


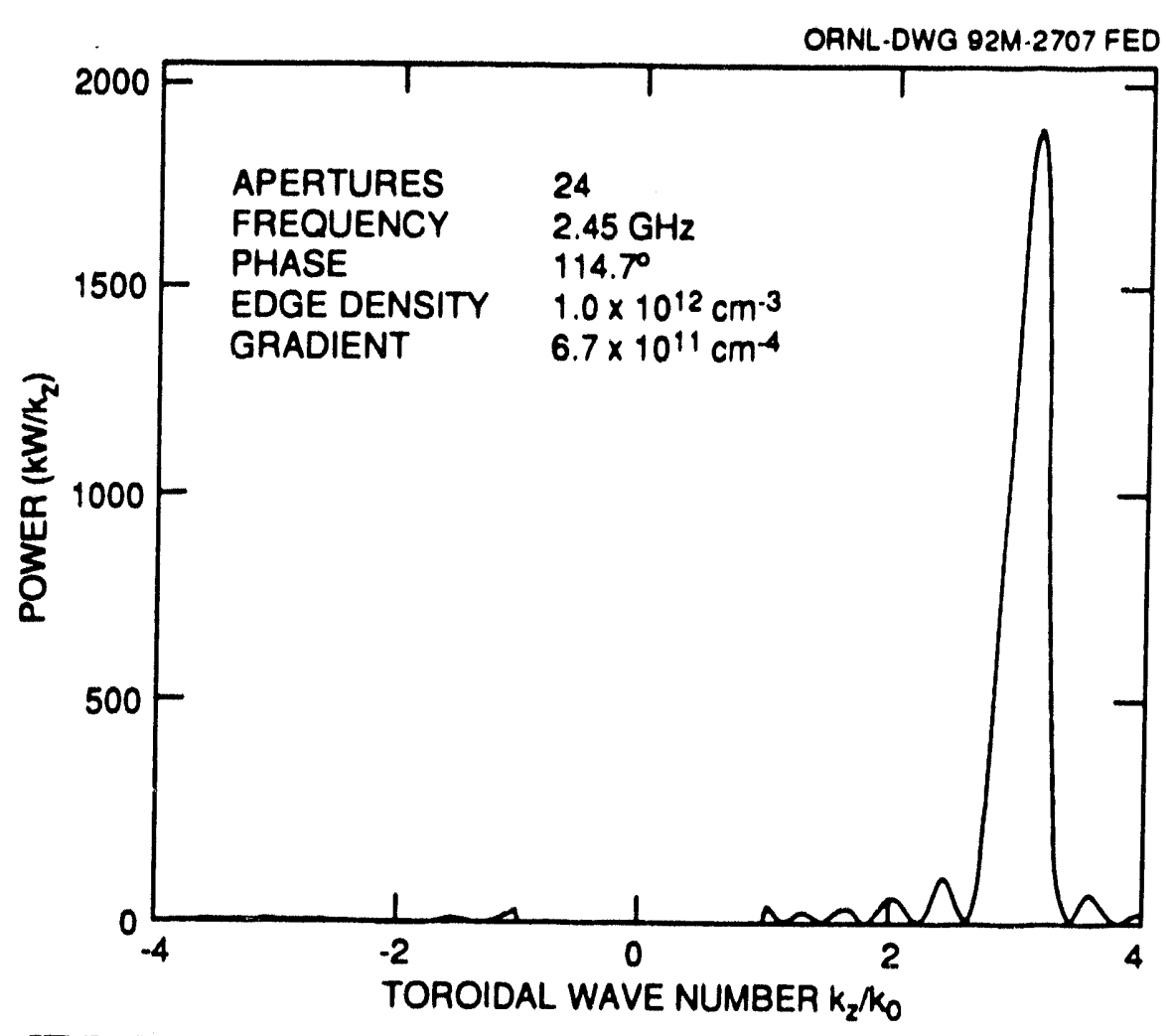

Fig. III.7. Power spectrum of the LH launcher shown in Fig. III.6, calculated for plasma properties expected for TST.

Figure III.8 shows the proposed microwave generation and launching system for LHCD on TST. This system makes maximum use of the PLT/ASDEX equipment, which comprises three 500-kW cw klystron amplifier tubes (Varian VKS 8269) and their associated sockets, focusing magnets, drive electronics, cooling interlocks, and high-power waveguide isolators. The systems were designed for 10-s pulses, so no significant additional cooling will be needed, but some control and interlock electronics will be required. The LH sources can be placed within $15.4 \mathrm{~m}(50 \mathrm{ft})$ of the TST device.

Many of the existing PLT waveguide components are suitable for use on TST, including water-cooled eight-way power dividers, directional couplers, long sections of rectangular and low-loss circular waveguide, flexible sections of waveguide, and other components. Some water cooling lines may have to be soldered on a few of the components. The high-power phase shifters used on PLT are not cooled and will have to be replaced, possibly with electronically controlled ferrite devices that are $\mathrm{cw}$ rated for this application. This will also allow high-speed control of the spectrum, which may be quite useful for current profile control.

Because of differences in the PLT and TST devices and the cw rating requirement, a new grill launcher assembly for TST will be needed. A 1 by 24 (or possibly a 2 by 12) array is proposed for the grill; this will easily fit into one TST midplane port and have a good launch spectrum. The launcher will be designed to slide $\pm 10 \mathrm{~cm}$ on a rail for optimizing the wave coupling and voltage standing wave ratio (VSWR). A large bellows will provide the flexible vacuum seal. Each waveguide will be $\sim 10$ by $1 \mathrm{~cm}$ and 


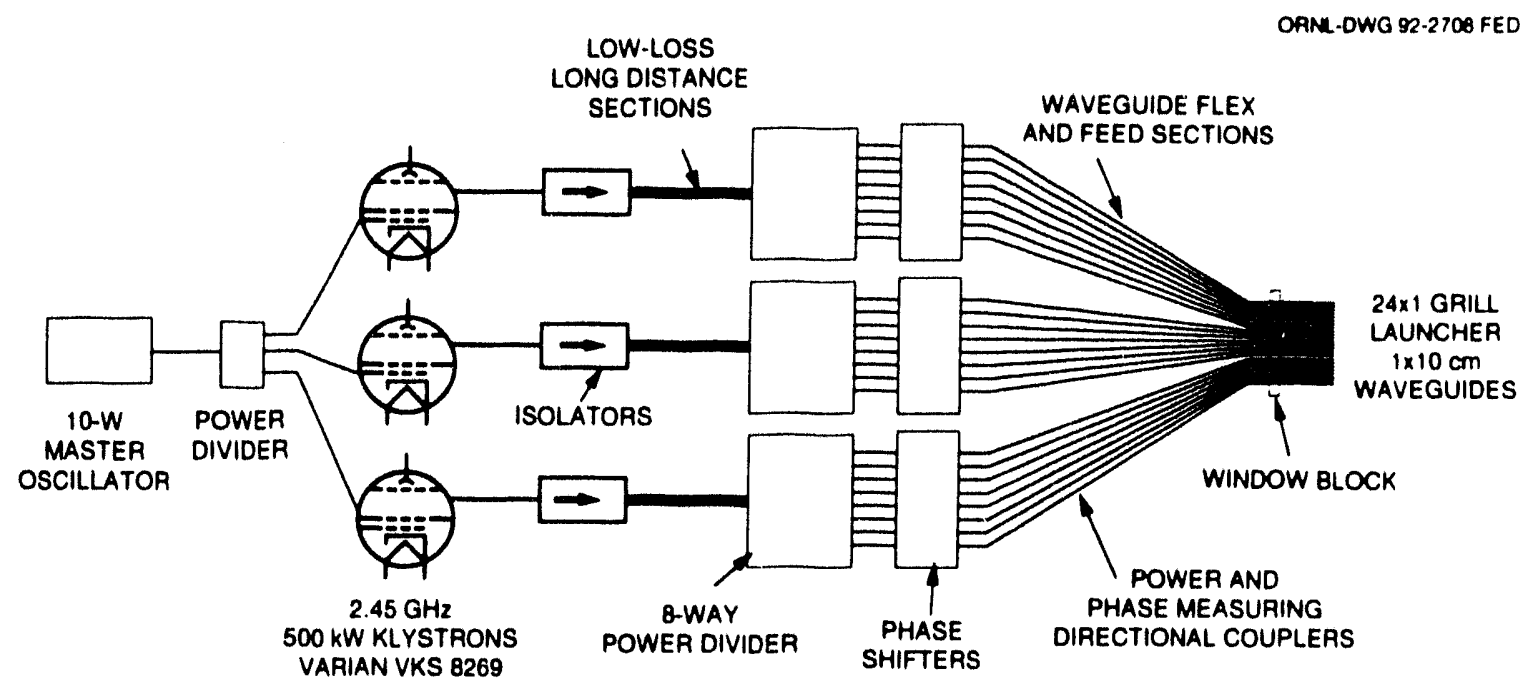

Fig. III.8. LH system diagram for TST.

will have a cooling line on two walls. Waveguides will be made of copper-plated stainless steel and/or Glidcop. Vacuum windows are required for each line and must be located in a high-field region near the TF coils so that the waveguides are pressurized near ECH resonant field regions. This reduces the likelihood of breakdown in the waveguides. Each window will consist of a high-purity alumina block brazed into an expansion-matched frame. Princeton Plasma Physics Laboratory (PPPL) has built similar windows for PLT and has offered to assist with this project. We plan to rely heavily on expertise from PPPL and the Max Planck Institute for Plasma Physics (IPPGarching) in the area of LH system design.

The three klystrons require a $-65-\mathrm{kV}$ dc supply with a total current capability of 50 A. The High Voltage Test Stand (used for neutral beam development in the past) located near the proposed TST site has a power supply that can be configured to supply the required voltage and current and will be used to power the klystrons. A regulated supply with fault interruption capability like that used for the gyrotron is essential to protect the klystrons. A modulator/regulator used on the ORNL Medium Energy Test Facility is available to protect the klystrons and will be used.

\section{III.2.3 Possible Enhancements}

An additional 1.5-MW, 2.45-GHz power system that is owned by ENEA (Frascati) is presently located at ASDEX. The possibility of obtaining it for use on TST as a future upgrade should be investigated. Our preliminary calculations indicate that sufficient current drive can be obtained at $\langle n\rangle=0.3 \times 10^{20} \mathrm{~m}^{-3}$ using only the PPPL 1.5-MW system, however.

\section{III.3 ICH SYSTEM}

ICH will be used to heat the plasma to obtain electron temperatures high enough for LHCD to be effective. In addition, as mentioned in Sect. II.5.2, preliminary results from JET indicate that the injection of $\mathrm{ICH}$ in a plasma can increase the efficiency of 
LHCD, probably by interacting with the tail electrons pulled out by the LH. Finally, it may be possible to drive current directly using FWCD with frequencies in the ion cyclotron range of frequencies (ICRF). Although this technique has not been verified on tokamaks, experiments are now under way at DIII-D and planned for JET. If these experiments prove the validity of the technique, then it may be possible to use the ICH system described here to drive current in TST directly. However, for this report, we assume that the rf launcher will be used for direct ion heating only.

Figure III.9 shows a diagram of the TST ICH system, which includes rf power sources, transmission lines, tuning and matching circuitry, and antennas. Details of the components of the system are given below.

ORNL.DWG 92M-2709 FED

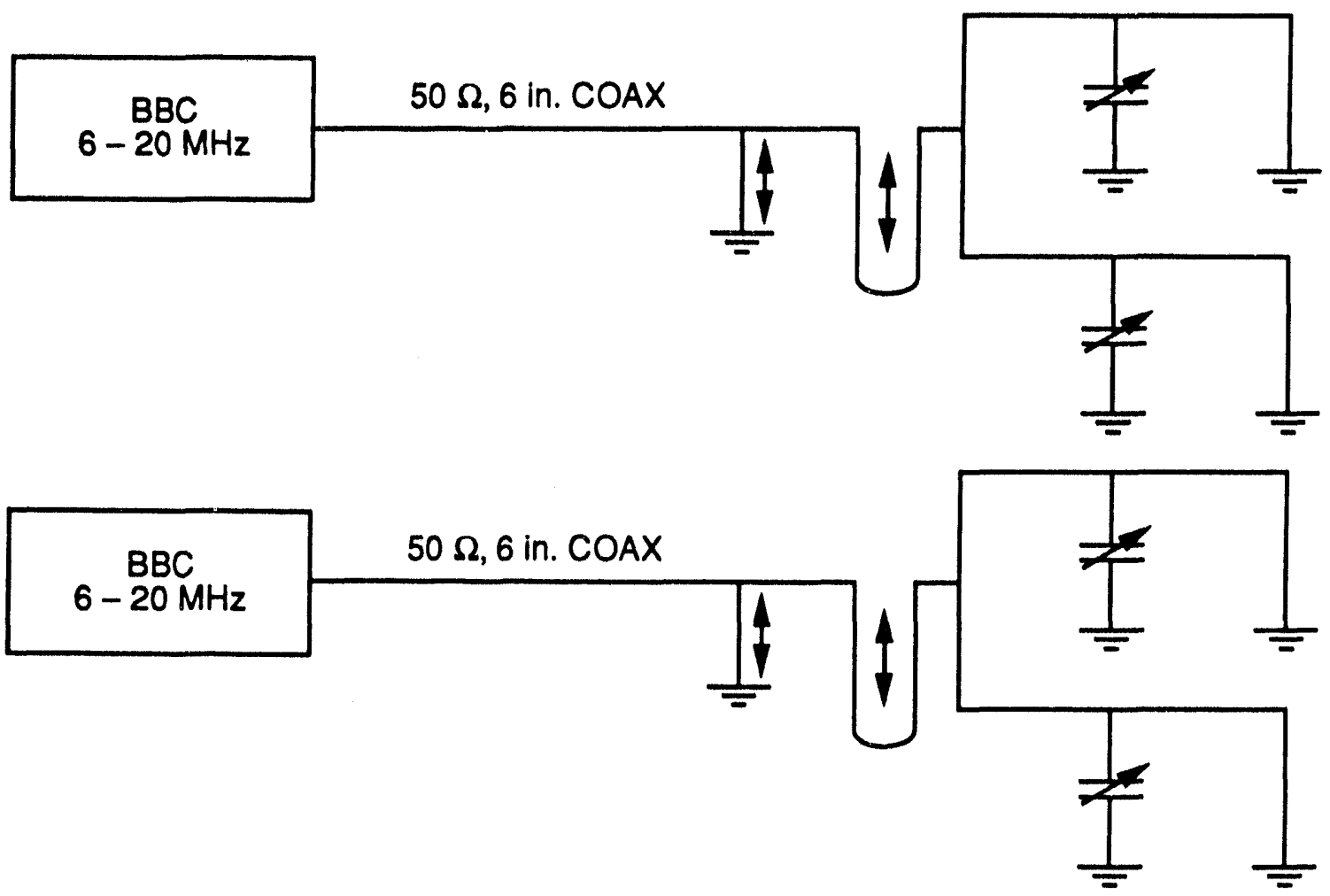

Fig. III.9. Schematic diagram of the TST ICH system.

\section{III.3.1 ICH Power Sources}

Three high-power ICH sources are installed at ORNL; their characteristics are described in Table III.3.

As described in Sect. II.3.2, the BBC power units will be used at $20 \mathrm{MHz}$ for minority heating of $\mathrm{He}^{3}$ ions in a majority of $\mathrm{D}$ ions. These power units can deliver up to $2 \mathrm{MW}$ for 30 -s pulses and $1 \mathrm{MW}$ steady state. 
Table III.3. ICH power systems at ORNL

\begin{tabular}{lccc} 
& Frequency range & \multicolumn{2}{c}{ Power $(\mathrm{MW})$} \\
\cline { 3 - 4 } \multicolumn{1}{c}{ Power unit } & $(\mathrm{MHz})$ & 30 -s pulsed & Steady state \\
\hline FMIT unit & $40-80$ & 1.5 & 1.0 \\
BBC (units 1 + 2) & $6-20$ & 2.0 & 1.0 \\
\hline
\end{tabular}

The FMIT power unit can be used to deliver an additional $1 \mathrm{MW}$ of heating power to the plasma, using direct electron heating, second harmonic $\mathrm{He}^{3}$, or second harmonic $\mathrm{H}$, as shown in Fig. II.5. Alternatively, this unit could be used to launch waves for FWCD. This system will not be used for initial operation but could be implemented later if needed.

\section{III.3.2 Antennas}

The antenna system that will be used for TST is shown in Fig. III.10. It consists of one antenna module inserted through a midplane port. The antenna module will consist
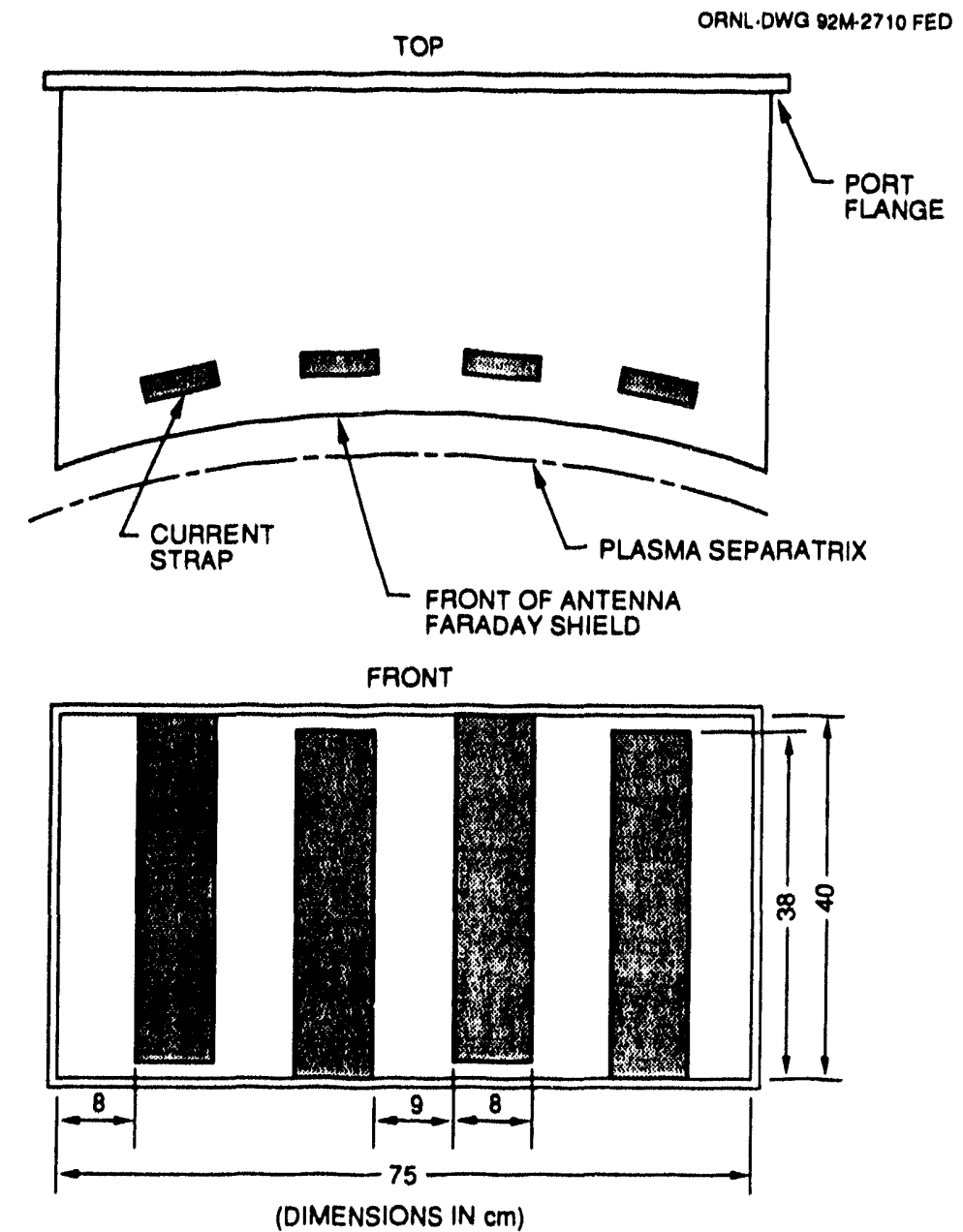

Fig. III.10. Antenna for TST, consisting of four current straps inserted through one port. 
of four current straps. These are grounded at one end and go through a vacuum feedthrough at the other end to the rf tuning and matching circuitry.

The antennas will be made of stainless steel or Inconel, with copper coating on all rf-current-carrying surfaces. Because of the steady-state operational requirement, the antenna components will be water cooled. Antennas with such components have been built at ORNL for use on Tore Supra and on TFTR and should pose no major engineering problems.

Each four-strap module is covered by a Faraday shield that is oriented to be approximately parallel to the local magnetic field lines during operation. The plasmafacing material could be one of several. Graphite or carbon-carbon composite can be brazed directly to Inconel or molybdenum. Alternatively, thin plasma-sprayed coatings of materials such as TiC [used at present on the Princeton Beta Experiment (PBX) antenna], $\mathrm{B}_{4} \mathrm{C}$ (to be used on Tore Supra and DIII-D antennas), or other such materials could be used. The decision of which material to use will be made during the detailed design phase, when improved experimental information is available.

\section{III.3.3 System Tuning and Matching}

The antenna system described here is very flexible. Since there are no tuned components in the vacuum region, all tuning and matching can be done externally. The tuning and matching system can be reconfigured depending on the way the system will be used. The tuning system is relatively straightforward for this case and will follow conventional design. Two current straps on the $20-\mathrm{MHz}$ antenna are driven by each $\mathrm{BBC}$ power unit. A resonantly tuned circuit with two capacitors is used to tune and match the loops to the transmission line, followed by a line-stretcher and stub tuner combination in each line for prematching.

The transmission lines from the power units to the tokamak area are 6-in.-OD, $50-\Omega$ coax lines that are now being used to supply if power to ATF. These are air cooled but will need no modification to run steady state.

\section{III.4 NEUTRAL BEAM SYSTEM}

\section{III.4.1 Purpose and Requirements}

A neutral beam system is not proposed as one of the H\&CD systems that will be present for the initial phase of TST operation. However, as described in Sect. II.4.1, the use of a neutral beam system may be desirable for operation at higher densities during a later phase of operation. An NBI system that will meet the steady-state requirements for TST can be constructed using parts from the ORNL neutral beam development program. In this section, the requirements, the potential performance, and the technical issues associated with the high heat flux and cryopumping for the operation of the steady-state beam system are discussed.

The prime requirements for the neutral beam system are:

1. the capability of operating essentially steady state for up to $4000 \mathrm{~s}$, and

2. beam power of up to $1.5 \mathrm{MW}$ of $\mathrm{H}$ or $\mathrm{D}$ neutrals at energies of 50 to $60 \mathrm{keV}$. 


\section{III.4.2 System Design}

To maximize the efficiency of beam heating and current drive, the neutral beam will be injected tangentially. The layout of the neutral beam in relation to the rest of the machine is shown in Sect. V (Fig. V.27). Existing megawatt beam systems [2] have been operated reliably to form 30-s pulsed ion beams and inject 10-s pulsed neutral beams. Some of these system are being upgraded to produce beam pulses up to $30 \mathrm{~s}$, with the possibility of eventually extending the pulse length up to $\sim 1000 \mathrm{~s}$. However, as listed in Table III.4, the present demonstrated capabilities of neutral beam systems are for far shorter times.

The proposed TST NBI system will be designed to operate for pulse lengths up to $4000 \mathrm{~s}$. It will be built largely from existing equipment to reduce costs [3]. Utilizing resources available at ORNL, the TST NBI system could be the first injector producing 4000-s beams at the megawatt level. Figure III.11 shows a sketch of the TST neutral injector. Table III.5 lists the major components in the system, including a rectangular ion source capable of forming 50-keV, 75-A hydrogen ion beams. This source is designed to be consistent with the projected ratings of the power supplies available at ORNL. The transmission efficiency will be optimized from the typical $60 \%$ to $66 \%$ by improving beamlet optics and minimizing drift duct loss. Assuming $66 \%$ transmission efficiency from the ion source to the TST plasma, the 75-A ion beam with an ion species ratio of $\mathrm{H}_{1}{ }^{+}: \mathrm{H}_{2}+: \mathrm{H}_{3}{ }^{+}=8: 1: 1$ will inject a $-1.5-\mathrm{MW}$ neutral beam with $\sim 1.1-\mathrm{MW}$ full-energy hydrogen atoms through a port $(40$ by $60 \mathrm{~cm})$ on the drift duct $6 \mathrm{~m}$ downstream.

Table III.4. Operating times of components in present multimegawatt neutral beam systems

\begin{tabular}{lll}
\multicolumn{1}{c}{ System } & \multicolumn{1}{c}{ Components } & $\begin{array}{c}\text { Demonstrated } \\
\text { pulse time }\end{array}$ \\
\hline $\begin{array}{l}\text { Ion source } \\
\text { Neutral beam line }\end{array}$ & $\begin{array}{c}\text { Neutralizer, ion deflection or bending magnet, ion } \\
\text { dumps, calorimeters, defining plates, drift duct }\end{array}$ & $\sim 30 \mathrm{~s}$ \\
Power supplies & $\begin{array}{c}\text { Accel supply including modulator, decel supply, } \\
\text { arc supply, filament supply, deflection magnet } \\
\text { supply }\end{array}$ & $\sim 30 \mathrm{~s}$ \\
Cryogenic system & $\begin{array}{c}\text { Liquid nitrogen system, liquid helium liquefaction } \\
\text { system, cryocondensation pumps }\end{array}$ & $\sim 30 \mathrm{~s}$ \\
Other utilities & $\begin{array}{c}\text { Cooling water system, computer instrumentation } \\
\text { and control system, safety interlock system }\end{array}$ & Steady state \\
\hline
\end{tabular}




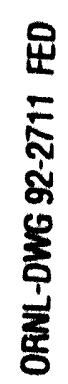
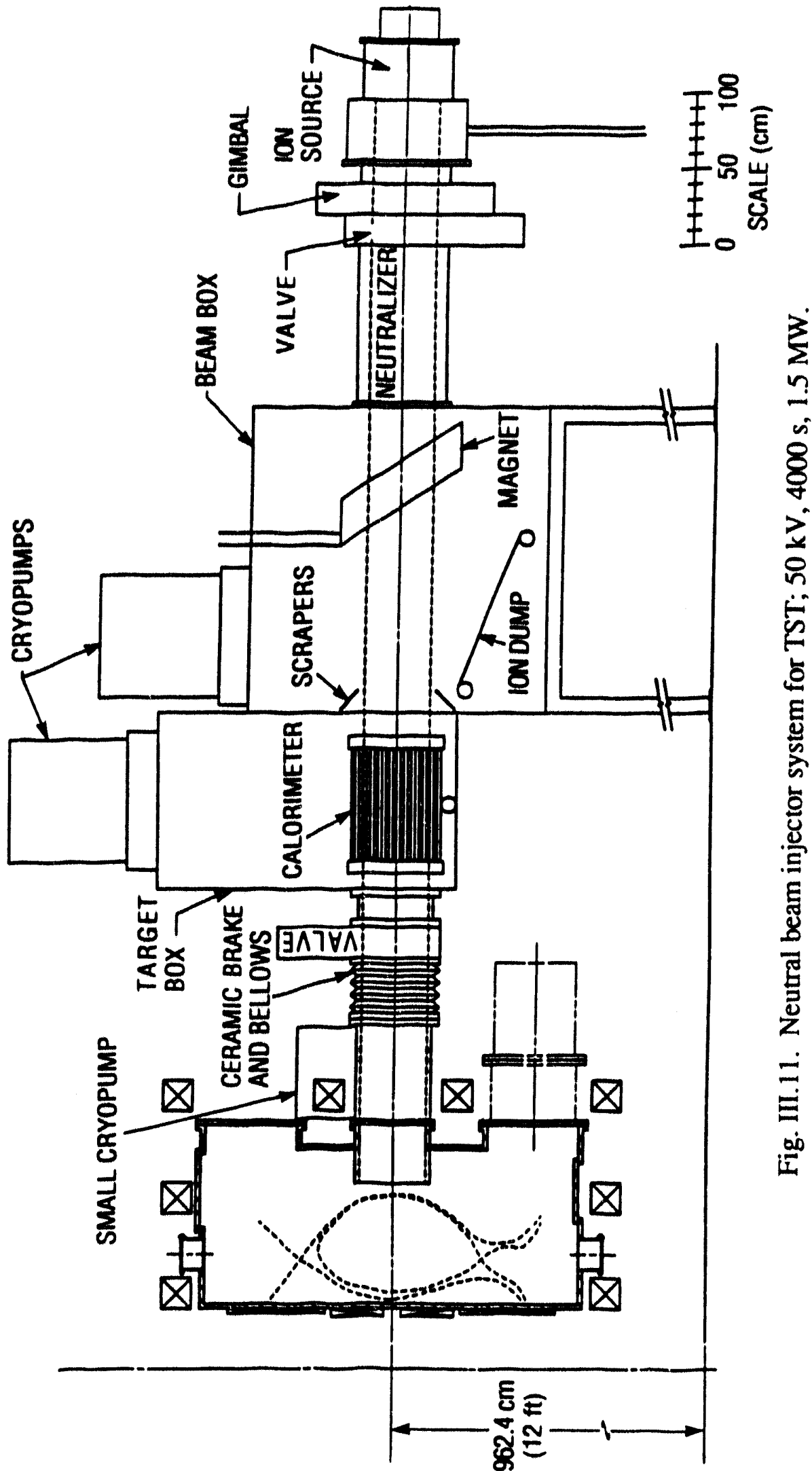
Table III.5. Components of TST steady-state, neutral beam system

\begin{tabular}{ll}
\hline \multicolumn{1}{c}{ Component } & \multicolumn{1}{c}{ Remarks } \\
\hline Mechanical & Testing and optimization needed for $4000 \mathrm{~s}$ \\
Ion source & Needs magnetic shield \\
Gimbal/valve & For source and neutralizer \\
Neutralizer & \\
Magnetic shields & \\
Beam box & \\
Bending magnet & \\
Ion dump & \\
Calorimeter & \\
Calorimeter moving & \\
mechanism & \\
Defining plates & \\
Target box & \\
Drift duct valve & \\
Cryopumps & \\
Support frame & \\
Electrical & \\
Accel supply & \\
Decel supply & \\
Arc supply & \\
Filament supply & \\
Deflection magnet supply & \\
Cables & \\
Cryogenic & \\
Liquid nitrogen system & \\
Liquid helium liquefaction & \\
system & \\
Cooling water system & \\
Computer I\&C and DAS & \\
\hline Safety interlock system & \\
\end{tabular}

For a 50-kV, 75-A source, Fig. III. 12 shows variations of the deposited beam power, neutral power ratio, and neutral particle ratio as a function of the beam energy from 10 to $60 \mathrm{keV}$. Such a performance level is consistent with the neutral beam injectors [4] for the Poloidal Divertor Experiment (PDX) and the Impurity Study Experiment (ISX), which were operated to inject $\sim 1.8-\mathrm{MW}$ hydrogen neutral beams from $50 \mathrm{keV}$ and $100 \mathrm{~A}$, and with the TEXTOR beam injectors [5], presently being upgraded for injecting 30-s beams. The PINI source [6] for the TEXTOR injectors has already formed $30-\mathrm{s}$ ion beams of $32 \mathrm{kV}$ and $31 \mathrm{~A}$. Other multisecond neutral beam injectors for DIII-D, TFTR, JET, and JT-60 would need substantial upgrades to inject neutral beams for thousands of seconds for H\&CD experiments on steady-state tokamaks. 

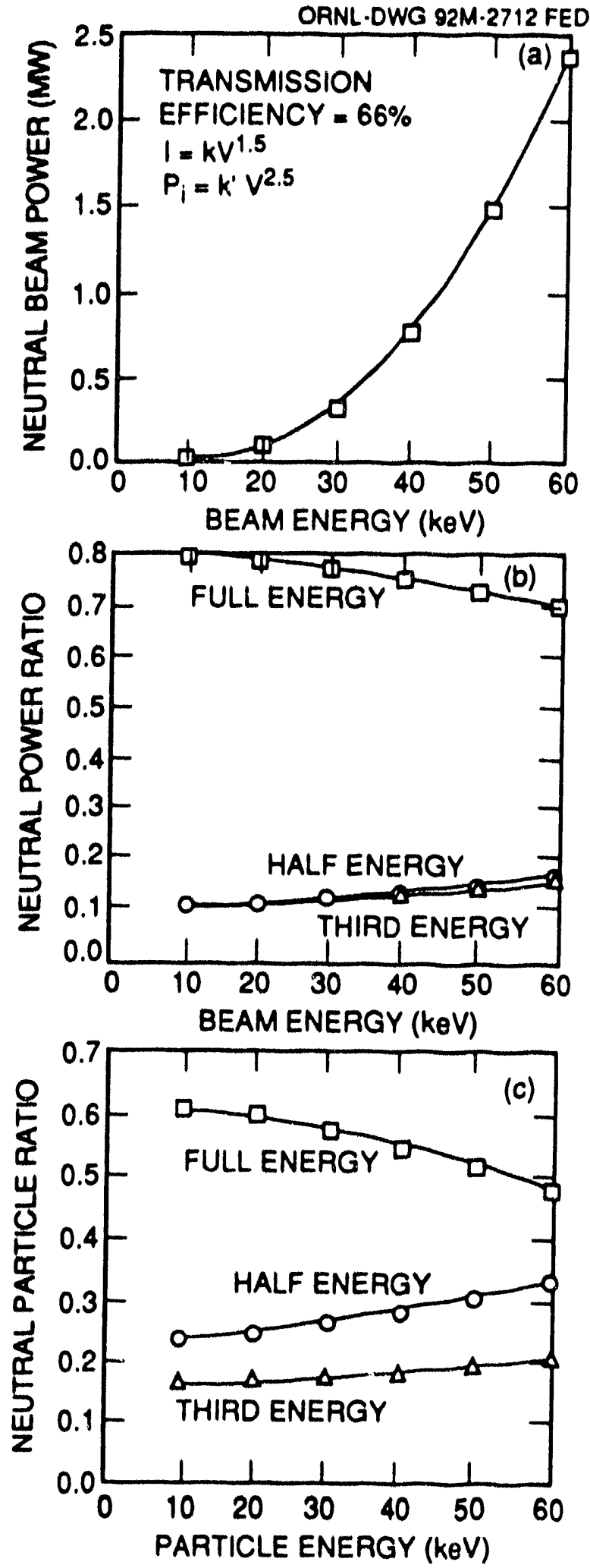

Fig. III.12. Beam parameters vs energy, for an ion power ratio of 8:1:1. (a) Total beam power vs energy. (b) Power in each energy component vs energy. (c) Particles in each energy component vs energy. 
The heart of each neutral beam injector is its ion source. At the moment, no ion sources have been operated to demonstrate reliable production of ion beams for thousands of seconds at the multimegawatt level. However, in the early 1980s, advanced positive ion sources (APISs) were developed at Lawrence Berkeley Laboratory (LBL) and ORNL for MFTF-B 30-s neutral beam injectors. Both prototype APIS sources were operated for reliable production of 30-s pulsed ion beams of 70-80 kV and 40-60 A. We propose to use a modified version of the ORNL APIS for the TST NBI system. The modifications include regapping the source grids to operate at $50 \mathrm{kV}$; in addition, the sources must be qualified experimentally to demonstrate reliable production of $4000-\mathrm{s}$ beams.

In a steady-state neutral beam injector, the ion dumps and calorimeters must be designed to handle a peak heat flux density of $5 \mathrm{~kW} / \mathrm{cm}^{2}$. A calorimeter made with copper swirl tubes was successfully used to handle ion beams with peak power densities of 15 to $20 \mathrm{~kW} / \mathrm{cm}^{2}$ during the $30-\mathrm{s}$ APIS ion source development [7]. It was subjected to 25,000 shots of full-power (>3-MW) beam pulses, with 5,000 shots of 1- to 30-s pulses and 20,000 shots of $<1$-s pulses. It is a proven technology for high-heat-flux survivability, long-pulse stability, system reliability, and thermal fatigue tests.

Targets made with swirl tubes can definitely be used for the ion dump and calorimeter in the TST NBI system. It is desirable to run the neutral beam system for one year without target maintenance. These targets may have to handle 250 shots of 4000 -s beams. Assuming a peak heat flux density of $5 \mathrm{~kW} / \mathrm{cm}^{2}$ and a sputtering coefficient of 0.08 [8], the erosion thickness of copper tubes due to beam sputtering could be 5 to $6 \mathrm{~mm}$. Obviously, targets made of thin $(1.6-\mathrm{mm})$ swirl tubes will have an unduly short lifetime. To extend the tube lifetime, the swirl tubes should be coated with a protective layer of low-sputtering material. For example, the sputtering coefficient of $\mathrm{TiC}$ is 0.01 (about one order of magnitude less than that of copper). Such swirl tubes with protective coatings should be capable of handling high heat flux and resistant to physical sputtering of beam particles.

Assuming $50 \%$ gas efficiency, $75-\mathrm{A}$ hydrogen ion beams need 15 torr $\cdot \mathrm{L} / \mathrm{s}$ of gas feed. For a 4000 -s beam pulse, the total gas load is 60,000 torr $\bullet \mathrm{L}$, which could be condensed on three existing cryopumps. During the beam shot, the cryopumps may need to use a forepump to evacuate the exhaust helium gas and to maintain cryopanels below $5 \mathrm{~K}$ so that the hydrogen vapor pressure is kept below $10^{-5}$ torr. Even successfully handling the gas load, the cryopumps should be regenerated after each 3000- to 4000-s beam pulse. This is a necessary precaution to minimize the potential explosion hazard of a hydrogen-oxygen mixture in case of a vacuum le kage accident during beam operations. In the future, continuous cryopumps [9], which are being developed for ITER, may be available and could be installed for the TST NBI system.

It is desirable to enhance the reliability and availability of the NBI system by pursuing an R\&D effort before the steady-state injector installation. The R\&D effort will carry out the much needed steady-state beam demonstration on an ion beam test stand. Consequently, the steady-state capability of the ion source, beam line components such as the ion dump and calorimeter, power supplies, and cryopumps will be verified. The test stand can be prepared by recommissioning the ORNL Medium Energy Test 
Facility, which was originally built for developing and qualifying the 30-s APIS sources.

\section{References for Sect. III}

[1] F. Leuterer et al., "Lower Hybrid Current Drive Efficiency at $2.45 \mathrm{GHz}$ on ASDEX," p. 1219 in 17th European Conference on Controlled Fusion and Plasma Heating, Amsterdam, 1990: Contributed Papers, Part III, European Physical Society, Petit-Lancy, Switzerland, 1990 [Europhys. Conf. Abstr. 14B, Part III, 1291 (1990)].

[2] W. B. Lindquist and H. S. Staten, p. 795 in Proceedings of the 12th Symposium on Fusion Engineering, IEEE, New York, 1987; W. B. Lindquist and H. S. Staten, p. 1130, ibid.; M. M. Menon et al., Rev. Sci. Instrum. 56, 242 (1985); M. Akiba et al., Rev. Sci. Instrum. 53, 1864 (1982); M. C. Vella et al., p. 149 in Proceedings of the 11 th Symposium on Fusion Engineering, IEEE, New York, 1985; G. Duesing et al., Fusion Technol. 11, 163 (1987).

[3] C. C. Tsai et al., p. 860 in Proceedings of the 11th Symposium on Fusion Engineering, IEEE, New York, 1985.

[4] W. L. Gardner et al., Rev. Sci. Instrum. 53, 424 (1982).

[5] H. Euringer et al., p. 991 in Proceedings of the 13th Symposium on Fusion Engineering, IEEE, New York, 1990.

[6] R. Uhlemann, personal communications.

[7] S. K. Combs et al., Rev. Sci. Instrum. 56, 1526 (1985).

[8] D. E. Schechter and C. C. Tsai, Nucl. Technol./Fusion 8, 559 (1985).

[9] C. A. Foster, ORNL, personal communications. 


\section{THE TEST DIVERTORS}

\section{IV.1 POWER AND PARTICLE HANDLING FOR STEADY-STATE OPERATION}

The development of components and techniques for steady-state power and particle handling while maintaining adequate core plasma conditions is a prerequisite for building steady-state machines such as ITER and SSAT. In contrast, power and particle handling in present machines is predominantly of a transient nature: (1) walls need to be conditioned between shots in order to optimize plasma performance, and (2) plasmafacing components (PFCs) are not actively cooled during the discharge; that is, they heat up during the shot and are cooled down between shots. As a result, the core plasma conditions are also transient in nature, except for cases where the plasma edge heat flux $\dot{Q}_{\perp}$ is kept low. The only (partial) exception is Tore Supra, in which all in-vessel components are actively cooled so that the component temperatures assume stationary values during the discharge. Particle control, on the other hand, is still dominated by transient wall effects and requires intermittent conditioning periods. Techniques for continuous particle control and heat removal in ITER and SSAT are not yet available.

TST, with its capability for steady-state operation, is uniquely suited to develop a database for steady-state power and particle handling while maintaining adequate core plasma conditions. This goal is complementary to the programs on edge physics and particle control in Tore Supra, DIII-D, and TEXTOR, as well as the plasma heating programs in Tore Supra, DIII-D, and TFTR.

\section{IV.1.1 Development of Steady-State Power and Particle Handling}

TST can address the following generic issues in dealing with steady-state operation:

1. Plasma heating. Specific issues include the testing of materials and coatings as well as improved designs for rf launching structures in steady state; examination of the effects of the if sheath on erosion, impurity evolution, density control, and heat removal in steady state; and exploration of steady-state plasma conditions that are compatible with high-power rf heating.

2. Heat removal. Steady-state operation at high heat fluxes would allow realistic testing of PFCs and corresponding water-cooled backing structures. Component lifetimes as determined by erosion/migration/redeposition can be tested in steady state and in realistic magnetic field geometries. In particular, long-time-scale changes in the heat removal characteristics due to erosion/redeposition processes can be investigated.

3. Particle control. For steady-state operation, TST would be equipped with water-cooled graphite panels. Steady-state operation would allow study of the continuous evolution of the wall characteristics, for example, recycling as well as erosion and impurity evolution. Steady-state operation requires new wall conditioning techniques (such as continuous boronization), which can be tested in TST. Steady-state plasma operation of TST will provide a test bed for continuous pellet fueling. The final goal will be to develop integrated particle control techniques that involve fueling, wall con- 
ditioning, and pumped divertors. Because of the long time constants of wall equilibration ( $10 \mathrm{~min})$, the steady-state feature of TST is a prerequisite for achieving this testing goal.

\section{IV.1.2 The Divertor Challenge: An Integrated Description}

A comprehensive discussion of the divertor challenge in ITER can be found in recent physics considerations of the ITER conceptual design [1, 2]. The ITER divertors are to handle the bulk of power and particle fluxes produced by the plasma $\left(P_{\alpha} \sim\right.$ $200 \mathrm{MW})$, which may also receive large amounts of auxiliary drive power $\left(P_{\text {aux }} \sim\right.$ $100 \mathrm{MW}$ ). Since the active divertor plate area in ITER can at best be $\sim 5 \%$ of the total wall area (which is $\sim 10^{3} \mathrm{~m}^{2}$ ), serious technical challenges should be expected. R\&D needs in both the plasma physics and the technology areas have been clearly identified $[2,3]$. However, a recent review of the ITER CDA [4] identified physics-technology integrated divertor solutions as an area in critical need of R\&D.

The severity of this divertor challenge is shown in Fig. S.1, which contrasts the kinetic heat flux at the plasma edge $\left(\dot{Q}_{\perp}\right)$ and plasma duration $\left(\tau_{\text {dura }}\right)$ projected for ITER $[4,5]$ and SSAT [6] with the values achieved in tokamaks to date. The gap to be covered spans three orders of magnitude in $\tau_{\text {dura }}$ for $\dot{Q}_{\perp}-0.1-0.3 \mathrm{MW} / \mathrm{m}^{2}$ and over one order of magnitude in $\dot{Q}_{\perp}$ for $\tau_{\text {dura }} \sim 10^{3}-10^{5} \mathrm{~s}$. While an advanced divertor is already in operation on DIII-D [7] and another is being installed on JET [8] to address this issue for $\tau_{\text {dura }}-10-100 \mathrm{~s}$, the duration will still be one to two orders of magnitude below the equilibration time scales for plasma-wall interaction and for divertor material erosion, migration, and redeposition.

The divertor solution must account for interactions between the tokamak plasma and the divertor components and perform under steady-state (for $10^{3}-10^{5} \mathrm{~s}$ ), H-mode, ITER-level SOL and divertor plasma conditions. These interactions are listed in Table IV.1 and can be characterized as follows:

1. The peak divertor plate heat flux $\left(\dot{Q}_{\text {div }}\right)$ for the ignition-phase ITER plasma is estimated to be near the thermohydraulic and thermomechanical limits $\left(\sim 15 \mathrm{MW} / \mathrm{m}^{2}\right)$ for sustained reliable operation, under a relatively conservative assumption of $\chi_{\perp}$ $\left(\sim 2.6 \mathrm{~m}^{2} / \mathrm{s}\right)$ for the cross-field heat diffusivity of the SOL plasma. The magnitude of $\dot{Q}_{\text {div }}$ depends strongly on the SOL thickness $\Delta_{Q}$, the electron temperature at the divertor sheath $T_{\text {ed }}$, and the inclination of the divertor plate $\theta_{\mathrm{d}}$.

2. The peak plasma temperature at the divertor sheath is estimated to be no less than $T_{\text {ed }} \sim 45 \mathrm{eV}$ for a plasma edge density of no more than $n_{x} \sim 3.5 \times 10^{13} \mathrm{~cm}^{-3}$ [9]. This value of $T_{\text {ed }}$ is too high to avoid excessive sputtering erosion of the graphite divertor plates, even assuming a $99 \%$ probability of in situ redeposition of the eroded material. The magnitude of $T_{\text {ed }}$ depends strongly on $n_{\times}$and the impurity density $n z$.

3. Sputtering of the divertor plate material introduces impuritie's in the SOL plasma. To prevent excessive accumulation of impurities in the core plasma, $\mathrm{H}$-mode operation characterized by edge-localized modes (ELMs) is necessary, degrading the core plasma confinement to $H_{\mathrm{f}} \approx 1.5[10,11]$. 
Table IV.1. Interactions, constraints, requirements, and key uncertainties of ITER divertor parameters

\begin{tabular}{|c|c|c|c|c|}
\hline Parameters & $\begin{array}{c}\text { Strong } \\
\text { interactions } \\
\end{array}$ & $\begin{array}{l}\text { Divertor } \\
\text { constraints }\end{array}$ & $\begin{array}{l}\text { Nondivertor } \\
\text { requirements }\end{array}$ & Uncertainties \\
\hline $\begin{array}{l}\dot{Q}_{\operatorname{div}} \\
\left(\mathrm{MW} / \mathrm{m}^{2}\right)\end{array}$ & $\Delta_{\Omega}, T_{\text {ed }}, \theta_{\mathrm{d}}$ & $\leq 15$ (heat removal) & $\geq 15$ (hea & $\chi_{\perp}, D_{\perp}$ \\
\hline$T_{\text {ed }}(\mathrm{eV})$ & $\dot{Q}_{\text {div }}, n_{\times}, n z$ & $\leq 25$ (erosion) & $\geq 45{\text { (heat flux })^{a}}$ & $\begin{array}{l}\text { Disruptions, RES, } \\
\text { redeposition }\end{array}$ \\
\hline$H_{\mathrm{f}}$ & $\begin{array}{r}n_{Z,} n_{\mathrm{He}} \\
\text { ELMs }\end{array}$ & $\begin{array}{l}\leq 1.5 \text { (impurity } \\
\text { removal) }\end{array}$ & $\geq 2.0$ (ignition) & H-mode scaling \\
\hline $\begin{array}{c}n_{\times}\left(10^{13}\right. \\
\left.\mathrm{cm}^{-3}\right)\end{array}$ & $\dot{Q}_{\perp}\left(\dot{Q}_{\mathrm{div}}\right)$ & $\begin{array}{l}\geq 3.5 \text { (minimize } T_{\mathrm{div}} \\
\text { and sputtering) }\end{array}$ & $\leq 3.5$ (disruption) & $\begin{array}{l}\text { Margin for dis- } \\
\text { ruption-free } \\
\text { operation }\end{array}$ \\
\hline$n_{\mathrm{Z}} / n_{\mathrm{e}}(\%)$ & $\begin{array}{c}\dot{Q}_{\text {div }}, T_{\text {ed }} \\
\text { disrup- } \\
\text { tions }\end{array}$ & Introduce impurities & $\leq 5($ Low $-Z)$ & $\begin{array}{l}\chi Z_{\perp}, D_{Z \perp}, \text { vortex } \\
\text { flow }\end{array}$ \\
\hline $\begin{array}{c}\dot{N}_{\mathrm{He}} / \dot{N}_{\mathrm{DT}} \\
(\%)\end{array}$ & $\dot{N}_{\mathrm{Z}}, \dot{N}_{\mathrm{DT}}$ & $\begin{array}{l}<5 \text { (X-point gas } \\
\text { puff) }\end{array}$ & $\begin{array}{l}-5 \text { (pump capa- } \\
\text { bility) }\end{array}$ & $\begin{array}{l}\text { Plasma-flush } \\
\text { requirements }\end{array}$ \\
\hline
\end{tabular}

apeak values after applying safety margins and strike-point sweeping.

4. Low levels of impurities cause thermal collapse of the SOL plasma when $n_{\times}$ exceeds a critical level $n_{\times c}$, leading to core plasma disruption [12]. For the ignitionphase plasma of ITER, $n_{\times c}$ is estimated to be $3.5 \times 10^{13} \mathrm{~cm}^{-3}$ [13] and sets a lower bound on $T_{\text {ed. }}$. In view of item 2, the ignition-phase plasma is expected to operate at the density limit for plasma disruption. This lower bound in $T_{\mathrm{ed}}$ increases with increasing impurity content in the SOL [12].

5. These constraints apply equally to both divertor channels. Since the outboard channel in ITER (DN divertor) is expected to receive four times as much power as the inboard channel [11], the disruption limit $n_{\times c}$ due to the inboard channel will force the outboard channel to operate at an $n_{\times}$substantially lower than otherwise possible. This raises $T_{\mathrm{ed}}$ in the outboard channel, accentuating the difficulty of plate erosion.

6. A vortex flow pattern is expected in the ITER divertor and SOL plasma $[14,15]$. This flow pattern enhances the exhaust of helium as well as a reflux of impurities from the divertor to the plasma edge, which enhances the speed of impurity accumulation in the core plasma. Schemes to stem the reflux of impurities while maintaining an adequate helium removal rate $\left(\dot{N}_{\mathrm{He}} / \dot{N}_{\mathrm{DT}}\right)$, such as divertor gas puffing and active pumping, are being installed and tested in DIII-D [7] and JET [8]. These schemes are expected to have an impact on essentially all of the divertor plasma parameters listed in Table IV.1. 
The divertor of the ITER CDA is therefore expected to be marginally acceptable under relatively optimistic assumptions [4]. Several general areas of R\&D are needed to remove the performance uncertainties and find solutions to this challenge [3]. In the plasma physics area, investigations are needed to clarify the mechanisms underlying $\chi_{\perp}$, $D_{\perp}$, disruptions, and impurity migration in the edge, SOL, and divertor plasmas; the interactions of these mechanisms with the $\mathrm{H}$-mode plasma; and the physics tests for innovative divertor concepts [16]. Such investigations require divertor experiments with relatively short plasma durations and modest plasma edge conditions, in SN or DN divertor configurations, as part of the divertor physics R\&D for ITER [3].

In the PFC technology area, development is needed in the areas of handling high heat fluxes, erosion-resistant materials, erosion and redeposition of plate materials, tritium retention and removal, system conditioning, disruption-load handling techniques, fatigue of high-heat-flux components, lifetime of components, and technology and material tests for innovative divertor concepts [16]. Such investigations can use linear magnetic devices [3] that provide plasma-material conditions and configurations close to those expected in the ITER divertor, augmented by small devices that carry out isolated tests at modest parameters [3].

These investigations and developments are expected to identify improved methods of divertor plasma operation for short durations, separate from steady-state technologies, and advanced techniques of power and particle handling isolated from the tokamak plasma. The elements of these advances must be integrated into divertor concepts and subjected to tests under steady-state, ITER-level plasma edge, SOL, and divertor conditions while maintaining adequate core plasma conditions. Issues of critical importance in this area $[3,4]$ include the verification of these methods and techniques and the development of additional approaches to control interactions among them and with the plasma core, failure modes, recovery from disruptions and component failure, operational lifetimes, and reliability under steady-state tokamak conditions. These development needs are expected to determine the performance, the features, and the overall duty factor of TST.

The "gaseous-target" divertor [17] exemplifies the integrated nature of the divertor plasma mechanisms, the plasma-materials interaction and high-heat-flux technologies, and the needed tests under steady-state, full-intensity conditions. Successful tests in a linear configuration [18] have so far been limited to relatively small plasmas (cold neutral ionization mean free path $\lambda_{\text {nc }}<d_{\text {plasma, }}$, less than that for Franck-Condon neutrals, $\lambda_{\mathrm{FC}}$ ). Integration of the gaseous-target divertor into ITER will encounter the issues of (1) the integrity of plasma-neutral interface when $\lambda_{\mathrm{FC}}$ « $d_{\text {plasma }}$, (2) the compatibility of the implied high $n_{\times}$with the disruption limit $n_{\times c}$ [12], (3) the compatibility of the implied high $n_{\times}$with H-mode operation [11], and (4) the robustness of such divertor operations under steady-state conditions.

New techniques to resolve these issues will be required. Exploration of such techniques and verification under steady-state conditions in a tokamak will most likely be attended by disruptions and loss of $\mathrm{H}$-mode. A near-term, low-cost, flexible, robust, and steady-state tokamak with ITER-level SOL and tivertor conditions is therefore needed in the effort to develop and verify such a divertor solution for ITER. 
Other divertor innovations identified recently [19] include liquid-metal divertors, in situ pumping of helium, if enhancement of helium removal, new materials for reduced erosion, advanced heat removal techniques, biased divertors, impurity seeding, ponderomotive control of heat and particle fluxes, and ergodic-field divertors. Most of these innovations need verification in a tokamak such as TST before consideration by SSAT [6], ITER, and DEMO [20], which are expected to have long turnaround times, high cost impact, and low programmatic tolerance in the event of divertor failure.

\section{IV.2 SOL AND DIVERTOR PLASMA CONDITIONS}

The discussion in Sect. IV.1 specifies the conditions needed to provide adequate tests of divertors for ITER [1] and other large, driven steady-state tokamaks [6]; they are summarized in Table IV.2. There, the subscript $\times$ denotes the plasma edge defined by the separatrix $\times$-point, the subscript $d$ the divertor plate, and $\lambda_{e}$ the electron collisional mean free path at the plasma edge. The average plasma edge heat flux, given by

$$
\dot{Q}_{\perp} \sim 0.7 P_{\text {tod }} / 4 \pi^{2} R_{0} \text { aK95 }
$$

assumes a $30 \%$ radiative loss of heating power from the plasma core. The plasma duration $\tau_{\text {dura }}$ in TST is assumed to be up to $10^{5} \mathrm{~s}$ per "discharge" to permit a divertor test duty cycle of $10-20 \%$.

The plasma disruption limit in Table IV.2 is estimated from [12]

$$
n_{\times \text {dis }} \sim 0.72 \dot{Q}_{\perp}^{0.57} B_{\mathrm{t}} 0.31 /\left(q_{95} R_{0}\right)^{0.09}
$$

for high-recycle divertors. Small amounts of impurity present in the divertor plasma are observed to reduce $n_{\times d i s}$, increase the electron temperature $T_{\mathrm{ed}}$ at the divertor plasma sheath (i.e., increase erosion), and lead to frequent disruptions [12]. The SOL connection length $L_{\text {SOL }}$ is made adequate by requiring high $q 95$ and relatively long divertor channels in TST. With $n_{\times d i s} \sim 3.2 \times 10^{13} \mathrm{~cm}^{-3}$, an adequate operating range in $n_{\times}$is

Table IV.2. Conditions needed for testing divertors

\begin{tabular}{ll}
\hline \multicolumn{1}{c}{ Condition } & \multicolumn{1}{c}{ Considerations } \\
\hline Poloidal divertors & Correct magnetic field configuration \\
$\dot{Q}_{\perp} \geq 0.2 \mathrm{MW} / \mathrm{m}^{2}$ & High average heat flux at edge \\
$T_{\times} \sim 0.1-0.2 \mathrm{keV}$ & H-mode plasma edge, plate erosion \\
$n_{\times} \sim(0.15-0.3) \times 10^{20} \mathrm{~m}^{-3}$ & High-recycle divertor conditions \\
$n_{\times} \leq n_{\times \mathrm{dis}} \sim 0.32 \times 10^{20} \mathrm{~m}^{-3}$ & Disruption-free operation \\
$L_{\mathrm{SOL}} \sim \lambda_{\mathrm{ex}} \sim 30 \mathrm{~m}$ & Connection length for perpendicular diffusion and \\
& electron-ion equilibration \\
$\dot{Q}_{\text {div }} \sim 5 \mathrm{MW} / \mathrm{m}^{2}$ & High average heat flux on plate \\
$T_{\text {ed }} \sim 5-50 \mathrm{eV}$ & High-recycle to high-erosion divertor conditions \\
$\tau_{\text {dura }} \sim 10^{5} \mathrm{~s}$ & Particle equilibration; plate impurity erosion, migration, \\
& and redeposition; duty factor of 10-20\% \\
\hline
\end{tabular}


provided. The electron temperature at the divertor sheath, $T_{\text {ed }}$, needs to be variable over $5-50 \mathrm{eV}$ to simulate the high-recycle as well as the high-erosion regimes of the divertor operation.

The width of the heat flux footprint on the divertor plate $\left(\Delta_{\text {div }}\right)$ also depends on the geometric expansion of the minimum SOL thickness for heat flux $\left(\Delta_{Q}\right)$ at the plasma edge. Assuming a plasma-divertor geometry similar to that of ITER (giving an expansion factor of about 17), we can approximate $\Delta_{Q}$ as [9]

$$
\Delta_{Q} \sim 3.5 \times 10^{-4}\left(n_{\times} \chi_{\perp} / \dot{Q}_{\perp}\right)\left(Z_{\mathrm{eff}} L_{\mathrm{L}}\right)^{2 \pi}, L_{\mathrm{t}} \sim 6 R_{0995} .
$$

Here, $\chi_{\perp}$ is the cross-field heat diffusivity in the SOL and $L_{\mathrm{t}}$ is the connection length from the "watershed" to the $\times$-point. For the case with $n_{\times} \sim 3 \times 10^{13} \mathrm{~cm}^{-3}$, assuming $\chi_{\perp} \sim 2.6 \mathrm{~m}^{2} / \mathrm{s}$ (assumed in the ITER CDA [2]) and $Z_{\text {eff }} \sim 2$, we calculate $\Delta_{Q} \sim 0.4 \mathrm{~cm}$ and $\Delta_{\text {div }} \sim 6 \mathrm{~cm}$. The average heat flux on the plate $\left(Q_{\text {div }}\right)$ over the footprint is therefore about $5 \mathrm{MW} / \mathrm{m}^{2}$, with the peak as high as $15 \mathrm{MW} / \mathrm{m}^{2}$.

The electron temperature $T_{e d}$ and density $n_{\mathrm{ed}}$ at the divertor sheath can be estimated by [12]

$$
\begin{aligned}
T_{\mathrm{ed}}(\mathrm{eV}) \sim & 1.7 \times 10^{-8}\left(\dot{Q}_{\perp} L_{V} \Delta_{Q}\right)^{20 / 9} n_{\times}-28 / 9 L_{\times}-\mathrm{d}^{2 / 9} \sim 10 \mathrm{eV}, \\
& n_{\mathrm{ed}} \sim 700 n_{\times} T_{\times} / 2 T_{\mathrm{ed}} \sim 4 \times 10^{14} \mathrm{~cm}^{-3} .
\end{aligned}
$$

This suggests that high-recycle conditions can be produced in TST for testing divertors. Recent measurements of the DIII-D edge and divertor plasmas [21] suggest that highrecycle conditions can be maintained in $\mathrm{H}$-mode plasmas for $n_{\times}$as low as $1.5 \times$ $10^{13} \mathrm{~cm}^{-3}$. These estimates suggest that TST can provide realistic conditions for testing divertors for ITER and other high-power, steady-state tokamaks.

To increase the confidence in the capability of TST to provide conditions appropriate for testing divertors, a sequence of 2-D fluid-model simulations [22] was carried out for the parameters indicated in Table IV.2. A version of the B2 code [23], updated with a radiation loss model of carbon impurities, was used. The plasma edge conditions and the distance from $\times$-point to divertor plate examined cover the ranges $n_{\times}=$ $(0.10-0.45) \times 10^{14} \mathrm{~cm}^{-3}{ }_{\psi} T_{x}=0.05-0.35 \mathrm{keV}, \dot{Q}_{\perp}=0.05-0.8 \mathrm{MW} / \mathrm{m}^{2}, n_{\mathrm{C}} / n_{\mathrm{e}} \sim 1 \%$, and $d_{\times-\mathrm{d}}=0.2-0.8 \mathrm{~m}$, for a tokamak with $R_{0} / a \approx 2.5$ and $B_{\mathfrak{t} 0} \approx 2 \mathrm{~T}$. The plasma transport properties in the SOL are assumed to be characterized by heat and particle diffusivities of $\chi_{\perp} \approx 4 \mathrm{~m}^{2} / \mathrm{s}$ and $D_{\perp} \approx 2 \mathrm{~m}^{2} / \mathrm{s}$ and by an inward particle pinch velocity $v_{\mathrm{p}} \approx$ $0 \mathrm{~m} / \mathrm{s}$ (ITER model) or $40 \mathrm{~m} / \mathrm{s}$ (DIII-D model).

The results of relevance to TST are summarized in Fig. IV.1. Over the range of $\dot{Q}_{\perp}$ of interest $\left(0.05-0.30 \mathrm{MW} / \mathrm{m}^{2}\right)$, the electron temperature $T_{\text {ed }}$ can cover the lowrecycle (high-erosion) and the high-recycle (low-erosion) conditions needed for testing divertors. A controlling parameter for this range is shown to be the edge density, ranging from $n_{\times}<0.15 \times 10^{14} \mathrm{~cm}^{-3}$ for the former condition to $n_{x}>0.2 \times 10^{14} \mathrm{~cm}^{-3}$ for the latter condition. The heat flux at the divertor plate $\dot{Q}_{\text {div }}$ can reach as high as $5 \mathrm{MW} / \mathrm{m}^{2}$ for full auxiliary drive power $\left(P_{\mathrm{tot}}=4.5 \mathrm{MW}\right.$, corresponding to $\dot{Q}_{\perp} \approx 0.22 \mathrm{MW} / \mathrm{m}^{2}$ ). 


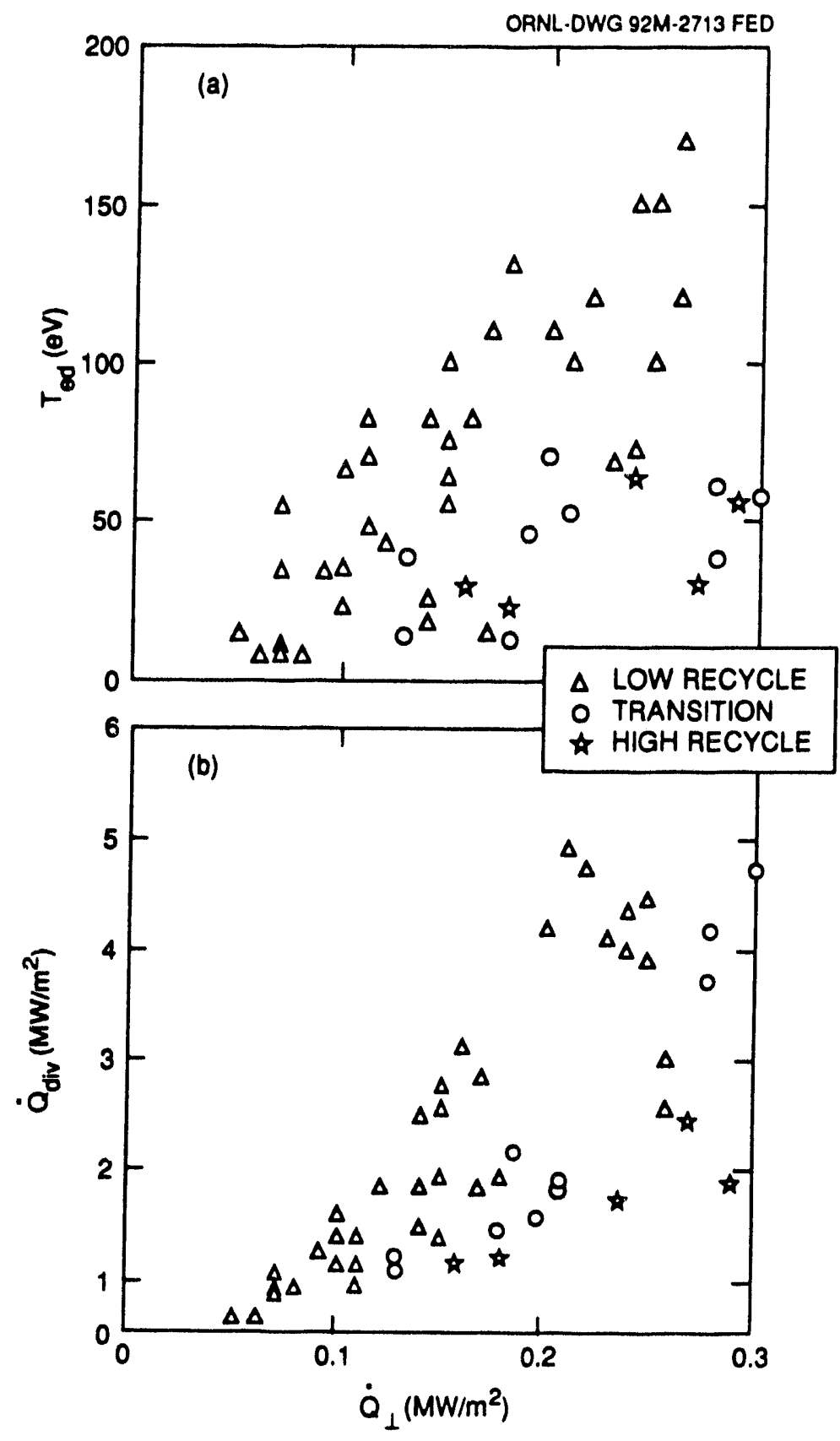

Fig. IV.1. The range of (a) the electron temperature $T_{\text {ed }}$ and (b) the heat flux $\dot{Q}_{\text {div }}$ at the divertor plate of interest to TST, for low-recycle $\left(\Delta, n_{\times}<0.15 \times 10^{14} \mathrm{~cm}^{-3}\right)$, transition $\left[0, n_{\times}=(0.15-0.20) \times 10^{14} \mathrm{~cm}^{-3}\right]$, and high-recycle $\left(\star, n_{\times}>0.20 \times\right.$ $10^{14} \mathrm{~cm}^{-3}$ ) conditions.

The maximum possible $\dot{Q}_{\mathrm{div}}$ and the electron temperature $T_{\mathrm{ed}}$ at the divertor plate are found to scale with $n_{\times}$roughly as

$$
\dot{Q}_{\mathrm{div}} \propto n_{\mathrm{X}}{ }^{-0.8}, T_{\mathrm{ed}} \propto n_{\mathrm{X}}{ }^{-1.8}
$$

for constant $\dot{Q}_{\perp}$. This suggests that TST should afford adequate control of the divertor conditions during operation. 
Figure IV.2 shows results from the $\mathrm{B} 2$ code for a low- $R$ V $a$ option of the TST with $n_{x}=0.3 \times 10^{14} \mathrm{~cm}^{-3}$ and $T_{x}=0.2 \mathrm{keV}$ under full-power conditions. The footprint of heat flux on the divertor plate with an inclination of $15^{\circ}$ from the poloidal field line is about $5 \mathrm{~cm}$, and the divertor density (peak of $>10^{14} \mathrm{~cm}^{-3}$ ) and temperature (peak ranging from 16 to $40 \mathrm{eV}$ ) are characteristic of high-recycle divertors. The peak divertor heat flux, corrected for the inclined plate, ranges from 8 to $17 \mathrm{MW} / \mathrm{m}^{2}$.
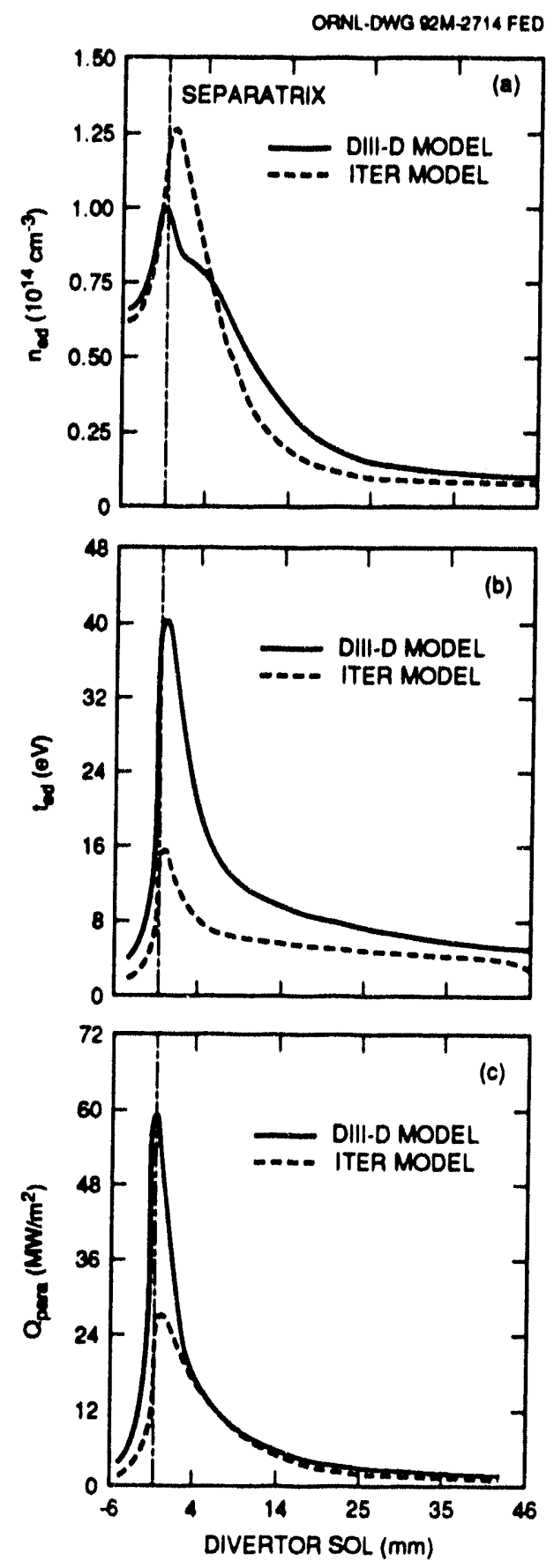

Fig. IV.2. Plasma conditions at the TST divertor plate calculated using the B2 code for the conditions described in the text, showing (a) the electron density, (b) the electron temperature, and (c) the heat flux in the direction parallel to the poloidal field, as functions of distance across the SOL. 
Finally, recent data from H-mode plasmas in DIII-D show that the ratio $n_{x} / n_{\mathrm{e}}$ is around 0.5 for $\left(T_{\times} n_{\times}\right)$over the range $(0.2-0.6) \times 10^{14} \mathrm{keV} \cdot \mathrm{cm}^{-3}$ (see Fig. IV.3). As discussed in Sect. III, this range corresponds to $P_{\text {tot }}=1.5-4.5 \mathrm{MW}$ and equivalently to Phase I (1 MW each of LHCD and ICH at $\left\langle n_{\mathrm{e}}\right\rangle$ up to $0.3 \times 10^{14} \mathrm{~cm}^{-3}$ ) and Phase II (1 MW of LHCD, $2 \mathrm{MW}$ of ICH, and $1.5 \mathrm{MW}$ of NBCD at $\left\langle n_{\mathrm{e}}\right\rangle$ up to $0.5 \times 10^{14} \mathrm{~cm}^{-3}$ ). It is therefore reasonable to assume that $n_{\times}$up to $0.15 \times 10^{14} \mathrm{~cm}^{-3}$ and $0.25 \times 10^{14} \mathrm{~cm}^{-3}$ can be produced in TST during Phase I and Phase II operation, respectively.

\section{IV.3 MECHANICAL DESIGN CONCEPT}

The TST device accommodates eight divertor cassettes complete with individual water headers, vacuum system, coils, current supplies, and divertor diagnostics. Eight large ports located in the outer vessel wall (see Fig. V.1) allow radial installation and removal of the cassettes for the (lower) SN configuration. Another eight identical ports will accommodate an array of upper divertors if $\mathrm{DN}$ operation is required. At present, both open and closed divertor configurations are being considered to show feasibility of the cassette concept. Since the cassette system has relatively generous access, it will accommodate other advanced test divertors through the TST program.

\section{IV.3.1 Design Criteria}

The design criteria for open and closed divertor configurations are shown in Tables IV.3 and IV.4, respectively.

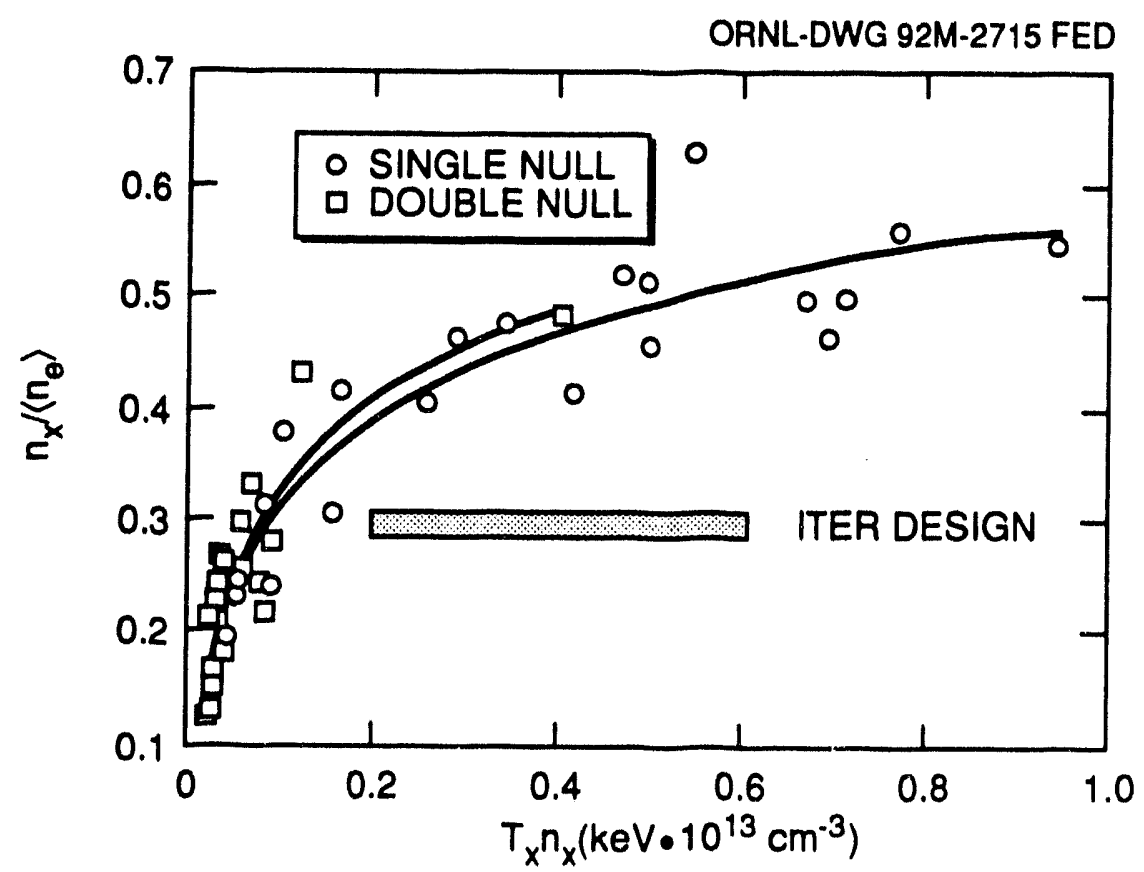

Fig. IV.3. Data for $n_{\times} /\left\langle n_{\mathrm{e}}\right\rangle$ for DIII-D H-mode plasmas with divertor configuration. 
Table IV.3. TST single-null divertc: design criteria

\begin{tabular}{|c|c|c|}
\hline Parameter & Value & Comment \\
\hline Aspect ratio $R \nabla / a$ & $2.5 \quad 1.8$ & $\begin{array}{l}\text { Different divertor cassette configura- } \\
\text { tion for different } R_{0} / a\end{array}$ \\
\hline $\begin{array}{l}\text { Distance from } \times \text {-point to strike } \\
\text { point } d_{\times d}, \mathrm{~cm}\end{array}$ & $\sim 50 / \sim 30$ & $\begin{array}{l}\text { Poloidal distance for outer/inner } \\
\text { channel }\end{array}$ \\
\hline Field line strike angle $\theta_{\text {strike, }}$ deg & $\geq 2$ & $\begin{array}{l}\text { Determined by divertor plate alignment } \\
\text { tolerance }\end{array}$ \\
\hline Total power to divertors $P_{\text {div }}, \mathrm{MW}$ & $P_{\text {tol }}$ & Maximum power expected \\
\hline Inner-to-outer channel power ratio & $1 / 2 \quad 1 / 3$ & $\begin{array}{l}\text { Similar to area ratio of plasma inboard- } \\
\text { to-outboard surfaces demarked by a } \\
\text { "watershed" point at }+45^{\circ}\end{array}$ \\
\hline $\begin{array}{l}\text { Peak steady-state power density } \\
\dot{Q}_{\text {pdiv }}, \mathrm{MW} / \mathrm{m}^{2}\end{array}$ & $\leq 15$ & Including safety margins of about 2 \\
\hline $\begin{array}{l}\text { Average heat flux on plate } \dot{Q}_{\text {adiv }} \text {, } \\
\mathrm{MW} / \mathrm{m}^{2}\end{array}$ & $\sim 5$ & $\Sigma \dot{Q}_{\text {adiv }} \times \Delta$ div $\times 2 \pi R_{\mathrm{d}}=P_{\mathrm{div}}$ \\
\hline $\begin{array}{l}\text { Width of footprint on divertor plate } \\
\text { at average heat flux } \Delta_{\text {div }}, \mathrm{cm}\end{array}$ & 6 & $\begin{array}{l}\text { Assuming SOL } \chi_{\perp} \sim 3 \mathrm{~m}^{2} / \mathrm{s} \text { and a } \\
\text { geometric expansion factor of } 17 \\
\text { from the "midplane" } \Delta_{Q}\end{array}$ \\
\hline $\begin{array}{l}\text { Alignment tolerance of tiles on } \\
\text { plate of each cassette } \delta_{\text {plate, }} \mathrm{mm}\end{array}$ & \pm 2 & Tentative, assume alignment in shop \\
\hline $\begin{array}{l}\text { Particle removal rate at divertor } \\
N_{\mathrm{div}}, \text { torr } \mathrm{L} / \mathrm{s}\end{array}$ & $\geq 10$ & $\begin{array}{l}\text { About } 3 \times \text { the neutral beam fueling rate } \\
\text { at } P_{\mathrm{NB}}=1.5 \mathrm{MW}\end{array}$ \\
\hline Divertor pressure $p_{\text {div }}$, mtorr & $\geq 1$ & $\begin{array}{l}\text { Defines maximum divertor pumping } \\
\text { capability }\end{array}$ \\
\hline
\end{tabular}

\section{IV.3.2 Description}

The divertor cassette concept is illustrated in Fig. IV.4 for the $\mathrm{SN}$ open configuration and in Fig. IV.5 for the SN closed configuration. In all cases, the cassette is carriage mounted and slides on rails on the vessel floor (or ceiling). The rails serve to react the magnetic loads and align the carriages. At their full inboard position the carriages key into each other, giving additional resistance to magnetic loading. The vessel flanges are integrated to the cassette assembly with some flexibility between the cassette and the flange. To adjust the strike point of the plasma, a divertor control coil is mounted on each divertor carriage. The coils are water-cooled "window-frame" units that are removable with the cassette. Their design may be changed to accommodate the individual needs of different divertor designs, but the units shown will work with most of the open and closed divertor configurations. 
Table IV.4. TST double-null divertor design criteria

\begin{tabular}{|c|c|c|}
\hline Parameter & Value & Comment \\
\hline Aspect ratio $R N / a$ & 2.51 .8 & $\begin{array}{l}\text { Different divertor cassette configura- } \\
\text { tion for different } R_{0} / a\end{array}$ \\
\hline $\begin{array}{l}\text { Distance from } \times \text {-point to strike } \\
\text { point, outer/inner, } d_{x \mathrm{do}} / d_{x \mathrm{di}} \mathrm{cm}\end{array}$ & $\geq 50 / 25$ & Poloidal distance \\
\hline Field line strike angle $\theta_{\text {strike }}$, deg & $\geq 2$ & $\begin{array}{l}\text { Determined by divertor plate align- } \\
\text { ment tolerance }\end{array}$ \\
\hline Total power to divertors $P_{\text {div }}, \mathrm{MW}$ & $P_{\text {aux }}$ & Maximum power expected \\
\hline Inner-to-outer channel power ratio & $1 / 4 \quad 1 / 6$ & $\begin{array}{l}\text { Similar to area ratio of plasma } \\
\text { inboard-to-outboard plasma surface } \\
\text { areas }\end{array}$ \\
\hline $\begin{array}{l}\text { Peak steady-state power density } \\
W_{\mathrm{d}}, \mathrm{MW} / \mathrm{m}^{2}\end{array}$ & 15 & Including safety margins \\
\hline $\begin{array}{l}\text { Width of heat flux footprint on } \\
\text { divertor plate } \Delta_{\text {div }}, \mathrm{cm}\end{array}$ & $\sim 1$ & Assuming SOL $x_{\perp \perp} \sim 2 \mathrm{~m}^{3} / \mathrm{s}$ \\
\hline $\begin{array}{l}\text { Alignment tolerance of plate } \\
\delta_{\text {plate }}, \mathrm{mm}\end{array}$ & \pm 2 & Related to $\theta_{1}$ \\
\hline $\begin{array}{l}\text { Particle removal rate at divertor } \\
N_{\mathrm{div}}, \text { torr } \cdot \mathrm{L} / \mathrm{s}\end{array}$ & $\geq 10$ & $\begin{array}{l}\text { About } 3 \times \text { the neutral beam fueling } \\
\text { rate at } P_{\mathrm{NB}}=1.5 \mathrm{MW}\end{array}$ \\
\hline Divertor pressure $p_{\text {div }}$, mtorr & $\geq 1$ & $\begin{array}{l}\text { Defines maximum divertor pumping } \\
\text { capability }\end{array}$ \\
\hline
\end{tabular}

\section{IV.3.3 Divertor Vacuum System}

A vacuum system dedicated to the divertors is required for the high gas flows anticipated for steady-state operation. Only the lower units are shown with this auxiliary vacuum system, but the design is compatible with a similar system on the upper units if it should be desired. One pump is mounted on each of the divertor vessel ports and is removed before removing the port flange. Design of this vacuum system is driven by the closed divertor, which requires a total hydrogen pumping rate of $\sim 10$ torr $\cdot \mathrm{L} / \mathrm{s}$ in a chamber maintained above 1 mtorr. Cryopumping is the most economical, and perhaps the only, means of achieving this goal. With the possible exception of the new SeikoSeiki [24] and Osaka [25] compound turbopumps, there are no systems that can operate at the high foreline pressures required and maintain any significant throughput. No test data are available on the compound pump throughputs, but their maximum hydrogen pumping rate is only $1300 \mathrm{~L} / \mathrm{s}$, one-eighth that of a typical commercial cryopump.

A torus vacuum system, separate from the divertor system, is required for roughing down. There are two reasons for this requirement: the divertor system is sized to pump hydrogen only and depends on the roughing system to remove all air and water, and the closed divertor pumping is totally segregated from the vacuum vessel proper and communicates only with a plenum mounted on the divertor cassette. 
운
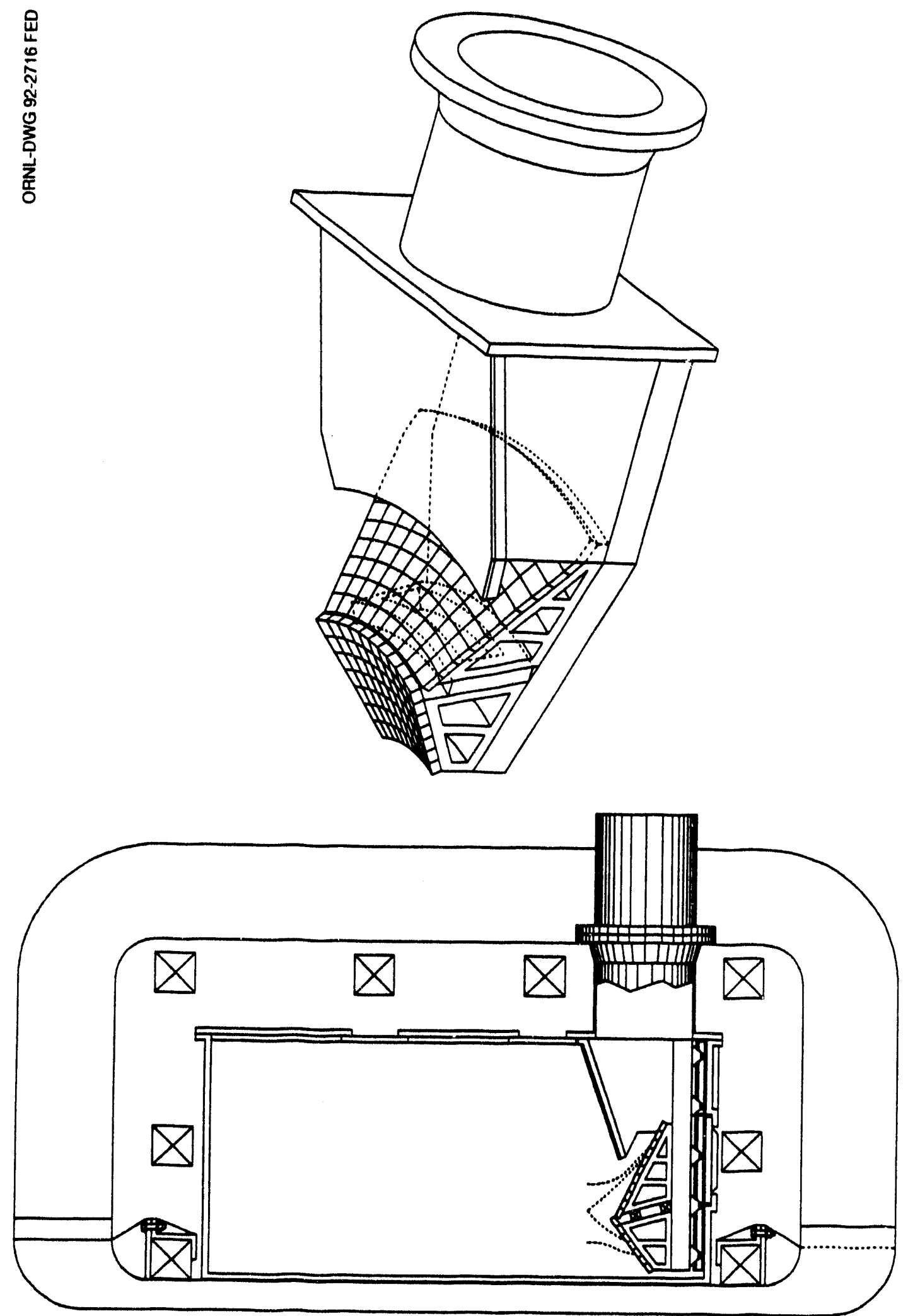

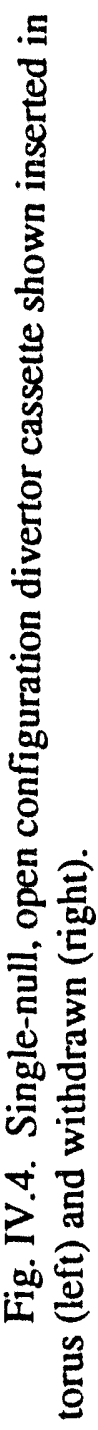



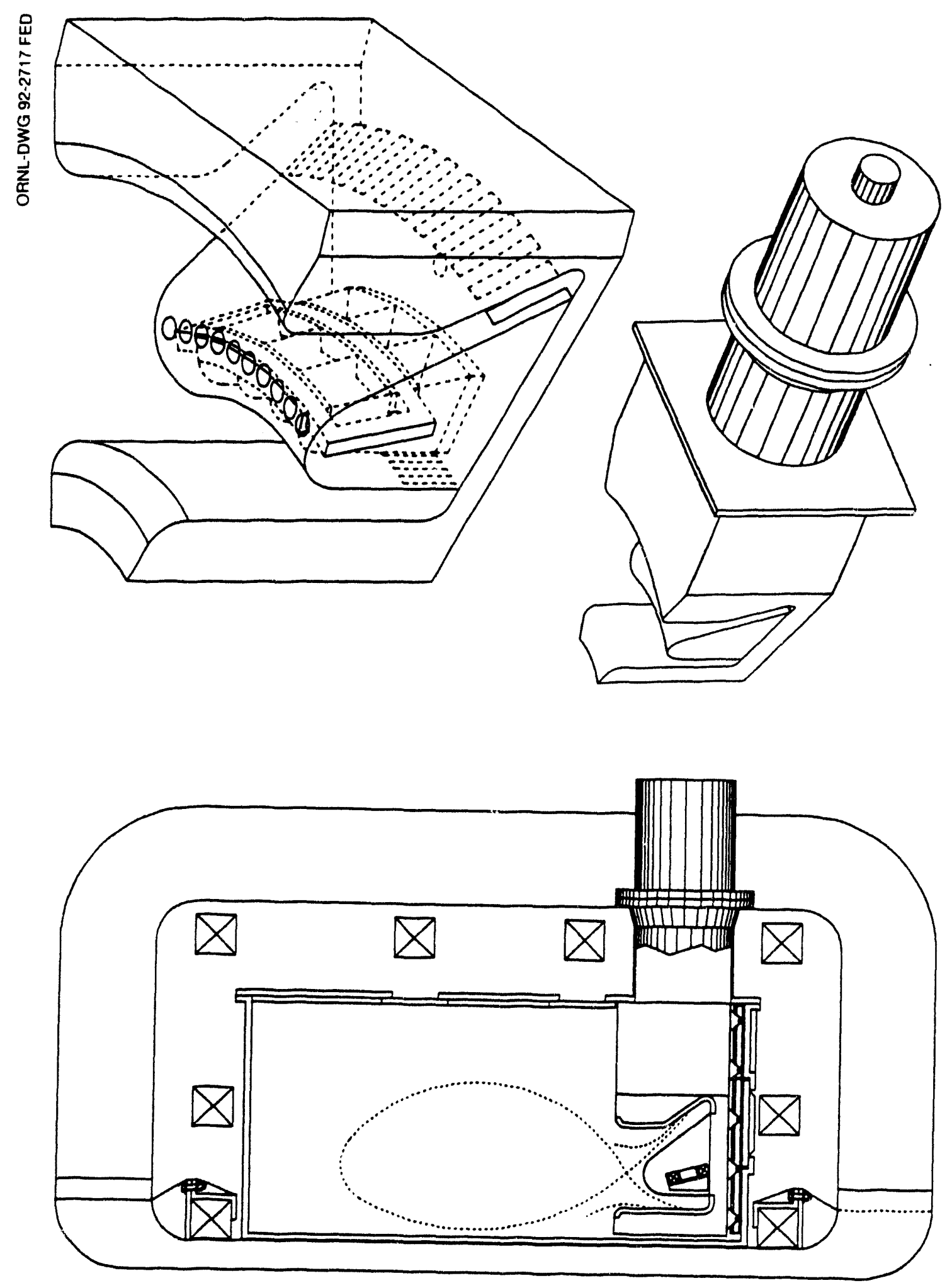

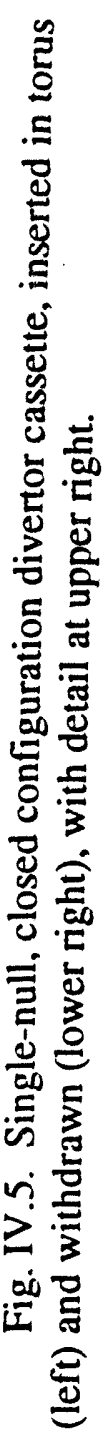




\section{Typical cryopump parameters}

Table IV.5 illustrates the performance parameters of a typical cryopump, in this case a CT500 from CTI Cryogenics [26]. This is a closed-loop, self-contained system that uses a remotely located compressor connected to a cold head via room-temperature pressure lines.

Table IV.5. Typical commercial cryopump parameters

\begin{tabular}{|c|c|}
\hline Hydrogen pumping rate & $10,000 \mathrm{~L} / \mathrm{s}$ per pump \\
\hline Hydrogen flow rate & 1.125 torr $\cdot \mathrm{L} / \mathrm{s}$ per pump \\
\hline Inside diameter & $53 \mathrm{~cm}$ \\
\hline Pressure at inlet & $1.12 \times 10^{-4}$ torr \\
\hline Hydrogen capacity & 16 std liters \\
\hline Mounting orientation & Any \\
\hline \multicolumn{2}{|l|}{ Limitations } \\
\hline $\begin{array}{l}\text { Maximum permissible } \\
\text { magnetic field }\end{array}$ & $\begin{array}{l}200-300 \mathrm{G} \text { (because of a stepping motor and dis- } \\
\text { placer piston located in the cold head) }\end{array}$ \\
\hline Time before regeneration & $\begin{array}{l}1 \mathrm{~h} \text { (calculated time is } 3 \mathrm{~h} \text {, but there is concern that } \\
\text { the high operating pressure may reduce this sig- } \\
\text { nificantly) }\end{array}$ \\
\hline Approximate cost & $\$ 30,000$ per pump, including all hardware \\
\hline
\end{tabular}

\section{Continuous cryopump options}

The plasma duration in TST is constrained primarily by time before regeneration of the cryopumps (estimated above to be about $1 \mathrm{~h}$ under full performance). To surpass this limitation, continuous cryopumps are needed. There are presently two options:

1. Doubling the number of cryopumps at each location and adding gate valves to permit regeneration during operation. This will roughly triple the cost of the divertor cryopump systems (and the NBI system, if the latter is installed).

2. Using the innovative "snail" continuous cryopump [27], which regenerates during normal operation. It is also cryostable at operating pressures as high as $10 \mathrm{mtorr}$, compared to the limit of about $0.1 \mathrm{mtorr}$ in conventional cryoabsorption and cryocondensation pumps. With such pumps, the total pumping speed required for divertor operations could be reduced to $\sim(1-3) \times 10^{4} \mathrm{~L} / \mathrm{s}$ while increasing the throughput capability from 10 torr $\cdot \mathrm{L} / \mathrm{s}$ to $30 \mathrm{torr} \cdot \mathrm{L} / \mathrm{s}$ at a divertor neutral pressure of $1 \mathrm{mtorr}$. On the other hand, this technique has been successful demonstrated only as a prototype. Additional assessment is required and warranted to determine the design and cost for such cryopumps. We assume a $30 \%$ increase in cost beyond the single conventional cryopump [28].

\section{IV.3.4 Safety}

The cryosystem/vessel geometry is inherently safe from hydrogen explosions because the cryopumps reach full capacity and must be regenerated long before the 
stored hydrogen reaches the equivalent of $4 \%$ by volume of the vessel (the lower ignition limit of hydrogen in oxygen). In addition, no oxygen will be stored in the cryopumps; they will not be cooled down until the vessel has been roughed below 10 mtorr and all water and air have been removed.

\section{IV.3.5 Divertor Configurations}

Two divertor configurations have been chosen to establish feasibility for the cassette geometry. The open divertor, shown in Fig. IV.4, is similar to most divertors in present-day tokamaks and prototypical of the divertor design proposed for the ITER device. The inboard and outboard strike points impinge on the divertor plates at a shallow angle, the inner one being open to the plasma and the outer overhung by a shroud that limits the neutral conduction from the pump chamber back to the vessel. High particle recycle at the divertor plate enhances the neutral pressure (to several millitorr) behind the shroud and permits efficient removal of particles for pumping. The divertor plate (or plates) is mounted over a water-cooled housing that contains the divertor control coils. The plate assemblies can be removed from the structure for repair without removing the housing or coils.

The closed design, shown in Fig. IV.5, is a new approach that permits active pumping of the inner channel. In this configuration the plates are mounted to structures separate from the coil housing. The "window-frame" coil, together with the PF coils external to the vessel, controls the angles and locations of the strike points of both divertor channels.

The recycling hydrogen is entrained in the long channels formed by the divertor plates and the centrally placed coil housing, producing a high neutral pressure near the strike points (1-10 mtorr). (See Sect. IV.2 for a more detailed description of the divertor design theory.) The gas enters a chamber in the window-frame coil housing. Up to $90 \%$ of the gas exits the holes at the top of the housing, which is close to the $x$-point in the "private flux" region of the divertor. The remainder (up to 1.13 torr $\mathrm{L} / \mathrm{s}$ per cassette) exits through an orifice in the floor of the chamber. The orifice area may be adjusted externally to maintain the desired pressure in the chamber. A vacuum plenum under the chamber connects directly to the cryopump mounted outside the torus. The net conductance between the plenum and the cryopump should be such that pressures of 0.52 mtorr and 0.13 mtorr are maintained at the plenum and the pump entrance, respectively, while permitting a pumping rate of about 1.13 torr $\cdot \mathrm{L} / \mathrm{s}$ per cassette. As with the other design, the divertor plates are easily replaceable (in shop) without disturbing the coils or coil housing.

\section{IV.4 DIVERTOR CASSETTE INTERFACE CONCEPT}

Because TST is a divertor test bed, the need for rapid and reliable divertor replacement is essential. A divertor cassette concept that embodies the "works in the drawer" philosophy has been prepared by Wardrop Engineering of Mississauga, Canada, under the sponsorship of the CFFTP. This cassette interface concept improves locational accuracy and decreases machine downtime by eliminating in situ maintenance and allows the divertors to be slid into and out of the tokamak through horizontal 
ports. The divertors are attached to a large movable table installed in the floor of the vacuum vessel.

The design consists of a support table, a pair of positioning yokes, and a drive system to provide the adjustments required in positioning the divertors. Mounted on the support table are eight pairs of telescoping rails. Each pair of rails supports a divertor and transports it into position in the tokamak (Fig. IV.6). The support table is fastened to the positioning yokes, which provide for $X, Y$, and tilt movement of the entire divertor assembly. The tokamak magnet system provides the axisymmetric adjustment by moving the plasma with respect to the divertors. Through a computer control system, the adjustments in the divertor assembly can be made either before or during a plasma burn. Each cassette can be pulled from the machine onto an external elevating trolley, then lowered from the port and transported to a maintenance facility.

\section{IV.4.1 Divertor Positioning and Support Table}

The positioning table, mounted inside the vacuum vessel just above the vessel lower plate support structure, is a segmented annular ring consisting of eight pieces, each electrically insulated from the others (Fig. IV.7). The ring segments can be inserted through the divertor ports for assembly inside the vacuum vessel. The assembled ring is fastened to a pair of concentric yoke plates, which in turn are mounted on a spherical ring bearing, thus providing both lateral and tilt adjustment. This assembly weighs about $1000 \mathrm{~kg}$. Through a system of motorized jacks and linkages, the table can be shifted in any direction in the horizontal plane and tilted as much as $1^{\circ}$ (Fig. IV.8). The jacks also act as a locking system to secure the table. The table and divertor rail mounting system is designed such that the divertors can be positioned and mounted on the assembled support table to the required tolerances outside the tokamak and then disassembled and reassembled inside the tokamak. Typically this setup and preassembly would be done at the manufacturer's shop with the aid of jigs. A master jig will be needed to fit a replacement divertor segment to the assembly or to outfit the machine with an entirely new divertor design. The rails can then be extended through the ports to receive the divertor cassettes. Each cassette can then be pushed into position and the vacuum vessel sealed. The design of the support table will be sufficient to accommodate the loading conditions including disruption loads.

\section{IV.4.2 External Handling Equipment}

Handling equipment is required to transport the divertor cassette to and from the port and position it for installation. The proposed design for such a unit consists of an articulated bed mounted on an elevating trolley. The trolley is parked under the divertor port and the cassette jacked into position. The rail system in the machine is extended under the divertor and fastened to it. The trolley is lowered enough to transfer the divertor load to the rails. A rodless pneumatic cylinder is used to insert the divertor. The trolley with the divertor assembly has a closed height of $1400 \mathrm{~mm}$, which should enable it to pass under auxiliary equipment and diagnostics located close to the machine. This is described in Fig. IV.9. 

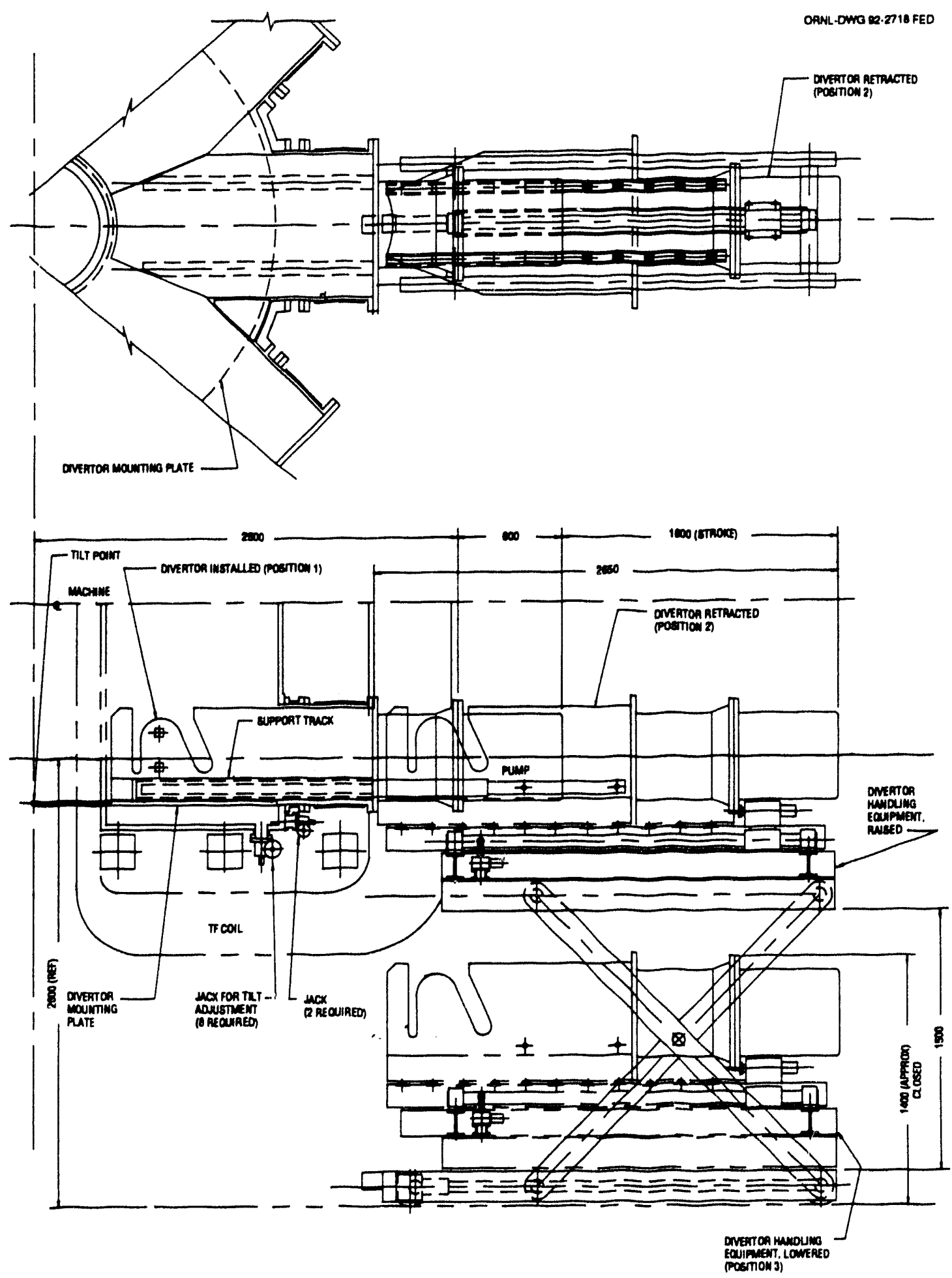

Fig. IV.6. Divertor handling equipment. 


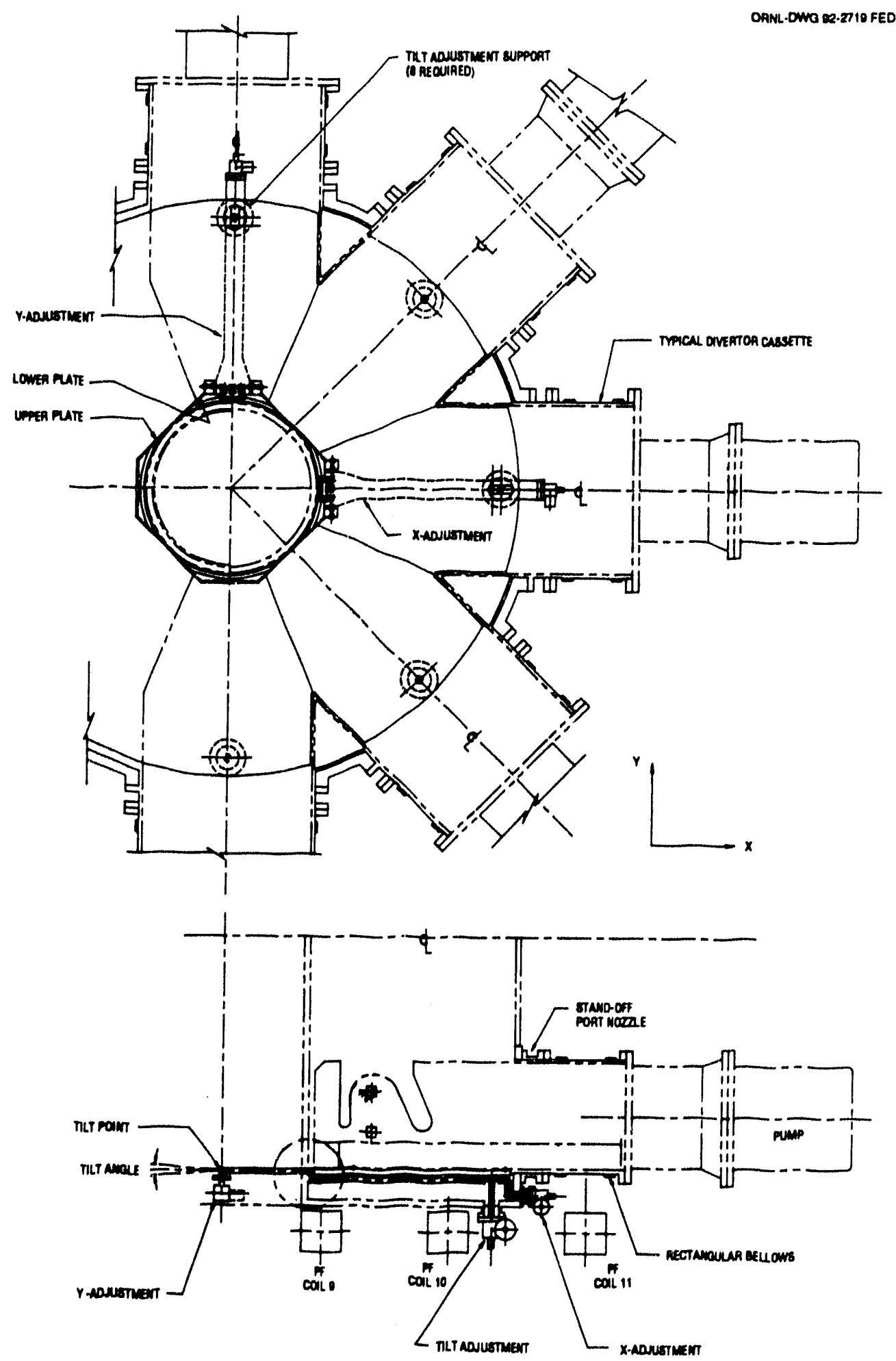

Fig. IV.7. Divertor positioning and alignment system. 

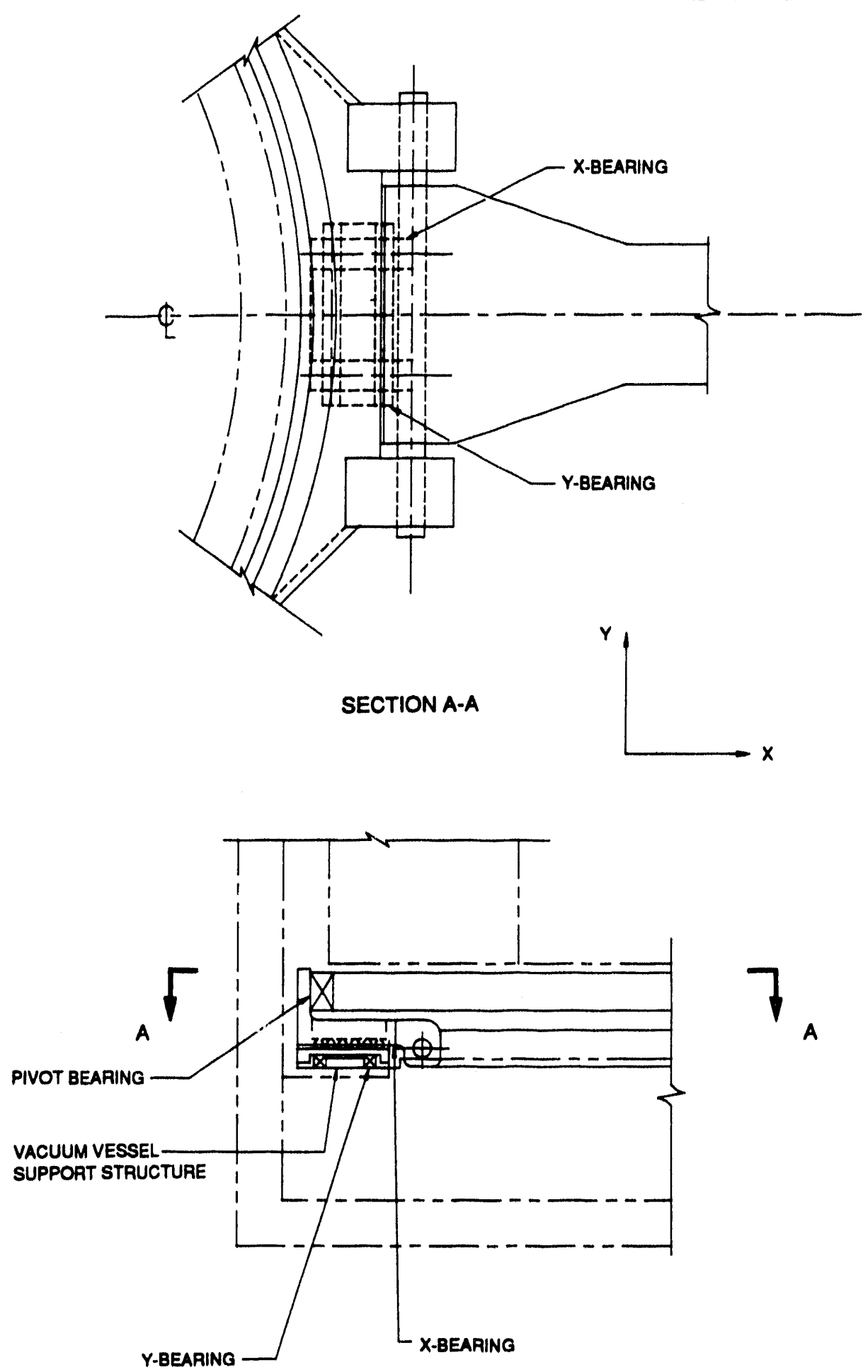

Fig. IV.8. Inner yoke details. 


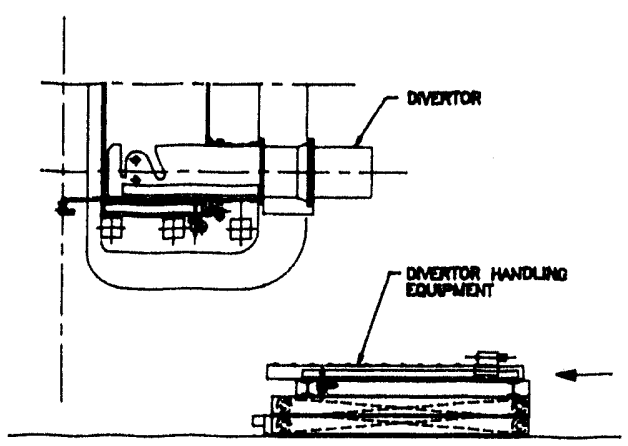

(a)

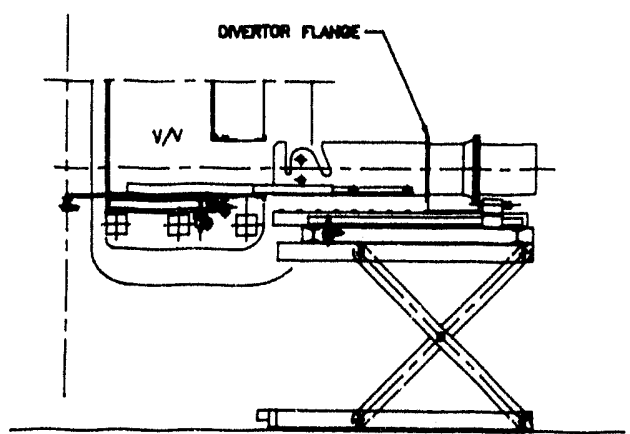

(c)

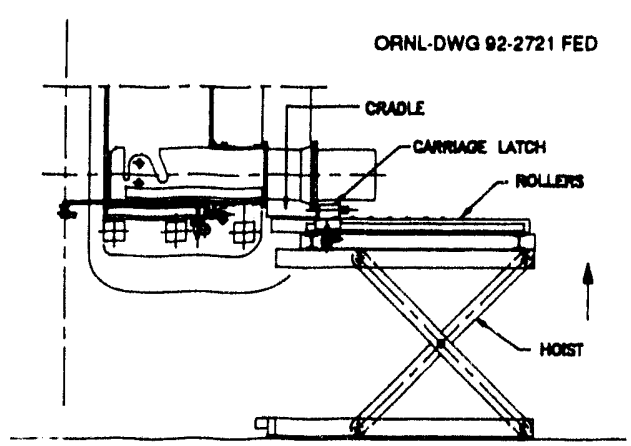

(b)

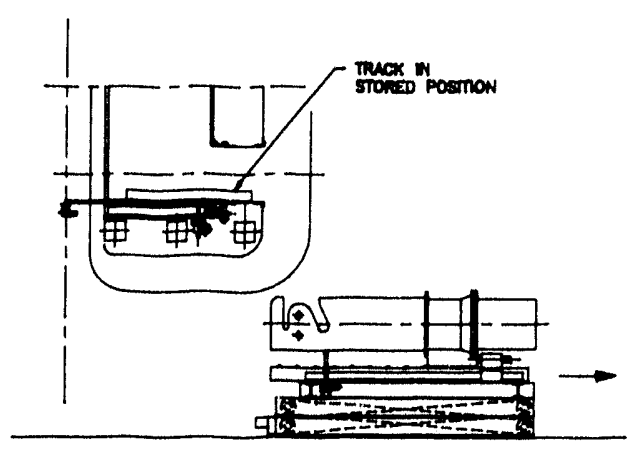

(d)

Fig. IV.9. Divertor handling procedure.

\section{IV.4.3 Design Requirements}

The interfacing system between the divertors and the vacuum vessel must be capable of repeatedly delivering and positioning the divertors in the vacuum vessel within the tolerances specified. The divertor surfaces must be aligned to within $1 \mathrm{~mm}$ of adjacent divertors such that they form an axisymmetric array. The position of the divertor array must be adjustable to be concentric to the plasma axis, with nonaxisymmetric adjustments of $\pm 10 \mathrm{~mm}$ and a tilt of $1^{\circ}$, as shown in Fig. IV.10. It is assumed that the PF coil set and focus coils can adjust the axisymmetric $\times$-point location. The components of the interface system must be electrically isolated from each other. Locking of the table and divertors may be required.

The cassette interfacing system imposes some requirements on the design of the divertor. The divertors are adjustable as a unit and independent of the vacuum vessel. This requires the mounting flanges, which seal the divertor port openings, to be isolated from the main body of each cassette. This could be accomplished with the use of a bellows. Imposing this requirement simplifies the alignment and machining associated with the fabrication of the vacuum vessel. Of particular concern will be the torsional forces introduced to bellows located on the ports that are on the divertor support table's axis of tilt. To compensate for this problem, a slip ring bearing joint needs to be incorporated to allow for small rotational motion of the divertor with respect to its mounting flange. 


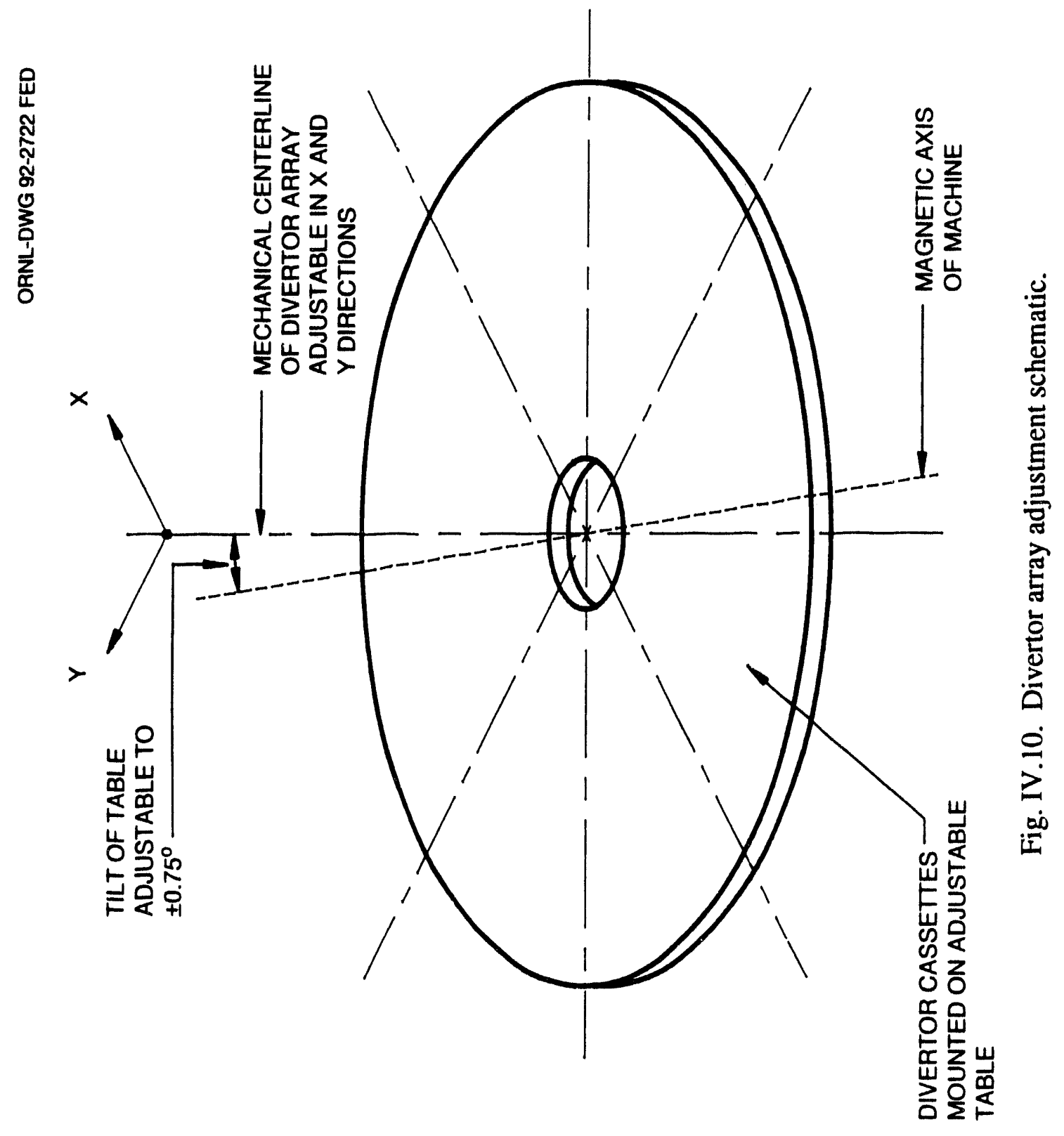




\section{References for Sect. IV}

[1] M. A. Abdou (Chair) et al., "Report of the Review Panel on ITER Plasma Facing Components," UCLA, December 1991.

[2] D. E. Post et al., ITER Physics, ITER Documentation Series No. 21, IAEA, Vienna, 1991, Chapters 2 and 3; T. Kuroda et al., ITER Plasma Facing Components, ITER Documentation Series No. 30, IAEA, Vienna, 1991.

[3] V. Alikaev et al., Research and Development Needs for ITER Engineering Design, C. A. Flanagan, ed., ITER Documentation Series No. 20, IAEA, Vienna, 1991; ITER Physics Group and International Contributors, Physics and Technology R\&D for ITER Conceptual Design: Part A, and J. Doggett et al., Physics and Technology R\&D for ITER Conceptual Design: Part B, ITER Documentation Series No. 19, IAEA, Vienna, 1991; S. A. Cohen et al., "Facilities for Technology Testing of ITER Divertor Concepts, Models, and Prototypes in a Plasma Environment," unpublished; G. Vieider and T. Kuroda, Long-Term Technology $R \& D$, ITER-IL-PC-1-0-14, IAEA, Vienna, August 27, 1990.

[4] D. E. Baldwin (Chair) et al., "U.S. National Review of the ITER Conceptual Design Activity," Univ. Texas, March 1991.

[5] P. H. Rebut, presentation to the U.S. Department of Energy Fusion Energy Advisory Committee, Panel 1, St. Louis, January 16, 1992.

[6] K. Thomassen et al., "Steady State Advanced Tokamak (SSAT), The Mission and the Machine," presentation to the U.S. Department of Energy Fusion Energy Advisory Committee, Panel 2, Livermore, California, February 24-25, 1992.

[7] A. Mahdavi et al., The DIII-D Collaborative Advanced Divertor Program, GA-A19547, General Atomics, San Diego, California, 1989.

[8] M. Keilhacker et al., "Modelling Impurity Control by Plasma Flows in the JET Pumped Divertor," paper IAEA-CN-53/E-5-1 presented at the 13th International Conference on Plasma Physics and Controlled Nuclear Fusion Research, Washington, D.C., October 1-6, 1990.

[9] M. F. A. Harrison and E. S. Hotston, "Edge Plasma and Surface Conditions in ITER," J. Nucl. Mater. 176 \& 177, 256 (1990).

[10] J. L. Luxon et al., "Recent Results from DIII-D and Their Implications for NextGeneration Tokamaks," Controlled Fusion Plasma Phys., accepted for publication.

[11] ASDEX Team, "The H-Mode of ASDEX," Nucl. Fusion 29, 1959 (1989).

[12] K. Borrass, "Disruptive Tokamak Density Limit as Scrape-Off Layer/Divertor Phenomenon," Nucl. Fusion 31, 1035 (1991).

[13] K. Borrass, "Scrape-Off Layer Based Model for the Disruptive Tokamak Density Limit and Implications for Next-Generation Tokamaks," p. 1393 in Plasma Physics and Controlled Nuclear Fusion Research 1990, Vol. 3, IAEA, Vienna, 1991.

[14] S. A. Cohen et al., "Two-Dimensional Fluid Simulations of the ITER SOL Plasma," J. Nucl. Mater. 176 \& 177, 908 (1990).

[15] F. Wagner and K. Lackner, in Physics of Plasma-Wall Interactions in Controlled Fusion, ed. D. Post and R. Behrisch, Plenum, New York, 1986; L. De Kock et al., 
in Plasma Physics and Controlled Nuclear Fusion Research 1988, Vol. 2, 1AEA, Vienna, 1989.

[16] R. E. Nygren and S. A. Cohen, organizers, Workshop on Innovative Technologies for Impurity Control, Princeton, New Jersey, January 11-12, 1990.

[17] M. Petravic et al., Phys. Rev. Lett. 48, 326 (1982).

[18] G. Fiksel et al., "Experimental Simulation of a Gaseous Plasma Collector," Phys. Fluids B 2, 837 (1990).

[19] R. E. Nygren, ed., Report of the Review Panel on the Division of Development and Technology Workshop on Innovative Technologies for Impurity Control, SAND91-0029, Sandia National Laboratories, Albuquerque, N.M., March 1992.

[20] Technical Planning Activity: Final Report, ANL/FPP-87-1, Argonne National Laboratory, 1987; Report of a Consultants' Meeting on DEMO Requirements, IAEA-TECDOC-441, IAEA, Vienna, 1987.

[21] S. L. Allen et al., J. Nucl. Mater. 162-164, 80 (1989).

[22] B. J. Braams, A Multi-Fluid Code for Simulation of the Edge Plasma in Tokamaks, NET Report 68, EUR-FU-XII-80/87/68, Commission of the European Communities, January 1987.

[23] J. T. Hogan, Oak Ridge National Laboratory, personal communication, 1992.

[24] High-throughput "H" series turbomolecular pumps, Seiko-Seiki Co, Ltd., 4-3-1, Yashiki, Narashino City, Chiba 275, Japan.

[25] Series TG compound molecular pumps, Osaka Vacuum, Ltd., Kitahama 3-chome, Higashi-Ku, Osaka 541, Japan.

[26] CTI-Cryogenics Division of Helix Co., Kelvin Park, 266 Second Ave., Waltham, MA 02254.

[27] C. A. Foster, "High-Throughput Continuous Cryopump," J. Vac. Sci. Technol. A 5, 2558 (1987).

[28] C. A. Foster, Oak Ridge National Laboratory, personal communications, 1992. 


\section{THE TST DEVICE}

The TST mission of testing advanced concept divertors under steady-state conditions and tokamak improvements at small aspect ratios imposes unique requirements on the TST device, which are summarized here with the device design. One of the most important design requirements is to use conventional engineering approaches whenever reasonable to reduce cost and limit the necessary $R \& D$. Table V.1 summarizes the basic TST parameters assumed in developing the engineering device concept.

Table V.1. TST general design parameters and requirements

\begin{tabular}{|c|c|c|c|}
\hline Parameter & \multicolumn{2}{|c|}{ Value } & Comment \\
\hline Aspect ratio $R_{N} / a$ & 2.5 & 1.8 & $\begin{array}{l}\text { Adequate database for } R_{0} / a=2.5 \text {; low }-R_{0} / a \\
\text { option also permits tokamak improvement } \\
\text { tests }\end{array}$ \\
\hline Major radius $R_{0}, \mathrm{~cm}$ & 75 & 68 & Range determined by available $R_{0} / a$ \\
\hline Minor radius $a, \mathrm{~cm}$ & 30 & 38 & $\begin{array}{l}\text { For adequate opacity to neutrals } \\
\left(n_{\mathrm{e}} a \geq 10^{15} \mathrm{~cm}^{-2}\right) \text { and plasma target }\end{array}$ \\
\hline Plasma duration $\tau_{s s}, \mathrm{~h}$ & \multicolumn{2}{|c|}{$1-8$} & For steady-state test mission \\
\hline $\begin{array}{l}\text { Toroidal field (at } R_{0} \text { ) } \\
B_{\mathrm{t} 0}, \mathrm{~T}\end{array}$ & 2.2 & 1.4 & $\begin{array}{l}\text { To permit } n_{\mathrm{e}} \approx 3 \times 10^{13} \mathrm{~cm}^{-3} \text { with lower } \\
\text { hybrid current drive for } R_{0} / a=2.5\end{array}$ \\
\hline Plasma current $I_{\mathrm{p}}, \mathrm{MA}$ & \multicolumn{2}{|c|}{$0.3-1.0$} & $\begin{array}{l}\text { For adequate } \mathrm{H} \text {-mode and suprathermal } \\
\text { confinement }\end{array}$ \\
\hline $\begin{array}{l}\text { Induction capability } \\
\psi_{\text {ind }}, \mathrm{Wb}\end{array}$ & 3.0 & 0.3 & $\begin{array}{l}\text { For inductive operation capability for } \\
\qquad R_{0} / a=2.5\end{array}$ \\
\hline$x$-point elongation $\boldsymbol{\kappa}_{x}$ & \multicolumn{2}{|c|}{$\sim 1.8$} & For single-null divertor \\
\hline$x$-point triangularity $\delta$ & \multicolumn{2}{|c|}{0.25} & For adequate inner divertor channel length \\
\hline $\begin{array}{l}\text { Auxiliary drive power } \\
P_{\text {aux }}, \mathrm{MW}\end{array}$ & \multicolumn{2}{|c|}{$2.0-4.5$} & $\begin{array}{l}\text { For edge heat fluxes adequate for testing } \\
\text { advanced divertors }\end{array}$ \\
\hline $\begin{array}{l}\text { TFC steady-state resistive } \\
\text { power } P_{\mathrm{TFC}}, \mathrm{MW}\end{array}$ & \multicolumn{2}{|c|}{$\leq 40$} & $\begin{array}{l}\text { Solid-state power supply capability available } \\
\text { in Building } 9201-2\end{array}$ \\
\hline $\begin{array}{l}\text { Total steady-state heat } \\
\text { removal } P_{\text {cool, }} \text { MW }\end{array}$ & \multicolumn{2}{|c|}{$\leq 50$} & $\begin{array}{l}\text { High-pressure water cooling capability } \\
\text { available in Building } 9201-2\end{array}$ \\
\hline
\end{tabular}




\section{V.1 DEVICE CONFIGURATION}

\section{V.1.1 Design Requirements}

The device configuration must satisfy the following requirements:

1. Maximum access and envelope for the test divertors, to permit flexibility in the test divertor concepts.

2. Provisions for efficient replacement of test divertor modules, to permit testing of a progression of advanced concept divertors.

3. Duty factor of $\geq 10 \%$, to accumulate ITER-level exposure to the divertor and first wall surfaces per annum, given that ITER-level heat and particle fluxes are provided. The device components need to be modular with relatively unencumbered interfaces to reduce the time to maintain, replace, or repair them.

4. Built-in capability for small-aspect-ratio plasmas by identical interfaces to a fat and a skinny central core assembly, without substantial cost increase.

\section{V.1.2 Configuration Concept}

The TST configuration has demountable TF coils surrounding a cylindrical vacuum vessel, similar to the ISX tokamak. Figures V.1-V.3 illustrate the proposed concept for the case of $A=2.5$. The main features of the device include cassette divertors and a compact central core assembly that can be removed and replaced to change $A$ to 1.8. The main systems are described below, with more information on key components in Sects. V.2-V.7.

\section{Divertor configuration and access}

The divertor assemblies are toroidally divided into eight identical modules (or cassettes) that are inserted into radial ports in the vacuum vessel. Each divertor assembly (and associated services) is integral with the port cover flange on the vacuum vessel and is removed and replaced as a unit. This allows quick repair or changeout of a divertor, without disturbing other systems. Also, since all service lines are routed through vacuum feedthroughs extending through the cover flange, no service connections are made inside the vacuum vessel. All piping, instrumentation, current feeds, etc., can be premade and leak checked before the cassette is installed. Finally, small "windowframe" coils can be readily incorporated in the divertor module to control the divertor strike point locations.

\section{Toroidal field coils and central core assembly}

Eight multiturn TF coils provide up to $2.2 \mathrm{~T}$ steady state at the major radius of $0.75 \mathrm{~m}$. Each coil is constructed from copper and will be water cooled. Each coil turn will be made from three sections connected at bolted joints. The jointed TF coil has several advantages. First, the PF coil set can be located inside the bore of the TF coils, which results in smaller, lower power PF coils; smaller out-of-plane forces on the TF coils; and easier replacement of the PF coil set. Second, the outer portion of the vacuum 


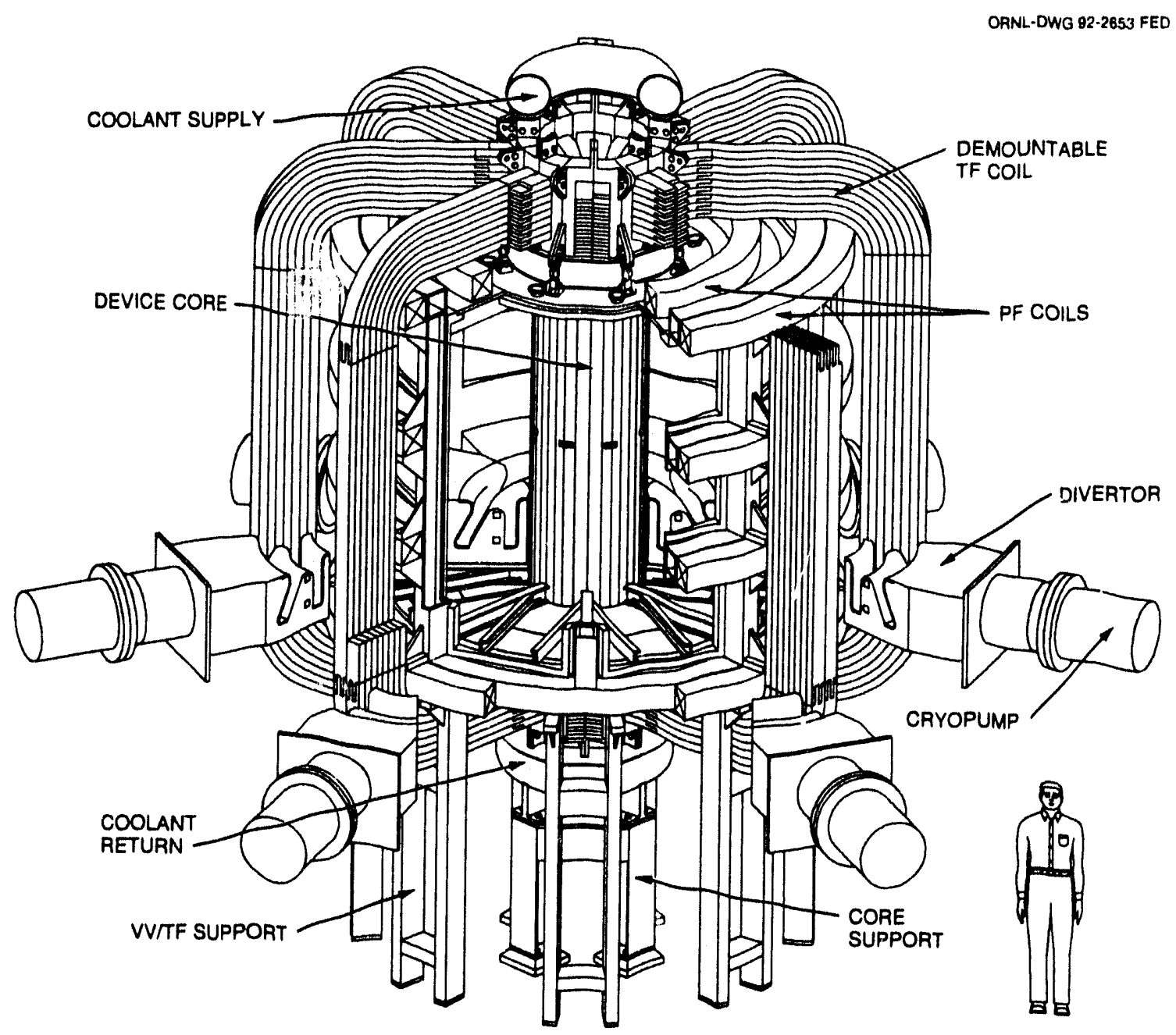

Fig. V.1. The TST device.

vessel can be fabricated as a complete unit that can be pretested before installation in the device. This allows more assembly and fabrication operations to proceed in parallel and can substantially shorten the overall construction schedule. Third, a section of the TF coil, including the central core assembly, can be replaced without disassembly of the entire machine.

The inner sections of all the TF coils form one assembly called the central core. The solenoid and divertor coils and the inner portion of the vacuum vessel are integral with the central core assembly. It is desirable to have demountable connections at both the top and bottom of the central core assembly to allow replacement of this critical item without dismantling the entire machine. This also provides flexibility to install a modified central core to allow operation at lower (or higher) aspect ratios. The legs of the central core should be bonded together as one assembly for strength and dimensional control. The upper and lower horizontal legs would attach to the central core at vertically bolted lap joints. The outer vertical TF coil legs would attach to the horizontal legs at bolted finger joints. The TF coil system is designed to be compatible with existing power supplies and to operate within the limits of existing cooling towers. 


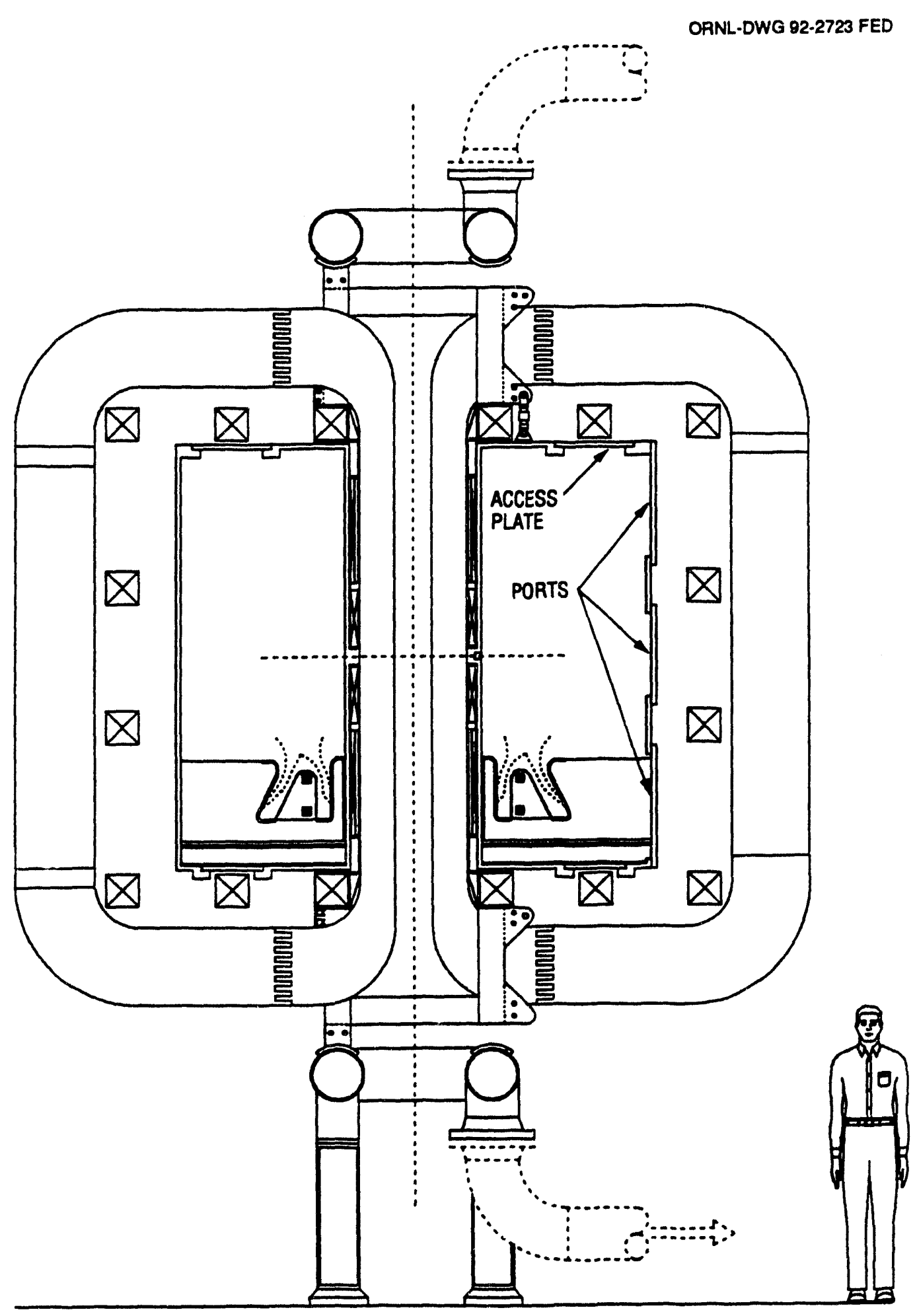

Fig. V.2. TST elevation view, $A=2.5$. 


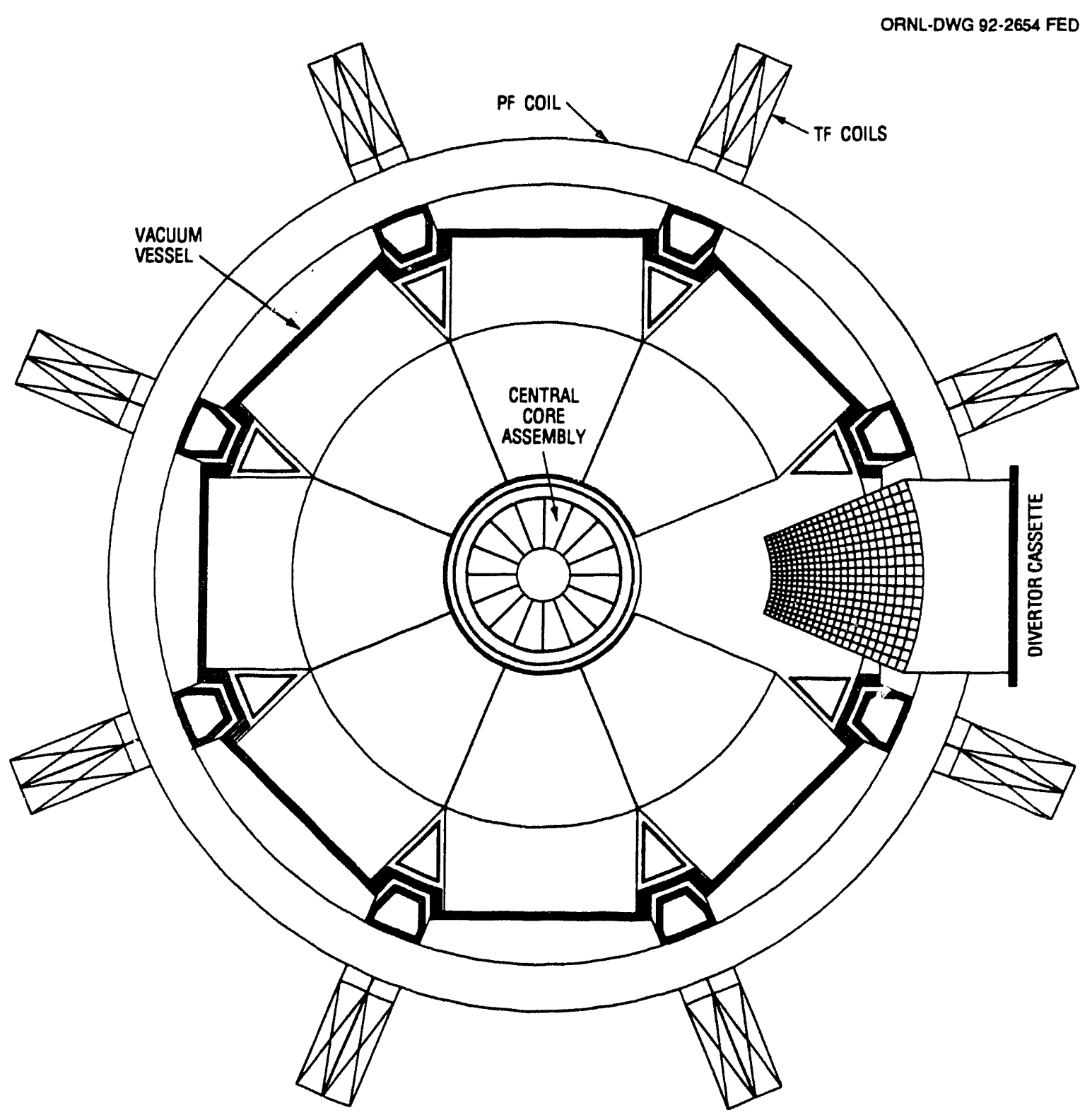

Fig. V.3. TST plan view, $A=2.5$. 


\section{Vacuum vessel}

The vacuum vessel serves as the vacuum boundary and the support interface for the divertor cassettes and passive stability structure. The toroidal resistance requirement, based on ECH-assisted startup, is sufficiently low that the vessel does not require an electrical break, which is a significant design advantage over many small, conventional tokamaks. Eight large radial ports at the midplane offer the maximum access possible for $\mathrm{H} \& \mathrm{CD}$ (normal or tangential), diagnostics, vacuum pumping, or other services. Additional large $(80-\mathrm{cm}$ by $50-\mathrm{m})$ radial ports above and below the midplane allow the cassette divertor modules to be inserted radially without disturbing the remainder of the tokamak device. The inner cylinder of the vessel is welded around the TF coil core and the inner PF coils, with bolted joints at the top and bottom cover flanges. Integral cooling will be required for the inner cylinder, while trace cooling may be adequate where space permits. Reinforcing ribs on the top and bottom covers may also be required. The radial flanges are arranged inboard of the outer PF coils, and the upper and lower cover flanges are arranged to allow the lower middle PF coil to be removed from above, without major machine disassembly.

\section{PF coils}

A versatile set of PF coils is provided to accommodate both $S N$ and DN plasma configurations and a range of aspect ratios from 1.8 to 3.2. All coils are located inside the bore of the TF coil set. The inner PF coils or solenoid coils are integral with the central core assembly and would be reconfigured with any changeout of the central core. The coils are water-cooled copper construction for steady-state operation and will be designed to match existing power supplies as closely as possible. Although there are no fast control coils inside the vacuum vessel, two passive stability loops on the outboard side of the plasma also serve as toroidal belt limiters.

\section{Support structure}

The support structure must react the out-of-plane loads on the TF coils and all the vertical loads on the PF coils. The structure consists of a cylindrical cage outboard of the vacuum vessel with upper and lower bridge structures between the PF and TF coils. In this way, maximum access for heating, diagnostics, and divertor cassettes is preserved. All interface hardware between the support structure and other components will be adjustable to provide for initial alignment of the components and to correct for fabrication inaccuracies.

\section{V.2 CENTRAL CORE ASSEMBLY}

The central core assembly consists of the inner legs of the TF coils, the inner solenoid coils and the divertor shaping coils, the inner cylinder of the vacuum vessel, and all associated water cooling lines, power leads, and instrumentation connections. These components are preassembled and installed as a unit. The central core assembly may be removed and replaced with a different assembly to change the aspect ratio of the device. Table V.2 lists the key parameters, and Figs. V.4 and V.5 show the core assemblies required for aspect ratios of 2.5 and 1.8 , respectively. 
Table V.2. TST central core assembly parameters

\begin{tabular}{lll}
\hline & $A=2.5$ & $A=1.8$ \\
\hline Diameter at midplane, m & 0.84 & 0.56 \\
Number of TF turns & 128 & 64 \\
Current per turn, kA & 65 & 65 \\
Solenoid coils, pairs & 2 & None \\
Divertor coils, pairs & 1 & 1 \\
Total weight of core, tonnes & 29 & 18 \\
Water flow rate through core, gal/min & 4360 & 2400 \\
\hline
\end{tabular}
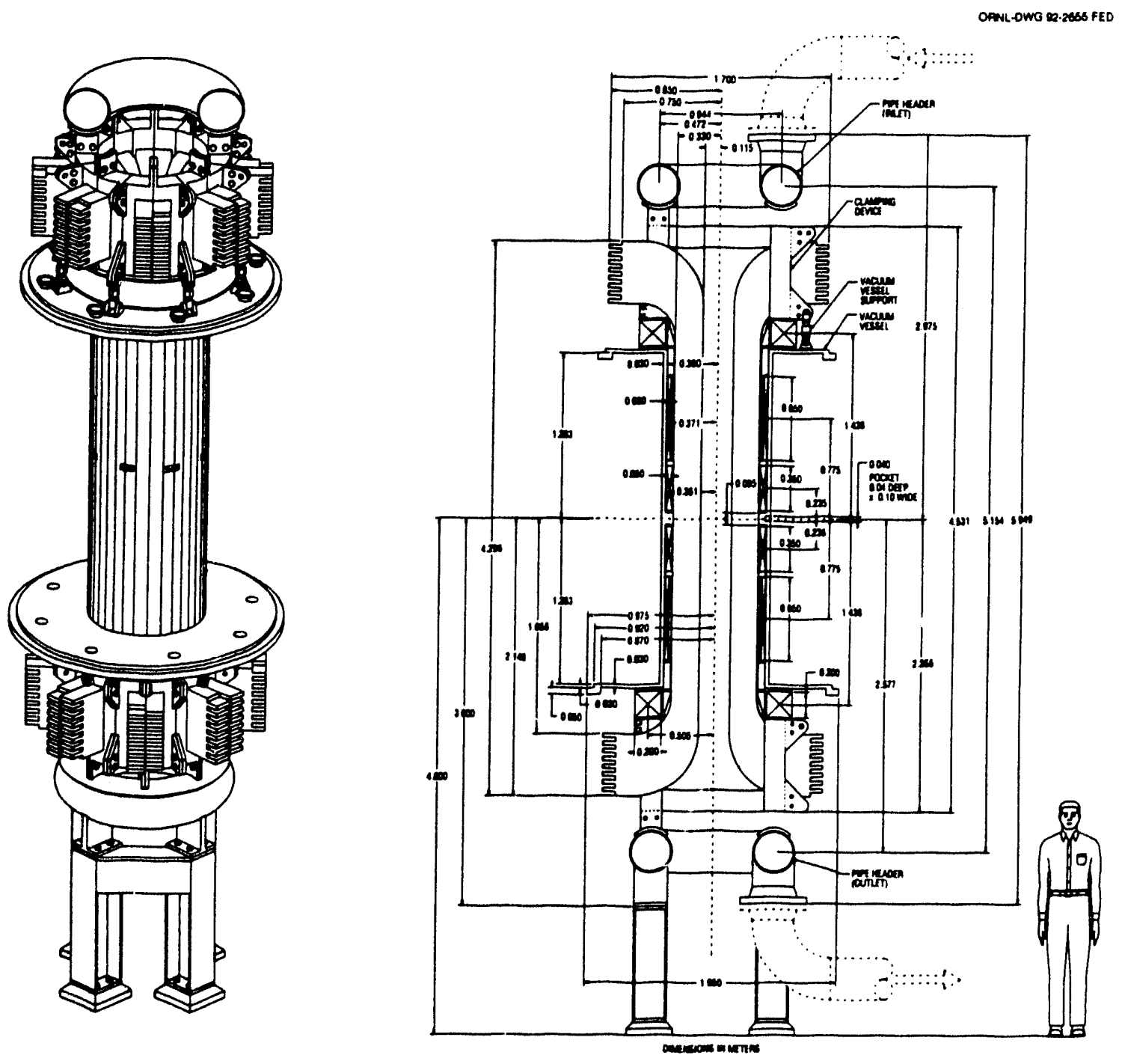

Fig. V.4. TST central core assembly, $A=2.5$. 

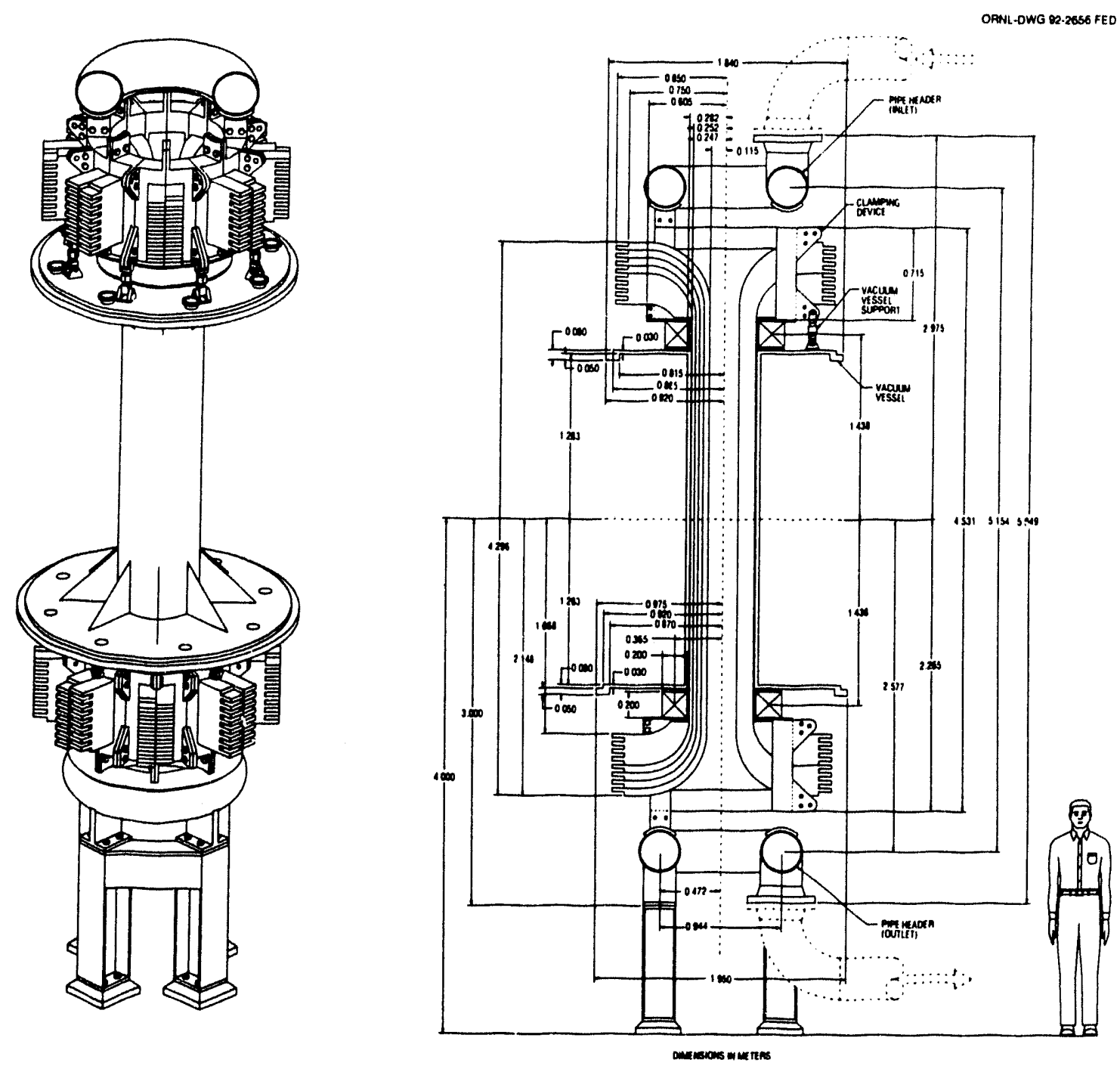

Fig. V.5. TST central core assembly, $A=1.8$.

\section{V.2.1 TF Coil Inner Legs}

As shown in Figs. V.4 and V.5, there is limited space at the midplane for the central core, and all the components must be compact. The TF coil inner legs are arranged in 16 sets of 8 turns (for the $A=2.5$ configuration), with sufficient cooling to operate steady state at $65 \mathrm{kA}$ per turn. The $A=1.8$ configuration is identical, except that only the four innermost turns are included per coil set. All the turns are bonded together for structural integrity and dimensional control (the loads and stresses are discussed in Sect. V.3).

\section{Turn configuration and cooling}

The number of turns was selected to match the capability of the existing ATF helical field (HF) coil power supply. Although turns made from vertically flat plates were desired, such turns would have been too thin to incorporate adequate cooling passages. 
The toroidal, layer-wound orientation of the turns permits even distribution of the cooling tubes, which are brazed into slots in the conductor. The turn thicknesses are tailored to keep the cross-sectional areas (and thus current density and temperature rise) constant. Each cooling line is made from a continuous piece of tubing to avoid assembly joints in inaccessible areas. The lines are routed to positions above and below the demountable joint areas, where electrically insulating hose connections meet the water manifolds. A supply manifold at the top and a return manifold at the bottom are integral with the core assembly. The details of the cooling analysis are summarized in Sect. V.3.

\section{Inboard TF joint configuration and crossover}

The inboard TF joints are relatively simple through-bolted lap joints. These joints do not slide, but are designed to carry the full in-plane electromagnetic loads and a portion of the out-of-plane loads (see Sect. V.3). The joint region is located well outboard of the vertical portion of the TF coil core in order to keep the joint stresses down, allow a generous bend radius for the conductor, provide space for cooling line routing, and allow access for assembly and periodic inspection. The joint width is presently about $12 \mathrm{~cm}$, but this dimension could be expanded if furcher analysis indicates a stress or cooling problem. Both joints also provide a turn-to-turn current crossover. This connection scheme allows the turn-to-turn insulation to be directly checked, since the coil set is effectively divided into two interleaved circuits. The two circuits are connected in series via bus feeds under the machine.

\section{TF core fabrication}

The fabrication sequence of the TF coil central legs is shown in Fig. V.6. The copper is machined to shape in the flat, with the cooling line grooves milled and the joint details machined at each end. The cooling lines are then brazed intc the grooves. Each turn is rough-formed to shape on a press, then clamped to a precision fixture and stress relieved. The turns are then cleaned, primed, wrapped with glass cloth, and stacked together, with the joints held in precision fixturing. The stack of turns is then vacuum impregnated with epoxy to form a structurally integrated, dimensionally accurate, and stable assembly.

\section{V.2.2 Solenoid and Divertor Coils}

The solenoid and divertor coils are wound from hollow copper conductor onto a stainless steel bobbin around the completed TF core assembly. The coils are wound two-in-hand to provide adequate cooling for continuous operation, with the electrical and cooling leads extended vertically to the accessible regions above and below the core assembly. The coil turns are individually wrapped with glass insulation, and the complete winding is vacuum impregnated with epoxy. A layer of compliant material between the solenoid bobbin and TF core allows differential thermal expansion. The divertor coils are made in the same manner, but these coils are powered independently. Details of the magnetic and thermal loads and analysis are presented in Sect. V.4. 

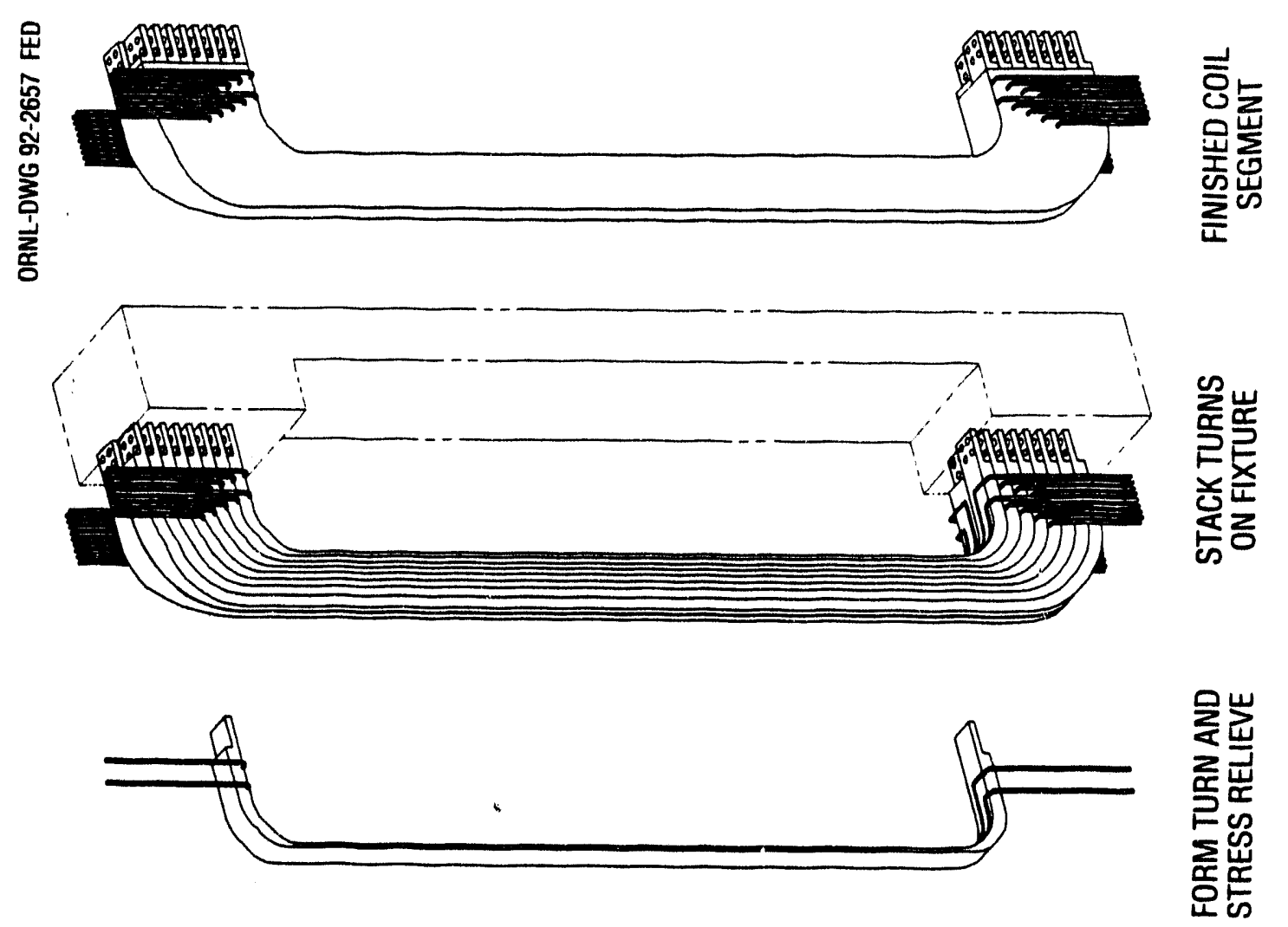

\&్

E

.ํㅡㄹ

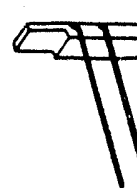

岩恣出

뭉

I

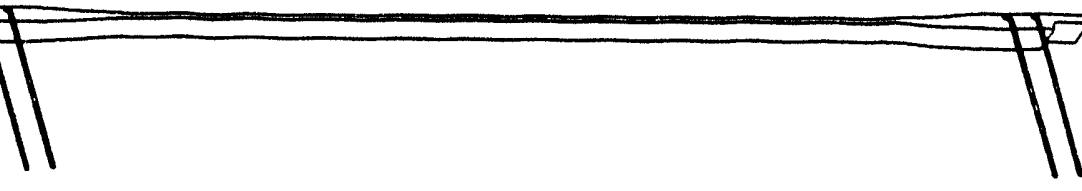

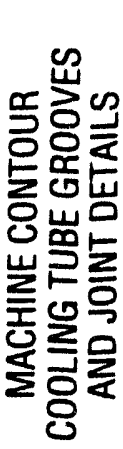

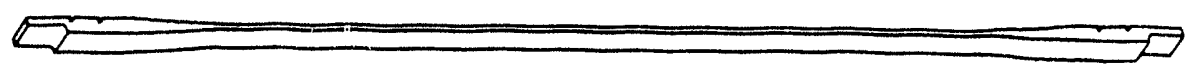

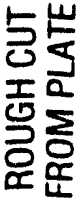




\section{V.2.3 Inboard Vacuum Vessel and First Wall}

The inboard cylinder of the vacuum vessel is a double-wall sandwich structure filled with cooling water. The inner and outer walls are approximately $0.5 \mathrm{~cm}$ thick, with a total thickness of $2 \mathrm{~cm}$. Conduction-cooled graphite tiles are attached directly to the plasma-facing surface. The cylinder is made in two $180^{\circ}$ halves and welded around the TF and solenoid coil assembly. The top and bottom interface flanges are also welded together from $180^{\circ}$ segments. Figure V.7 illustrates the vacuum vessel and core assembly. Structural connections between the inner and outer sections of the vacuum vessel are made from inside the vacuum vessel during final assembly of the machine. Details of the structural loads and analysis are presented in Sect. V.5.

\section{V.3 TF COILS}

\section{V.3.1 Requirements and Configuration}

The TF coil system is required to produce a magnetic field of $2.2 \mathrm{~T}$ at a major radius of $68-80 \mathrm{~cm}$ (Table V.3). Other design requirements include minimization of field ripple at the plasma edge, and limits set by existing power supplies. A jointed, water-cooled copper coil is proposed to meet these requirements.

\section{High-aspect-ratio configuration $(A=2.5)$}

As shown in Fig. V.8, the system is composed of 16 coils, distributed toroidally in 8 parts, with 8 poloidally wound turns per coil, for a total of 128 turns. Each coil is demountable above and below the inner leg and at two places on the outer leg to allow access to the vessel and PF coil set. The 16 inner legs are wedged and bonded together to support in-plane centering forces and form a cylindrical core, with an outside diameter of $66 \mathrm{~cm}$ and a 23-cm hole through the center. The outer return legs are positioned to minimize toroidal field ripple and create a $162-$ by $308-\mathrm{cm}$ bore that accommodates the vacuum chamber and PF coils. Turn thicknesses vary from $1.6 \mathrm{~cm}$ minimum in the central core to $6.0 \mathrm{~cm}$ in the return legs. The maximum current density in the central core is $3.2 \mathrm{kA} / \mathrm{cm}^{2}$.

\section{Low-aspect-ratio configuration $(A=1.8)$}

Low-aspect-ratio operation requires a smaller central core to accommodate the plasma and vacuum chamber in the high-aspect-ratio device. Each coil requires 4 turns, varying in thickness from 2.6 to $6.0 \mathrm{~cm}$, for a total of 64 turns. The inner legs form a cylinder with an outside diameter of $49 \mathrm{~cm}$. The maximum current density in the central core is increased to $3.8 \mathrm{kA} / \mathrm{cm}^{2}$.

\section{V.3.2 Electromagnetic Loads}

Because TST will be a steady-state device, it will operate at relatively low current densities. As a consequence, more material will be available to withstand a given intensity of electromagnetic loads. Moreover, fatigue will not be critical and therefore higher stresses may be allowed, for both the conductor and the insulation materials. 


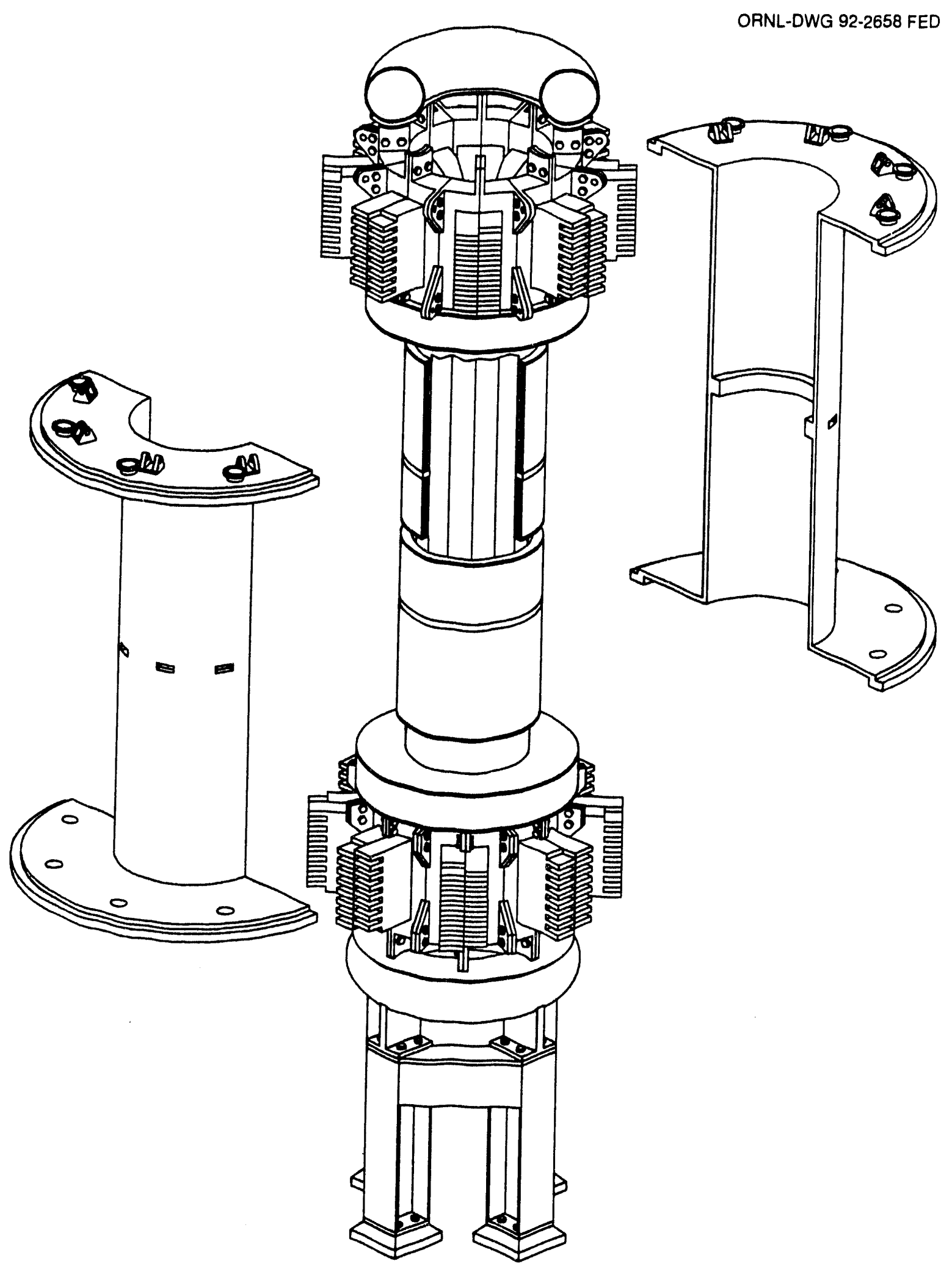

Fig. V.7. TST central core, exploded view. 
Table V.3. TF coil design requirements

\begin{tabular}{lllll}
\hline & \multicolumn{5}{c}{ Aspect ratio $A$} \\
\cline { 2 - 5 } Parameter & \multicolumn{1}{c}{3.2} & \multicolumn{2}{c}{2.5} & \multicolumn{2}{c}{2.2} & \multicolumn{1}{c}{1.8} \\
\hline Major radius, m & 0.80 & 0.75 & 0.538 & 0.675 \\
Minor radius, m & 0.25 & 0.30 & 0.25 & 0.375 \\
Field on axis, T & 2.1 & 2.2 & 1.8 & 1.4 \\
Field ripple at plasma edge, \% & 0.5 & 0.5 & 0.5 & 0.5 \\
Power supply current, $\mathrm{kA}$ & 65.6 & 69.5 & 75.7 & 73.8 \\
Steady-state power limit, MW & 40 & 40 & 40 & 40 \\
\hline
\end{tabular}

On the other hand, limitations on the maximum current available from the ORNL power sources impose the need to work with a large number of turns, in a multilayered TF coil. The envisaged coil is rectangular with rounded corners, so that it can be built from copper bars or plates bent to the appropriate shape.

Rectangular TF coils are generally characterized by high bending moments and shear forces at the outer corners and high shear forces at the inner corners. The shear stresses in the insulation of such a multilayered coil must be investigated with care.

The TF coils are usually dimensioned from a mechanical point of view, considering the loads produced by their self-field. Afterwards, the coils are checked against out-of-plane loads predicted for normal and abnormal conditions, considering a suitable lateral supporting system.

A first-order approximation of the in-plane loads is obtained by assuming a uniform current density along the cross section of the coil, as well as a linear decay of the intensity of the toroidal magnetic field along the coil thickness (Fig. V.9). Integrating the electromagnetic forces over the cross section of the coil, one obtains a span load:

$$
f=\int_{\mathrm{A}_{\mathrm{s}}} j \times B d s \quad(\text { in } \mathrm{N} / \mathrm{m}) .
$$

This yields for the outer leg of the coil

$$
f=\frac{1}{2} I B_{3} \quad \text { (directed outward) }
$$

and, for the upper and lower horizontal limbs,

$$
f=\frac{1}{2} I B(r) \quad \text { (respectively upward and downward). }
$$
therefore

For the inner leg, one must consider that the coil thickness is not constant and

$$
\begin{gathered}
f=\int_{R_{1}}^{R_{2}} j B_{2} \frac{r-R_{1}}{\Delta R} \frac{2 \pi r}{N} d r . \\
f=\frac{\pi}{3} \frac{j B_{2}}{N \Delta R}\left[2\left(R_{2}\right)^{3}-3 R_{1}\left(R_{2}\right)^{2}+\left(R_{1}\right)^{3}\right] \text { (directed to the machine vertical axis) } .
\end{gathered}
$$

For the TST parameters $\left(R_{1}=0.115 \mathrm{~m}, R_{2}=0.33 \mathrm{~m}, R_{3}=1.95 \mathrm{~m}, R_{4}=2.43 \mathrm{~m}, N I=\right.$ 8.25 MA•turn), the loads shown in Fig. V.10 are determined. 


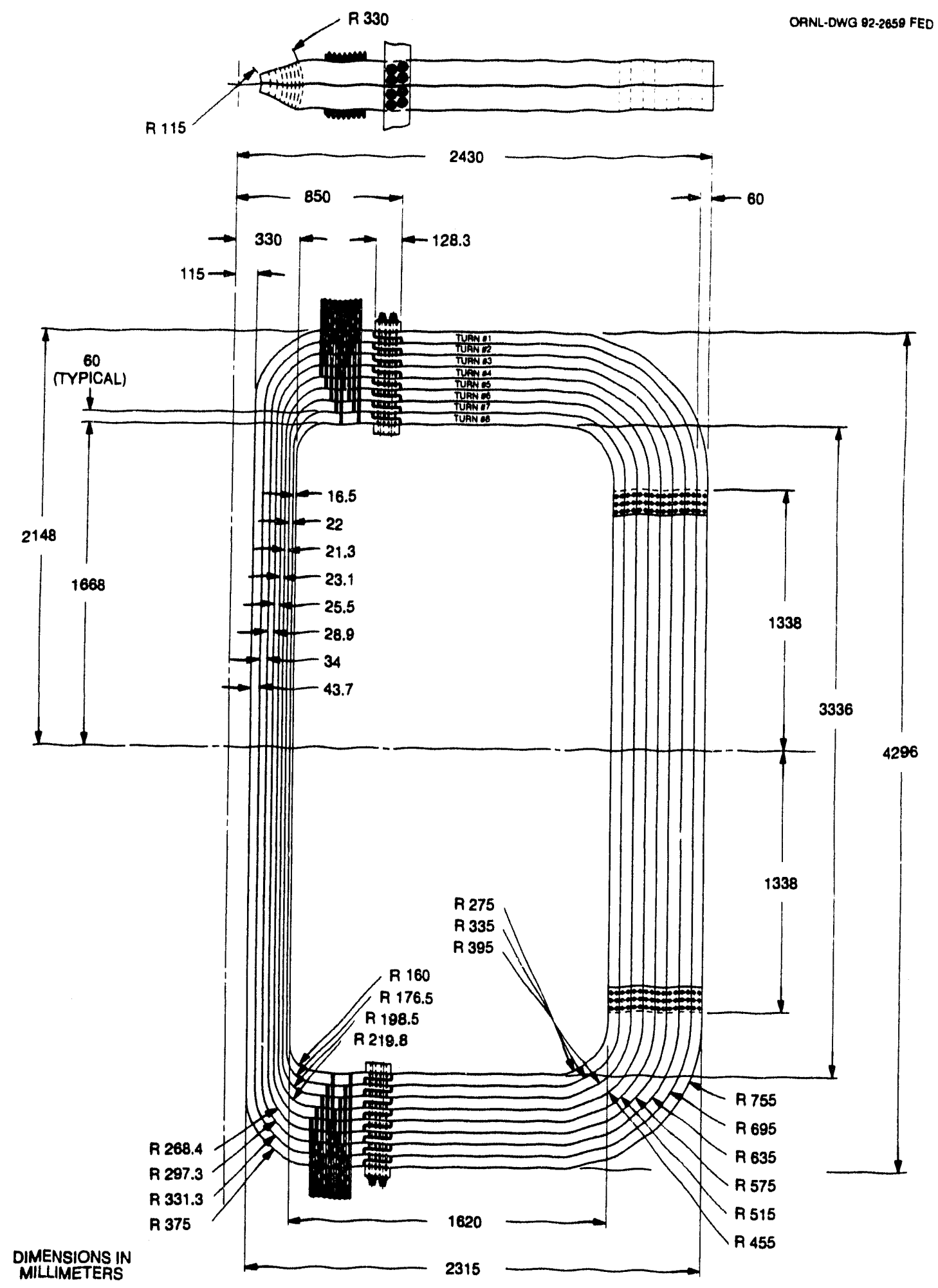

Fig. V.8. TF coil. 


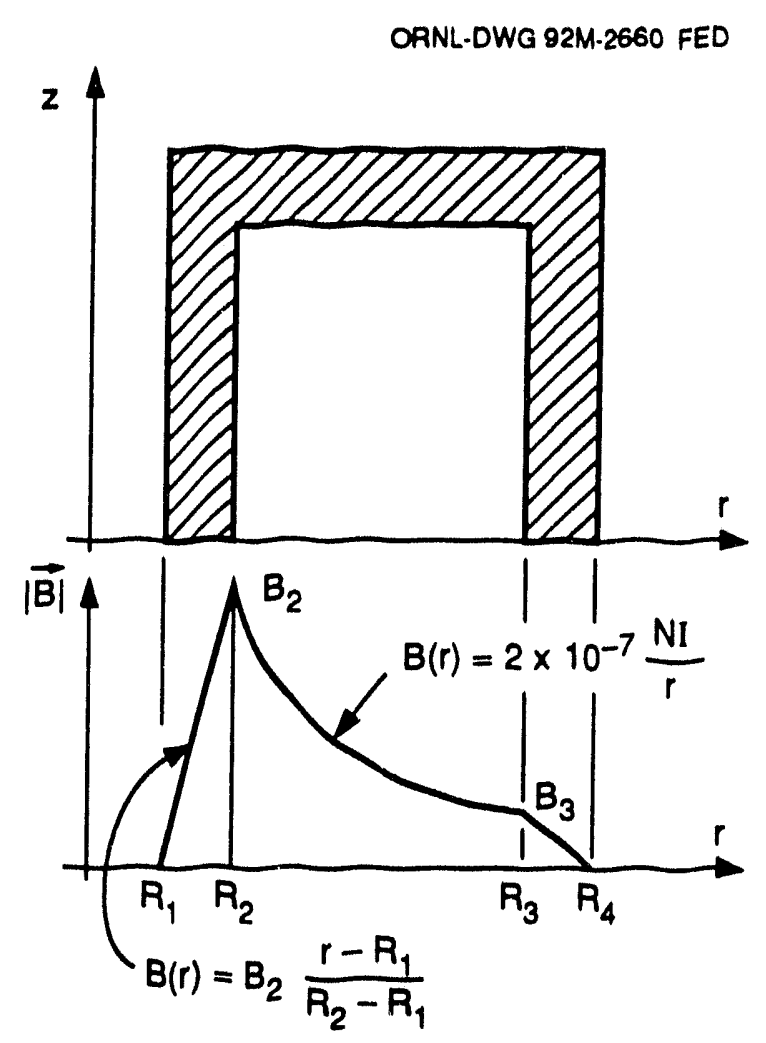

Fig. V.9. Toroidal field intensity.

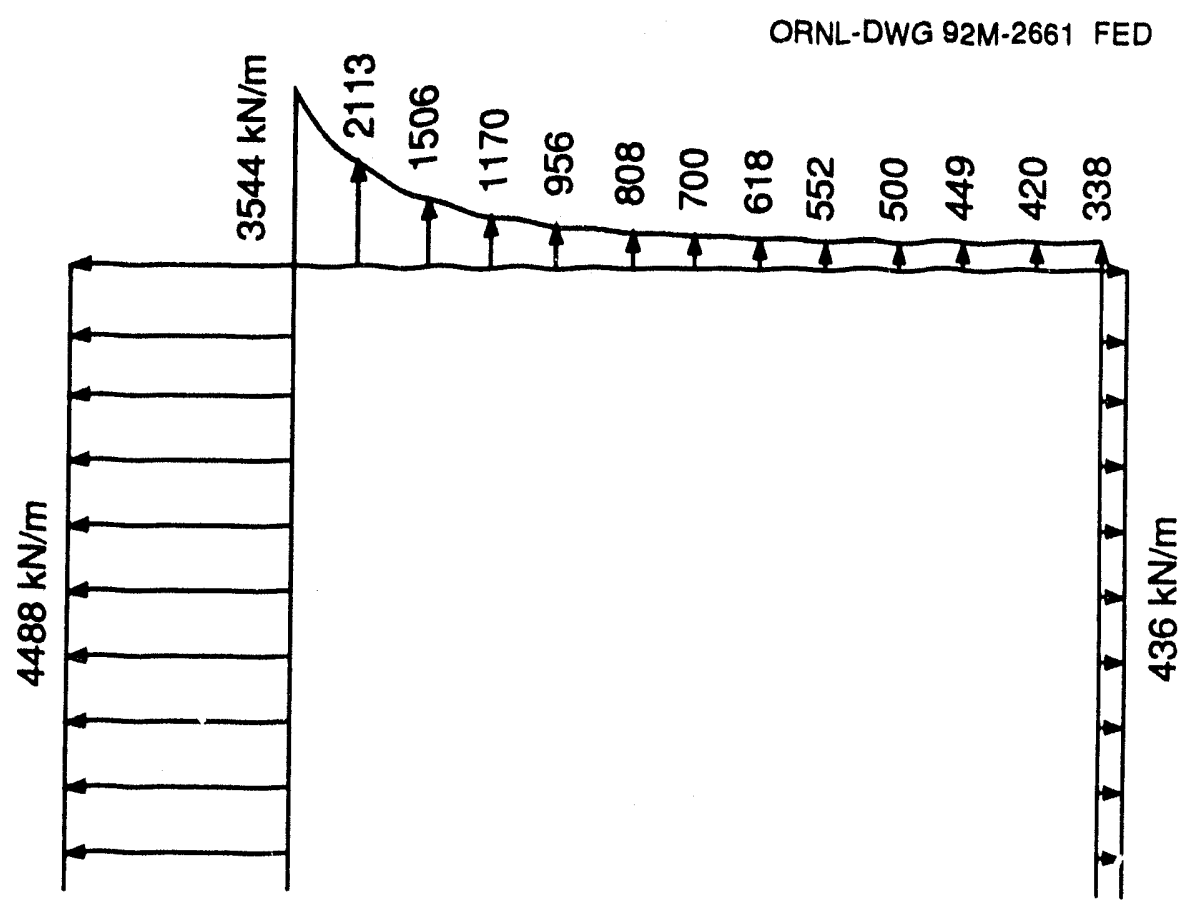

Fig. V.10. Loads due to toroidal field. 


\section{V.3.3 Stress Analysis}

The TF coil behavior under the in-plane loads may be well represented by a simple onedimensional (1-D) beam model, if the fact that the inner legs of the TF coils confine each other is represented. They behave like a thick cylinder under axisymmetric loads, equilibrating the net centering force on each coil by hoop compression. Bending moments applied at the ends of such a cylinder are dumped very quickly. To capture this behavior in a beam model, springs may be introduced to oppose the radial displacement of the elements representing the inner leg. In fact, there exists a perfect analogy between the problem of a cylindrical shell under axisymmetric loads and that of a beam under elastic foundation.

The magnitude of the spring stiffness required to represent the behavior of the inner TF coil legs is roughly

$$
k=\frac{2 \pi \Delta R h}{N R_{2}} E
$$

where $\Delta R$ is the thickness of the central column (CC), $h$ is the spacing between the nodes defined along it, $E$ is an equivalent modulus of elasticity (to assimilate conductors, insulation, and cooling holes), $N$ is the number of coils, and $R_{2}$ is the external radius of the $\mathrm{CC}$. Assuming $E=100 \mathrm{GPa}$ and $h=0.17 \mathrm{~m}$, a spring constant $k=8.3$ $\mathrm{GN} / \mathrm{m}$ is obtained.

Figure V.11 shows the beam model of the TF coil, which takes advantage of the symmetry with respect to the equatorial plane. The code ANLEF was employed in the analysis. Figure V.12 shows displacements, bending moments, and shear and norrnal forces along the axis of the coil.

Results obtained with this model compare well with those obtained by determining the loads with the code MAGFOR and then modeling the coils with the NASTRAN code. Figure V.13 shows the variation of the bending moment along the axis of the coil, as determined by NASTRAN. Different modeling assumptions resulted in a $5 \%$ difference in the maximum bending moment (which occurs at the outer comer) with respect to the ANLEF model.

\section{Stresses in the central column}

Static equilibrium in the radial direction requires a compressive hoop stress of $27 \mathrm{MPa}$ in the inner legs of the TF coil. A positive normal stress $S_{Z}=29 \mathrm{MPa}$ also arises, due to a normal force $N=1076 \mathrm{kN}$. Strain compatibility between copper and insulation therefore imposes a normal stress $S_{Z}=7 \mathrm{MPa}$ in the insulation layers. Thus the maximum shear stress in the CC, due to the in-plane forces only, reaches about $18 \mathrm{MPa}$. In pulsed machines, shear stresses in glass-reinforced epoxy are limited to $15 \mathrm{MPa}$. For TST, with a low number of cycles predicted during its operational life $\left(10^{4}\right)$, a less restrictive limit may be imposed. Nevertheless, the insulation layers of the $\mathrm{CC}$ will be further stressed by the torque provoked by the out-of-plane loads. The stresses due to the out-of-plane loads must be carefully evaluated as soon as possible. A candidate material for the insulation must be defined, and the allowable stresses for the designed number of cycles of TST must be assessed. 


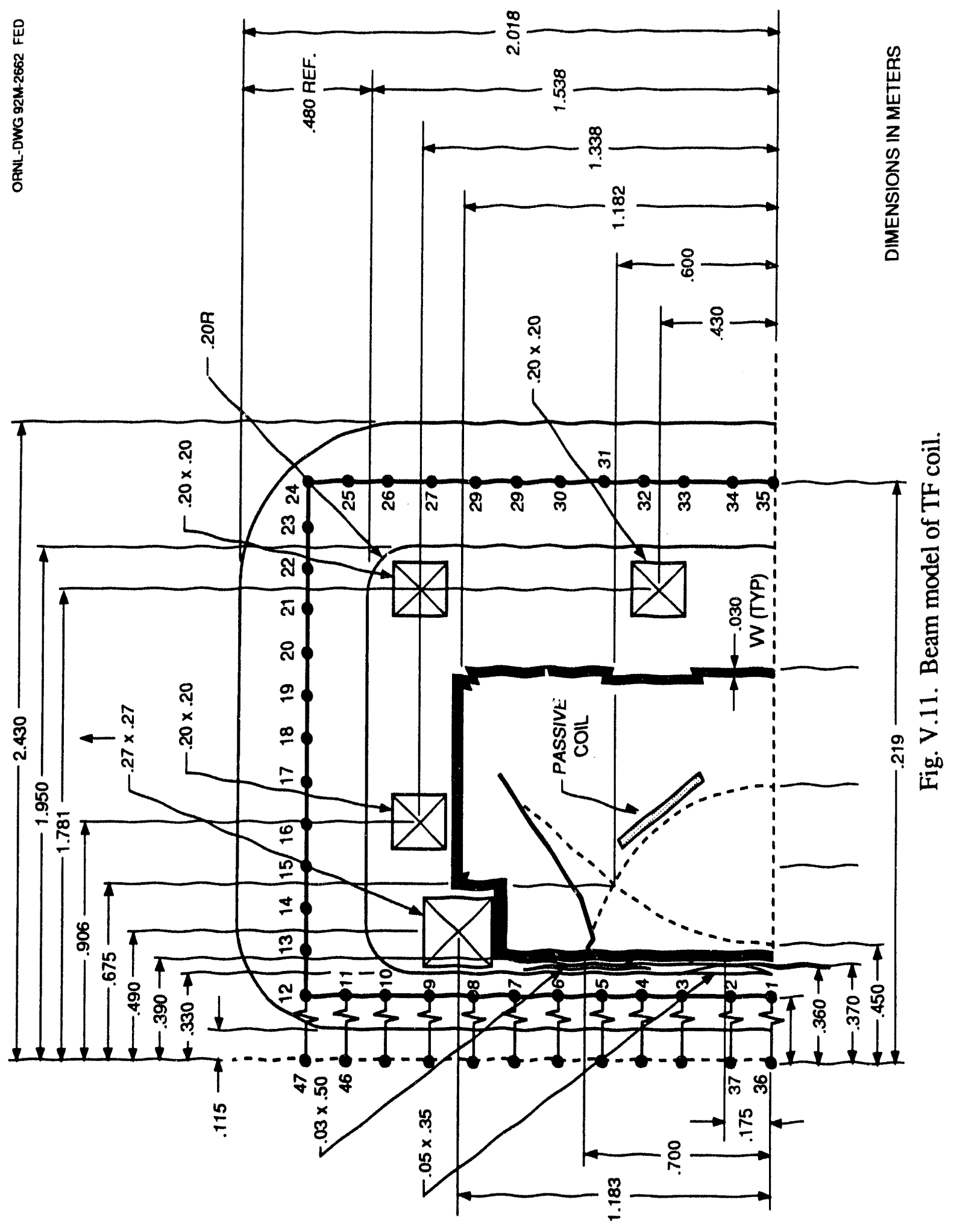


(a)

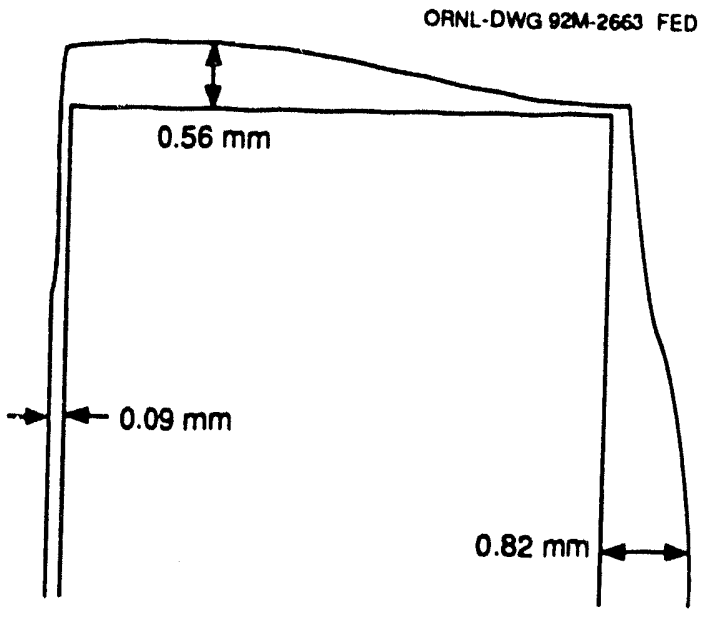

(b)
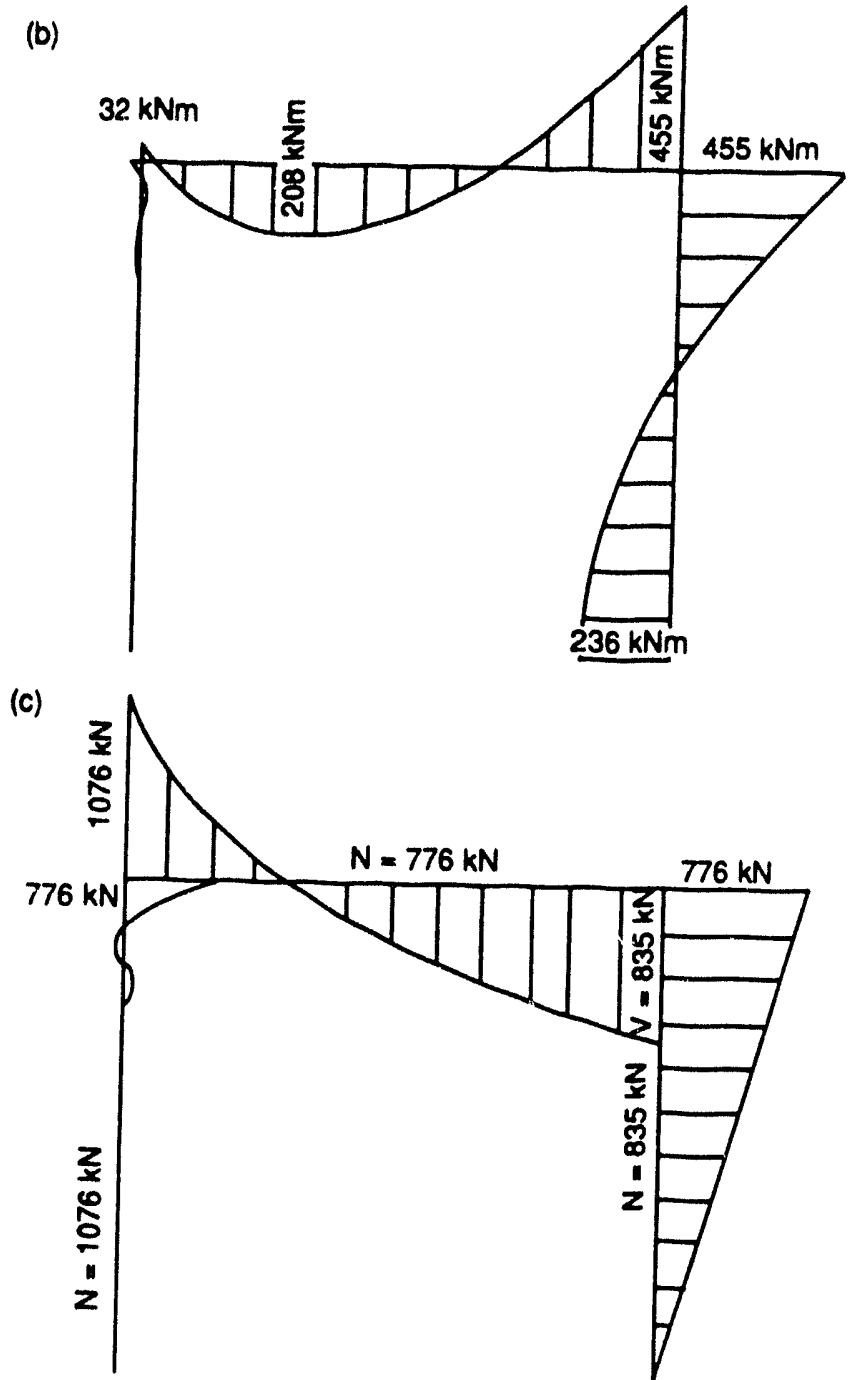

Fig. V.12. Beam model results. (a) Displacements $\delta$. (b) Bending moments $-M$. (c) Shear $(V)$ and normal $(N)$ forces. 


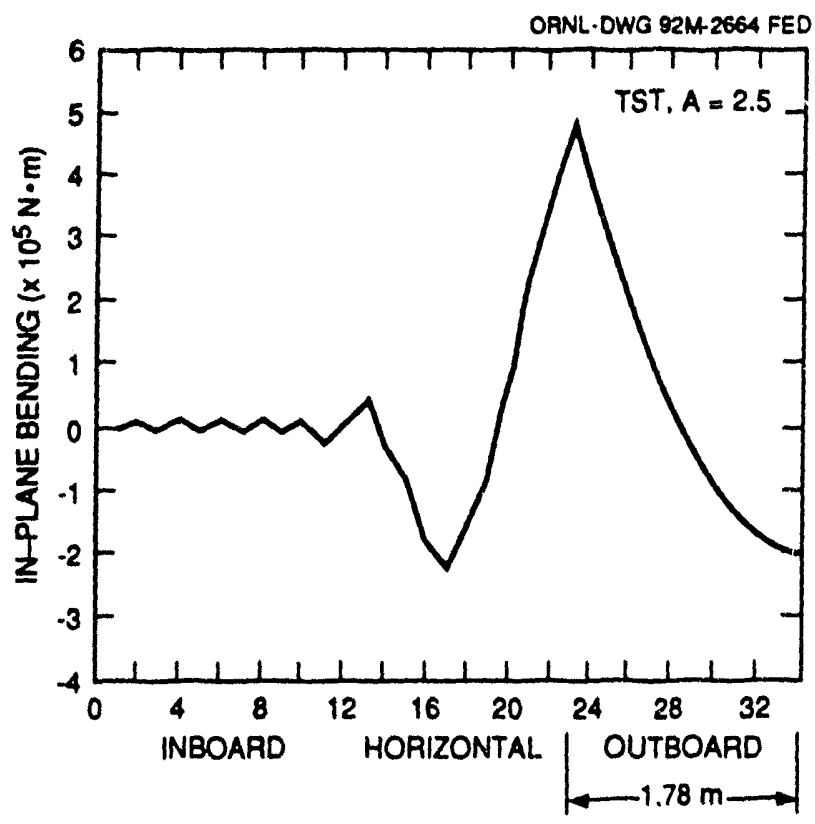

Fig. V.13. Bending moment distribution.

\section{Stresses in the outer corner}

Analytical evaluation. To evaluate the stresses in the outer corner, one must consider the stress magnification in a curved beam. Stresses along the cross section of an elastic, homogeneous, Bernouilli-Navier beam under the action of a bending moment $M$ are given by (refer to Fig. V.14)

$$
S_{b}(y)=\frac{M y}{A(R-\Omega)(\Omega-y)},
$$

where

$$
\Omega=\frac{R_{\mathrm{i}}-R_{\mathrm{o}}}{\ln \left(R_{\mathrm{i}} / R_{\mathrm{o}}\right)} .
$$

Figure V.15 shows the variation of the normal stresses in the bend for $M=480 \mathrm{kN} \cdot \mathrm{m}$. The maximum stress appears at the inner surface, $S_{b}=81 \mathrm{MPa}$, and the minimum stress at the outer surface, about $-36 \mathrm{MPa}$. The neutral axis is displaced $5 \mathrm{~cm}$ with respect to the geometrical axis. An additional tension $S_{n}=7 \mathrm{MPa}$ is imposed on the conductors by the normal force $(N=835 \mathrm{kN})$ acting in the outer leg, increasing the maximum normal stress in the copper, at the inner surface, to $88 \mathrm{MPa}$. Strain compatibility between copper and insulation makes it possible to scale normal stresses according to the ratio of the elastic moduli. The result is a maximum $S_{b}+S_{b}=13 \mathrm{MPa}$ in the innermost insulation layer.

A shear load $V=785 \mathrm{kN}$ adds a parabolic shear stress distribution along the cross section (with a maximum of about $10 \mathrm{MPa}$ at the geometric axis, vanishing at the inner and outer surfaces). Static equilibrium requires the same level of shear stresses in the copper and in the insulation layers. Hence the largest shear stress in the insulation, due to the shear load only, reaches $T(V)=9.7 \mathrm{MPa}$, in the layers closer to the beam axis. 


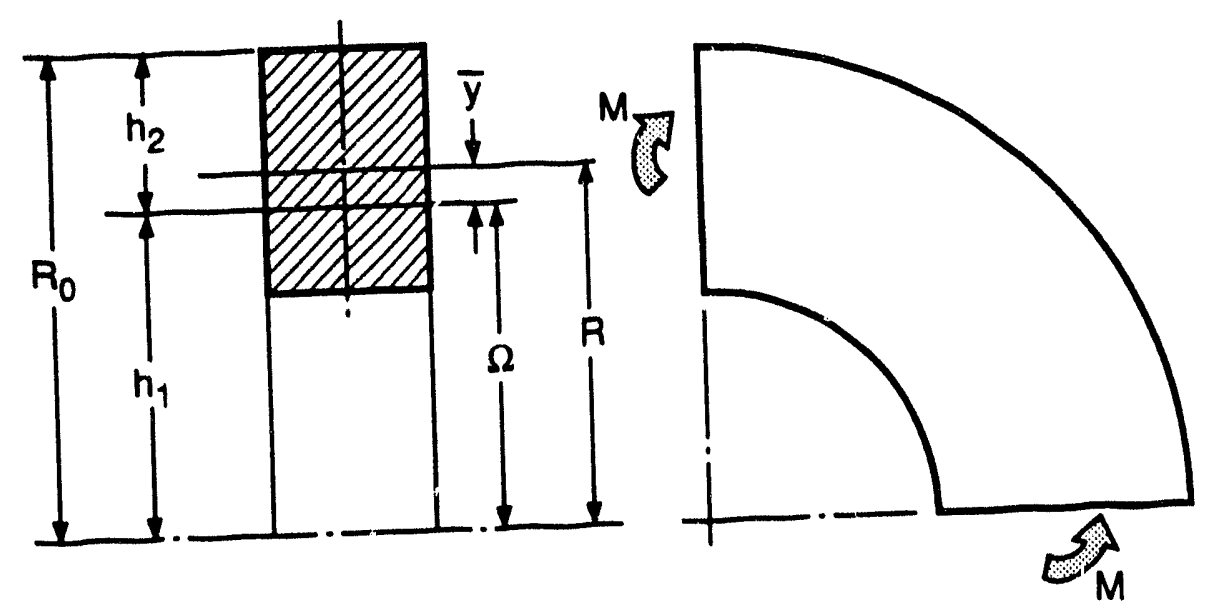

Fig. V.14. Bending of a curved beam.

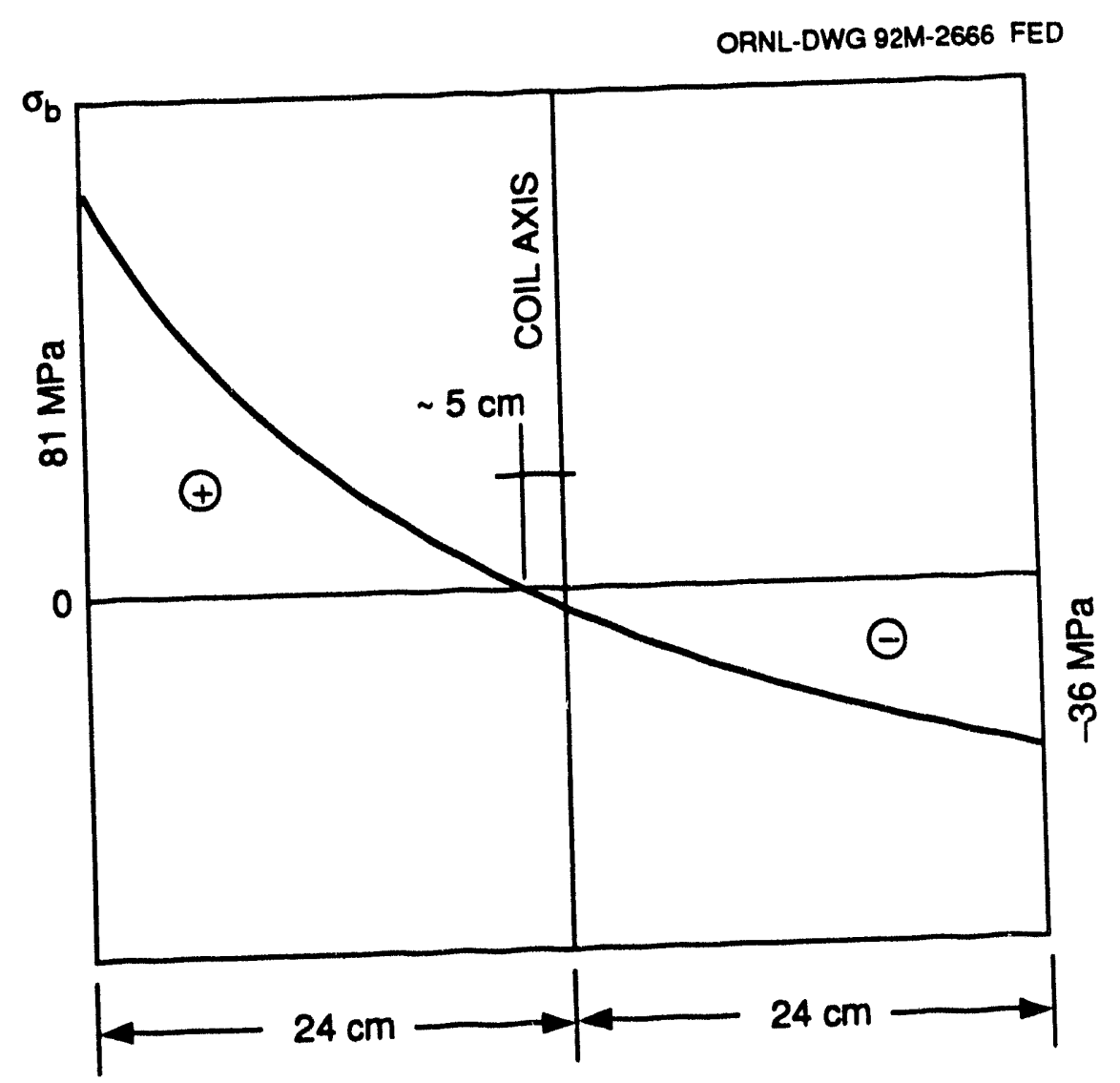

Fig. V.15. Normal stress due to bending.

The maximum shear stress at any point of the beam is

$$
T_{\max }=\sqrt{(S / 2)^{2}+T^{2}},
$$

and combining $\left(S_{n}+S_{b}\right)$ with $T(V)$ for the insulation layers, a maximum shear stress of 9.8 $\mathrm{MPa}$ is determined for the layers closer to the beam axis. 
Numerical evaluation. The stresses in the insulation layers of the outer corner region have also been investigated with a more refined 2-D, plane-stress finite element model (Fig. V.16), using the NASTRAN code. A shear load $V=785 \mathrm{kN}$ was imposed on the free end of the model, and the length of the straight segment was chosen such that at the interface with the curved segment a bending moment $M=480 \mathrm{kN} \cdot \mathrm{m}$ resulted. The normal force was disregarded. Figure V.17 shows the resultant levels of von Mises equivalent stress. Figure V.18 shows the normal stresses $\left(S_{b}\right)$ in the interface cross section, and Fig. V.19 shows the maximum shear stresses $[T(M+V)]$ in the same region. The numerical results for stresses in the copper are in fair agreement with the previous analytical estimate. Normal stresses in the insulation are somewhat higher than those predicted by simply scaling according to the ratio of the moduli. The shear stress distribution is confirmed to be a combination of the effects of the bending moment and the shear force. However, the maximum shear stress, about $11 \mathrm{MPa}$, is higher than the analytical result and is reached at the second insulation layer. Consideration of the normal force would increase this value only slightly.

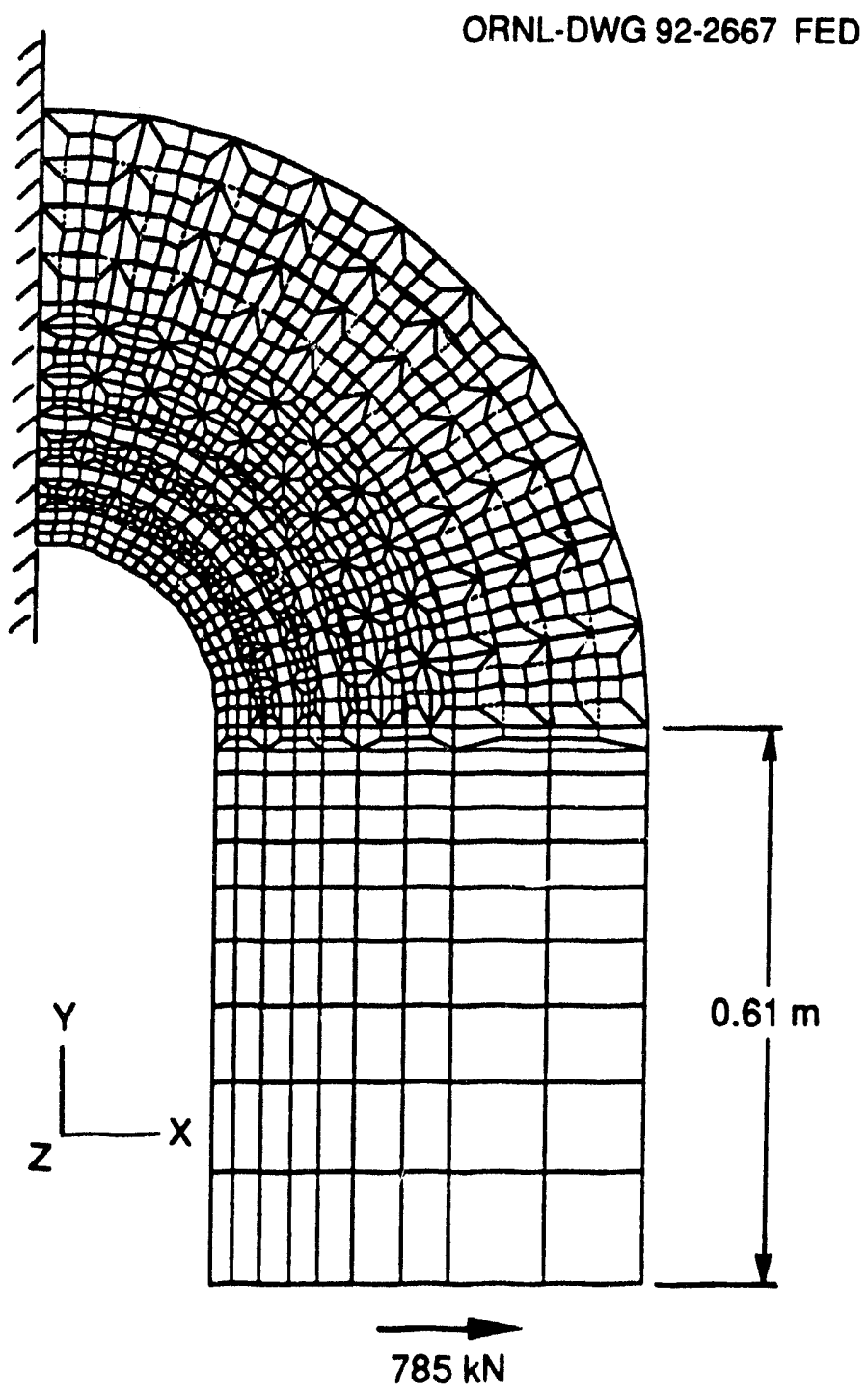

Fig. V.16. 2-D finite element model of outer corner. 


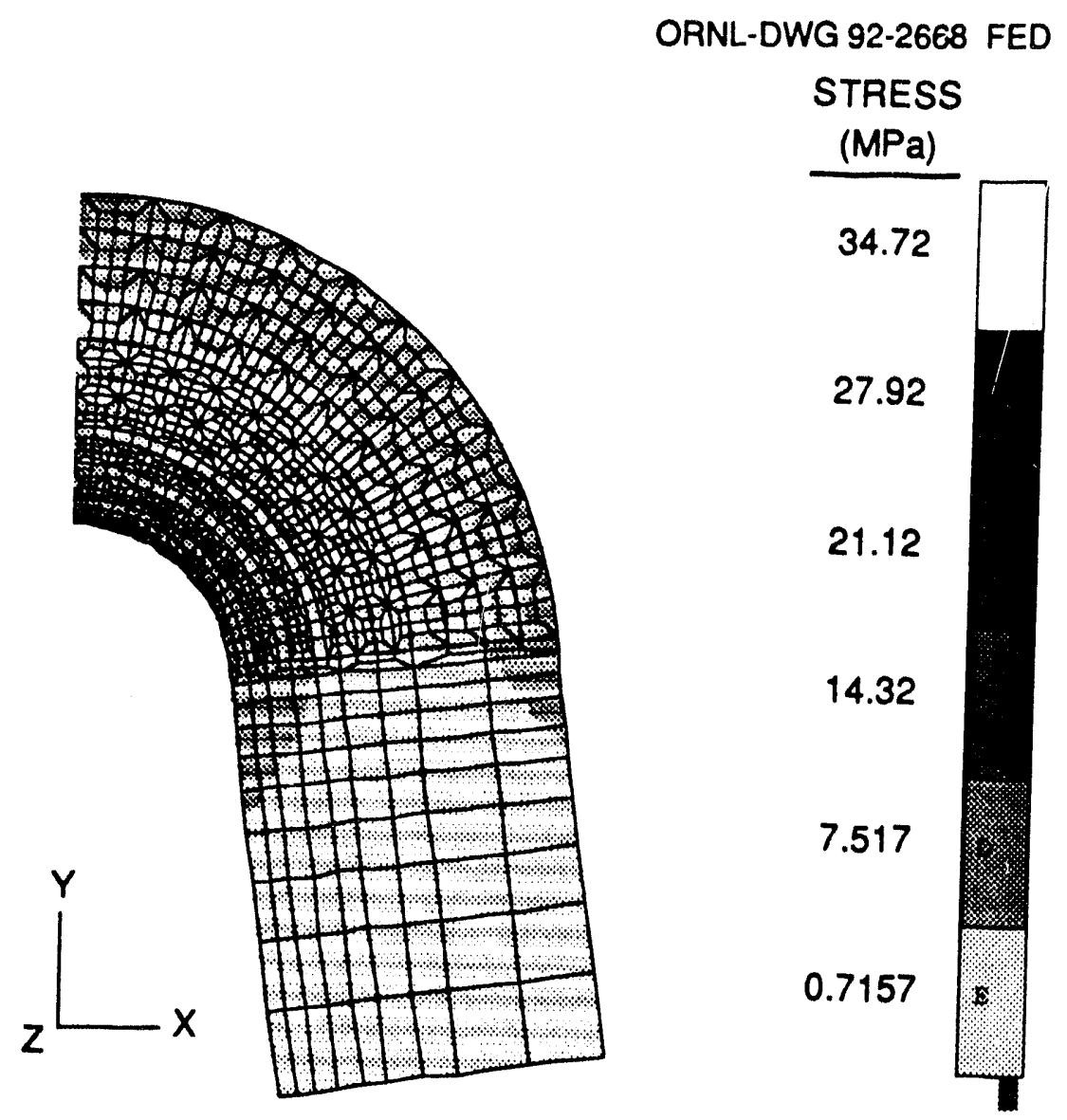

Fig. V.17. Distribution of von Mises stress.

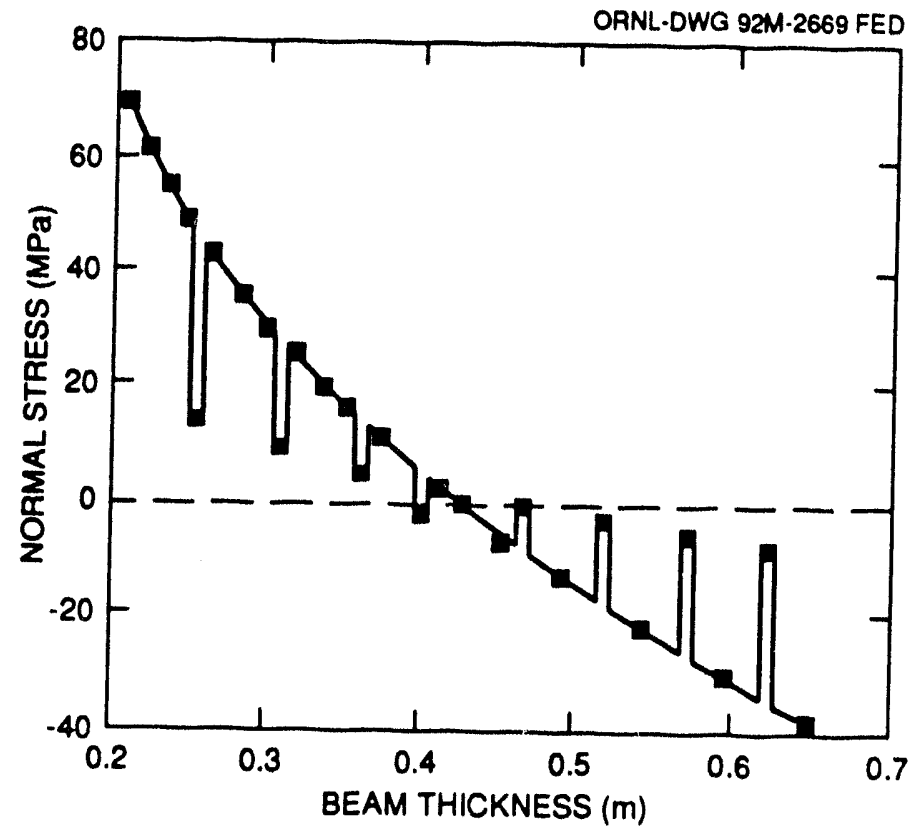

Fig. V.18. Normal stress through thickness. 


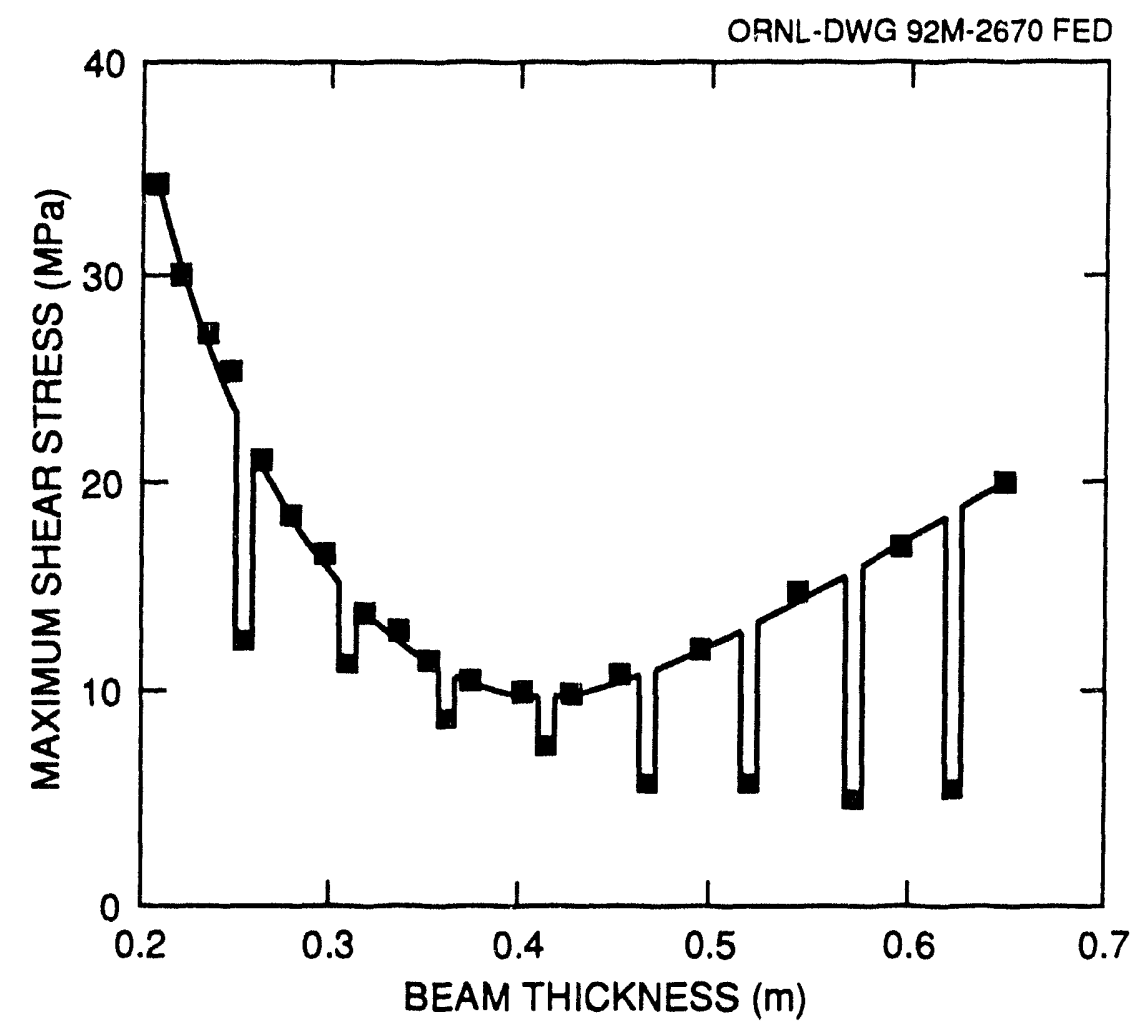

Fig. V.19. Maximum shear stress.

\section{Inclusion of rounded corners in the beam model}

The rectangular coil considered so far is a worst case in terms of bending moments at the outer corner. A more refined model (Fig. V.20) was examined with ANLEF. Loads have been calculated for the straight segments and then linearly interpolated along the curved segments. Figure V.21 shows displacements, bending moments, shear, and normal forces along the coil. The maximum bending moment is $310 \mathrm{kN} \cdot \mathrm{m}$, $35 \%$ smaller than the previous estimate. Hence, one can expect a proportionai reduction in stresses. The maximum shear will reach about $7 \mathrm{MPa}$ in the insulation and $30 \mathrm{MPa}$ in the copper.

\section{Upper/lower coil joints}

The joints between the horizontal legs and the $\mathrm{CC}$ constitute a key issue in the design of the TST TF coils. The proposed solution (Fig. V.22) consis s of two finger joints; the lower one is also employed to transfer the electrical current from one coil to another.

This type of solution has already been used in the ATF HF coils and has behaved satisfactorily, even if not exempt from problems with the insulation. An important difference is that the TST joints, unlike the ATF joints, must be periodically disassembled. Local plastification of the fingers or the bolts may not jeopardize the safety of the coil, given the low number of cycles required, but may complicate the disassembling process, because of excessive plastic deformation. Furthermore, in the attempt to achieve 


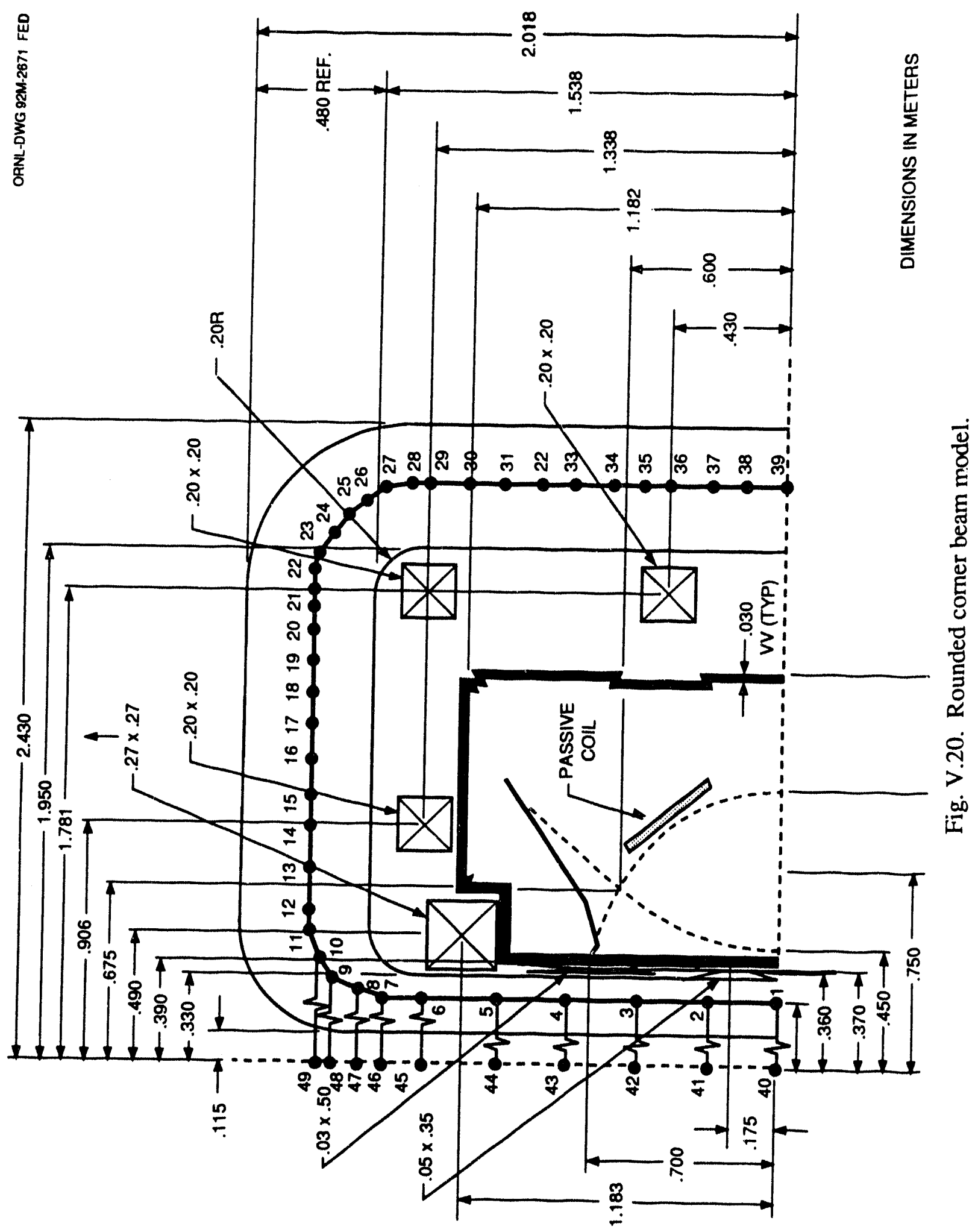


(a)

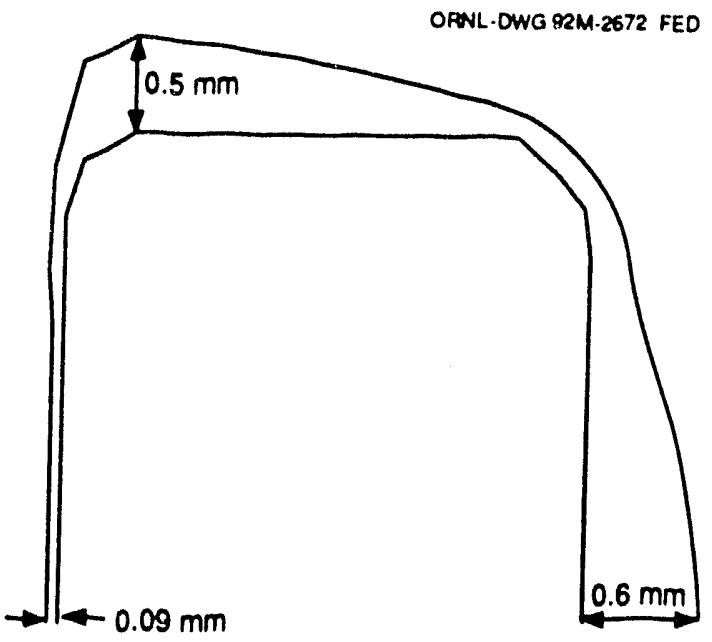

(b)

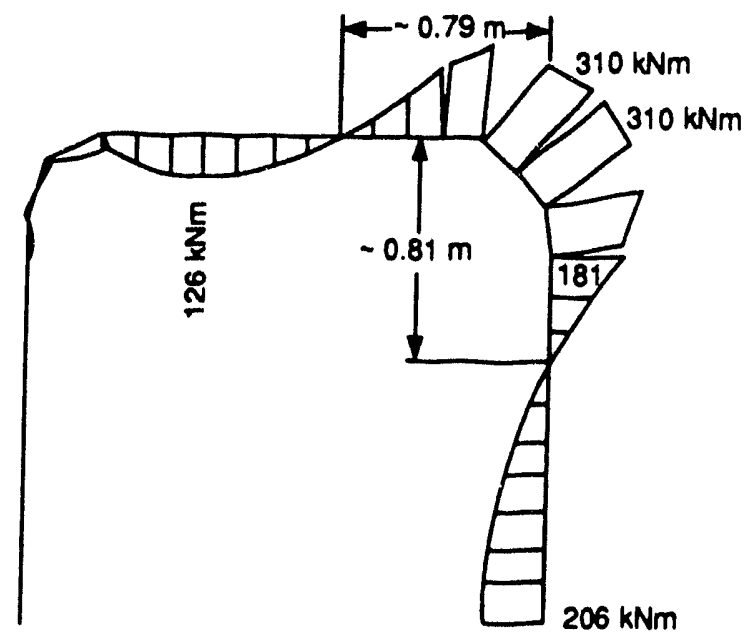

(c)

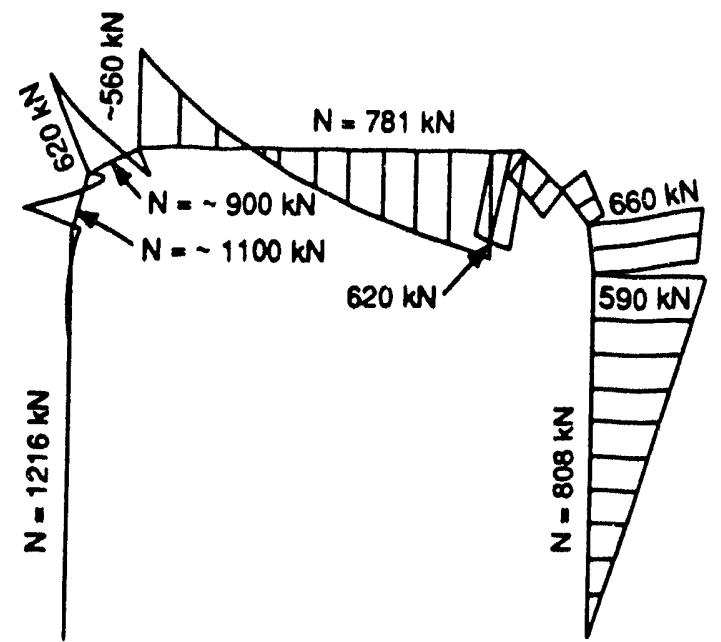

Fig. V.21. Rounded corner beam model results. (a) Displacements $\delta$. (b) Bending moments $-M$. (c) Shear $(V)$ and normal $(N)$ forces. 
ORNL-DWG 92-2673 FED

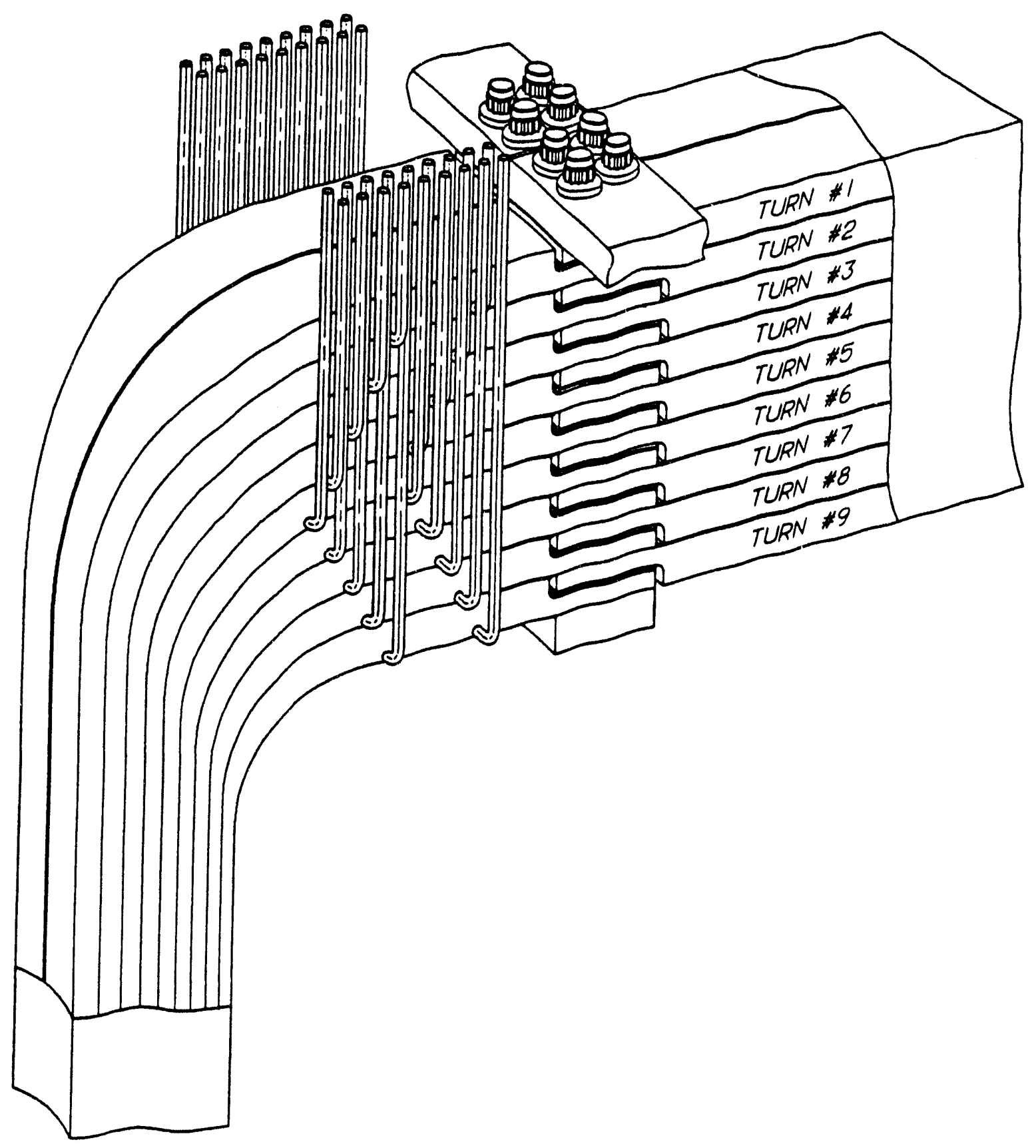

Fig. V.22. Upper/lower TF coil joint. 
enough contact pressure between the fingers, the insulation may be excessively squeezed.

The high number of turns and their disposition in the coil require a scrupulous design to avoid short circuits between the layers. Heating in the joints will be about four times higher than in the rest of the outer segment of the coil, and cooling in this region will not be as efficient as elsewhere.

Assessing the safety and reliability of the proposed joints will probably require relatively complex models, incorporating details of the geometry and nonlinearities due to friction and gaps. The alternative of an experimental model is not excluded.

Nevertheless, some brief calculations may be performed starting from the previous beam models.

Because space is needed for the pipes of the CC cooling system, the joints must be placed close to the region of maximum negative bending moment $(-126 \mathrm{kN} \cdot \mathrm{m}$, at a radius of about $70 \mathrm{~cm}$ ). The joint will also be under a traction of $780 \mathrm{kN}$. Because it is the derivative of the bending moment, the shear force in this region is obviously null.

Considering an effective cross-sectional area $A_{\text {eff }}=0.0321 \mathrm{~m}^{2}$ (a packing factor of $90 \%$ is assumed), for each side of the joint, there will be an average normal stress $S_{n}=$ $24 \mathrm{MPa}$ in the copper conductors. Due to the bending moment, a maximum stress of $13 \mathrm{MPa}$ will appear, yielding a combined maximum normal stress $S_{n}+S_{b}=37 \mathrm{MPa}$. Stress concentrations around the holes may well increase this value to a peak of about $100 \mathrm{MPa}$.

Another way to look at the load distribution among the fingers is to consider that, because of the bending moment, each one will carry a load $F_{i}$ such that

$$
\sum F_{i} \cdot y_{i}=M
$$

where $y_{i}$ is the distance from the $i$ th finger axis to the axis of the coil. If $F_{i}$ varies linearly with $y_{i}$, the result is a maximum force $F_{\max }(M)=144 \mathrm{MN}$ in the external fingers. Combining this with the force due to $N$, one has $F_{\max }(M+N)=231 \mathrm{kN}$, which, divided by the effective area of one finger, gives a maximum normal stress of about $38 \mathrm{MPa}$, close to the previous figure.

The shear stress in the bolts may be evaluated by considering the expression for the maximum shear stress in a beam of circular cross section,

$$
T_{\max }=\frac{4 V}{3 A}=\frac{A E_{\text {bolt }}(S+N)}{3 n A_{\text {bolt }}}
$$

where $n$ is the number of bolts in the joint. For $n=8, T_{\max }=76 \mathrm{MPa}$. Further, to shear the bolts, the loads $F_{i}(M+N)$ will provoke compression of the insulation jackets. For a sinusoidal distribution, the maximum compression is

$$
S=\frac{4 F_{\max }(M+N)}{\pi n h \phi}
$$

where $\phi$ is the diameter of the bolt and $h$ is the thickness of the finger. A compression of $30 \mathrm{MPa}$ is thus obtained.

In crder to reach a pressure contact $S_{\text {cont }}=30 \mathrm{MPa}$, a tension $S_{n}^{\text {bolt }}=190 \mathrm{MPa}$ must be imposed on the bolts (considering the ratio between the total cross-sectional 
area of the bolts, $A_{\text {bolts }}=0.0041 \mathrm{~m}^{2}$, and the net contact area between fingers, $A_{\text {cont }}=$ $0.0259 \mathrm{~m}^{2}$ ). Thus, the combination of normal and shear forces yields a maximum shear of about $120 \mathrm{MPa}$, indicating that a high-strength alloy must be selected.

Finally, one may consider the maximum load that could be resisted exclusively by friction between the fingers. For a conservative friction coefficient $\mu=0.1$, the friction load-carrying capacity is

$$
C=\mu A_{\text {cont }} S_{\text {cont }}=78 \mathrm{kN} \text {; }
$$

therefore, the friction alone will probably not be enough to withstand $F_{\max }(M+N)$.

\section{Summary of stress analysis results}

The following stresses can be tabulated based on the load conditions analyzed:

Central column

Hoop compression (conductors and insulation)

Vertical tension in the conductors

Vertical tension in the insulation

$$
\begin{aligned}
& S_{\text {hoop }}=-27 \mathrm{MPa} \\
& S_{Z}=29 \mathrm{MPa} \\
& S_{Z}=7 \mathrm{MPa} \\
& T_{\max }=18 \mathrm{MPa} \\
& S_{n}+S_{b}=60 \mathrm{MPa} \\
& T_{\max }=7 \mathrm{MPa} \\
& \\
& S_{n}+S_{b}=38 \mathrm{MPa} \\
& S_{\text {peak }} \sim 100 \mathrm{MPa} \\
& T_{\text {max }}=120 \mathrm{MPa} \\
& S_{n}=190 \mathrm{MPa}
\end{aligned}
$$

Maximum normal stress in the conductors

Maximum shear in the insulation

Finger joints

Normal stress in the fingers

Peak stress around the holes

Maximum shear in the bolts

Normal stress in the bolts

\section{Thermal performance}

Two 1.3-cm-diam cooling passages are required per turn to dissipate resistive heating during steady-state operation. The central core requires $4360 \mathrm{gal} / \mathrm{min}$ of $30^{\circ} \mathrm{C}$ cooling water. The return legs require $2030 \mathrm{gal} / \mathrm{min}$, for a total of $6390 \mathrm{gal} / \mathrm{min}$ for the system. The maximum temperature gradient through the conductor is $9^{\circ} \mathrm{C}$. Table V.4 summarizes the thermal-hydraulic data.

Table V.4. TF coil cooling data

\begin{tabular}{llll}
\hline & \multicolumn{1}{c}{ Core } & Return & Total \\
\hline Number of turns & 128 & 128 & 256 \\
Number of cooling paths & 256 & 256 & 512 \\
Passage diameter, in. & 0.527 & 0.402 & - \\
Path length, ft & 14.1 & 24 & - \\
Cooling load, Btu/h & $8 \times 10^{7}$ & $3.5 \times 10^{7}$ & $11 \times 10^{7}$ \\
Flow rate, gal/min & 4357 & 2028 & 6385 \\
Flow velocity, ft/s & 25 & 20 & - \\
Maximum copper temperature, ${ }^{\circ} \mathrm{F}$ & 176 & 138 & - \\
\hline
\end{tabular}




\section{V.4 PF COILS}

The PF magnet design parameters are listed in Tables V.5-V.7. The PF coil set has a total weight of 20.7 tonnes and a steady-state power requirement of $8.7 \mathrm{MW}$. The coil set consists of solenoid windings, shaping coils, divertor coils, and vertical field coils. The solenoid and vertical field coils will be powered in series, while asymmetric currents are required in the shaping and divertor coils for single-null plasma configurations. All coils will be wound from hollow-conductor, oxygen-free, high-conductivity (OFHC) copper with water cooling. Thermal-hydraulic properties of the coils are summarized in Table V.8. The electromagnetic loads and resulting stresses on the PF coils are relatively small because of the low current density, as described in Sect. V.6.

Table V.5. PF coil geometry data

\begin{tabular}{lrrrrrc}
\hline $\begin{array}{c}\text { Coil } \\
\text { number }\end{array}$ & $\begin{array}{c}R_{c} \\
(\mathrm{~cm})\end{array}$ & $\begin{array}{c}Z_{c} \\
(\mathrm{~cm})\end{array}$ & $\begin{array}{c}d r \\
(\mathrm{~cm})\end{array}$ & $\begin{array}{c}d z \\
(\mathrm{~cm})\end{array}$ & Volume $\left(\mathrm{cm}^{3}\right)$ & $\begin{array}{c}\text { Weight } \\
(\text { tonnes })\end{array}$ \\
\hline PF1 & 36.00 & 23.50 & 5.0 & 35.0 & $3.96 \times 10^{4}$ & 0.3 \\
PF2 & 37.00 & 77.50 & 3.0 & 65.0 & $4.53 \times 10^{4}$ & 0.3 \\
PF3 & 49.00 & 143.80 & 20.0 & 20.0 & $1.23 \times 10^{5}$ & 0.9 \\
PF4 & 111.00 & 143.80 & 20.0 & 20.0 & $2.79 \times 10^{5}$ & 2.1 \\
PF5 & 178.10 & 143.80 & 20.0 & 20.0 & $4.48 \times 10^{5}$ & 3.3 \\
PF6 & 178.10 & 43.00 & 20.0 & 20.0 & $4.48 \times 10^{5}$ & 3.3 \\
PF7 & 36.00 & -23.50 & 5.0 & 35.0 & $3.96 \times 10^{4}$ & 0.3 \\
PF8 & 37.00 & -77.50 & 3.0 & 65.0 & $4.53 \times 10^{4}$ & 0.3 \\
PF9 & 49.00 & -143.80 & 20.0 & 20.0 & $1.23 \times 10^{5}$ & 0.9 \\
PF10 & 111.00 & -143.80 & 20.0 & 20.0 & $2.79 \times 10^{5}$ & 2.1 \\
PF11 & 178.10 & -143.80 & 20.0 & 20.0 & $4.48 \times 10^{5}$ & 3.3 \\
PF12 & 178.10 & -43.00 & 20.0 & 20.0 & $4.48 \times 10^{5}$ & 3.3 \\
PF13a & 65.00 & -75.00 & 5.0 & 5.0 & & \\
PF14a & 65.00 & -95.00 & 5.0 & 5.0 & & \\
\hline
\end{tabular}

aPF13 and PF14 represent the top and bottom legs of the window-frame coils located in the divertor modules. 
Table V.6. PF coil operating parameters

\begin{tabular}{lrrrcc}
\hline $\begin{array}{c}\text { Coil } \\
\text { number }\end{array}$ & $\begin{array}{c}I_{\text {ss,max }} \\
(\mathrm{kA})\end{array}$ & $\begin{array}{c}I_{\text {peak }} \\
(\mathrm{kA})\end{array}$ & $\begin{array}{c}J_{\text {ss }} \\
\left(\mathrm{A} / \mathrm{cm}^{2}\right)\end{array}$ & $\begin{array}{c}J_{\text {peak }} \\
\left(\mathrm{A} / \mathrm{cm}^{2}\right)\end{array}$ & $\begin{array}{c}\text { Steady-state } \\
\text { power }(\mathrm{MW})\end{array}$ \\
\hline PF1 & 297.0 & 875.0 & 2106 & 6203 & 0.28 \\
PF2 & 344.0 & 650.5 & 1955 & 3697 & 0.31 \\
PF3 & 866.0 & 1331.0 & 3402 & 5299 & 1.81 \\
PF4 & 63.0 & 470.8 & 163 & 1215 & 0.01 \\
PF5 & 107.0 & 339.0 & 276 & 875 & 0.07 \\
PF6 & 377.0 & 377.0 & 1261 & 1261 & 1.06 \\
PF7 & 297.0 & 875.0 & 2106 & 6203 & 0.28 \\
PF8 & 344.0 & 650.5 & 1955 & 3697 & 0.31 \\
PF9 & 866.0 & 1331.0 & 4889 & 7514 & 1.54 \\
PF10 & 63.0 & 470.8 & 163 & 1215 & 0.01 \\
PF11 & 134.0 & 339.0 & 1580 & 3997 & 1.89 \\
PF12 & 430.0 & 430.0 & 1439 & 1439 & 1.38 \\
PF13a & 30.0 & 30.0 & 1412 & 1412 & \\
PF14 ${ }^{a}$ & 30.0 & 30.0 & 1412 & 1412 & \\
\hline
\end{tabular}

${ }^{\circ}$ PF13 and PF14 represent the top and bottom legs of the window-frame coils located in the divertor modules. 
Table V.7. PF coil startup currents

\begin{tabular}{|c|c|c|c|c|}
\hline \multirow{2}{*}{$\begin{array}{c}\text { Coil } \\
\text { number }\end{array}$} & \multicolumn{4}{|c|}{ Currents in PF coils (kA) } \\
\hline & $t=0$ & $t=0.5$ & $t=0.75$ & $t \geq 1$ \\
\hline \multicolumn{5}{|c|}{ Single null, $A=2.5$} \\
\hline PF1 & -875.0 & 180.0 & 196.0 & 290.0 \\
\hline PF2 & -650.5 & 152.0 & 241.0 & 344.0 \\
\hline PF3 & -208.2 & -1175.0 & -921.0 & -724.0 \\
\hline PF4 & 0.0 & 0.0 & 0.0 & 0.0 \\
\hline PF5 & -312.0 & -187.0 & -62.0 & -107.0 \\
\hline PF6 & 150.6 & 214.0 & 361.0 & 377.0 \\
\hline PF7 & -875.0 & 180.0 & 196.0 & 290.0 \\
\hline PF8 & -650.5 & 152.0 & 241.0 & 344.0 \\
\hline PF9 & -208.2 & -1116.0 & -805.0 & -643.0 \\
\hline PF10 & -470.8 & 2.0 & -21.0 & 21.0 \\
\hline PF11 & -312.0 & 215.0 & -49.0 & -134.0 \\
\hline PF12 & 150.6 & 243.0 & 404.0 & 430.0 \\
\hline PF13 & 0.0 & -30.0 & -30.0 & -30.0 \\
\hline PF14 & 0.0 & 30.0 & 30.0 & 30.0 \\
\hline \multicolumn{5}{|c|}{ Double null, $A=2.5$} \\
\hline PF1 & -875.0 & 186.0 & 203.0 & 297.0 \\
\hline PF2 & -650.5 & 152.0 & 232.0 & 337.0 \\
\hline PF3 & -208.2 & -1331.0 & -1025.0 & -866.0 \\
\hline PF4 & -470.8 & -65.0 & -107.0 & -63.0 \\
\hline PF5 & -312.0 & 339.0 & 130.0 & 41.0 \\
\hline PF6 & 150.6 & 198.0 & 339.0 & 365.0 \\
\hline PF7 & -875.0 & 186.0 & 203.0 & 297.0 \\
\hline PF8 & -650.5 & 149.0 & 232.0 & 337.0 \\
\hline PF9 & -208.2 & -1331.0 & -1025.0 & -866.0 \\
\hline PF10 & -470.8 & -65.0 & -107.0 & -63.0 \\
\hline PF11 & -312.0 & 339.0 & 130.0 & 41.0 \\
\hline PF12 & 150.6 & 198.0 & 339.0 & 365.0 \\
\hline PF13 & 0.0 & 0.0 & 0.0 & 0.0 \\
\hline PF14 & 0.0 & 0.0 & 0.0 & 0.0 \\
\hline
\end{tabular}


Table V.8. PF coil thermal data

\begin{tabular}{lcclrrrrr}
\hline $\begin{array}{c}\text { Coil } \\
\text { number }\end{array}$ & $\begin{array}{c}\text { Number } \\
\text { of turns }\end{array}$ & $\begin{array}{c}\text { Cooling } \\
\text { paths }\end{array}$ & $\begin{array}{c}\text { Passage } \\
\text { diameter } \\
\text { (in.) }\end{array}$ & $\begin{array}{c}\text { Path } \\
\text { length } \\
\text { (ft) }\end{array}$ & $\begin{array}{c}\text { Cooling } \\
\text { load } \\
(\mathrm{Btu} / \mathrm{h})\end{array}$ & $\begin{array}{c}\text { Flow rate } \\
(\mathrm{gal} / \mathrm{min})\end{array}$ & $\begin{array}{c}\text { Flow } \\
\text { velocity } \\
(\mathrm{ft} / \mathrm{s})\end{array}$ & $\begin{array}{c}\text { Maximum } \\
\text { copper } \\
\text { temperature } \\
\left({ }^{\circ} \mathrm{F}\right)\end{array}$ \\
\hline PF1 & 20 & 2 & 0.625 & 74 & 959,000 & 38.3 & 20 & 152.8 \\
PF2 & 20 & 2 & 0.5 & 76 & $1,060,000$ & 33.1 & 27 & 178.9 \\
PF3 & 20 & 2 & 1.25 & 101 & $6,160,000$ & 206.8 & 27 & 180.4 \\
PF4 & 4 & 1 & 0.5 & 92 & 49,000 & 3.1 & 5 & 125.5 \\
PF5 & 2 & 1 & 1 & 73 & 223,000 & 61.3 & 25 & 102.9 \\
PF6 & 40 & 8 & 0.75 & 184 & $3,620,000$ & 220.6 & 20 & 127.3 \\
PF7 & 20 & 2 & 0.625 & 74 & 959,000 & 38.3 & 20 & 152.8 \\
PF8 & 20 & 2 & 0.5 & 76 & $1,060,000$ & 33.1 & 27 & 178.9 \\
PF9 & 20 & 3 & 1.25 & 40 & $5,260,000$ & 287.2 & 25 & 166.1 \\
PF10 & 4 & 1 & 0.5 & 92 & 49,000 & 3.1 & 5 & 125.5 \\
PF11 & 2 & 2 & 1.25 & 147 & $6,450,000$ & 191.5 & 25 & 179.0 \\
PF12 & 40 & 8 & 0.75 & 184 & $4,720,000$ & 220.6 & 20 & 138.6 \\
Totals & - & 34 & - & - & $30,569,000$ & 1336.9 & - & - \\
\hline
\end{tabular}




\section{V.5 VACUUM VESSEL}

A continuous, thin-walled cylindrical structure is proposed for the plasma chamber. The primary design requirements are that it fit within the envelope of the PF coils without capture, satisfy electrical toroidal resistance requirements, and be water-cooled for steady-state operation. Table V.9 summarizes the design requirements.

The proposed design consists of inner and outer cylinders connected by flat circular plates on top and bottom (Fig. V.23). The inner cylinder is integral with the TF coil core assembly and is replaced when reconfiguring the device from low to high aspect ratio. The outer portion of the vessel is used for all configurations. The walls are composed of face sheets separated by poloidal rib stiffeners or, optionally, by a thick wall with a dimpled plate-type water jacket. The outer cylinder has 24 ports with additional access in the top/bottom plates for diagnostics.

Preliminary calculations indicate that there is sufficient strength for vacuum and disruption loads, if major structural loads are bridged around the vessel. Table V.10 summarizes the main design parameters for the vacuum vessel.

Table V.9. Vacuum vessel design requirements

\begin{tabular}{lllll}
\hline & \multicolumn{4}{c}{ Aspect ratio } \\
\cline { 2 - 5 } Parameter & \multicolumn{1}{c}{3.2} & 2.5 & \multicolumn{1}{c}{2.2} & \multicolumn{1}{c}{1.8} \\
\hline Major radius, m & 0.80 & 0.75 & 0.538 & 0.675 \\
Minor radius, m & 0.25 & 0.30 & 0.25 & 0.375 \\
$\quad$ Inner cylinder & 5 & 5 & 5 & 5 \\
$\quad L / R$ time, ms & & & & \\
$\quad$ Outer cylinder & 50 & 50 & 50 & 50 \\
$\quad L / R$ time, ms & & & & \\
Operating temperature, ${ }^{\circ} \mathrm{C}$ & $20-80$ & $20-80$ & $20-80$ & $20-80$ \\
Bakeout temperature, ${ }^{\circ} \mathrm{C}$ & 350 & 350 & 350 & 350 \\
Steady-state heat load, $\mathrm{MW}$ & 4.8 & 5.3 & 3.2 & 4.0 \\
Distribution (MW) & & & & \\
Inboard & 2.9 & 3.2 & 1.9 & 2.4 \\
$\quad$ Top & 0.3 & 0.3 & 0.2 & 0.2 \\
$\quad$ Outboard & 1.4 & 1.6 & 1.0 & 1.2 \\
$\quad$ Bottom & 0.3 & 0.3 & 0.2 & 0.2 \\
\hline
\end{tabular}


ORNL-DWG 92-2674 FED

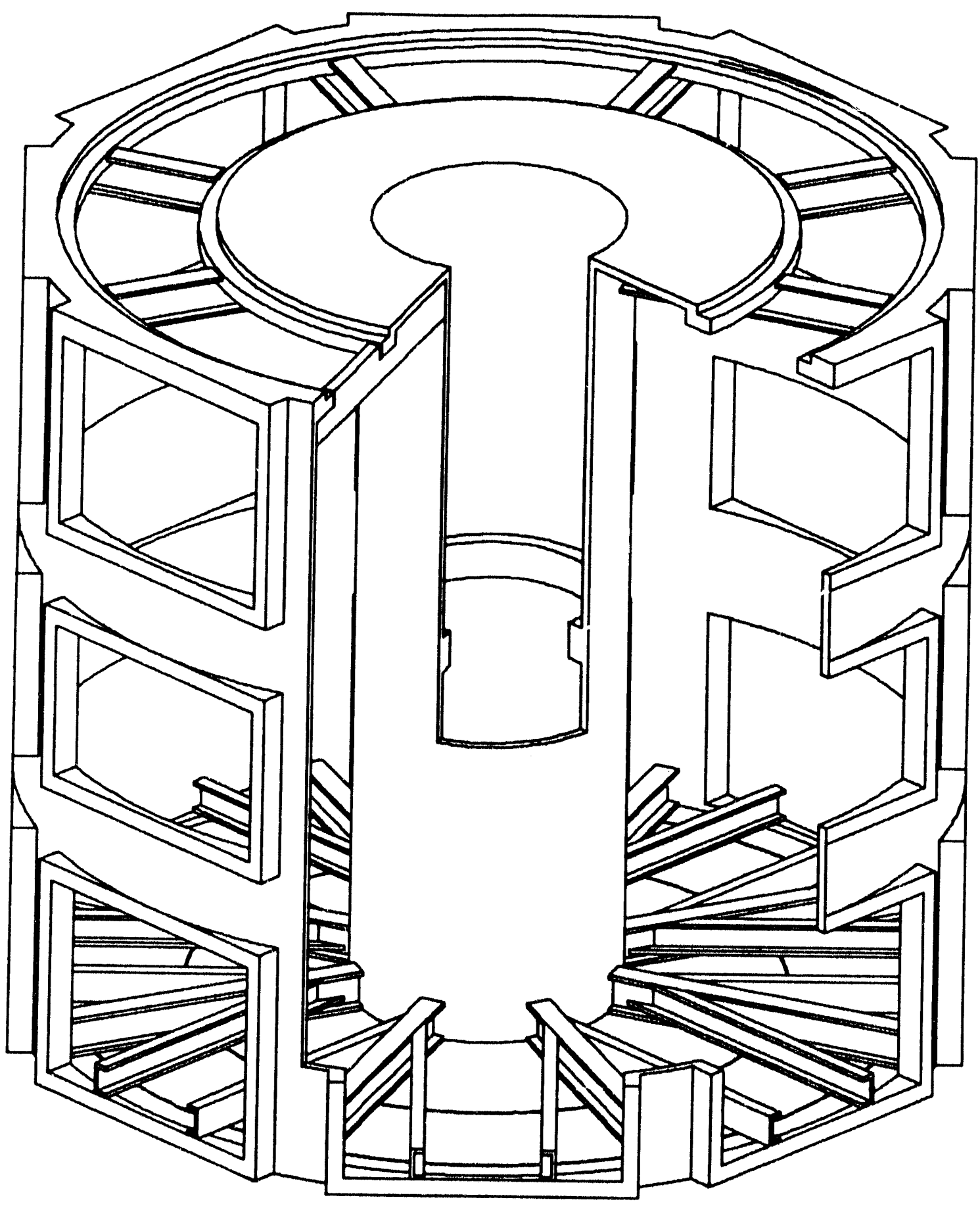

Fig. V.23. Vacuum vessel. 
Table V.10. Vacuum vessel design parameters

\begin{tabular}{lllll}
\hline & \multicolumn{5}{c}{ Aspect ratio } \\
\cline { 2 - 5 } \multicolumn{1}{c}{ Parameter } & 3.2 & 2.5 & 2.2 & 1.8 \\
\hline Major radius, m & 0.800 & 0.750 & 0.538 & 0.675 \\
Minor radius, m & 0.250 & 0.300 & 0.250 & 0.375 \\
Inner cylinder mean radius, m & 0.505 & 0.405 & 0.243 & 0.255 \\
Outer cylinder mean radius, m & 1.470 & 1.470 & 1.470 & 1.470 \\
Section thickness, m & & & & \\
$\quad$ Vessel wall & 0.006 & 0.006 & 0.006 & 0.006 \\
$\quad$ Cooling passage & 0.006 & 0.006 & 0.006 & 0.006 \\
$\quad$ Vessel wall & 0.096 & 0.006 & 0.006 & 0.006 \\
$\quad$ Gap & 0.002 & 0.002 & 0.002 & 0.002 \\
$\quad$ Graphite tile & 0.010 & 0.010 & 0.010 & 0.010 \\
Height, m & 1.182 & 1.182 & 1.182 & 1.182 \\
Inner cylinder heating, MW & 2.9 & 3.2 & 1.9 & 2.4 \\
Minimum water flow rate, & 498 & 549 & 326 & 412 \\
$\quad$ inner cylinder, gal/min & & & & \\
Outer cylinder heating, MW & 1.9 & 2.1 & 1.3 & 1.6 \\
Minimum water flow rate, & 326 & 360 & 223 & 274 \\
$\quad$ outer cylinder, gal/min & & & & \\
\hline
\end{tabular}

\section{V.6 SUPPORT STRUCTURE}

A steel support structure is required to react electromagnetic and gravity loads for all coils and to bridge major loads around the vacuum vessel. It is proposed to use a cylindrical frame composed of box-beam rings connected by vertical posts in the bore of each TF coil (Fig. V.24). This arrangement will minimize interference with and allow access to the divertor ports.

The torque produced by the out-of-plane forces acting on the TF coils will provoke bending in the beams that compose the external supporting frame. Therefore, to reduce the twisting of the central core, this frame must be as rigid as possible. For the same reason, the innermost lateral supports of the TF coils should be placed as close as possible to the core. A compromise between this requirement and those of the cooling system and of vertical access for diagnostics is required.

A preliminary structural analysis has been performed using electromagnetic loads for several normal operating scenarios, as given in Table V.11 and Fig. V.25. Results indicate that when composed of $1.3-\mathrm{cm}$-thick beam sections, the support structure will deflect approximately $1.5 \mathrm{~mm}$ and experience von Mises stress due to torsion and bending of $26 \mathrm{MPa}$ ( $3.8 \mathrm{ksi})$. This is illustrated in Fig. V.26, which shows finite element centroidal stresses for an $A=2.5$, DN plasma operating scenario. 
ORNL-DWG 92-2675 FED

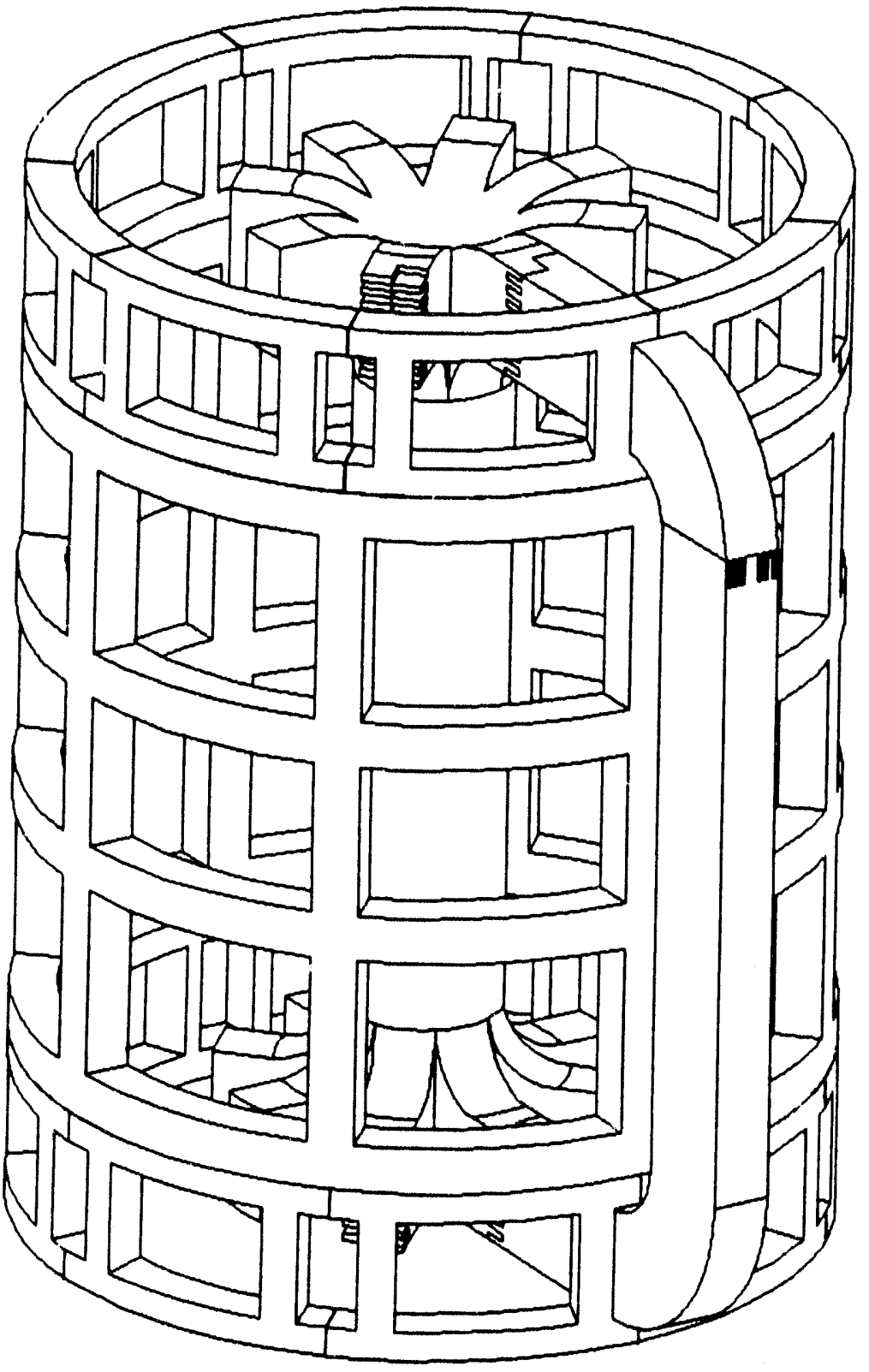

Fig. V.24. TF and PF coil support structure. 
Table V.11. Electromagnetic loads on support structure

\begin{tabular}{|c|c|c|c|c|c|}
\hline \multirow{3}{*}{$\begin{array}{c}\text { Coil } \\
\text { number }\end{array}$} & \multirow{3}{*}{$\begin{array}{l}\text { Circum. } \\
\text { length }(m)\end{array}$} & \multicolumn{4}{|c|}{ Total vertical load $(\mathrm{kN})$} \\
\hline & & \multicolumn{2}{|c|}{$A=2.5$} & \multicolumn{2}{|c|}{$A=1.8$} \\
\hline & & DN & SN & $\mathrm{DN}$ & SN \\
\hline PF1 & 2.26 & +0.72 & +2.77 & 0 & 0 \\
\hline PF2 & 2.32 & -9.32 & -22.34 & 0 & 0 \\
\hline PF3 & 3.08 & +11.36 & +31.52 & -4.46 & +1.63 \\
\hline PF4 & 5.69 & -0.43 & -0.86 & 0 & -2.74 \\
\hline PF5 & 11.19 & -1.58 & +133.85 & 0 & -14.71 \\
\hline PF6 & 11.19 & -31.33 & -365.12 & -19.14 & -0.84 \\
\hline PF7 & 2.26 & -0.72 & -2.76 & 0 & 0 \\
\hline PF8 & 2.32 & +9.32 & +10.41 & 0 & 0 \\
\hline PF9 & 3.08 & -11.36 & -38.31 & +4.44 & -3.17 \\
\hline PF10 & 5.69 & +0.43 & -4.30 & 0 & +3.54 \\
\hline PF11 & 11.19 & +1.58 & -20.30 & 0 & +23.24 \\
\hline PF12 & 11.19 & +31.41 & +262.29 & +19.14 & -5.66 \\
\hline
\end{tabular}

ORNL-DWG 92-2676 FED
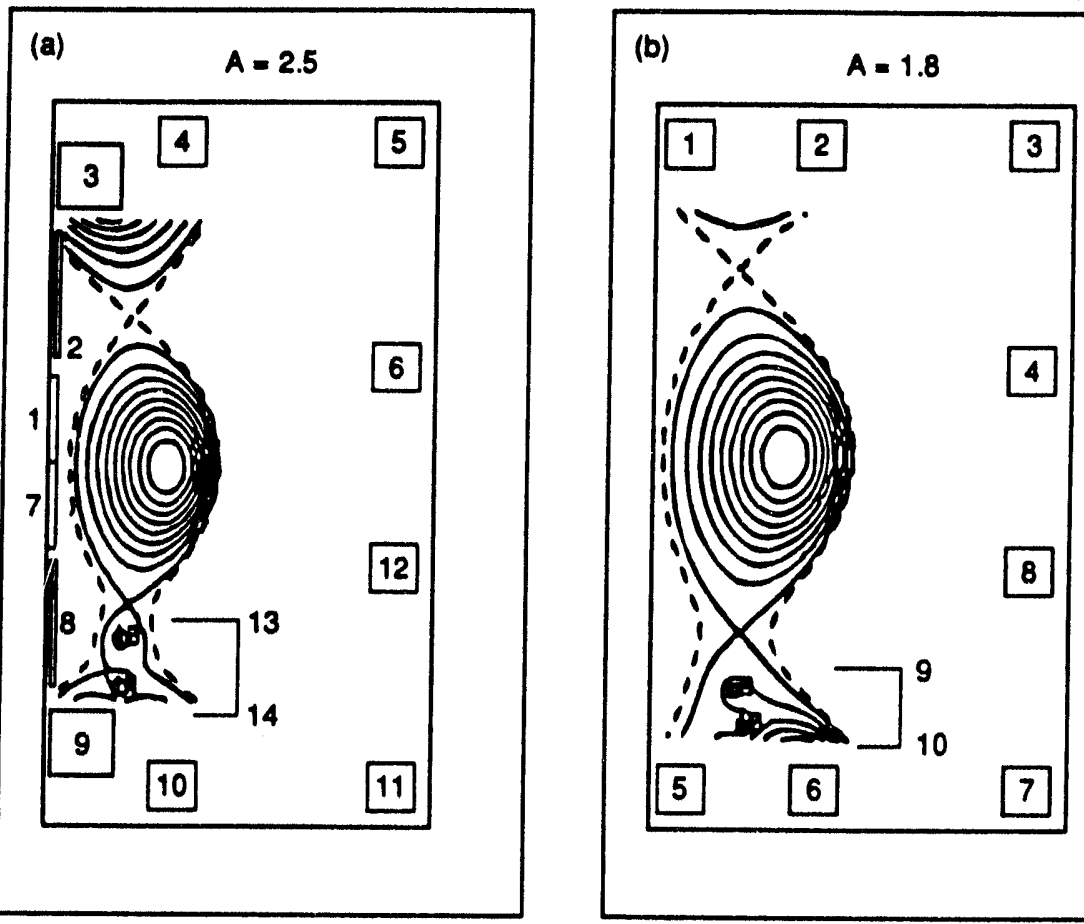

Fig. V.25. Model for electromagnetic analysis of support structure. 
ORNL.DWG 92.2677 FED

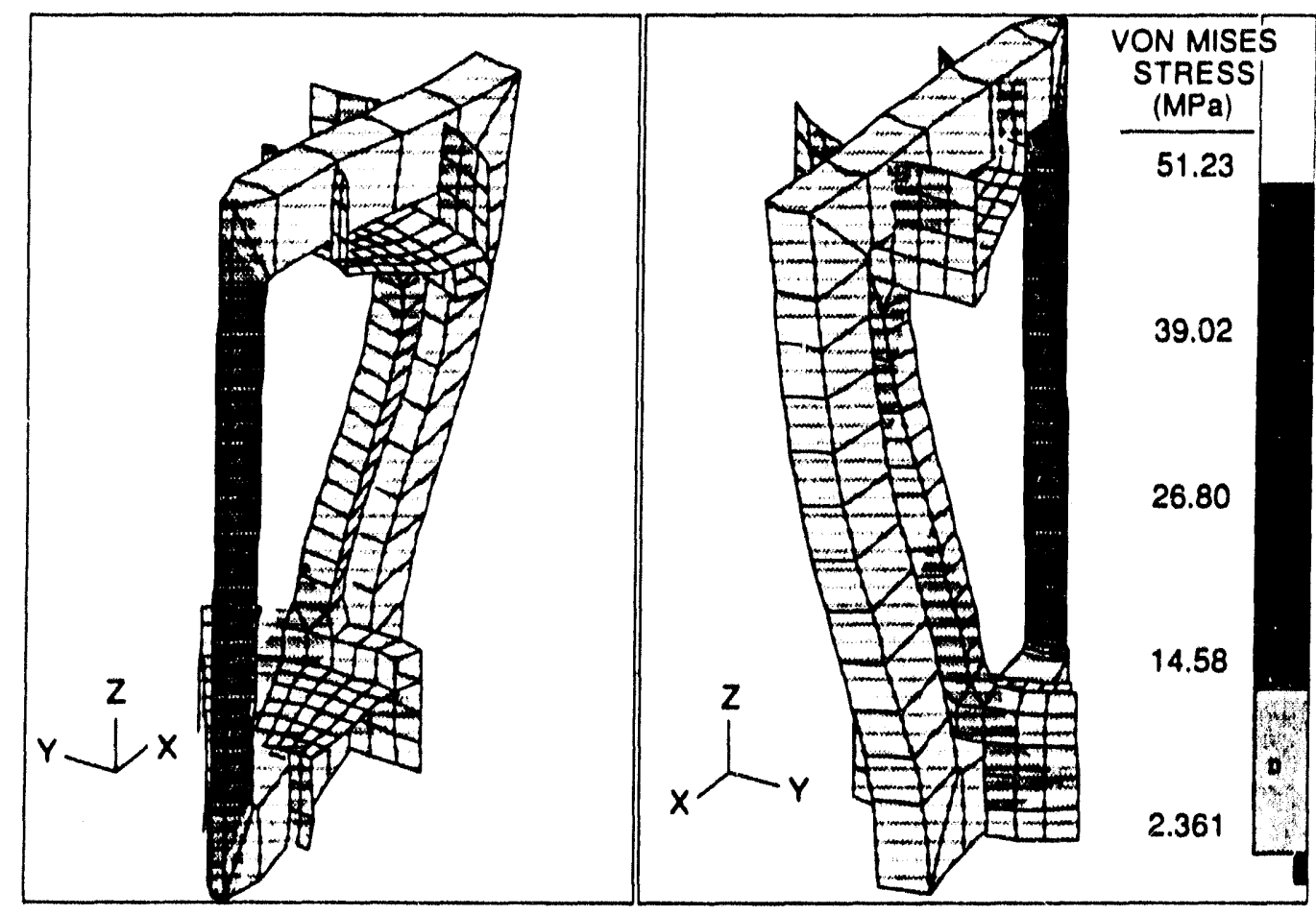

Fig. V.26. Deflection and stress due to electromagnetic loads.

In this configuration, the upper and lower PF coil supports work as cantilever beams, which under fault condition loading may not provide sufficient vertical stiffness. Future design activity will focus on developing options such as a grill of interconnected plates to provide increased rigidity while still maintaining modular assembly characteristics.

\section{V.7 DEVICE LOCATION}

The TST device can be located in the high bay of Building 9201-2 at the Oak Ridge Y-12 Plant, just west of the existing ATF facility. As shown in Figs. V.27-V.29, this location provides adequate space for radial insertion and withdrawal of the divertor cassettes and for all diagnostic and heating systems. The device will be centered over existing large columns to take the estimated weight. An additional reinforced concrete $\mathrm{pad}, 2 \mathrm{ft}$ thick, will be required to span the gap between columns. In addition to the pad, a concrete block enclosure will be required; it will use the existing wall of the high bay and the ATF enclosure wall as the south and east boundaries, respectively. Two 20-tonne capacity cranes are available for device assembly and maintenance.

All coil power supplies are located inside Building 9201-2 except the TF power supply, which is in a separate building immediately to the east. The heating power supplies (NBI, ICH, LH, and ECH) are all in Building 9201-2. Figures V.29 and V.30 show the power supply locations. 


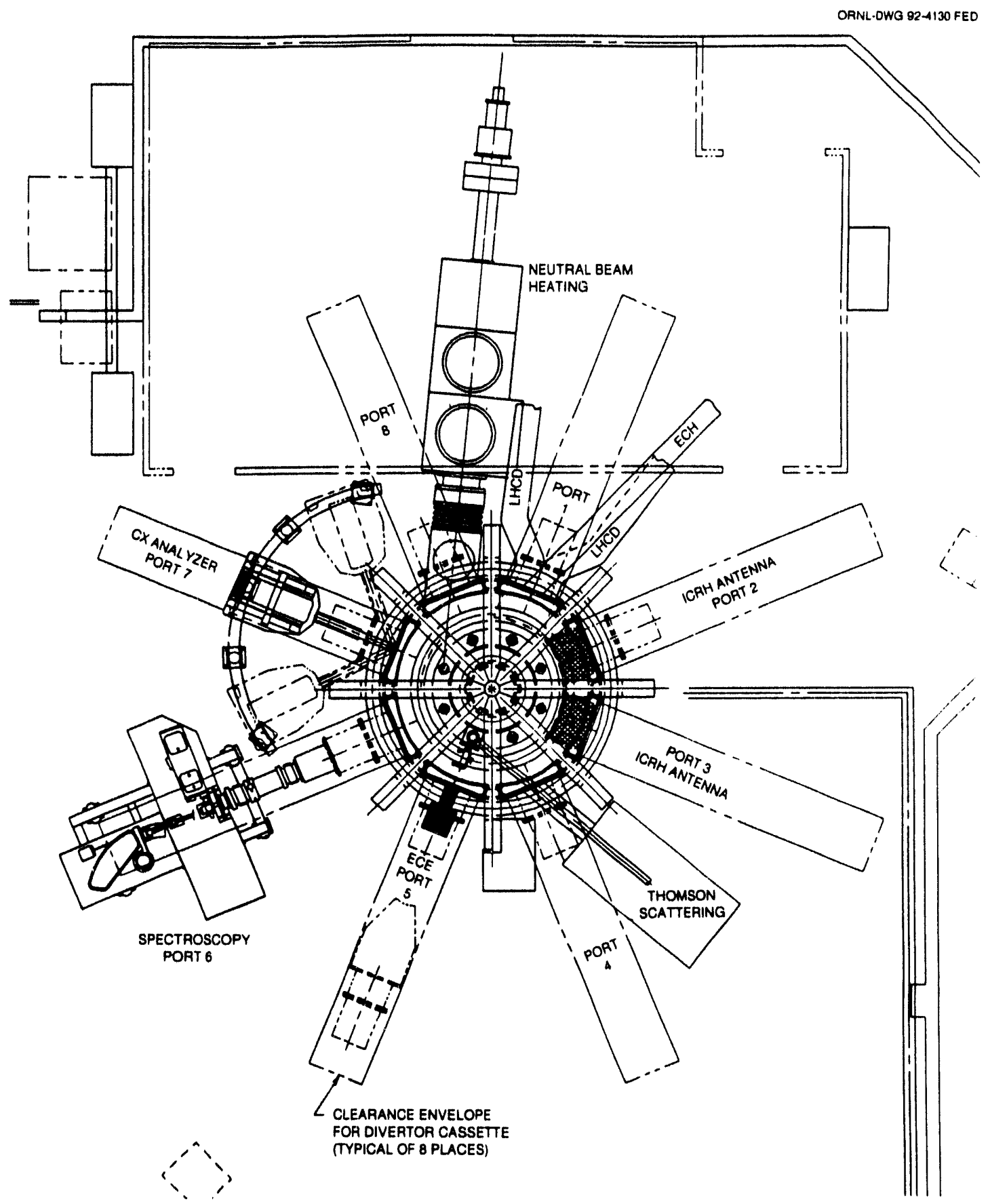

Fig. V.27. Plan view of TST in enclosure. 


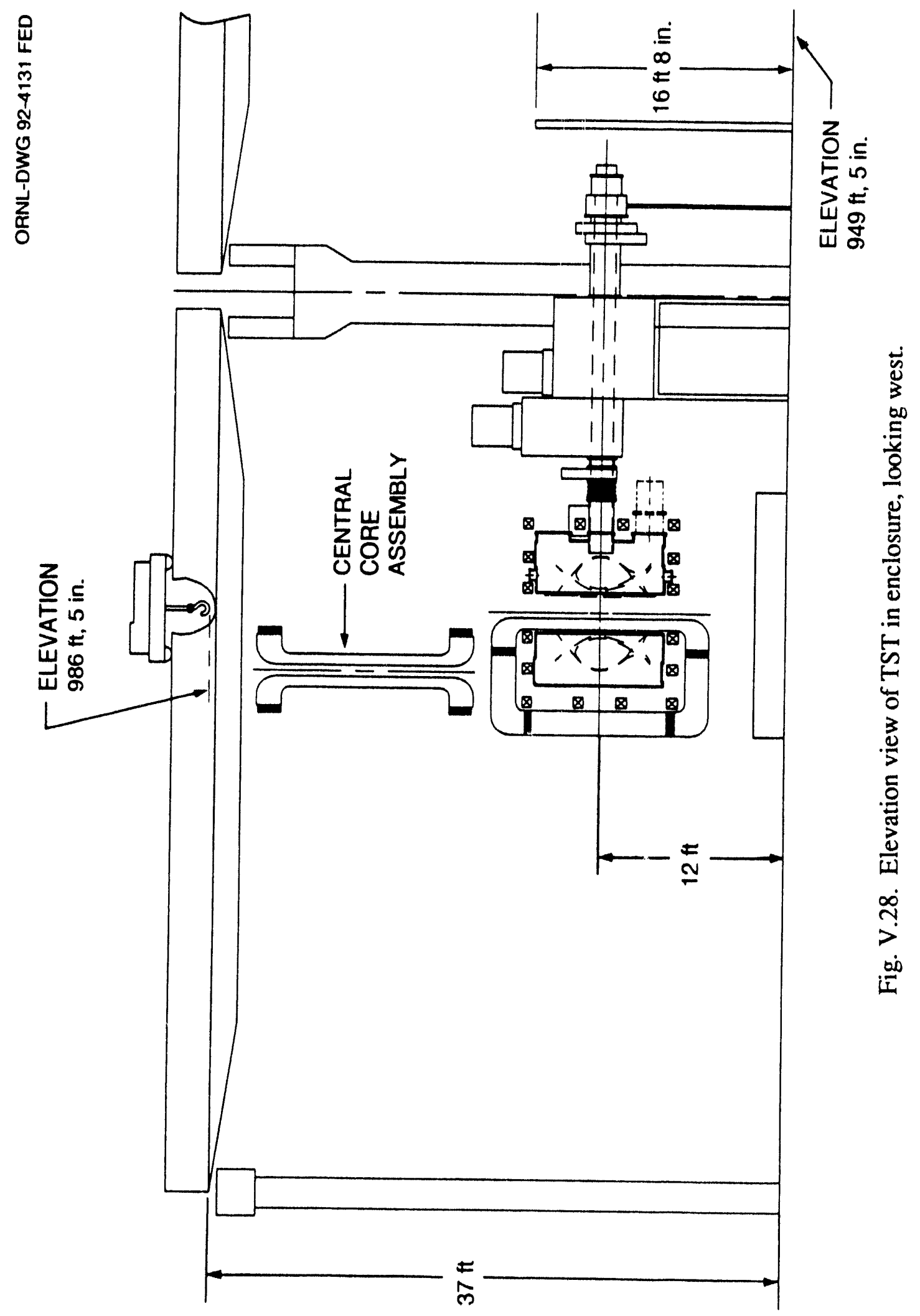




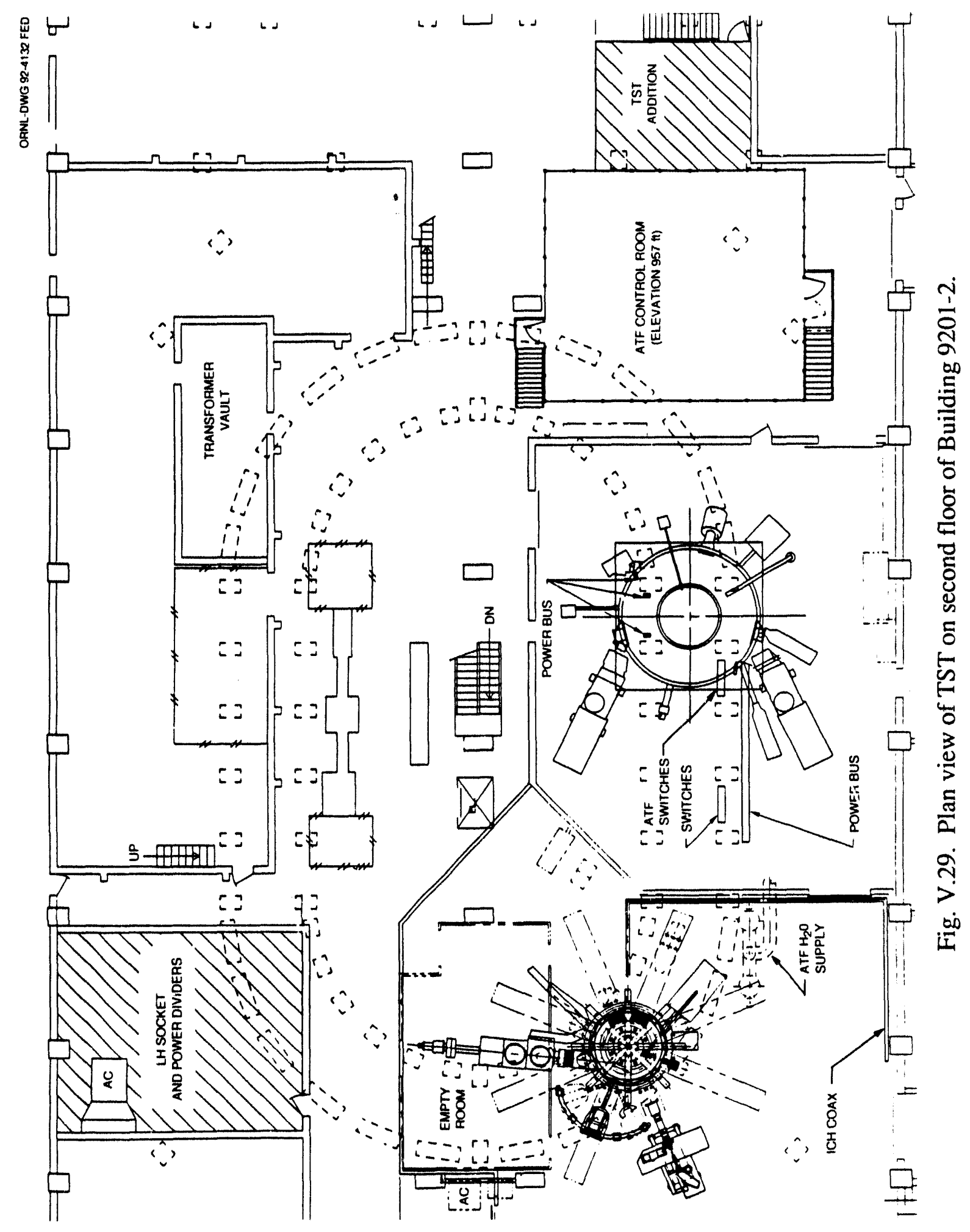




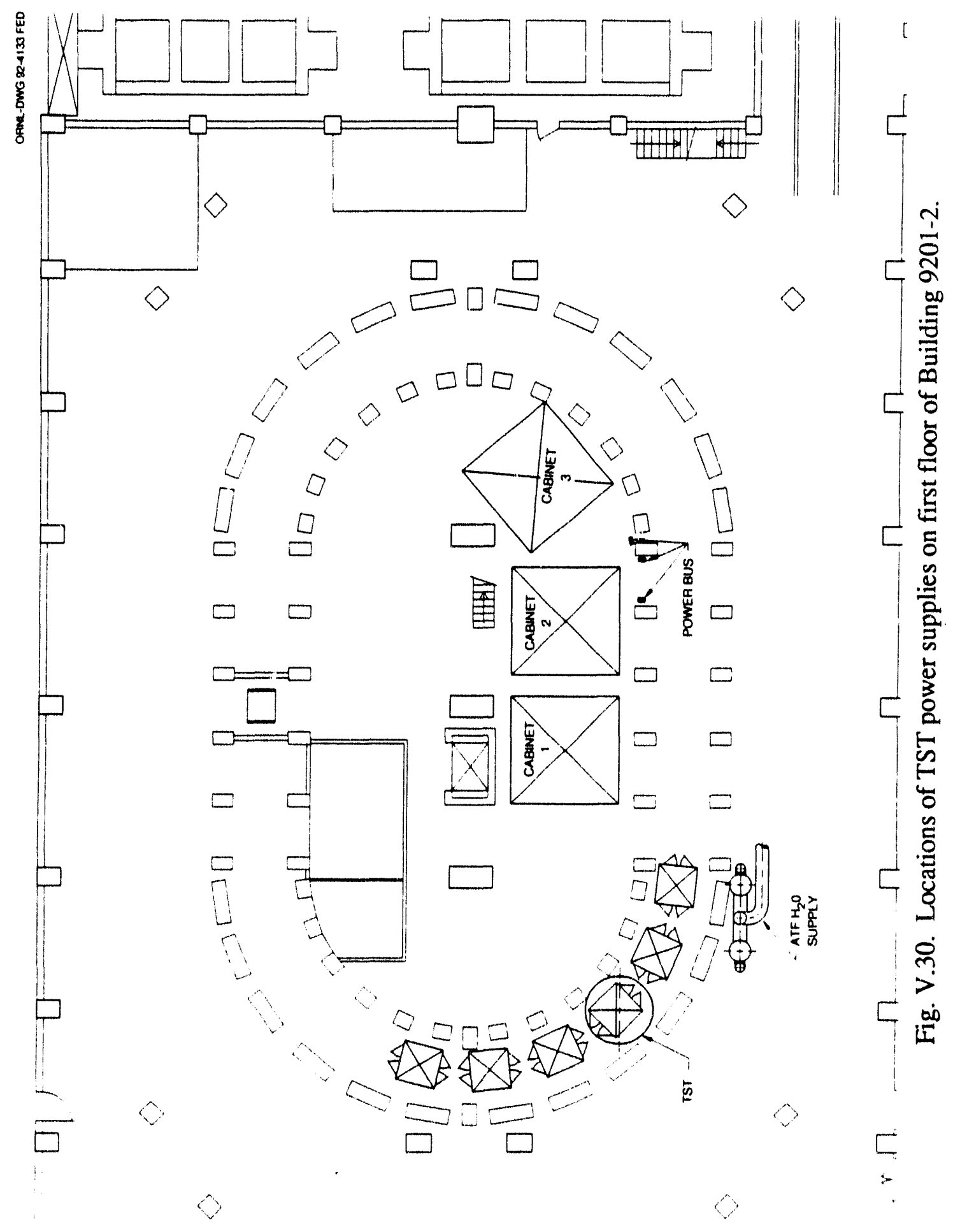




\section{ANCILLARY SYSTEMS}

This chapter contains descriptions of the ancillary systems, which include device support facilities, such as the coil power supplies and water cooling system, and experimental support systems and facilities, such as the diagnostics and control room. The TST device has been conceived to take advantage of as many existing facilities and systems as possible; those at ORNL are used here.

\section{VI.1 POWER SUPPLIES}

Existing power supplies owned by ORNL's Fusion Energy Division were evaluated to determine their compatibility as magnet power supplies for the coils as proposed for the TST device. Power supply voltage and current ratings were matched to the ampere-turn requirements of the TF coil set and the $12 \mathrm{PF}$ coils to determine a satisfactory number of turns for each coil. The power supplies included in this study were the ATF HF power supply, ATF's three vertical field power supplies, and six power supplies on standby from the International Fusion Superconducting Magnet Test Facility (IFSMTF), also known as the Large Coil Test Facility (LCTF).

\section{VI.1.1 Toroidal Field}

ATF's HF power supply was designed to operate at $62.5 \mathrm{kA}$ on a continuous duty cycle with only moderate modifications to existing equipment. This is readily compatible with TF coils consisting of nine turns each. With relatively minor additional changes, this power supply could provide the $64.5 \mathrm{kA}$ required for eight-turn coils. The modifications involve replacement of current shunts and the addition of fan cooling to the rectifier transformers. In either case, the bus between the power supply and the TST device would have to be upgraded from the existing 30-kA nominal continuous rating. Most of the modifications of the power supply and the upgrade of the bus are planned as part of the ATF steady-state operation program.

\section{VI.1.2 Poloidal Field}

The $12 \mathrm{PF}$ coils presented a more challenging exercise in determining power supply compatibilities. Six of the coils could be arranged in three sets of two coils in series, each driven by one power supply. The remaining six coils require some degree of independence and, therefore, dedicated power supplies.

The attempt to match the three ATF vertical field power supplies to the most likely TST coil sets resulted in requirements for a larger than acceptable number of turns in the coils. The ATF power supplies are basically high-voltage, low-current supplies when rated for steady state. Modifications necessary to upgrade these power supplies to the steady-state requirements of TST are more costly than could be justified when compared to the procurement of three new supplies built to specifications. If the existing supplies were modified, they would no longer be compatible with ATF, as operated in the past. In addition, considerable downtime would be required for the modifications. 
The six power supplies currently on standby from LCTF are more directly compatible with TST coil requirements. These supplies are rated for low-voltage, highcurrent, steady-state operation. The addition of fan cooling for the transformers and of SCRs to one power supply to provide for a negative current are the only modifications necessary. These supplies would have to be relocated and installed near the TST device.

\section{VI.1.3 Summary}

TST's TF coils can be powered by the ATF HF power supply. Most modifications required for the supply and the output bus will be accomplished during upgrades for steady-state operation of ATF. Switches on the bus will provide the flexibility needed for sharing of this power supply between ATF and TST.

Specifications will be generated for the procurement of three power supplies for the poloidal field coil system. Six existing power supplies will be relocated to near TST, and minor modifications will be made as required. The building's existing $13.8-\mathrm{kV}$ and 480-V distribution systems will provide electrical power for this equipment.

Table VI.1 summarizes the power supply and coil assignments.

Table VI.1. TST power supplies and coil assignments

\begin{tabular}{ll}
\hline Coil number & \multicolumn{1}{c}{ Power supply } \\
\hline TF coil set & Existing ATF HF power supply \\
PF coils 1, 7 & New power supply \\
PF coils 2, 8 & New power supply \\
PF coil 3 & Existing LCTF power supply \\
PF coil 4 & Existing LCTF power supply \\
PF coil 5 & Existing LCTF power supply \\
PF coils 6, 12 & New power supply \\
PF coil 9 & Existing LCTF power supply \\
PF coil 10 & Existing LCTF power supply \\
PF coil 11 & Existing ICTF power supply \\
\hline
\end{tabular}

\section{VI.2 WATER COOLING SYSTEM}

The TST magnets and heating systems require about $50 \mathrm{MW}$ of steady-state cooling, which will be provided by an existing demineralized water system. The total flow required by the device is $11,000 \mathrm{gal} / \mathrm{min}$, with a small additional amount required by the magnet and drive system power supplies. Table VI.2 lists the TST cooling loads.

The cooling system consists of a closed-loop demineralized water system operating in the range of 30 to 250 psi. Heat is rejected via 7 heat exchangers and a process water loop chilled by 11 cooling towers. The system has a nominal cooling capacity of $40 \mathrm{MW}$ in the summer, but this rating assumes a flow rate of $20,000 \mathrm{gal} / \mathrm{min}$, a wet 
Table VI.2. TST device water cooling requirements

\begin{tabular}{lccc}
\hline System & $\begin{array}{c}\text { Cooling load } \\
(\mathrm{MW})\end{array}$ & $\begin{array}{c}\text { Flow rate } \\
\text { (gal/min) }\end{array}$ & $\begin{array}{c}\text { Number of } \\
\text { flow paths }\end{array}$ \\
\hline PF1 & 0.28 & 38 & 2 \\
PF2 & 0.31 & 33 & 2 \\
PF3 & 1.81 & 207 & 2 \\
PF4 & 0.01 & 3 & 1 \\
PF5 & 0.07 & 61 & 1 \\
PF6 & 1.06 & 221 & 8 \\
PF7 & 0.28 & 38 & 2 \\
PF8 & 0.31 & 33 & 2 \\
PF9 & 1.54 & 287 & 3 \\
PF10 & 0.01 & 3 & 1 \\
PF11 & 1.89 & 191 & 2 \\
PF12 & 1.38 & 221 & 8 \\
TF core & 23.30 & 4357 & 256 \\
TF return & 10.10 & 2028 & 256 \\
Divertor and vessel & 4.50 & 2280 & TBD $a$ \\
Buswork & 3.50 & 800 & TBD \\
Heating and CD & 2.50 & 500 & TBD \\
Total (TF coils) & 33.4 & 6385 & 512 \\
Total (PF coils) & 8.95 & 1337 & 34 \\
Machine total & 52.9 & 11302 & \\
\hline
\end{tabular}

aTo be determined.

bulb temperature of $78^{\circ} \mathrm{F}$, and a water return temperature of $110^{\circ} \mathrm{F}$. A water return temperature of $118^{\circ} \mathrm{F}$ increases the cooling capacity to $50 \mathrm{MW}$. In winter the cooling capacity is substantially higher.

The cooling system will be shared with the ATF facility, and the modest upgrades in piping required for full flow will be part of a general upgrade of ATF for steady-state operation.

\section{VI.3 DIAGNOSTICS}

The set of diagnostics proposed for TST is similar to that used on the ATF torsatron. The heart of the system is a Nd:YAG laser Thomson scattering system that can pulse at $20-50 \mathrm{~Hz}$. This system will obtain density and electron temperature profiles. Ion temperature will be monitored by charge-exchange spectroscopy and by charge-exchange analysis of neutral atoms. The steady-state nature of the discharges and the lack of access to the center column of the TST tokamak offer challenges in 
diagnostic application. The TST applications for each diagnostic are discussed below. Table VI.3 provides a summary.

Table VI.3. Summary of TST diagnostics

\begin{tabular}{|c|c|c|c|}
\hline & \multicolumn{2}{|c|}{ Also used in } & \multirow{2}{*}{$\begin{array}{l}\text { Needed at } \\
\text { startup }\end{array}$} \\
\hline & SOL & Divertor & \\
\hline Thomson scattering & $\bullet$ & & $\bullet$ \\
\hline $\mathrm{ECE}$ & & & \\
\hline FIR interferometer & & & \\
\hline Spectroscopy & - & - & \\
\hline Impurity monitors & $\bullet$ & $\bullet$ & $\bullet$ \\
\hline Laser ablation & - & • & \\
\hline Charge-exchange analysis & & & \\
\hline Visible bremsstrahlung & & & \\
\hline Microwave interferometer & & & • \\
\hline Bolometers & & - & \\
\hline Soft $\mathrm{X}$-ray diodes & & & \\
\hline $\begin{array}{l}\text { Magnetic pickup loops and } \\
\text { equilibrium coils }\end{array}$ & & & $\bullet$ \\
\hline Rogowski and voltage loop & & & - \\
\hline Hard X-ray and neutron monitors & & & - \\
\hline Visible TV camera & & & $\bullet$ \\
\hline Langmuir probes & - & • & \\
\hline IR TV camera & & - & \\
\hline Reflectometer & $\bullet$ & - & \\
\hline
\end{tabular}

\section{VI.3.1 Thomson Scattering}

The standard system for determining electron temperature and density profiles in tokamaks has been Thomson scattering. However, Thomson scattering is both expensive and labor-intensive. A more attractive system for steady-state tokamaks would be a combination of electron cyclotron emission (ECE) for electron temperature profile determination and a far-infrared (FIR) interferometer for density profile information. Unfortunately, LHCD creates fast electrons that could add noise to the ECE signal, and the FIR interferometer suffers from access problems and from not being applicable to steady-state conditions.

Thomson scattering is a short-pulse diagnostic. The ATF system is based on a $\sim 20-J$ ruby laser. Thermal conductivity of the ruby dictates a pulse interval of about a minute. Recently, C. E. Thomas proposed a 1-J Nd:YAG laser system capable of 20$50 \mathrm{~Hz}$ for ATF long pulses. Such systems have been successfully operated at IPP Garching, MIT, and General Atomics. The detection system would consist of a single spectrometer with an array of avalanche photodiodes for detectors. Such a system 
would be relatively inexpensive and easy to maintain. It would require a dedicated workstation if temperatures were to be offered every $50 \mathrm{~ms}$.

The laser beam would reside in the same module as the collecting optics and would enter from above the TST tokamak. A beam dump would be required at the bottom. Figure VI.1 illustrates the general geometry. The laser beam can be scanned over a range of major radii so that the center of the shifted plasma can be measured, as well as the separatrix. Modifications to the divertor to allow for a beam dump must be included in the original construction plans.

ORNL-DWG 92M-2724 FED

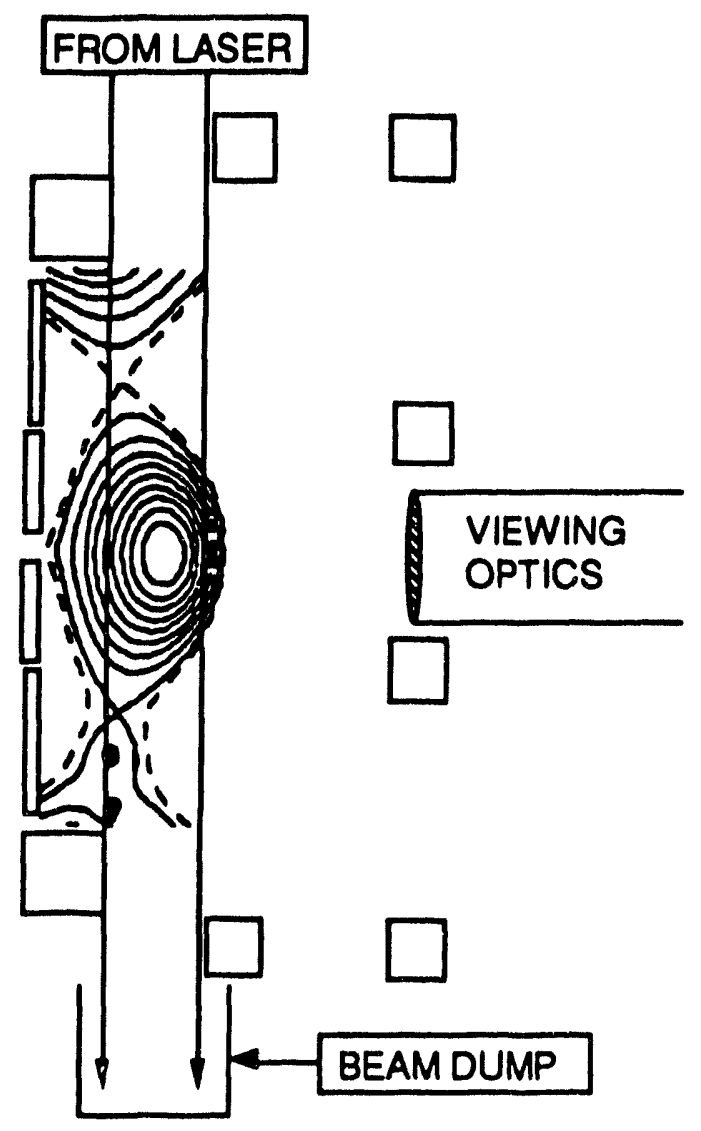

Fig. VI.1. General geometry of the Thomson scattering system.

\section{VI.3.2 ECE}

A second method of measuring the electron temperature profile in steady state is to use ECE. The various frequencies involved and the optical depths are shown in Fig. VI.2. The plasma temperature and densities assumed, along with the magnetic field, are plotted as functions of major radius in Fig. VI.3. Figure VI.2 (curve 6) shows that second harmonic ECE at $B_{0}=2.2 \mathrm{~T}$ is optically thick (curve 9) from $R_{0}=-20 \mathrm{~cm}$ to $+20 \mathrm{~cm}$. Furthermore, there is no harmonic overlap with the third cyclotron harmonic (curve 7) in the outer two-thirds of the plasma. From these considerations, ECE should 


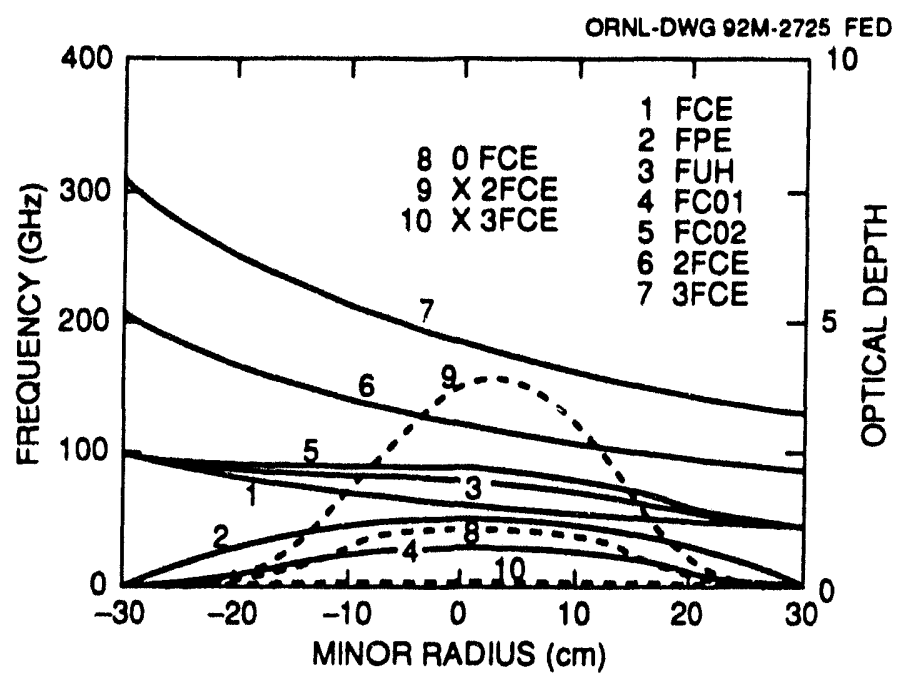

Fig. VI.2. Frequencies and optical depths of relevance to the ECE diagnostics.

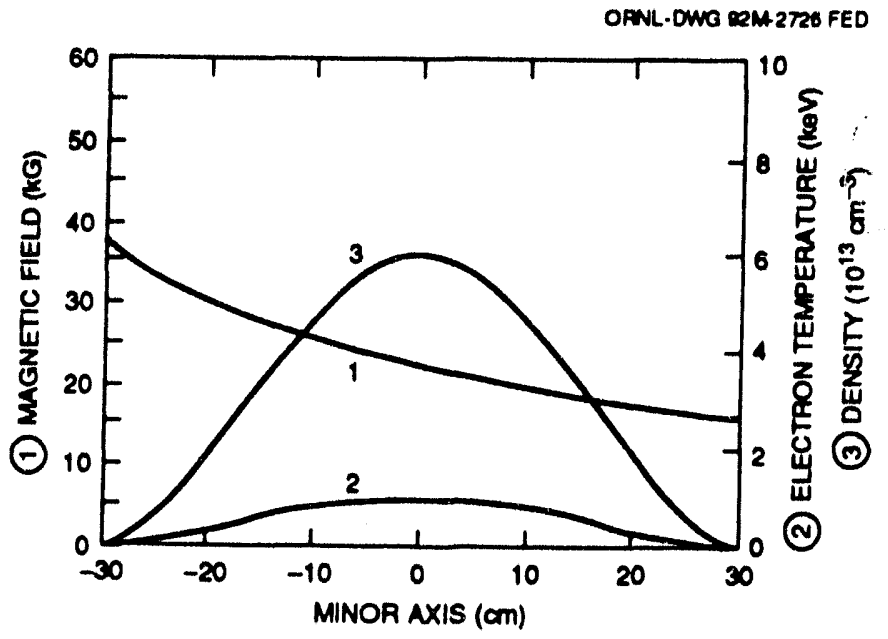
radius.

Fig. VI.3. Plasma temperature, density, and magnetic field as a function of minor

work well. The caveat is that LHCD creates fast electrons with velocity vectors mainly along the field lines. However, any motion perpendicular to field lines will cause copious ECE, which will distort the emission spectrum of the thermal electrons.

Because of the low aspect ratio of TST, the toroidal magnetic field falls off quickly with radius (see Fig. VI.3). While this implies good spatial resolution for the ECE measurement (about $1 \mathrm{~cm}$ ), is also gives a rather broadband microwave frequency space $(90-140 \mathrm{GHz})$ that must be spanned (see Fig. VI.2). 


\section{VI.3.3 FIR Interferometer}

FIR interferometers can accurately determine the density along a chord, and measurements along a series of chords may be Abel-inverted to give the density profile. This measurement is absolute and is relatively free from signal loss due to high density gradients. Modern FIR interferometers operate at short wavelengths, which can yield fringe shifts of $2 \pi$ or less. This implies that the systems must either be free from mechanical vibration or be vibration-compensated. In order to obtain profile information, individual FIR beams must have access to an appreciable area of the plasma cross section.

The problems of installing an interferometer in TST are:

1. In order to cover an appreciable part of the TST cross section, the FIR beams must be oriented vertically. Access to the bottom of TST is difficult since the beam must pass through the divertor area, where the density is ten times (or more) that in the main plasma.

2. Vibration could pose a problem. The use of a $\mathrm{CO}_{2}$ laser at $0.0106 \mathrm{~mm}(10.6 \mu \mathrm{m})$ has been advocated because of the copious power available and the inexpensive optical components available at that wavelength. The total phase shift in passing through the plasma would be a fraction of a fringe. In order to compensate for vibrational displacements of $\sim 0.0106 \mathrm{~mm}$, a laser at another frequency would be used for positional tracking.

3. Interferometer fringe shifts are tracked from zero before the plasma is introduced. A loss of signal causes the fringe count to be lost. Fringe count loss can occur due to vibration, disruptions, UFOs, or electronic glitches. For this reason, there is no way presently known to operate an FIR interferometer steady state.

Unless these problems can be overcome, the FIR interferometer is not an attractive candidate for TST.

\section{VI.3.4 Spectroscopy}

Spectroscopy can be used to determine the plasma impurities and ion temperatures. Impurity lines of interest are in the visible and in the ultraviolet. Attenuation of glass in the ultraviolet dictates the vacuum coupling of spectrometers to the plasma region.

The same general configuration of spectrometers used on ATF is envisioned for TST. The three ATF spectrometers share a midplane port: a McPherson grazingincidence spectrometer, a Czerny-Turner visible spectrometer, and an optical multichannel spectrometer that can view wavelengths to $1200 \AA$. For TST, the grazingincidence spectrometer would be replaced by a multichannel spread system. The spectrometers would be oriented perpendicular to the neutral beam for determination of temperatures by charge-exchange spectroscopy. 


\section{VI.3.5 Impurity Monitors}

Impurity monitors consist of phototubes with optical notch filters set to look at the various lines from carbon and oxygen. The monitor signals are fed directly into the data collection system and provide a convenient reference for impurity radiation throughout a discharge cycle and a day-to-day comparison between discharges.

\section{VI.3.6 Laser Ablation}

By studying the evolution of impurities introduced into the plasma by laser ablation, it is possible to determine the transport rate of impurities in the plasma in the scrape-off layer. A small amount of material is ablated from a glass slide by a highpower laser, and spectrometers are used to monitor the evolution of the various lines of the impurity introduced. This method can be used to determine how the impurity transport compares to neoclassical models.

\section{VI.3.7 Charge-Exchange Analysis}

The charge-exchange analyzer (CXA) used on ATF is of the same type as used on TFTR and should be ideal for use on TST. Ion temperatures from $100 \mathrm{eV}$ up to several kiloelectron volts can be measured with this type of instrument, and neutrals with energies up to several hundred kiloelectron volts can be detected. Analyzer control and data acquisition are through CAMAC.

The CXA on ATF is held in a frame that can be translated both horizontally and vertically. Although the vertical scanning capability is convenient for observation of poloidal asymmetries, horizontal scans are more important for determination of fast ion slowing-down, and this capability would be maintained in the TST analyzer.

Several analyzers have been removed from TFTR, and one could be made available for use on TST. The main cost of the TST system would be for design and fabrication of the translational mechanism and for electronics and system installation.

\section{VI.3.8 Visible Bremsstrahlung}

Visible bremsstrahlung detectors consist of photodiodes preceded by an optical filter and a lens. As such, they are quite rugged and reliable. They give a good indication of the relative density as a function of radius. Their signals could be used for feedback control of the plasma position, which will be difficult to monitor with the traditional magnetic field pickup loops because of the steady-state nature of the plasma.

\section{VI.3.9 Microwave Interferometer}

The microwave interferometer has been the mainstay of tokamak plasma density measurements. It is more susceptible to losing fringe count than the FIR interferometer because it has a longer wavelength $(2 \mathrm{~mm})$ and hence is more easily diffracted. It is thus even less suited to steady-state plasmas. It is, however, necessary to calibrate the laser system against the microwave interferometer standard and should prove to be very useful during startup. 


\section{VI.3.10 Bolometers}

Bolometers are used to measure the total radiation emitted from the plasma and thus determine the amount of impurity emission. Wide-angle detectors view emission from the entire plasma, while arrays can give more detailed radial information. Bolometers will view both the main plasma and the divertor region on TST to determine the energy balance between the two regions.

\section{VI.3.11 Soft X-Ray Diodes}

Arrays of soft X-ray diodes are commonly used to determine the MHD activity present in the center of the plasma and to find the $q=1$ sawtooth inversion radius. Even single diodes provide a good monitor of MHD activity. Multiple diodes fabricated on a single chip using semiconductor technology provide economical diode arrays. Soft $\mathrm{X}$-ray diodes (along with visible bremsstrahlung detectors) are a candidate for feedback control of the steady-state plasma position.

\section{VI.3.12 Magnetic Pickup Loops and Equilibrium Coils}

Magnetic pickup loops are used to determine the plasma position and the shape of the current profile and to monitor MHD activity near the edge of the plasma. In order to determine the magnetic field, the coil signal must be integrated. Since integrators tend to drift over long time periods, the absolute magnetic field will drift as well. However, it may be possible to periodically reset the integrators and rely on differential measurements for position control. MHD measurements rely on the raw coil signals and so do not suffer from integrator drift.

To determine the plasma current shape, it is necessary to have signals from coils distributed around and fairly close to the plasma. The principal problem with lowaspect-ratio devices is placing pickup coils in the central column. Fortunately, the coils can be made quite small. However, eddy current magnetic fields as well as fields from the $\mathrm{OH}$ solenoid and noise from the toroidal field act to mask the magnetic fields from the plasma. The design of the central loops must be carefully considered during the initial tokamak design stage.

\section{VI.3.13 Rogowski and Voltage Loops}

The loop voltage induced by a transformer is typically measured by one-turn loops of wire toroidally encircling the plasma. The plasma current is measured by a Rogowski coil, which is a wire coil poloidally encircling the plasma current. The integrated signal from the Rogowski coil gives the plasma current. For steady-state plasmas, it may be possible to periodically reset the integrators after full current is attained and use differential measurement to monitor plasma current changes. 


\section{VI.3.14 Hard X-Ray and Neutron Monitors}

Hard X-ray and neutron monitors are typically used to monitor X-rays from runaway electrons and neutrons from the interaction of fast deuterium ions. Although useful as diagnostics in their own right, they typically serve as radiation monitors.

\section{VI.3.15 Visible TV Camera}

A CCD-type TV camera can be used to monitor light coming from the plasma. The pictures are typically recorded on video tape to provide a record of discharge conditions. TV images are particularly useful in discovering UFOs and unusual plasma (fault) conditions. CCD cameras with electronics that are insensitive to the magnetic field must be used.

\section{VI.3.16 Langmuir Probes}

Langmuir probes are versatile diagnostics that monitor the electron temperature, density, and fluctuations in the plasma edge. A number of such probes will be incorporated into the divertors and the diverted plasma regions. The plasma energy flux can cause Langmuir probes to overheat. Steady-state applications and deep plasma edge penetrations will necessitate the use of reciprocating Langmuir probes, which can sample the plasma momentarily.

\section{VI.3.17 IR TV Camera}

The heat flux and resultant temperature of the divertor tiles will be a topic of principal interest in TST. The surface temperature of the carbon tiles in the divertor region will be monitored by a calibrated IR camera. The bulk temperature of the carbon tiles will be determined by thermocouple measurements. IR TV measurements can be made through windows on the divertor ports.

\section{VI.3.18 Reflectometer}

A knowledge of density gradients in the SOL is crucial to understanding divertor physics. Tests of a reflectometer for density measurements in the edge lay/er of TFTR are being conducted by staff from ORNL. If these measurements prove fruitful, the reflectometer could prove to be a useful tool for understanding divertor and SOL physics.

\section{VI.3.19 Arrangement of Major Diagnostics on TST}

The arrangement of the major diagnostics and heating systems in the midplane ports of TST is shown in Fig. VI.4. The CXA and spectrometers are positioned so as to look across the neutral beam. 


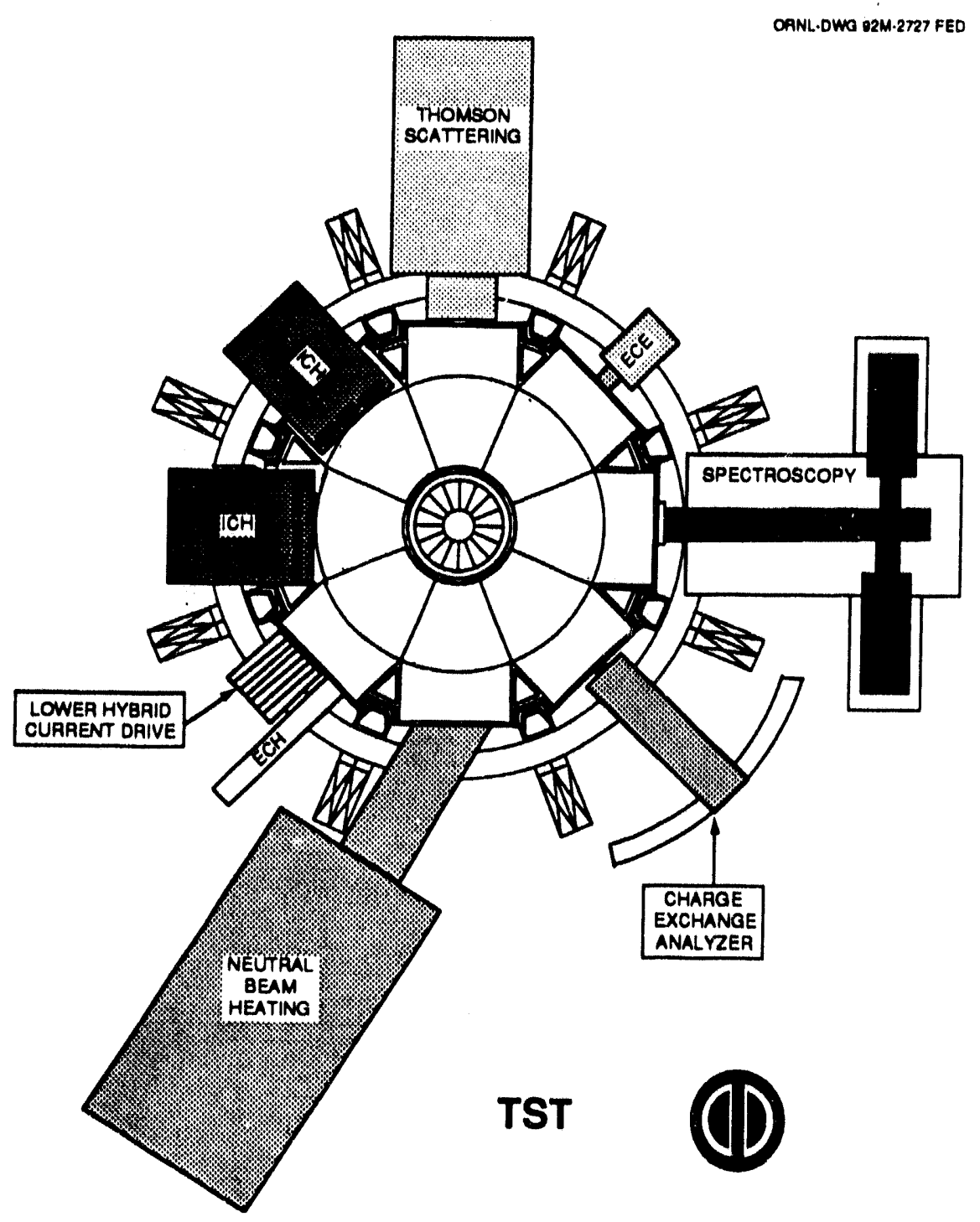

Fig. VI.4. Major diagnostics.

\section{VI.4 TST CONTROL ROOM AND DATA ACQUISITION}

If the TST is constructed at ORNL, the most cost-effective approach to providing a TST control room is to combine the present ATF control room with an addition for TST. Since device power supplies will be shared, concurrent utilization of the control room and data acquisition systems is avoided. However, space must be shared.

The ATF control room is used both for data acquisition and machine control. Each diagnostic has dedicated data terminals that interconnect with the local VAXcluster of computers, consisting of one VAX 8600 and two VAX 8700 machines. CAMAC highways lead to CAMAC diagnostic stations, which are controlled by a mixture of CAMAC and analog signals routed from the control room. A clean solution for multiple use is to use only CAMAC control for TST diagnostics via the VAX system. This would avoid the introduction of new diagnostic controls in the present control room. 
However, several new workstations will be needed because of the steady-state nature of TST. Plasma and machine parameters must be processed and displayed in real time during a run period. Data from diagnostics may be fed into workstations that process and locally archive the data. These workstations will interface with the ORNL data management system (presently used on many U.S. tokamaks) for archival storage and retrieval. Interfacing workstations with the VAX network is an ORNL task that has been proposed for DOE support. Analog-to-digital hybrid systems, such as those presently installed on Alcator C-Mod, will be considered for use by TST.

The TST device will require a number of poloidal field power supplies not used on ATF, and their controls will require adcitional space. New CD and plasma heating systems will also be incorporated on TST. An addition to the present control room would accommodate these additional requirements, as shown in Fig. VI.5.

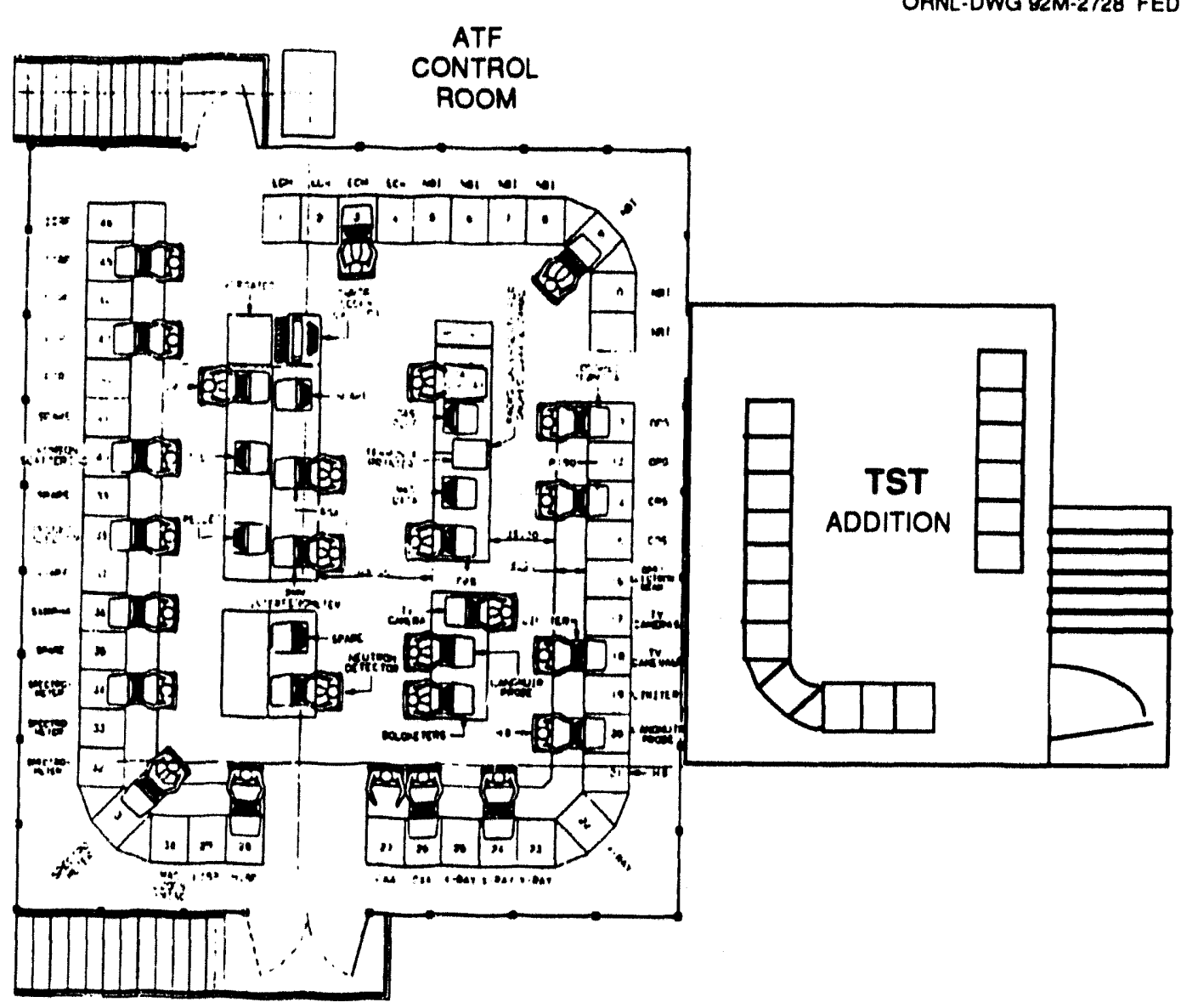

Fig. VI.5 ATF control room and TST addition. 


\section{Appendix A MODELING ASSUMPTIONS AND RESULTS FOR TST TRADES}

The constraints and major modeling assumptions used in the cost sensitivities described in Sect. I.6 are briefly described here. These models are described in more detail in Ref. [1]. Two cases, shown in Tables A.1 and A.2, were addressed:

- Reference TST parameters (minimum- $P_{\text {injection }}$ run for a fixed device), Table A.1.

- Minimum-cost cases with the minor radius $a \geq 0.30 \mathrm{~m}$ and $B \geq 2 \mathrm{~T}$, Table A.2.

\section{Constraints}

Plasma power balance, with ITER-Power $\mathrm{H}$-factor $\leq 2$

Beta limit, with gTroyon $\leq 3$

Volt-second capability: $23 \times$ startup requirement (normalized to base case)

Divertor heat load $\geq 5 \mathrm{MW} / \mathrm{m}^{2}$

Divertor plasma collision length $\leq 1.5 \times$ connection length

$n_{\mathrm{e}} \times a \geq 0.17 \times 10^{20} \mathrm{~m}^{-2}$ (normalized to base case, for neutral shielding)

\section{Heating and Current Drive}

Bootstrap fraction $\leq 0.60$ (ITER model)

Current drive:

Beams, up to $1.5 \mathrm{MW}, \gamma$ scaled with ITER formula, $4 \$ / \mathrm{W}$

$\mathrm{LH}$ to drive the rest of the current, $\gamma=0.1\left(10^{20} \mathrm{~A} / \mathrm{W} \cdot \mathrm{m}^{2}\right), 2 \$ / \mathrm{W}$

Heating:

$\mathrm{ICH}$, at $1 \$ / \mathrm{W}$ for the first $2 \mathrm{MW}, 2 \$ / \mathrm{W}$ for additional.

The steady-state current drive scenario is assumed to be independent of $B_{\mathfrak{l} 0}$.

\section{Configuration}

Outer TF coil location determined by the more stringent of:

- Minimum distance between plasma and TFC

- Ripple

Plasma size:

$a \geq 0.3 \mathrm{~m}$

\section{Costs}

- Find minimum-cost cases.

- Use the simple cost method developed last year [1], based on ATF experience (\$/kg approach), for relative cost. 


\section{Reference}

[1] J. Galambos, Y.-K. M. Peng, B. Nelson, S. P. Hirshman, and P. J. Fogarty, "Scoping Studies for Small Steady-State Tokamaks for Divertor Testing," p. 1114 in Proceedings of the 14th IEEE Symposium on Fusion Engineering, San Diego, 1991, IEEE, New York, 1991.

Table A.1. Base case parameters

Minimum $P_{\text {injection run }}$

\begin{tabular}{lll}
\hline \multicolumn{1}{c}{ Parameter } & Value & \multicolumn{1}{c}{ Comment } \\
\hline Relative cost & 1.0 & See notes. \\
Device & & \\
$R, \mathrm{~m}$ & 0.75 & Fixed \\
$a, \mathrm{~m}$ & 0.30 & Fixed \\
$B_{\mathrm{t}}, \mathrm{T}$ & 2.2 & Fixed \\
$I_{\mathrm{p}}, \mathrm{MA}$ & 0.51 & Fixed \\
Plasma & & \\
$T_{\mathrm{e}}, \mathrm{keV}$ & 1.2 & \\
$n_{\mathrm{e}}, 10^{20} \mathrm{~m}^{-3}$ & 0.57 & \\
$\mathrm{H}$ factor & 1.7 & \\
gTroyon & 1.5 & \\
$q_{\mathrm{edge}}$ & 7.8 & To provide $I_{\mathrm{p}}=0.5 \mathrm{MA}$ \\
Volt-seconds & $2.7^{*}$ & See notes. \\
Divertor & & \\
$H_{\text {div }}, \mathrm{MW} / \mathrm{m}^{2}$ & $5.0^{*}$ & \\
$L_{\text {collision }} / L_{\text {connect }}$ & $1.5^{*}$ & \\
Heating and current drive & & \\
Bootstrap fraction & 0.26 & \\
Beam power, MW & $1.50^{*}$ & \\
Beam current, MA & 0.07 & \\
LH power, MW & 1.3 & \\
LH current, MA & 0.31 & \\
ICH power, MW & 2.7 & \\
TF coil & & \\
$J_{\text {inner, }} \mathrm{kA} / \mathrm{cm}{ }^{2}$ & 2.75 & \\
$P_{\text {resistive, MW (in/out) }}$ & $21 / 10$ & \\
Mass, $1000 \mathrm{~kg}$ (in/out) & $5.3 / 55$ & \\
\hline & & \\
\hline
\end{tabular}

NOTES:

The reference base case uses a set of vertical PF coils that is not used for the other cases presented here (roughly a $\$ 1$ million penalty).

The asterisk indicates a value at a design constraint. 
Table A.2. Minimum-cost parameters with $a \geq 0.30 \mathrm{~m}$ and $B \geq 2 \mathrm{~T}$

\begin{tabular}{llll}
\hline & $A=2.1$ & $A=2.5$ & $A=3.2$ \\
\hline Relative cost & 1.58 & 0.86 & 1.72 \\
Device & & & \\
$R, \mathrm{~m}$ & 0.97 & 0.75 & 0.96 \\
$a, \mathrm{~m}$ & 0.46 & $0.30^{*}$ & $0.30^{*}$ \\
$B_{\mathrm{l}}, \mathrm{T}$ & $2.0^{*}$ & $2.0^{*}$ & 4.96 \\
$I_{\mathrm{p}}, \mathrm{MA}$ & 0.75 & 0.58 & 0.83 \\
Plasma & & & \\
$T_{\mathrm{e}}, \mathrm{keV}$ & $1.0^{*}$ & 1.2 & 2.8 \\
$n_{\mathrm{e}}, 10^{20} \mathrm{~m}^{-3}$ & 0.87 & 0.57 & 0.62 \\
$\mathrm{H}$ factor & $2.0^{*}$ & 1.6 & 1.8 \\
$g_{\text {Troyon }}$ & 2.1 & 1.3 & 1.0 \\
$q_{\text {edge }}$ & 10.0 & 6.5 & 7.5 \\
Volt-seconds & $5.0^{*}$ & $3.4^{*}$ & $7.4^{*}$ \\
Divertor & & & \\
$H_{\text {div, }}, \mathrm{MW} / \mathrm{m}^{2}$ & $5.0^{*}$ & $5.0^{*}$ & $5.0^{*}$ \\
$L_{\text {collision }} / L_{\text {connect }}$ & 0.7 & $1.5^{*}$ & $1.5^{*}$ \\
Heating and current drive & & & \\
Bootstrap fraction & 0.52 & 0.18 & 0.21 \\
Beam power, MW & $1.5^{*}$ & $1.5^{*}$ & $1.5^{*}$ \\
Beam current, MA & 0.04 & 0.07 & 0.12 \\
LH power, MW & 2.7 & 1.7 & 3.2 \\
LH current, MA & 0.32 & 0.40 & 0.54 \\
ICH power, MW & 8.2 & 2.0 & 3.5 \\
TF coil & & & \\
$J_{\text {inner, } \mathrm{kA} / \mathrm{cm}}{ }^{2}$ & 2.75 & 2.75 & 2.75 \\
$P_{\text {resistive, }} \mathrm{MW}$ (in/out) & $32 / 20$ & $20 / 12$ & $61 / 42$ \\
Mass, 1000 kg (in/out) & $8.1 / 66$ & $5.0 / 35$ & $15 / 120$ \\
\hline
\end{tabular}

NOTE:

The asterisk indicates a value at a design constraint or limit. 


\section{Appendix B \\ VOLTAGE REQUIREMENTS FOR TST OHMIC HEATING SUPPLIES ON STARTUP}

The Ohmic heating coils $(\mathrm{OH})$ coils can be used to start the discharge, build up the plasma current, hold the plasma current constant until current drive takes over, and help to shape the flux surfaces. The coil currents and power supply voltages necessary during the start of operation are estimated in this appendix for the $A=2.5$ case.

\section{B.1 VACUUM VESSEL AND SOLENOID PARAMETERS}

Four coils make up the $\mathrm{OH}$ system. The vacuum vessel (VV) wall is also tightly electrically coupled with the $\mathrm{OH}$ coils and must be considered an integral part of the $\mathrm{OH}$ system. Assuming $40 \mathrm{turns} / \mathrm{coil}$, the turns/length, resistances, and inductances are:

$$
\begin{gathered}
\frac{N_{1}}{\ell_{1}}=114 \text { turns } / \mathrm{m} \quad R_{1}=3.5 \mathrm{~m} \Omega \quad L_{1}=2.3 \mathrm{mH}, \\
\frac{N_{2}}{\ell_{2}}=80 \text { turns } / \mathrm{m} \quad R_{2}=4.1 \mathrm{~m} \Omega \quad L_{2}=1.7 \mathrm{mH}, \\
\frac{N_{\mathrm{VV}}}{\ell_{\mathrm{VV}}}=0.5 \text { turns } / \mathrm{m} \quad R_{\mathrm{VV}}=1.55 \mathrm{~m} \Omega \quad L \mathrm{VV}=0.6 \mu \mathrm{H} .
\end{gathered}
$$

To simplify the calculation of the coupling between the vacuum vessel and the four solenoid coils, the coils are considered to be one circuit with average parameters:

$$
\begin{aligned}
\frac{N_{\text {sol }}}{\ell_{\text {sol }}} & =97 \mathrm{turns} / \mathrm{m} \quad R_{\text {sol }}=15.2 \mathrm{~m} \Omega \quad L_{\text {sol }}=8.1 \mathrm{mH}, \\
M & =48 \mu \mathrm{H},
\end{aligned}
$$

where $M$ is the mutual inductance between the solenoid and the vacuum vessel.

\section{B.2 COUPLING BETWEEN THE SOLENOID AND VACUUM VESSEL}

Since the vacuum vessel does not have an electrical break, currents will be induced in the vacuum vessel by the transformer action of the $\mathrm{OH}$ solenoid. And, since the inner wall of the vacuum vessel and the solenoid are coaxial and in proximity, the two circuits are closely coupled. A diagram of the two circuits is shown in Fig. B.1. The equations for the two circuits are:

$$
L_{\text {sol }} \frac{d i_{\text {sol }}}{d t}-M \frac{d i v \mathrm{~V}}{d t}+R_{\text {sol }} i_{\text {sol }}=V_{\text {sol }},
$$



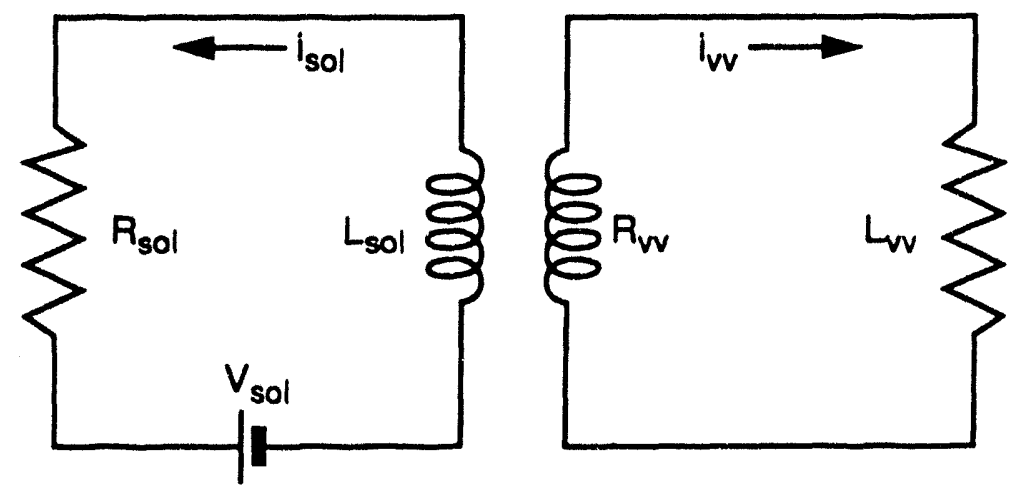

Fig. B.1. Vacuum vessel and solenoid circuits.

$$
L \mathrm{VV} \frac{d i_{\mathrm{VV}}}{d t}-M \frac{d i_{\mathrm{sol}}}{d t}+R_{\mathrm{VV} i \mathrm{VV}}=0
$$

Solving these coupled differential equations in the limit $R_{\text {sol }} L \mathrm{VV}$ « $R \mathrm{VV} L_{\text {sol }}$ and assuming that $V_{\text {sol }}$ is constant, we find

$$
\begin{gathered}
I_{\text {sol }} \cong \frac{V_{\text {sol }}}{R_{\text {sol }}}\left(1-e^{-t / \tau_{1}}\right), \\
I_{\mathrm{VV}}=\frac{V_{\text {sol }}}{R_{\mathrm{VV}}} \frac{M}{L_{\mathrm{sol}}}\left(e^{-t / \tau_{1}}-e^{-t / \tau_{2}}\right),
\end{gathered}
$$

where the time constants are

$$
\begin{aligned}
& \tau_{1} \cong \frac{L_{\text {sol }} L_{\mathrm{VV}}-M^{2}}{R_{\mathrm{sol}} L_{\mathrm{VV}}} \cong 0.28 \mathrm{~s}, \\
& \tau_{2} \cong \frac{L_{\mathrm{sol}} L_{\mathrm{VV}}-M^{2}}{R_{\mathrm{VV}} L_{\mathrm{sol}}} \cong 2 \mathrm{~ms} .
\end{aligned}
$$

\section{B.3 PLASMA LOOP VOLTAGE}

The voltage induced at the plasma will be

$$
\begin{aligned}
& V_{\text {loop }}=\frac{\partial \phi}{\partial t}=\mu_{0} \frac{N_{\text {sol }}}{\ell_{\text {sol }}} A_{\text {sol }} \frac{\partial I_{\text {sol }}}{\partial t} \\
& =-\mu_{0} \frac{N_{\text {sol }}}{\ell_{\text {sol }}} \frac{A_{\text {sol }}}{R_{\text {sol }}}\left(\frac{V_{\text {sol }}}{\tau_{1}} e^{-t / \tau_{1}}\right) .
\end{aligned}
$$




\section{B.4 VOLT-SECONDS CONSUMED DURING STARTUP}

The volt-seconds consumed during startup are derived from Eq. (B.11),

$$
\mathrm{V} \cdot \mathrm{s}=\int_{0}^{t} V_{\text {loop }} d t=\mu_{0} \frac{N_{\text {sol }}}{\ell_{\text {sol }}} \frac{A_{\text {sol }}}{R_{\text {sol }}} V_{\text {sol }}\left(1-e^{-t / \tau_{1}}\right)
$$

\section{B.5 ESTIMATE OF THE VOLT-SECONDS REQUIRED FOR STARTUP}

The best information on the voltage necessary for startup comes from DIII-D [1]. The loop voltage is the sum of the resistive and inductive terms:

$$
V_{\text {loop }} \cong I_{\mathrm{p}} R_{\mathrm{p}}+\frac{1}{I_{\mathrm{p}}} \frac{d}{d t}\left(\frac{1}{2} L_{\mathrm{p}} I_{\mathrm{p}}^{2}\right) .
$$

The total necessary volt-seconds are

$$
\mathrm{V} \cdot \mathrm{s}=\int_{0}^{t} V_{\text {loop }} d t \approx \int_{0}^{t}\left(I_{\mathrm{p}} R_{\mathrm{p}}+L_{\mathrm{p}} \frac{d I_{\mathrm{p}}}{d t}\right) d t,
$$

where the approximation has been made that the plasma current profile changes more slowly than the rate of evolution of the plasma current. Then

$$
\mathrm{V} \cdot \mathrm{s} \approx I_{\mathrm{p}} R_{\mathrm{p}} \Delta t+\left(L_{\mathrm{i}}+L_{\mathrm{ext}}\right) \Delta I_{\mathrm{p}}
$$

In Eq. (B.16) it has been assumed that the product $R_{\mathrm{p}} I_{\mathrm{p}}$ stays constant as the current is ramped up, as observed in DIII-D [1]. The plasma resistance at full current is calculated from the systems code [2] to be:

$$
R_{\mathrm{p}}=1.52 \times 10^{-6} \Omega
$$

The external inductance is calculated using Ref. [3], assuming $a / R=2.5$ and a plasma elongation of 2 :

$$
L_{\text {ext }}=0.75 \mu \mathrm{H}
$$

The internal inductance is

$$
L_{i}=\frac{\mu_{0} V_{\mathrm{ol}} \ell_{\mathrm{i}}}{\oint d \ell} \text {, }
$$

and $V_{\mathrm{ol}} \approx 3.2 \mathrm{~m}^{3}$ is the plasma volume, $\ell_{\mathrm{i}}$ is the internal inductance (assumed to be 0.8 ), and $\oint d \ell \approx 2.93 \mathrm{~m}$ is the distance around the plasma periphery. Using these values, $L_{\mathrm{i}} \approx$ $0.37 \mu \mathrm{H}$. Assuming $I_{\mathrm{p}}=0.5 \mathrm{MA}, \Delta t=0.5 \mathrm{~s}$, and using the values from Eqs. (B.17) and (B.18) in Eq. (B.16), 


$$
\begin{aligned}
V \bullet s & \equiv\left(0.5 \times 10^{6}\right)\left(1.52 \times 10^{-6}\right)(0.5)+(0.37+0.75) \times 10^{-7}\left(0.5 \times 10^{-6}\right) \\
& =0.94 \mathrm{~V} \bullet \mathrm{s} .
\end{aligned}
$$

The initial breakdown of the gas will require a voltage of about $5 \mathrm{~V}$ or less [1] if a good field null can be achieved. Initial breakdown should add $10-15 \%$ to the total voltsecond requirements calculated in Eq. (B.20).

\section{B.6 SOLENOID POWER SUPPLY REQUIREMENTS FOR STARTUP}

The total voltage required for startup can be found in Eq. (13),

$$
\Delta V_{\text {sol }}=\left(\frac{0.94}{3.3 \times 10^{-3}}\right)\left(1-e^{-t / \tau_{1}}\right)=284\left(1-e^{-t / \tau_{1}}\right) \mathrm{V}
$$

and the breakdown voltage at the plasma will be [from Eq. (12), setting $t=0$ ]

$$
K_{\text {oop }}=-\mu_{0} \frac{N_{\text {sol }}}{\ell_{\text {sol }}} \frac{A_{\text {sol }}}{R_{\text {sol }}} \frac{V_{\text {sol }}}{\tau_{1}} \approx-3.6 \mathrm{~V}
$$

if internal power supply capacitances are not important. Four volts is at the lower end of the voltage range for assured startup. The obvious problem with maintaining the loop voltage is the long time constant $\tau_{1} \approx 0.28 \mathrm{~s}$ (mainly attributable to the $L R$ time of the $\mathrm{OH}$ coils). Note that this is the voltage for a "composite" magnet made up of four separate magnets. The voltage for each magnet will be about a quarter of this. The maximum required current will be the same for all magnets,

$$
I_{\text {sol }}=\frac{\Delta V_{\text {sol }}}{R_{\text {sol }}}=\frac{284}{15.2 \times 10^{-3}}\left(1-e^{-t / \tau_{1}}\right)=18.7\left(1-e^{-t / \tau_{1}}\right) \mathrm{kA}
$$

The corresponding current density will be

$$
J_{\mathrm{sol}}=\frac{N_{\mathrm{sol}} \Delta_{\mathrm{sol}}}{A_{\mathrm{sol}}}=\left(1-e^{-t / \tau_{1}}\right)=4.6\left(1-e^{-t / \tau_{1}}\right) \mathrm{kA} / \mathrm{cm}^{2}
$$

The current flowing in the inner vacuum vessel wall can be calculated from Eq. (B.8),

$$
\Delta V V=-1147\left(e^{-t / \tau_{1}}-e^{-t / \tau_{2}}\right) A
$$

which is relatively modest.

\section{References for Appendix B}

[1] B. Lloyd, G. L. Jackson, T. S. Taylor, E. A. Lazarus, T. C. Luce, and R. Prater, Nucl. Fusion 31, 2031 (1991).

[2] J. D. Galambos, Oak Ridge National Laboratory, personal communication, 1992.

[3] S. P. Hirshman and G. H. Neilson, Phys. Fluids 29, 790 (1986). 
ORNL/TM- 12216

Dist. Category UC-420

\section{INTERNAL DISTRIBUTION}

1. Director, ORNL Fusion Energy Division

2. C. C. Baker

3. D. B. Batchelor

4. L. A. Berry

5. B. A. Carreras

6. R. A. Dory

7. J. L. Dunlap

8. T. E. Shannon

9. R. P. Leinius

10. Laboratory Records, ORNL-RC

11-12. Laboratory Records Department
13-14. Central Research Library

15. Document Reference Section

16. Fusion Energy Division Library

17-18. Engineering Technology/Fusion Energy Division Publications Office

19. ORNL Patent Office

20-29. Y-K. M. Peng

30. R. J. Colchin

31. D. W. Swain

32. B. E. Nelson

33. J. F. Monday

34. G. H. Neilson

\section{EXTERNAL DISTRIBUTION}

35. Office of the Assistant Manager for Energy Research and Development, U.S. Department of Energy Field Office, Oak Ridge, P.O. Box 2000, Oak Ridge, TN 37831

36. N. A. Davies, Director, Office of Fusion Energy, Office of Energy Research, ER-50 Germantown, U.S. Department of Energy, Washington, DC 20545

37. M. Roberts, International Programs, Office of Fusion Energy, Office of Energy Research, ER-52 Germantown, U.S. Department of Energy, Washington, DC 20545

38. D. E. Baldwin, Lawrence Livermore National Laboratory, P.O. Box 5511, Livermore, CA 94550

39. R. W. Conn, Mechanical, Aerospace, and Nuclear Engineering Department, 6291 Boelter Hall, University of California, Los Angeles, CA 90024-1597

40. P. C. Liewer, MS 138-208, Jet Propulsion Laboratory, 4800 Oak Grove Drive, Pasadena, CA 91109

41. R. Parker, Plasma Fusion Center, Massachusetts Institute of Technology, 167 Albany St., NW 16-288, Cambridge, MA 02139

42. K. I. Thomassen, L-637, Lawrence Livermore National Laboratory, P.O. Box 5511, Livermore, CA 94550

43. J. D. Callen, Department of Nuclear Engineering, University of Wisconsin, Madison, W1 53706-1687

44. S. O. Dean, Fusion Power Associates, Inc., 2 Professional Drive, Suite 248, Gaithersburg, MD 20879 
45. H. K. Forsen, Bechtel Group, Inc., Research Engineering, P.O. Box 3965 , San Francisco, CA 94119

46. R. W. Gould, Department of Applied Physics, California Institute of Technology, Pasadena, CA 91125

47. R. A. Gross, Plasma Research Laboratory, Columbia University, New York, NY 10027

48. R. J. Hawryluk, Princeton Plasma Physics Laboratory, P.O. Box 451, Princeton, NJ 08543

49. D. M. Meade, Princeton Plasma Physics Laboratory, P.O. Box 451, Princeton, NJ 08543

50. W. M. Stacey, School of Nuclear Engineering and Health Physics, Georgia Institute of Technology, Atlanta, GA 30332

51. D. Steiner, Nuclear Engineering Department, NES Building, Tibbetts Avenue, Rensselaer Polytechnic Institute, Troy, NY 12181

52. R. Varma, Physical Research Laboratory, Navrangpura, Ahmedabad 380009, India

53. Bibliothek, Max-Planck Institut für Plasmaphysik, Boltzmannstrasse 2, D-8046 Garching, Federal Republic of Germany

54. Bibliothek, Institut für Plasmaphysik, KFA Jülich GmbH, Postfach 1913, D-5170 Jülich, Federal Republic of Germany

55. Bibliothek, KfK Karlsruhe GmbH, Postfach 3640, D-7500 Karlsruhe 1, Federal Republic of Germany

56. Bibliotheque, Centre de Recherches en Physique des Plasmas, Ecole Polytechnique Fédérale de Lausanne, 21 Avenue des Bains, CH-1007 Lausanne, Switzerland

57. J. Jacquinot, CEN/Cadarache, Departement de Recherches sur la Fusion Contrôlée, F-13108 Saint-Paul-lez-Durance Cedex, France

58. Bibliothèque, CEN/Cadarache, F-13108 Saint-Paul-lez-Durance Cedex, France

59. Library, JET Joint Undertaking, Abingdon, Oxfordshire OX14 3EA, England

60. Library, FOM-Instituut voor Plasmafysica, Rijnhuizen, Edisonbaan 14, 3439 MN Nieuwegein, The Netherlands

61. Library, National Institute for Fusion Science, Chikusa-ku, Nagoya 464-01, Japan

62. Library, International Centre for Theoretical Physics, P.O. Box 586, I-34100 Trieste, Italy

63. Library, Centro Richerche Energia Frascati, C.P. 65, I-00044 Frascati (Roma), Italy

64. Library, Plasma Physics Laboratory, Kyoto University, Gokasho, Uji, Kyoto 611 , Japan

65. Plasma Research Laboratory, Australian National University, P.O. Box 4, Canberra, A.C.T. 2601, Australia

66. Library, Japan Atomic Energy Research Institute, Naka Fusion Research Establishment, 801-1 Mukoyama, Naka-machi, Naka-gun, Ibaraki-ken, Japan

67. G. A. Eliseev, I. V. Kurchatov Institute of Atomic Energy, P.O. Box 3402, 123182 Moscow, Russia

68. V. A. Glukhikh, Scientific-Research Institute of Electro-Physical Apparatus, 188631 St. Petersburg, Russia 
69. I. Shpigel, Institute of General Physics, U.S.S.R. Academy of Sciences, Ulitsa Vavilova 38, Moscow, Russia

70. D. D. Ryutov, Institute of Nuclear Physics, Siberian Branch of the Academy of Sciences, Sovetskaya St. 5, 630090 Novosibirsk, Russia

71. O. Pavlichenko, Kharkov Physical-Technical Institute, Academical St. 1, 310108 Kharkov, Ukraine

72. Deputy Director, Southwestern Institute of Physics, P.O. Box 15, Leshan, Sichuan, China (PRC)

73. Director, The Institute of Plasma Physics, P.O. Box 1126, Hefei, Anhui, China (PRC)

Argonne National Laboratory, 9700 South Cass Avenue, Argonne, IL 60439

74. Y. Gohar, Bldg. 205

75. A. M. Hassanein, Bldg. 205

76. R. F. Mattas

General Atomics, P.O. Box 85608, San Diego, CA 92138-5608

77. D. Overskei

78. F. A. Puhn

79. K. R. Schultz

80. R. D. Stambaugh

81. J. C. Wesley

82. P. Politzer

Lawrence Livermore National Laboratory, P.O. Box 5511, Livermore, CA 94550

83. J. N. Doggett

84. W. Nevins

85. L. J. Perkins, L-644

Los Alamos National Laboratory, P.O. Box 1663, Los Alamos, NM 87545

86. R. L. Miller, MS-F641

87. R. Krakowski

Massachusetts Institute of Technology, 77 Massachusetts Avenue, Cambridge, MA 02139

88. D. R. Cohn

89. D. B. Montgomery, Plasma Fusion Center

90. M. Porkolab, Plasma Fusion Center

91. D. J. Sigmar, Plasma Fusion Center

92. R. J. Thome, Francis Bitter National Magnet Laboratory 
Ontario Hydro, 700 University Avenue, Toronto, Ontario M5G 1X6, Canada

93. J. Blevins

94. P. Gierszewski

95. K. M. Kalyanam, H11-F26

Princeton Plasma Physics Laboratory, P.O. Box 451, Princeton, NJ 08544

96. R. Goldston

97. K. McGuire

98. S. Kaye

99. S. Jardin

100. N. Sauthoff

101. S. Bernabei

102. F. W. Perkins

103. D. E. Post

104. P. H. Rutherford

105. G. V. Sheffield

106. K. M. Young

107. F. Engelmann, NET Team, Max-Planck-Institut für Plasmaphysik, D-8046 Garching, Federal Republic of Germany

108. N. Fugisawa, Japan Atomic Energy Research Institute, Naka Fusion Research Establishment, Naka-machi, Naka-gun, Ibaraki-ken 311-02, Japan

109. J. Holdren, University of California, Berkeley, CA 94720

110. T. Kammash, Department of Nuclear Engineering, University of Michigan, Cooley Building, North Campus, Ann Arbor, MI 48109

111. G. H. Miley, Nuclear Engineering Laboratory, University of Illinois, 103 South Goodwin Avenue, Urbana, IL 61801

112. R. R. Stasko, Canadian Fusion Fuels Technology Project, 2700 Lakeshore Road West, Mississauga, Ontario L5J 1K3, Canada

113. H. Weitzner, Courant Institute of Mathematical Sciences, New York University, 251 Mercer Street, New York, NY 10012

114. Laboratorio Associado de Plasma, Instituto Nacional de Pesquisas Espaciais, Caixa Postal 515, 122201, São Jose dos Campos, SP, Brazil

115. J. C. Nascimento, Instituto de Fisica, University of São Paulo, C.P. 20516, 10498- São Paulo, Brazil

116. S. A. Eckstrand, Office of Fusion Energy, Office of Energy Research, U.S. Department of Energy, Washington, DC 20545

117. R. A. Blanken, Office of Fusion Energy, Office of Energy Research, U.S. Department of Energy, Washincton, DC 20545

118. C. W. Bolton, Office of Fusion Energy, Office of Energy Research, U.S. Department of Energy, Washington, DC 20545

119. J. W. Willis, Office of Fusion Energy, Office of Energy Research, U.S. Department of Energy, Washington, DC 20545 
120. D. H. Crandall, Office of Fusion Energy, Office of Energy Research, U.S. Department of Energy, Washington, DC 20545

121. S. E. Berk, Office of Fusion Energy, Office of Energy Research, U.S. Department of Energy, Washington, DC 20545

122. T. R. James, Office of Fusion Energy, Office of Energy Research, U.S. Department of Energy, Washington, DC 20545

123-162. Given distribution as shown in OSTI-4500, Magnetic Fusion Energy (Category Distribution UC-420) 


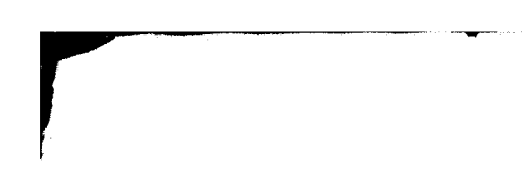

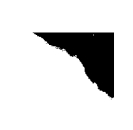
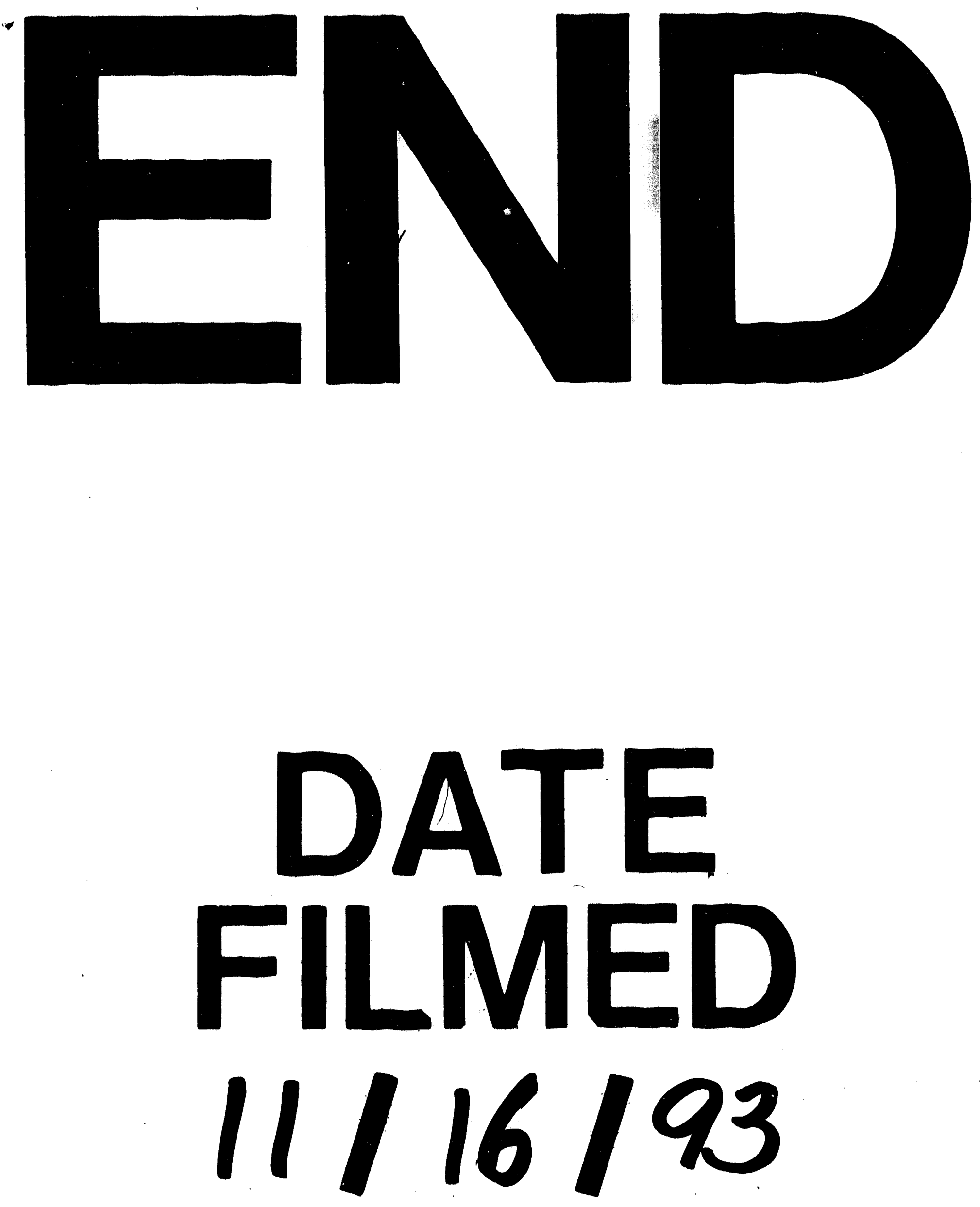


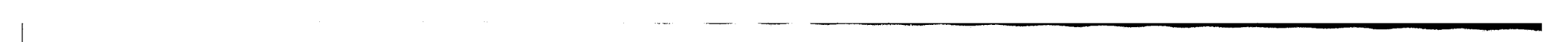

